\title{
Carbon Capture and Water Emissions Treatment System (CCWESTRS) at Fossil-Fueled Electric Generating Plants
}

\section{Final Technical Report October 1, 2000 - December 31, 2005}

P. Alan Mays, Project Manager, Tennessee Valley Authority, Knoxville, TN Bert R. Bock, Tennessee Valley Authority, Muscle Shoals, AL Gregory A. Brodie, Tennessee Valley Authority, Chattanooga, TN L. Suzanne Fisher, Tennessee Valley Authority, Knoxville, TN J. Devereux Joslin, Tennessee Valley Authority, Knoxville, TN Donald L. Kachelman, Tennessee Valley Authority, Muscle Shoals, AL Jimmy J. Maddox, Tennessee Valley Authority, Muscle Shoals, AL N. S. Nicholas, Tennessee Valley Authority, Knoxville, TN Larry E. Shelton, Tennessee Valley Authority, Knoxville, TN Nick Taylor, Tennessee Valley Authority, Chattanooga, TN Mark H. Wolfe, Tennessee Valley Authority, Knoxville, TN Dennis H. Yankee, Tennessee Valley Authority, Knoxville, TN John Goodrich-Mahoney, Electric Power Research Institute, Washington, D.C.

DOE Award Number DE-FC26-00NT40930

Submitted by:

Tennessee Valley Authority

Research \& Technology Applications

1 Reservation Road

Muscle Shoals, Alabama 35662-1010 


\section{Disclaimer}

This report was prepared as an account of work sponsored by an agency of the United States Government. Neither the United States Government nor any agency thereof, nor any of their employees, makes any warranty, express or implied, or assumes any legal liability or responsibility for the accuracy, completeness, or usefulness of any information, apparatus, product, or process disclosed, or represents that its use would not infringe privately owned rights. Reference herein to any specific commercial product, process, or service by trade name, trademark, manufacturer, or otherwise does not necessarily constitute or imply its endorsement, recommendation, or favoring by the United States Government or any agency thereof. The views and opinions of authors expressed herein do not necessarily state or reflect those of the United States Government or any agency thereof. 


\begin{abstract}
The Tennessee Valley Authority (TVA), the Electric Power Research Institute (EPRI), and the Department of Energy - National Energy Technologies Laboratory (DOE-NETL) are evaluating and demonstrating integration of terrestrial carbon sequestration techniques at a coal-fired electric power plant through the use of Flue Gas Desulfurization (FGD) system gypsum as a soil amendment and mulch, and coal fly ash pond process water for periodic irrigation. From January to March 2002, the Project Team initiated the construction of a 40 ha Carbon Capture and Water Emissions Treatment System (CCWESTRS) near TVA's Paradise Fossil Plant on marginally reclaimed surface coal mine lands in Kentucky. The CCWESTRS is growing commercial grade trees and cover crops and is expected to sequester 1.5-2.0 MT/ha carbon per year over a 20- year period. The concept could be used to meet a portion of the timber industry's needs while simultaneously sequestering carbon in lands which would otherwise remain non-productive. The CCWESTRS includes a constructed wetland to enhance the ability to sequester carbon and to remove any nutrients and metals present in the coal fly ash process water runoff. The CCWESTRS project is a cooperative effort between TVA, EPRI, and DOENETL, with a total budget of $\$ 1,574,000$. The proposed demonstration project began in October 2000 and has continued through December 2005. Additional funding is being sought in order to extend the project.
\end{abstract}

The primary goal of the project is to determine if integrating power plant processes with carbon sequestration techniques will enhance carbon sequestration cost-effectively. This goal is consistent with DOE objectives to provide economically competitive and environmentally safe options to offset projected growth in U.S. baseline emissions of greenhouse gases after 2010, achieve the long-term goal of $\$ 10 /$ ton of avoided net costs for carbon sequestration, and provide half of the required reductions in global greenhouse gases by 2025. Other potential benefits of the demonstration include developing a passive technology for water treatment for trace metal and nutrient release reductions, using power plant by-products to improve coal mine land reclamation and carbon sequestration, developing wildlife habitat and green-space around production facilities, generating Total Maximum Daily Load (TMDL) credits for the use of process water, and producing wood products for use by the lumber and pulp and paper industry.

Project activities conducted during the five year project period include:

- Assessing tree cultivation and other techniques used to sequester carbon

- Project site assessment

- Greenhouse studies to determine optimum plant species and by-product application

- Designing, constructing, operating, monitoring, and evaluating the CCWESTRS system

- Reporting (ongoing)

The ability of the system to sequester carbon will be the primary measure of effectiveness, measured by accessing survival and growth response of plants within the CCWESTRS. In addition, costs associated with design, construction, and monitoring will be evaluated and compared to projected benefits of other carbon sequestration technologies. The test plan involves the application of three levels each of two types of power plant by-products - three levels of FGD gypsum mulch, and three levels of ash pond irrigation water. This design produces nine treatment levels which are being tested with two species of hardwood trees (sweet gum and sycamore). The project is examining the effectiveness of applications of 0, 8$\mathrm{cm}$, and 15-cm thick gypsum mulch layers and $0,13 \mathrm{~cm}$, and $25 \mathrm{~cm}$ of coal fly ash water for irrigation. Each treatment combination is being replicated three times, resulting in a total of 54 treatment plots ( 3 FGD gypsum levels $X 3$ irrigation water levels $\times 2$ tree species $\times 3$ replicates). Survival and growth response of plant species in terms of sequestering carbon in plant material 
and soil will be the primary measure of effectiveness of each treatment. Additionally, the ability of the site soils and unsaturated zone subsurface materials will be evaluated for their effectiveness at treating the irrigation water for various pollutants.

\section{Year 1}

In Year 1 of the project, greenhouse tests and field testing evaluated (1) Tolerance of certain tree species to soil-borne boron; (2) Tolerance of certain tree species to water-borne boron; and (3) Optimum depth of FGD gypsum by-product to serve as mulch. Results suggested that using the Paradise power plant FGD waste water as a source of irrigation without first diluting the boron (B) concentration will require careful planning and management. Year 1 findings suggested that:

(1) FGD water should be blended to $4 \mathrm{mg} \mathrm{B/l}$ or less prior to use.

(2) Trees should be allowed to become fully established before applying diluted irrigation water.

(3) Soil should not be saturated with boronated waste water.

(4) B and nitrogen $(\mathrm{N})$ in leaves should be initially monitored to help schedule irrigation and fertilization.

(5) Accumulation of B in the soil profile should be monitored.

(6) Periodic irrigation with low B water should be considered to prevent toxic levels of B accumulation in the soil.

(7) A search should continue for more tolerant trees and crop management techniques to reduce the risk of irrigating with boronated waste water.

Results from the B leaching study indicated that if wastewater containing B was drip-irrigated to match evapotranspiration during the growing season, most of the applied B would be retained in the upper part of the rooting zone during the growing season. Since B is somewhat mobile at the study site, winter precipitation likely would leach much of the B out of the rooting zone, resulting in lower levels of soil $B$ at the beginning of each growing season. With this type of pattern, application of $25 \mathrm{~cm}$ ( $9.84 \mathrm{in}$ ) of water containing $7 \mathrm{mg} \mathrm{B} / \mathrm{l}$ irrigation water (e.g., fly ash pond water) would result in an accumulation of about $7 \mathrm{mg} \mathrm{B} / \mathrm{kg}$ soil in the rooting zone by the end of each growing season. During the first part of each growing season, significantly less than an additional $7 \mathrm{mg} \mathrm{B} / \mathrm{kg}$ soil would have accumulated. The greenhouse B tolerance study indicated that sycamore, eastern cottonwood, sweet gum, and red maple will tolerate $10 \mathrm{mg}$ $\mathrm{B} / \mathrm{kg}$ soil reasonably well for about one growing season or less. Some B leaf damage would probably occur during the last part of the growing season and concentrate in the autumn leaf litter to be leached out by rainfall during the winter months. The combined results of the greenhouse B tolerance study and the field B leaching study suggested that sycamore, cottonwood, sweet gum, and red maple would tolerate an annual application of $25 \mathrm{~cm}$ fly ash pond water reasonably well, but that $25 \mathrm{~cm}$ of FGD wastewater ( $70 \mathrm{mg} \mathrm{B} / \mathrm{l})$ would be very damaging to the trees.

Year 1 project expenditures were $\$ 241,601$.

\section{Year 2}

Based on a 2001-2002 field study and April-November 2002 inspections of replicated test plots FGD gypsum placed on actively growing fescue, the Project Team determined that the full-scale demonstration should be tested with zero, $10 \mathrm{~cm}$, and $20 \mathrm{~cm}$ depths of the FGD gypsum for mulch. FGD gypsum was applied as mulch at three levels: no mulch, low mulch $=10 \mathrm{~cm}$ depth and high mulch $=20 \mathrm{~cm}$ depth. The 40.5-hectare research area was subdivided into nine zones, each covered with one of the three levels of FGD gypsum mulch replicated three times. Exact 
application levels applied to each zone were randomly chosen. FGD gypsum was applied in 3.7$\mathrm{m}$ wide strips, separated by 1.2-m wide strips of existing grass cover crop. $34,500 \mathrm{~m}^{3}$ of FGD gypsum was placed over a three month period from December 2001 to February 2002 at $10 \mathrm{~cm}$ and $20 \mathrm{~cm}$ depths. The total cost for placing the material was $\$ 159,000$, or about $\$ 4.61 / \mathrm{m}^{3}$. It is thought that the total cost is approximately one third higher than a "best case" estimate due to weather delays and inexperience at working with FGD gypsum as an agricultural amendment.

After extensive Year 1 greenhouse testing of a number of tree species for tolerance to $B$, and consideration of other factors such as drought tolerance, growth rate, and commercial value, sycamore (Platanus occidentalis L.) and sweet gum (Liquidambar styraciflua L.) were chosen as the optimum species for planting. Two rows of two-year-old tree seedlings were planted in February-March 2002 in each 3.7-m wide row of gypsum treatment (except in plots with zero gypsum treatment) at $2.44 \mathrm{~m} \times 2.44 \mathrm{~m}$ spacing. This planting pattern resulted in a $2.4-\mathrm{m}$ wide strip of gypsum on one side of a tree row, and 0.6-m wide strip of mulch plus $1.2 \mathrm{~m}$ of grass plus a second $0.6 \mathrm{~m}$ of mulch on the opposite side of a row. Within each of the nine zones of FGD gypsum treatment, three irrigation treatments were replicated randomly. Within each of the 27 irrigation areas (3 replicates of the nine possible gypsum-irrigation level combinations), half of the area was planted to sycamore and half to sweet gum, in a split-plot design. This resulted in 54 treatment plots of approximately 0.75 hectares each.

Tree planting of $\sim 63,000$ sycamore and sweet gum seedlings began 2-23-02 and was completed 3-7-02. In May 2002, a survivorship survey was conducted in all plots for both tree species indicating that the percent survivorship for both species was greater than $85 \%$. In September 2002, seedling survival and vigor was poor across the entire study area. Sycamore average survival rate $(27 \%)$ was over twice that of sweet gum $(12 \%)$, and the percentage of healthy sycamore seedlings was considerably higher $(17 \%$ vs. $4 \%)$. Both species performed best under the high mulch treatment and worst under the zero mulch treatment. The high mulch application was more effective in reducing weed competition, especially from tall fescue and lespedeza species. Foliage was collected in June 2002 from all plots at the CCWESTRS site and analyzed for nutrients, $B$ and a number of metals.

In addition to the 54 test plots conducted as part of the general field study, small field experiments were conducted March-April, 2002 on a variety of tree species to test for boron tolerance. The small field test cell tree species did not perform adequately. Therefore, they were not considered for field use. The primary reason for the laboratory plot was to evaluate potential survival of the species under actual field conditions. Several relevant observations were observed.

Due to various reasons and decisions, the irrigation system was not installed in 2002 as planned. One of the reasons was the initial poor performance of the seedlings, which showed significant leaf damage and symptoms of boron toxicity and heat stress, presumably from the FGD gypsum mulch. Rather than subject the trees to additional B stress from irrigation with water from the FGD pond, it was decided to allow the trees to adapt to conditions in a slower manner. Although rainfall was adequate through June 2002, July and August rainfall was below normal and temperatures were above normal. Competition from weeds was, however, particularly intense in many plots. Temporary irrigation with non-industrial fresh water was done in August 2002, however poor tree survival prompted a decision to cease irrigation and to replant the site in 2003.

August 2002 measurements indicated that on the zero mulch plots, above-ground biomass was reduced considerably from baseline levels (from $6.45 \mathrm{~T} / \mathrm{ha}$ to an average of $2.82 \mathrm{~T} / \mathrm{ha}$ ), probably largely the result of bush-hogging the entire study area in late spring 2002. 
Monthly precipitation and temperature were monitored. Monthly precipitation at the CCWESTRS site was higher during seedling establishment, while the summer months experienced below normal precipitation from May through early August. Temperatures for the year were characterized as "much above normal".

Soil moisture data was measured in early August 2002 indicating that the soil moisture in the zero mulch and mulched test plots was below the wilting point of about $9 \%$. During this same period, soil moisture in the FGD mulch exceeded the wilting point. Later soil moisture measurements in August and October, however, indicated that soil moisture was adequate. Soil surface temperatures in the very dark FGD mulch were in excess of air temperatures (they were hot to the touch), but no actual subsurface soil temperature readings were obtained.

In preparation for replanting activities scheduled for late February of 2003, surviving seedlings and all weedy vegetation were treated with contact and pre-emergent herbicides in late fall. After treatment efficiencies were documented, additional spraying was required in the few areas missed in the initial treatment. Herbicidal treatments were effective in greatly reducing fescue and lespedeza cover across most of the study area.

Year 2 project expenditures were $\$ 446,897$.

\section{Year 3}

In February 2003, the entire site was bush-hogged to remove standing dead debris and facilitate planting. After inspecting and selecting quality seedling stock from state nurseries in Kentucky and Tennessee, replanting began on 2-11-03 and was completed on 3-12-03. Cursory survivorship estimates in early spring indicated that greater than $90 \%$ of the seedlings had survived and broken dormancy. By August, a more quantitative survey would reveal that sycamore and sweet gum survivorship was greater than $80 \%$, as compared to $27 \%$ and $12 \%$ respectively in 2002.

Installation of the drip irrigation system began in early March as tree planting was being completed. As designed, the irrigation system has the capacity to apply of up to $5 \mathrm{~cm}$ of irrigation water per week to all plots at an average rate of 1,413 liters per minute. The system was divided into two zones, with Zone 2 receiving one-half of the amounts of water that is applied to Zone 1. The irrigation water is pumped from an adjacent ash settling pond and is distributed through 1,107 drip lines that total 104,880 meters in length. Automated, daily checks and routine maintenance of the system insured proper operation throughout the growing season and resulted in targeted soil moisture regimes within each treatment. Runoff generated by the irrigation system was minimized through the strategic placement of straw bales and barriers.

Fourteen pressure vacuum lysimeters were installed at seven locations within the site in August 2003 to evaluate the efficiency of the vegetation, soils and underlying geology in removing metals and nutrients from the incoming irrigation water. The lysimeters were set at $1.5 \mathrm{~m}$ and $5.0 \mathrm{~m}$ depths for collecting samples of unsaturated zone flow-through as the irrigation water migrates vertically through the soil column. Samples were collected from the lysimeters in August and September 2003. Sample analyses were not performed during this reporting period, but will be completed for a full suite or metals, non-metals, nutrients, and field parameters.

Abundant spring precipitation, effective weed control, and the installation of the irrigation system greatly improved seedling survival and vigor for both species in 2003. As seen in 2002, differences in seedling survival and vigor were also related to species differences and the level 
of mulch. Both species reacted favorably to higher irrigation rates, but differed significantly in respect to mulch depth. Survival rates of sycamore seedlings were only slightly reduced in higher mulch plots while the percentage of sweet gum survival dropped as mulch depth increased. Overall, seedling vigor (visual estimate) appeared high for both species throughout all treatments. Foliage samples taken in mid-summer revealed sufficient macronutrient levels in both species except for calcium which was low in all treatments. Calcium (Ca) concentration seems to be slightly improved by mulching but not by irrigation. Boron is within normal range for zero mulch/zero irrigation treatments, but very high for both treatments with high irrigation (mulching also seems to increase B levels even further). Although boron levels are high, sycamore seedlings show no signs of any toxicity. Sweet gum seedlings do not look as healthy as sycamore, but their appearance does not point to any particular nutrient limitation or excess

In August 2003, measurements of above ground biomass were taken following herbicidal treatments (applied the previous fall and spring), bush-hogging and replanting. The above ground biomass consisted almost entirely of weed cover, since the tree seedlings planted earlier in the year were still quite small and widely spaced. For all plots, the mean above ground biomass had been reduced considerably from the baseline levels of $6.45 \mathrm{~T} / \mathrm{ha}$ (2001) and 2.40 T/ha (2002) to a mean of $0.99 \mathrm{~T} / \mathrm{ha}$.

Year 3 project expenditures were $\$ 286,866$.

\section{Year 4}

In April 2004, visual estimates of seedling survivorship indicated that essentially all of the seedlings had survived from 2003. Irrigation of the site was conducted from May to November and resulted in phenomenal growth of both the herbaceous cover and seedlings. As a result, the mean above ground biomass level had climbed dramatically from $0.99 \mathrm{~T} / \mathrm{ha}$ (2003) to 5.42 T/ha.

As in the previous year, foliage samples taken in mid-summer revealed sufficient macronutrient levels in both species except for calcium which was low in all treatments. Calcium (Ca) concentration seems to be slightly improved by mulching but not by irrigation. Boron is within normal range for zero mulch/zero irrigation treatments, but very high for both treatments with high irrigation (mulching also seems to increase B levels even further). Although boron levels are high, sycamore seedlings show no signs of any toxicity. Sweet gum seedlings appeared much healthier than in the proceeding year. Foliar discoloration in sweet gum seedlings (as seen in 2003) was limited primarily to low-lying, poorly-drained portions of the site and did not point to any particular nutrient limitation or excess.

Soils were more intensively sampled and evaluated during 2004. Soils were sampled shortly after the cessation of irrigation activities in November 2003 and again in April 2004 in order to access possible changes in soil chemistry as a result of irrigation and winter/spring rains. In general, mulching with FGD materials resulted in an overall increase in calcium, sulfur, and boron throughout the soil profile.

Year 4 project expenditures were $\$ 127,500$.

\section{Year 5}

The seasonal operation of the drip irrigation system began in early May and ended in midOctober (five weeks earlier than in previous years) due to a complete pump engine failure. Due to the degree of senesce observed in both tree species and the assumed adequacy of the existing soil moisture levels, a decision was made to forego obtaining a new engine until the 
beginning of the 2006 growing season. It was apparent from observations made during the year that the irrigation was enhancing growth of both the herbaceous cover and seedlings, especially sycamores. Precipitation at the site during 2005 was below normal. Plots not receiving irrigation continued to experience seedling mortally, especially those planted in sweet gum. The decline in biomass of sweet gum was offset by the increases in biomass of the sycamores and herbaceous layer. As a result, the mean above ground carbon level continued to climb to 6.34 $\mathrm{MT} / \mathrm{ha}$.

As in the previous years, foliage samples taken in mid-summer revealed sufficient macronutrient levels in both species except for calcium which was low in most treatments. Calcium (Ca) concentration seems to be slightly improved by mulching but not by irrigation. Manganese (Mn) concentrations were slightly deficient in some plots and may be attributed to its low availability in soils with a high soil $\mathrm{pH}$, high organic matter or poor drainage. Boron was within normal range for zero mulch/zero irrigation treatments, but very high for both treatments with high irrigation (mulching also seems to increase B levels even further). Although boron levels were higher than in previous years, sycamore seedlings showed no signs of boron toxicity. Boron levels in sweet gum seedlings were lower than in 2004 and could possibly be attributed to the overall stagnation in growth and lower plant uptake.

Below-ground biomass was measured in all plots during December. The average amount of carbon being stored below ground (roots and soil by depth increment across all treatments) in 2005 indicated a shift in carbon distribution with depth, as well as an overall decline in root carbon as compared to baseline estimates made in 2001. Baseline $C$ in coarse roots in the 0 to $30 \mathrm{~cm}$ interval was estimated at $1.65 \mathrm{~T} / \mathrm{ha}$ in 2001. 2005 estimates of the same root fraction (including some fine roots) indicated a $67 \%$ decrease or $0.545 \mathrm{~T} / \mathrm{ha}$. Similar declines in root C were observed in the 30 to $60 \mathrm{~cm}$ and 60 to $90 \mathrm{~cm}$ depth intervals as well. This decline in the carbon stored in the roots may be due to shifts in the vegetation type (from a fescue dominated system to one dominated by Lespedeza and planted trees) or possibly affected as a result of herbicide treatments to remove vegetation prior to mulching and planting trees. In the base line estimates made in $2001,90 \%$ of the root carbon was found in the 0 to $30 \mathrm{~cm}$ depth interval. In 2005 , carbon measurements revealed that only $63 \%$ of root carbon is in the surface representing a shift in depth distribution that may also be attributed to vegetation changes.

FGD and soil from all plots were sampled at two depths $(0-25 \mathrm{~cm}$ and $26-50 \mathrm{~cm})$ in conjunction with below-ground biomass determinations. The sampling of the FGD gypsum was in response to the observation that plants (primarily in the herbaceous layer, but includes trees) are rooting directly in the mulch in many plots. Most nutrients were at acceptable levels for plant growth, although soil potassium and phosphorous in all plots were considered to be at deficient levels for optimum growth. Boron, calcium and sulfur concentrations are all higher in the FGD than the mineral soil, but do not differ significantly by either mulch or irrigation treatment as in the soil. Boron concentrations are significantly impacted by irrigation treatments, while calcium and sulfur concentrations are tied directly to mulch treatments. The results of the higher irrigation treatment is the continued accumulation of $B$ in the top $50 \mathrm{~cm}$ of the soil profile that is significantly higher than in either the zero or low irrigation treatments Calcium and sulfur continue to leach from the FGD mulch as indicated by the significant difference between their concentrations in the mulched and non-mulched plots.

Analysis of the surface and pore water data indicated that the irrigation source for the CCWESTRS site (coal ash pond) had levels of antimony, arsenic, cadmium, cobalt, chromium, copper, lead, mercury, nickel, selenium, and thallium at or below their Minimum Detection Limit. Levels of boron, calcium, magnesium and sulfate were slightly elevated and remained fairly constant as the water moves through the irrigation system, with only slight increases in sulfate and magnesium. After on-site application as irrigation water and subsequent percolation 
through the FGD mulch and upper soil horizons, levels of nitrogen, iron, magnesium, and sulfate increase, while boron decreases. Boron levels decrease and indicates that boron, at least initially, is being removed from the water and is potentially accumulating in the FGD mulch and upper horizons soil horizons. Boron levels in surface waters are similar to levels found in the ash pond (irrigation source). This may indicate the existence of surface runoff of the irrigation water or shallow lateral movement (via the upper layers of mulch and soil) of boron into the ponds. Iron and manganese levels in the ponds are similar to levels found in the irrigation water and are lower than groundwater levels. Surface water levels of magnesium, sulfate, ammonia and calcium are roughly midway between irrigation source and groundwater levels.

Year 5 project expenditures were $\$ 116,000$. 


\section{Table of Contents}

Disclaimer

Abstract

1.0 Introduction

1.1 General project overview

2.0 Executive Summary

3.0 Experimental methods description

4.0 Task 1. Review and Assessment

4.1 Boron Literature Reviews

4.1.1 Boron Tolerance

4.1.2 Soil Boron Loading Rates and Tolerances

4.2 Apparent Contradiction with Reeds and Cattails Growing in FGD Channel

4.3 Boron Treatment Literature Review

4.4 Other Terrestrial C Sequestration Projects

5.0 Task 2 - Site Assessment

5.12 .1 - Environmental Assessment and Permitting

5.22 .2 - Site Selection and Assessment

5.2.1 General site description

5.2.2 Surface water

5.2.3 Soil

5.2.4 Vegetation

5.2.5 Geology and Geohydrology

5.2.6 Surveys

5.2.7 Baseline Carbon Storage

5.2.7.1 Estimation of Baseline AG C at CCWESTRS Site

5.2.7.2 Estimation of Baseline BG $C$ at CCWESTRS Site

6.0 Task 3 - Greenhouse and Field Studies

6.1 Boron tolerance study

6.1.1 Introduction

6.1.2 Preliminary Test

6.1.2.1 Experimental Methods

6.1.2.2 Results and Discussion

6.2 Plant Screening Studies

6.2.1 Materials and Methods

6.2.2 Results

6.2.3 Water Use

6.2.3 Visual Toxicity Symptoms

6.2.4 Plant Tissue Boron Concentrations

6.2.4 Summary Discussion of Boron Tolerance Testing

6.2.5 Conclusions of Boron Tolerance Testing

6.3 Boron Leaching from Drip-Irrigated FGD Wastewater at the CCWESTRS Field Site

6.3.1 Background

6.3.2 Experimental Methods

6.3.3 Results

6.3.4 Conclusions for Boron Leaching Study

6.4 FGD Mulch Depth Field Study 
7.0 Task 4 - Engineering Design of CCWESTRS

7.1 Silvicultural Plan

7.2 Irrigation system

8.0 Task 5 - Construction of CCWESTRS

8.1 FGD Mulch Application

8.2 Tree Planting

8.2.1 2002 Tree Planting

8.2.2 2003 Tree Planting

8.3 Irrigation System Installation

9.0 Task 6 - Monitoring

9.1 Soils monitoring

9.1 .12002

9.1 .22003

9.1 .32004

9.1 .42005

9.2 Carbon Sequestration Monitoring

9.2.12002

9.2 .22003

9.2 .32004

9.2 .42005

9.3 Vegetation monitoring

9.3.1 Seedlings - survival and vigor

9.3.1.1 2002

9.3.1.2 2003

9.3.1.3 2004

9.3.1.4 2005

9.3.2 Ground Cover

9.3.2.1 2002

9.3.2.2 2003

9.3.2.3 2004

9.3.2.4 2005

9.3.3 Potato Pond Sub-Experimental Tree Planting

9.4 Water monitoring

9.4.1 Irrigation system monitoring

9.4.1.1 Operation - start-up

9.4.1.2 Operation \& Maintenance - 2003

9.4.1.3 Operation \& Maintenance - 2004

9.4.2 Surface and pore water monitoring

9.5 Meteorology

9.6 FGD Mulch Depth Field Study Monitoring

10.0 Project costs

11.0 Conclusions

References Cited

Selected Background Literature

List of Acronyms and Abbreviations

Appendices 


\section{Listing of Figures}

Figure 1. Aerial photograph showing pre-construction CCWESTRS site and adjacent areas.

Figure 2. Photo of soil exploration pit face showing foam and feeder roots extending from adjoining area of finely fractured rock.

Figure 3. Comparison of greenhouse seedling morphology of white pine grown in soil amended with (left to right) $0,10,35$, and $70 \mathrm{mg} \mathrm{B} / \mathrm{kg}$ soil and irrigated with FGD waste water containing $70 \mathrm{mg} / \mathrm{L}$ boron.

Figure 4. Comparison of greenhouse seedling morphology of white oak grown in soil amended to contain (left to right) $0,10,35$, and $70 \mathrm{mg} \mathrm{B} / \mathrm{kg}$ soil irrigated with FGD wastewater containing $70 \mathrm{mg} / \mathrm{l}$ boron.

Figure 5. Growth of white oak in response to soil B treatments and irrigated FGD waste water at 230 DAP.

Figure 6. Effect of B soil treatments and B irrigation on the 24 hour gravimetric water loss of tree test species at specified days after planting (DAP). Sycamore and cottonwood $=154$ DAP, red maple = 180 DAP, and sweetgum and tulip poplar = 104 DAP.

Figure 7. Seedling morphology of sycamore grown in soil amended to contain (left to right) 0 , 10 , and $35 \mathrm{mg} \mathrm{B} / \mathrm{kg}$ soil and irrigated with water containing $35 \mathrm{mg} \mathrm{B/L}$.

Figure 8. Seedling morphology of Eastern cottonwood grown in soil amended to contain (left to right) 0,10 , and $35 \mathrm{mg} \mathrm{B} / \mathrm{kg}$ soil and irrigated with water containing $35 \mathrm{mg} \mathrm{B} / \mathrm{l}$.

Figure 9. Seedling morphology of red maple grown in soil amended to contain (left to right) 0,10 , and $35 \mathrm{mg} \mathrm{B} / \mathrm{kg}$ soil and irrigated with water containing $35 \mathrm{mg} \mathrm{B/L}$.

Figure 10. Seedling morphology of sweetgum grown in soil amended to contain (left to right) $0,10,35 \mathrm{mg} \mathrm{B} / \mathrm{kg}$ soil and irrigated with water containing $35 \mathrm{mg} \mathrm{B} / \mathrm{L}$.

Figure 11. Seedling morphology of tulip poplar grown in soil amended to contain (left to right) 0,10 , and $35 \mathrm{mg} \mathrm{B} / \mathrm{kg}$ soil and irrigated with water containing $35 \mathrm{mg} / \mathrm{kg}$.

Figure 12 Effect of soil amended $B$ and irrigated $B$ on dry weight of attached tree leaves and stems of sycamore $(A)$, cottonwood (B), red maple (C), sweetgum (D), and tulip poplar (E) at designated harvest days after planting (DAP).

Figure 13. Effect of soil amended $B$ and irrigated $B$ on red maple stem growth rate $(\mathrm{cm})$ between 144 DAP and 209 DAP.

Figure 14. Effect of soil amended B (70 mg/kg soil) on red mulberry leaves.

Figure 15. Soil moisture content as affected by drip irrigation.

Figure 16. Hot water-extractable $B$ as affected by drip irrigation.

Figure 17. Calcium chloride-extractable $B$ as affected by drip irrigation.

Figure 18. $\mathrm{KCl}$-extractable $\mathrm{NH}_{4}$ as affected by drip irrigation.

Figure 19. $\mathrm{KCl}$-extractable $\mathrm{NO}_{3}$ as affected by drip irrigation.

Figure 20. Schematic of CCWESTRS test plan showing FGD mulch depth (colored) and irrigation levels $(\mathrm{Hi}=25 \mathrm{~cm} / \mathrm{yr}$, Lo $=12.5 \mathrm{~cm} / \mathrm{yr}$, Ze = zero irrigation).

Figure 21. Photo of intensive vegetative competition impacting seedlings in some areas of the CCWESTRS site during 2002.

Figure 22. Schematic diagram of the CCWESTRS irrigation system.

Figure 23. Photo of TORO's $16 \mathrm{~mm}$ drip emitters used in the study.

Figure 24. Initial survivorship of all seedlings planted in February and March 2002.

Figure 25. Ground application equipment used to apply herbicides on October 22, 2002.

Figure 26. Effect of mulching on changes in soil boron concentrations over time and by depth.

Figure 27. Soil boron concentrations as a function of depth and irrigation treatment.

Figure 28. Accumulation of $\mathrm{Ca}$ and $\mathrm{S}$ in the upper $45 \mathrm{~cm}$ of soils as a function of mulch treatment.

Figure 29. Impact of irrigation on soil S changes at various depths.

Figure 30. Effects of irrigation on changes to the percentages of soil organic matter by depth.

Figure 31. Effect of irrigation treatment on mean boron concentrations in FGD and soil by depth. 
Figure 32. Effect of mulch trt. on mean calcium concentrations in FGD and soil by depth.

Figure 33. Effect of mulch treatment on mean sulfur concentrations in FGD and soil by depth

Figure 34. Effect of Treatments on Aboveground Carbon after First Growing Season.

Figure 35. Aboveground biomass by mulch treatment for 2003 compared to mean

aboveground biomass in 2002 and pre-treatment baseline levels in 2001.

Figure 36. Seedling/tree standing biomass in 2004 as a function of treatments.

Figure 37. Average carbon being stored in the above ground biomass from 2001-2005.

Figure 38. Distribution of healthy seedlings by plot on CCWESTRS site August 2002.

Figure 39. Survival by Species and Mulch Treatment after First Growing Season

Figure 40. Percentage of Healthy Seedlings after One Growing Season.

Figure 41. Overall percentages of live seedlings and seedlings considered healthy in 2003.

Figure 42. Effect of irrigation on percent survival of sycamore and sweet gum seedlings in 2003.

Figure 43. Effect of irrigation on seedling health of sycamore and sweet gum seedlings in 2003.

Figure 44. Effect of FGD mulch on survival of sycamore and sweet gum seedlings in 2003.

Figure 45. Effect of FGD mulch on seedling health in 2003.

Figure 46. Boron concentrations in sycamore and sweet gum foliage for three treatment combinations and compared to normal healthy concentration ranges.

Figure 47. Calcium concentrations in sycamore and sweet gum foliage for three treatment combinations and compared to normal healthy concentration ranges.

Figure 48. Boron concentrations in both species by treatment and year.

Figure 49. Tree biomass (dry weight) in 2005 by species and mulch treatment.

Figure 50 . Tree biomass (dry weight) in 2005 by species and irrigation treatment.

Figure 51. Leaf boron concentrations in both species by treatment and year from 2003-2005.

Figure 52. distribution of aboveground biomass across the experimental site.

Figure 53. Ground cover by weed species, FGD mulch, and bare soil by mulch treatment.

Figure 54. Ground cover by weed species, irr. treatment, and soil by mulch treatment.

Figure 55. Ground cover percentages as a function of mulch treatment in 2004.

Figure 56. Ground cover percentages as a function of irrigation treatment in 2004.

Figure 57. Ground cover percentages as a function of irrigation treatment in 2005.

Figure 58. Precipitation and precipitation plus irrigation totals for the three water treatment levels used in the CCWESTRS study during 2003.

Figure 59. Precipitation and precipitation plus irrigation totals for the three water treatment levels used in the CCWESTRS study during 2004.

Figure 60. Precipitation and precipitation plus irrigation totals for the three water treatment levels used in the CCWESTRS study during 2005.

Figure 61. Boron in surface and pore waters from April 2003 - August 2004.

Figure 62. Calcium in surface and pore waters from April 2003 - August 2004.

Figure 63. Magnesium in surface and pore waters from April 2003 - August 2004.

Figure 64. Nitrogen (nitrate-nitrite) in surface and pore waters from April 2003 - August 2004.

Figure 65. Nitrogen (ammonia) surface and pore waters from April 2003 - August 2004.

Figure 66. Manganese in surface and pore waters from April 2003 - August 2004.

Figure 67. Sulfate in surface and pore waters from April 2003 - August 2004.

Figure 68. January - October 2002 CCWESTRS Precipitation Totals with Regional Norms.

Figure 69. Comparison of rainfall data May to October 2002 collected at Paradise meteorological station and at CCWESTRS site.

Figure 70. Quarterly precipitation amounts at the CCWESTRS site from July 2000 through November 2003. 
Figure 71. Maximum, mean, and long-term mean regional ambient air temperatures for the CCWESTRS site.

Figure 72. Monthly precipitation comparison at the CCWESTRS site for 2003-2005.

Figure 73. Wind speed statistics for the CCWESTRS site during the 2005 growing season.

Figure 74. Percent vegetative cover on FGD Depth Study sub-plots as a function of FGD mulch depth. Values represent a mean of three replications for each treatment.

Figure 75. Photo showing colonization of moss species on surfaces of FGD mulch.

Figure 76. Percentage of sub-plot surface covered by vegetation from 2001-2004. 


\section{Listing of Tables}

Table 1. CCWESTRS Treatment Design

Table 2. Selected chemical analysis (by depth) for all soils at the CCWESTRS site.

Table 3. Recommended yearly fertilization rates $\left(\mathrm{kg} \mathrm{ha}^{-1}\right)$ for CCWESTRS soils based on soil status/seedling requirements.

Table 4. Mean, minimum and maximum percentages of rock and soil from excavated soil exploration pits at the CCWESTRS site.

Table 5. Species identified within the 28 sample plots and their relative abundance.

Table 6. Belowground carbon by depth and type of carbon.

Table 7. Schedule of B Water Irrigation and Harvest Dates

Table 8. Leaf damage index as an indicator of $B$ tolerance $(8 / 13 / 01)$

Table 9. Effect of soil amended $B$ and irrigated $B$ on tree survival and surviving tree height.

Table 10. Effect of soil amended $B$ and simulated FGD wastewater (35 mg B/L) on $B$ concentrations $(\mathrm{mg} \mathrm{B} / \mathrm{kg}$ ) in stems and leaves of harvested trees.

Table 11. Costs for tree planting in 2003.

Table 12. Mean, minimum and maximum percentages of rock and soil from excavated soil pits at the CCWESTRS site.

Table 13. Below ground carbon by depth in 2005.

Table 14. Foliage sampling configuration for June 2002.

Table 15. Boron analysis of sweet gum (SG), sycamore (SY), and control (unplanted) seedlings taken from the CCWESTRS site in 2002.

Table 16. Survival Counts on Potato Pond Plot as of August 1, 2002.

Table 17. Constituents analyzed in lysimeter water samples.

Table 18. Results of soil moisture measurements.

Table 19. Regional wind speed comparison.

Table 20. Average coverage of fescue, moss/other vegetation and FGD Mulch. 


\subsection{Introduction}

\subsection{General project overview}

The ability of plants and microbes to remove and immobilize carbon dioxide from the atmosphere is a phenomenon which has long been recognized as a means of temporarily sequestering carbon, (e.g., Delcourt and Harris, 1980; Emanuel et al., 1980; Ausmus et al., 1976; Harris et al., 1975; Reichle et al., 1973). Consequently, utilities and other organizations (e.g., UtiliTree Carbon Company) are studying, proposing, and using afforestation techniques as a means of removing carbon dioxide from the atmosphere. However, most of these projects are geographically located in areas far removed from human-made carbon sources. Furthermore, these afforestation systems are not closely integrated with sources of anthropogenic carbon production. As a result, previous demonstrations of afforestation have not benefited from the use of industrial by-products, such as flue gas desulfurization (FGD) gypsum, which may enhance plant growth and subsequently, carbon sequestration.

In this project, the Tennessee Valley Authority (TVA), the Electric Power Research Institute (EPRI), and the Department of Energy - National Energy Technologies Laboratory (DOE-NETL) are evaluating and demonstrating integration of terrestrial carbon sequestration techniques with use of byproducts and wastewater from a coal-fired electric power plant. The industrial byproducts used during the demonstration include gypsum and process water from FGD and coal fly ash sluice system. The gypsum will be used as a soil amendment and the process water for periodic irrigation of the trees.

The integrated system is referred to as the "Carbon Capture and Water Emissions Treatment System" (CCWESTRS, or "C-kwesters"). The CCWESTRS was constructed near TVA's Paradise Fossil Plant (PAF) in Kentucky on adjacent marginally reclaimed surface coal mine lands located next to PAF. PAF is a 3-unit, 2,558 Mw, power station which burns bituminous coal and currently has FGD systems on Units 1 and 2, and a selective catalytic reduction system (SCR) (Srivastava et al. 1997; Khan et al., 1997) for nitrogen oxide control on Unit 2. All three PAF units will eventually have FGD and SCR systems.

The CCWESTRS demonstration system is constructed on gently rolling reclaimed coal mine lands consisting of mine spoil overlying Pennsylvanian age bedrock. The lands are partially vegetated, predominantly with grasses and other herbaceous plants, but have a relatively low productivity potential. The lands were reclaimed by returning the spoil to the mined-out areas, grading where necessary, and planting with grasses. These reclamation methods met the standards of the time, however, higher standards have since been established and areas reclaimed under the current regulatory standards are generally more productive.

During the demonstration, the CCWESTRS system will be used primarily as a means of growing commercial grade trees for use in either the lumber or pulp and paper industry. Vegetation will be a mix of deciduous hardwoods and cover crops. The cover crops will be used to prevent soil erosion as the trees mature. Due to the emphasis on the use of commercial grade trees, the project participants believe that the carbon captured will remain sequestered for a longer period of time than in most projects of this nature. For example, carbon sequestration is expected to be higher in CCWESTRS than in projects where the vegetation is allowed to die and decay or in projects where the vegetation is used as a fuel in co-fired electrical production facilities. The CCWESTRS system is expected to sequester between 1.5 to 2.0 metric tons of carbon per year per hectare of land over a twenty year period. Given the large amounts of reclaimed mined land available in the Eastern United States, the Project Team believes the CCWESTRS concept could be used to meet a significant proportion of the timber industry's needs, while 
simultaneously sequestering significant levels of carbon in lands which would otherwise remain relatively non-productive.

In addition to trees and cover crops, the CCWESTRS system will include surface-flow, aerobic, marsh-type wetlands to enhance the ability of the systems to sequester carbon and remove nutrients and metals present in the coal fly ash process water runoff. In addition to the wetlands, existing impoundments within or adjacent to the demonstration site will be enhanced through vegetative plantings, de-channelization, and erosion repair as necessary.

The CCWESTRS project is a cooperative effort between TVA, EPRI, and the Kentucky Department for Natural Resources. TVA provided $\$ 423,000$ in project funding, the PAF byproducts, the reclaimed mine lands, project management, technical expertise, and operating personnel. EPRI provided \$423,000 in funding and expertise in economic and technical analysis. DOE-NETL provided $\$ 729,000$ in funding along with project management and technical assistance.

The proposed demonstration project began in October 2000 and is anticipated to continue through December 2005, a period of approximately five years. The primary goal of the project is to determine if the concept of integrating power plant processes with local carbon sequestration systems will enhance carbon sequestration cost-effectively. The project participants believe this goal is consistent with the following DOE objectives:

- Provide economically competitive and environmentally safe options to offset projected growth in U.S. baseline emissions of greenhouse gases after 2010,

- Achieve the long-term goal of $\$ 10 /$ ton of avoided net costs for carbon sequestration, and

- Provide half of the required reductions in global greenhouse gases by 2025.

Other potential benefits of the demonstration include:

- Developing a passive technology for water treatment for trace metal and ammonia release reductions,

- Using power plant byproducts to improve coal mine land reclamation and carbon sequestration,

- Developing wildlife habitat and green-space around production facilities,

- Generating Total Maximum Daily Load (TMDL) credits for the use of process water, and

- Producing wood products for use by the lumber and pulp and paper industry.

Project tasks to be conducted during the five year project period include:

Task 1. Reviewing and assessing relevant terrestrial carbon sequestration literature.

Task 2. Conducting project site assessment.

Task 3. Conducting greenhouse studies on optimum plant species and FGD depths.

Task 4. Designing the CCWESTRS system.

Task 5. Constructing the system

Task 6. Monitoring

Task 7. Reporting

During the monitoring phase of the project, the Project Team will examine the effectiveness of three applied thicknesses of FGD gypsum and irrigating with three levels of coal fly ash process water on the CCWESTRS system. The ability of the system to sequester carbon will be the primary measure of effectiveness. This characteristic will be measured by accessing survival 
and growth response of terrestrial and aquatic plants, and by quantifying the change in $\mathrm{C}$ sequestered in the plants and soils within the CCWESTRS system. In addition, the costs associated with the design, construction, and operation of CCWESTRS at other sites will be evaluated and compared to projected benefits of other carbon sequestration technologies.

TVA plans to continue to operate the CCWESTRS system after the demonstration, to conduct follow-up tests on the system, and to issue periodic reports. Currently TVA is planning to reexamine system performance up to the year 2013. If additional funding becomes available, additional work will be conducted. 


\subsection{Executive Summary}

The Tennessee Valley Authority (TVA), the Electric Power Research Institute (EPRI), and the Department of Energy - National Energy Technologies Laboratory (DOE-NETL) are evaluating and demonstrating integration of terrestrial carbon sequestration techniques with use of byproducts and wastewater from a coal-fired electric power plant. Flue Gas Desulfurization (FGD) system gypsum will be used as a soil amendment and the coal fly ash process water will be used for periodic irrigation an integrated system named the "Carbon Capture and Water Emissions Treatment System" (CCWESTRS). In 2002, construction was initiated on the CCWESTRS near TVA's Paradise Fossil Plant (PAF) on adjacent reclaimed surface coal mine lands in the state of Kentucky.

The CCWESTRS demonstration system is being constructed on 40 hectares of gently rolling, partially vegetated, low productivity land. During the demonstration, the CCWESTRS system will be used primarily as a means of growing commercial grade trees for use in either the lumber or pulp and paper industry. Vegetation will be a mix of trees and cover crops. The CCWESTRS system is expected to sequester between 1.5 to 2.0 metric tons of carbon per year per hectare of land over a twenty year period. The CCWESTRS concept could be used to meet a significant proportion of the timber industry's needs, while simultaneously sequestering significant levels of carbon in lands which would otherwise remain relatively non-productive.

In addition to trees and cover crops, the CCWESTRS system will include surface-flow, aerobic, marsh-type wetlands to enhance the ability of the systems to sequester carbon and remove nutrients and metals present in the coal fly ash process water runoff. In addition to the wetlands, existing impoundments within or adjacent to the demonstration site will be enhanced through vegetative plantings, de-channelization, and erosion repair as necessary.

The CCWESTRS project is a cooperative effort between TVA, EPRI, and the Kentucky Department for Natural Resources. TVA will provide $\$ 423 \mathrm{~K}$ in project funding, the PAF byproducts, the reclaimed mine lands, project management, technical expertise, and operating personnel. EPRI will provide \$ 423 in funding and expertise in economic and technical analysis. The Kentucky Department of Natural Resources will review the technical approach and will provide assistance in local implementation. DOE is funding the project with $\$ 729 \mathrm{~K}$.

The proposed demonstration project began in October 2000 and will continue through December 2005, a period of approximately five years. Additional funding will be sought in order to extend the project.

The primary goal of the project is to determine if the concept of integrating power plant processes with local carbon sequestration systems will enhance carbon sequestration costeffectively. The project participants believe this goal is consistent with the following DOE objectives:

- Provide economically competitive and environmentally safe options to offset projected growth in U.S. baseline emissions of greenhouse gases after 2010,

- Achieve the long-term goal of $\$ 10 /$ ton of avoided net costs for carbon sequestration, and

- Provide half of the required reductions in global greenhouse gases by 2025.

Other potential benefits of the demonstration include:

- Developing a passive technology for water treatment for trace metal and ammonia release reductions, 
- Using power plant by-products to improve coal mine land reclamation and carbon sequestration,

- Developing wildlife habitat and green-space around production facilities,

- Generating Total Maximum Daily Load (TMDL) credits for the use of process water, and

- Producing wood products for use by the lumber and pulp and paper industry.

Project activities to be conducted during the five year project period include:

- Reviewing and assessing tree cultivation and other techniques to be used to sequester carbon at the site,

- Conducting a project site assessment,

- Conducting greenhouse studies to determine which plant species to use and developing recommendations for byproduct application,

- Designing the CCWESTRS system,

- Constructing the system,

- Operating the system and monitoring system progress and,

- Writing a final report.

During the monitoring phase of the project, the Project Team will examine the effectiveness of applying three levels $(0,10 \mathrm{~cm}$, and $20 \mathrm{~cm})$ of gypsum and irrigating with three levels $(0,13 \mathrm{~cm}$, and $25 \mathrm{~cm}$ ) of coal fly ash process water on the CCWESTRS system. The ability of the system to sequester carbon will be the primary measure of effectiveness. This characteristic will be measured by accessing survival and growth response of terrestrial and aquatic plants within the CCWESTRS system. In addition, the costs associated with the design, construction, and operation of CCWESTRS at other utilities will be evaluated and compared to projected benefits of other carbon sequestration technologies.

In Year 1 of the project, greenhouse tests and field testing evaluated the following:

(1) Tolerance of certain tree species to soil-borne boron (B)

(2) Tolerance of certain tree species to water-borne B

(3) Optimum depth of FGD gypsum byproduct to serve as mulch

Using the Paradise power plant FGD waste water as a source of irrigation on tree seedlings without first diluting the $B$ concentration will require careful planning and management. It is suggested that:

(1) The FGD water should be blended to $4 \mathrm{mg} \mathrm{B/l}$ or less prior to use.

(2) Allow trees to become fully established before applying diluted water.

(3) Do not saturate the soil with boronated waste water.

(4) Initially monitor $B$ and nitrogen $(N)$ in leaves to help schedule irrigation and fertilization.

(5) Monitor the accumulation of B in the soil profile.

(6) Schedule leaching irrigation with low B water to prevent B accumulation in the soil.

(7) Continue to search for more tolerant trees and crop management techniques to reduce the risk of irrigating with boronated waste water.

Overall, results from this B leaching study indicate that if wastewater containing B is dripirrigated to match evapotranspiration during the growing season, most of the applied B will be retained in the upper part of the rooting zone during the growing season. Since B is somewhat mobile at our study site, winter precipitation likely will leach much of the B out of the rooting zone, resulting in lower levels of soil B at the beginning of each growing season. With this type 
of pattern, application of $25 \mathrm{~cm}$ (9.84 in) of water containing $7 \mathrm{mg} \mathrm{B/l}$ irrigation water (e.g., the fly ash pond water) would result in an accumulation of about $7 \mathrm{mg} \mathrm{B} / \mathrm{kg}$ soil in the rooting zone by the end of each growing season. During the first part of each growing season, significantly less than an additional $7 \mathrm{mg} \mathrm{B} / \mathrm{kg}$ soil will have accumulated. The greenhouse B tolerance study indicated that sycamore, cottonwood, sweet gum, and red maple will tolerate $10 \mathrm{mg} \mathrm{B} / \mathrm{kg}$ soil reasonably well for about one growing season or less. Some B leaf damage would probably occur during the last part of the growing season and concentrate in the autumn leaf litter to be leached out by rainfall. The combined results of the greenhouse B tolerance study and the field B leaching study suggest that sycamore, cottonwood, sweet gum, and red maple will tolerate an annual application of $25 \mathrm{~cm}(\sim 10 \mathrm{in})$ fly ash pond water reasonably well, but that $25 \mathrm{~cm}(\sim 10 \mathrm{in})$ of FGD wastewater ( $\sim 70 \mathrm{mg} \mathrm{B/l})$ would be very damaging to the trees.

Based on a field study of replicated plots placed on actively growing fescue, the Project Team determined that the full-scale demonstration should be tested with zero, $10 \mathrm{~cm}$, and $20 \mathrm{~cm}$ depths of the FGD gypsum for mulch. A depth of $10 \mathrm{~cm}$ for the mulch appeared to be adequate.

The preliminary test plan involves the application of three levels each of two types of power plant by-products -- three levels of FGD gypsum mulch, and three levels of coal fly ash pond irrigation water. This design produces nine treatment levels $(3 \times 3)$, which will be tested with two species of hardwood trees (i.e., sweet gum and sycamore). Each treatment combination will be replicated three times, resulting in a total of 54 treatment plots ( 3 FGD gypsum levels $X 3$ irrigation water levels $\times 2$ tree species $\times 3$ replicates). Survival and growth response of plant species in terms of sequestering of carbon in plant material and soil will be the primary measure of effectiveness of each treatment.

In year 2 of the project, construction of the CCWESTRS site began with the placement of the FGD gypsum mulch and tree planting.

After extensive greenhouse testing of a number of tree species for tolerance to $B$, and consideration of other factors such as drought tolerance, growth rate, and commercial value, sycamore (Platanus occidentalis L.) and sweet gum (Liquidambar styraciflua L.) were chosen as the optimum species for planting. The planting of $\sim 63,000$ sycamore and sweet gum seedlings began 2-23-02 and was completed 3-7-02. Two rows of two-year-old tree seedlings were planted in February-March 2002 in each 3.7-m wide row of gypsum treatment (except in plots with zero gypsum treatment) at $2.44 \mathrm{~m} \times 2.44 \mathrm{~m}$ spacing. This planting pattern resulted in a 2.4$\mathrm{m}$ wide strip of gypsum between rows of trees on one side of a row and 0.6-m wide strip of mulch plus $1.2 \mathrm{~m}$ of grass plus a second $0.6 \mathrm{~m}$ of mulch between rows on the opposite side. Within each of the nine zones of FGD gypsum treatment, the three irrigation treatments were planned to be replicated randomly. Within each of the 27 irrigation areas (3 replicates of the nine possible gypsum-irrigation level combinations), half of the area was planted to sycamore and half to sweet gum, in a split-plot design. This resulted in 54 treatment plots of approximately 0.75 hectares each.

By May 2002, a survivorship survey was conducted in all plots for both tree species indicating that the percent survivorship for both species was greater than 85\%. In September 2002, seedling survival and vigor was poor across the entire study area. Sycamore average survival rate $(27 \%)$ was over twice that of sweet gum $(12 \%)$, and the percentage of healthy sycamore seedlings was considerably higher (17\% vs. $4 \%)$. Both species performed best under the high mulch treatment and worst under the zero mulch treatment. The high mulch application was more effective in reducing weed competition, especially from tall fescue and lespedeza species. 
Laboratory experiments conducted March-April, 2002 on a variety of tree species were tested for boron tolerance in addition to the 54 test plots conducted under field conditions. The laboratory test cell tree species did not perform adequately. Therefore, they were not considered for field use. The primary reason for the laboratory plot was to evaluate potential survival of the species under actual field conditions. Several relevant observations were observed.

August 2002 measurements indicated that on the zero mulch plots, above-ground biomass was reduced considerably from baseline levels (from $6.45 \mathrm{~T} / \mathrm{ha}$ to an average of $2.82 \mathrm{~T} / \mathrm{ha}$ ), probably largely the result of bush-hogging the entire study area in late spring 2002.

Due to various reasons and decisions, the irrigation system was not installed in 2002 as planned. One of the reasons was the initial poor performance of the seedlings, which showed significant leaf damage and symptoms of boron toxicity and heat stress, presumably from the FGD gypsum mulch. Rather than subject the trees to additional B stress from irrigation with water from the FGD pond, it was decided to allow the trees to adapt to conditions in a slower manner. Although rainfall was adequate through June 2002, in July and August rainfall was below normal and temperatures were above normal. Temporary irrigation with non-industrial fresh water was done in August 2002, however poor tree survival prompted a decision to cease irrigation and to replant the site in 2003.

Monthly monitored precipitation at the CCWESTRS site was higher during seedling establishment, while the summer months experienced below normal precipitation from May through early August. Monitored temperatures for the year were characterized as "much above normal".

Soil moisture data was measured in early August that indicated that the soil moisture in the zero mulch and mulched test plots was below the wilting point of about $9 \%$. During this same period, soil moisture in the FGD mulch exceeded the wilting point. Additional soil moisture measurements in August and October, however, indicated that soil moisture was adequate. Soil surface temperatures in the very dark FGD mulch were in excess of air temperatures (they were hot to the touch), but no actual subsurface soil temperature readings were obtained.

In year 3 of the project, the site was replanted, an irrigation system was installed and lysimeters were added to the study design to measure soil pore water.

Replanting was preceded by the removal of competing vegetation through herbicide applications and bush-hogging of the entire site. After inspecting and selecting quality seedling stock from state nurseries in Kentucky and Tennessee, replanting began 2-11-03 and was completed 3-12-03. Cursory survivorship estimates in early spring indicated that greater than $90 \%$ of the seedlings had broken dormancy. By August, a more quantitative survey would reveal that sycamore and sweet gum survivorship was greater than $80 \%$, as compared to $27 \%$ and $12 \%$ respectively in 2002 .

Installation of the drip irrigation system began in early March as tree planting was being completed. As designed, the irrigation system has the capacity to apply of up to $5 \mathrm{~cm}$ system was divided into two zones, with Zone 2 receiving one-half of the amounts of water that is applied to Zone 1. The irrigation water is pumped from an adjacent ash settling pond and is distributed through 1,107 drip lines that total 104,880 meters in length. Automated, daily checks and routine maintenance of the system insured proper operation throughout the growing season and resulted in targeted soil moisture regimes within each treatment. 
Fourteen pressure vacuum lysimeters were installed at 7 locations within the site in August 2003 to evaluate the efficiency of the vegetation, soils and underlying geology in removing metals and nutrients from the incoming irrigation water. The lysimeters were set at $1.5 \mathrm{~m}$ and $5.0 \mathrm{~m}$ depths for collecting samples of unsaturated zone flow-through as the irrigation water migrates vertically through the soil column. Two sets of samples were collected from the lysimeters in August and September 2003. Sample analyses were not performed during this reporting period, but will be completed for a full suite or metals, non-metals, nutrients, and field parameters.

Abundant spring precipitation and the installation of the irrigation system greatly improved seedling survival and vigor for both species in 2003. As seen in 2002, differences in seedling survival and vigor were also related to species differences and the level of mulch. Both species reacted favorably to higher irrigation rates, but differed significantly in respect to mulch depth. Survival rates of sycamore seedlings were only slightly reduced in higher mulch plots while the percentage of sweet gum survival dropped as mulch depth increased. Overall, seedling vigor (visual estimate) appeared high for both species throughout all treatments. Foliage samples taken in mid-summer revealed sufficient macronutrient levels in both species except for calcium which was low in all treatments. Calcium seems to be slightly improved by mulching but not by irrigation. Boron is within normal range for zero mulch/zero irrigation treatments, but very high for both treatments with high irrigation (mulching also seems to increase B levels even further). Although B levels are high, sycamore seedlings show no signs of any toxicity. Sweet gums do not look as healthy, but their appearance does not point to any particular nutrient limitation or excess

In August 2003, measurements of above ground biomass were taken following herbicidal treatments (applied the previous fall and spring), bush-hogging and replanting. The above ground biomass consisted almost entirely of weed cover, since the tree seedlings planted earlier in the year were still quite small and widely spaced. For all plots, the mean above ground biomass had been reduced considerably from the baseline levels of 6.45 T/ha (2001) and 2.40 T/ha (2002) to a mean of $0.99 \mathrm{~T} / \mathrm{ha}$.

In year 4 of the project, irrigation was continued in order to enhance seedling growth. Soil chemistry, soil water chemistry and seedling health were evaluated.

In April 2004, visual estimates of seedling survivorship indicated that essentially all of the seedlings had survived from 2003. Irrigation of the site was conducted from May to November and resulted in phenomenal growth of both the herbaceous cover and seedlings. As a result, the mean above ground biomass level had climbed dramatically from $0.99 \mathrm{~T} / \mathrm{ha}$ (2003) to 5.42 T/ha.

As in the previous year, foliage samples taken in mid-summer revealed sufficient macronutrient levels in both species except for calcium which was low in all treatments. Calcium (Ca) concentration seems to be slightly improved by mulching but not by irrigation. Boron is within normal range for zero mulch/zero irrigation treatments, but very high for both treatments with high irrigation (mulching also seems to increase B levels even further). Although boron levels are high, sycamore seedlings show no signs of any toxicity. Sweet gum seedlings appeared much healthier than in the proceeding year. Foliar discoloration in sweet gum seedlings (as seen in 2003) was limited primarily to low-lying, poorly-drained portions of the site and did not point to any particular nutrient limitation or excess.

Soils were more intensively sampled and evaluated during 2004. Soils were sampled shortly after the cessation of irrigation activities in November 2003 and again in April 2004 in order to 
access possible changes in soil chemistry as a result of irrigation and winter/spring rains. In general, mulching with FGD materials resulted in an overall increase in calcium, sulfur, and boron throughout the soil profile.

In year 5 of the project, irrigation was continued and differences between the two selected tree species became evident as sycamores flourished and sweet gums were challenged by site conditions.

The seasonal operation of the drip irrigation system began in early May and ended in midOctober. It was apparent from observations made during the year that the irrigation was enhancing growth of both the herbaceous cover and seedlings, especially sycamores. Precipitation at the site during 2005 was below normal. Plots not receiving irrigation continued to experience seedling mortally, especially those planted in sweet gum. As in the previous years, foliage samples taken in mid-summer revealed sufficient macronutrient levels in both species except for calcium which was low in most treatments. Boron was within normal range for zero mulch/zero irrigation treatments, but very high for both treatments with high irrigation (mulching also seems to increase B levels even further). Although boron levels were higher than in previous years, sycamore seedlings showed no signs of boron toxicity. Boron levels in sweet gum seedlings were lower than in 2004 and could possibly be attributed to the overall stagnation in growth and lower plant uptake.

The decline in biomass of sweet gum was offset by the increases in biomass of the sycamores and herbaceous layer. As a result, the mean above ground carbon level continued to climb to 6.34 MT/ha. Below-ground biomass was measured in all plots during December. The average amount of carbon being stored below ground in 2005 indicated a shift in carbon distribution with depth, as well as an overall decline in root carbon as compared to baseline estimates made in 2001. This decline in the carbon stored in the roots may be due to shifts in the vegetation type (from a fescue dominated system to one dominated by Lespedeza and planted trees) or possibly affected as a result of herbicide treatments to remove vegetation prior to mulching and planting trees. In the base line estimates made in $2001,90 \%$ of the root carbon was found in the 0 to $30 \mathrm{~cm}$ depth interval. In 2005, carbon measurements revealed that only $63 \%$ of root carbon is in the surface representing a shift in depth distribution that may also be attributed to vegetation changes.

FGD and soil from all plots were sampled at two depths $(0-25 \mathrm{~cm}$ and $26-50 \mathrm{~cm})$. The sampling of the FGD gypsum was in response to the observation that plants (primarily in the herbaceous layer, but includes trees) are rooting directly in the mulch in many plots. Most nutrients were at acceptable levels for plant growth, although soil potassium and phosphorous in all plots were considered to be at deficient levels for optimum growth. Boron, calcium and sulfur concentrations are all higher in the FGD than the mineral soil, but do not differ significantly by either mulch or irrigation treatment as in the soil. Boron concentrations are significantly impacted by irrigation treatments, while calcium and sulfur concentrations are tied directly to mulch treatments. The results of the higher irrigation treatment is the continued accumulation of $B$ in the top $50 \mathrm{~cm}$ of the soil profile that is significantly higher than in either the zero or low irrigation treatments Calcium and sulfur continue to leach from the FGD mulch as indicated by the significant difference between their concentrations in the mulched and non-mulched plots.

Analysis of the surface and pore water data indicated that the irrigation source for the CCWESTRS site (coal ash pond) had levels of antimony, arsenic, cadmium, cobalt, chromium, copper, lead, mercury, nickel, selenium, and thallium at or below their Minimum Detection Limit. Levels of boron, calcium, magnesium and sulfate were slightly elevated and remained fairly constant as the water moves through the irrigation system, with only slight increases in sulfate 
and magnesium. After on-site application as irrigation water and subsequent percolation through the FGD mulch and upper soil horizons, levels of nitrogen, iron, magnesium, and sulfate increase, while boron decreases. Boron levels decrease and indicates that boron, at least initially, is being removed from the water and is potentially accumulating in the FGD mulch and upper horizons soil horizons. Boron levels in surface waters are similar to levels found in the ash pond (irrigation source). This may indicate the existence of surface runoff of the irrigation water or shallow lateral movement (via the upper layers of mulch and soil) of boron into the ponds. Iron and manganese levels in the ponds are similar to levels found in the irrigation water and are lower than groundwater levels. Surface water levels of magnesium, sulfate, ammonia and calcium are roughly midway between irrigation source and groundwater levels.

Year 1 project expenditures were $\$ 241,601$. Year 2 project expenditures were $\$ 446,897$. Year 3 project expenditures were $\$ 286,866$. Year 4 project expenditures were $\$ 127,500$. Year 5 project expenditures were $\$ 116,000$. 


\subsection{Experimental methods description}

The project is divided into 7 tasks:

Task 1 - Review and Assessment

Task 2 - Site Assessment

Task 3 - Greenhouse Study

Task 4 - Engineering Design of CCWESTRS

Task 5 - Construction of CCWESTRS

Task 6 - Monitoring

Task 7 - Reporting

In Year 1 of the project, progress occurred as planned on Task 1, Task 2, Task 3, Task 4, and Task 7. In Years 2 - 5, progress occurred as planned on Tasks 1-7. Progress on each task is described in the following sections with respect to the experimental or planned design, results, discussion, conclusions, and recommendations. All plants are referred to in this report as common names with scientific names listed in Appendix 1.

\subsection{Task 1. Review and Assessment}

This task consisted of initial literature reviews, detailed planning of the greenhouse, preliminary field, and final experimental studies. Literature searches and reviews were conducted to identify past and existing projects or studies related to this proposal with regard to silvicultural approaches to the reclamation of disturbed land, irrigation aspects, ammonia and boron toxicity, gypsum soil amendment, and other relevant topics to complete the project design. Results of these literature reviews are described in subsequent sections. An extensive bibliography of literature related to terrestrial carbon sequestration is found at the end of this report.

This task developed in detail the proposed experimental plan, which will evaluate the effectiveness of the application of three levels of FGD gypsum and three levels of coal fly ash pond water on the reclamation of mine spoil land with an herbaceous cover crop. Survival and growth response of plant species in terms of sequestering of carbon in plant material and soil will be the primary measure of effectiveness. The approach provides a three-by-three-by-two experimental design as outlined in Table 1. Each treatment combination will be replicated three times, resulting in a total of 54 treatment plots ( 3 gypsum levels $\times 3$ water levels $\times 2$ species mixes $x 3$ replications). The same design would be applied to both species. Treatment plots are currently estimated to be about 0.75 ha in area. All treatments will receive lime and N-P-K fertilization as the need indicated by soil and foliar tests. Quantities of FGD gypsum and irrigant to be used in the high and low treatments are based upon results of greenhouse research described later in this report.

\begin{tabular}{|l|l|l|l|}
\hline & $\begin{array}{l}\text { High FGD } \\
\text { Gypsum }\end{array}$ & $\begin{array}{l}\text { Low FGD } \\
\text { Gypsum }\end{array}$ & $\begin{array}{l}\text { Control (no FGD } \\
\text { Gypsum) }\end{array}$ \\
\hline High irrigation & $\mathrm{X}$ & $\mathrm{X}$ & $\mathrm{X}$ \\
\hline Low irrigation & $\mathrm{X}$ & $\mathrm{X}$ & $\mathrm{X}$ \\
\hline Control (no water) & $\mathrm{X}$ & $\mathrm{X}$ & $\mathrm{X}$ \\
\hline
\end{tabular}

Table 1. CCWESTRS Treatment design. 


\subsection{Boron Literature Reviews}

One of the major challenges of the project resulted from the presence of significant concentrations of B in the proposed irrigation water. Under Task 1, the Project Team developed an experimental plan to test the tolerance of various tree species with respect to soil and irrigant $B$. The plan and results of these tests are described in a following section of this report.

Boron is of greatest interest in this project because it is highly soluble, present in the proposed irrigation water (i.e., the Paradise Fossil Plant FGD process and ash pond water) at average concentrations of about $7 \mathrm{mg} / \mathrm{l}$ (ash pond water) and $58 \mathrm{mg} / \mathrm{l}$ (FGD water), and considered phytotoxic at sufficient concentrations. The $\mathrm{B}$ concentration in the final fly ash pond discharge is about $4.2 \mathrm{mg} / \mathrm{l}$. The following is a brief review of key literature sources concerning the likely extent that $B$ in these wastewater sources will be phytotoxic if used to irrigate trees.

\subsubsection{Boron Tolerance}

At low concentrations, B poses no threat to environmental health and is required in soils at continuous levels for optimum plant growth and seed production (Brown and Shelp, 1997). Leyshon and Jame (1993), Van der Leeden et al. (1990), and Bond et al. (1973) each provide the same lists of plants that are classified as tolerant, semi-tolerant, and sensitive along with limits for B in irrigation water and/or soil water. Sposito and Calderone (1988) summarized the literature for vascular plants including about 42 species of trees and have provided the most complete list found. These lists include trees and mostly agronomic crops. Examples of more tolerant species are alleppo pine, turnips, sugar beets, and cotton. Examples of moderately tolerant plants are Arizona cypress, barley, peas, corn, potato, tobacco, and tomato. Examples of sensitive species are American elm, black locust, live oak, incense cedar, peach, grapes, kidney beans, and figs (Appendix 1). In general, the plant tissue B concentration is 10 or more times higher in dicots than in monocots and even higher in dicots with a latex system (e.g., dandelion and poppy). This suggests that dicots are more tolerant of high $B$ levels than monocots. Little B sensitivity data were found for specific tree species. In general, B toxicity tends to predominate in xeric habitats where B is not leached out of the soil. Trees usually aren't grown in these dry areas unless they are irrigated. This may account for the lack of published information on B toxicity for trees.

Leyshon and Jame (1993) indicated that the upper limit for B in irrigation water for the most tolerant species is $4 \mathrm{mg} / \mathrm{l}$. The upper B limit is slightly lower in Van der Leeden et al. (1990) and Bond et al. (1973). Non-fruit producing hardwoods (e.g., walnut and American elm) are listed as sensitive with a B limit in irrigation water of about $1 \mathrm{mg} / \mathrm{l}$. No data are listed for pines. Leyshon and Jame (1993) provide the most specific definition for tolerance: "Relative tolerance is based on $B$ in irrigation water at which B toxicity symptoms were observed when plants were grown in sand culture. This does not necessarily mean reduction in yield."

These levels are obviously much lower than $\sim 58 \mathrm{mg} / \mathrm{l}$ of $\mathrm{B}$ in the Paradise FGD wastewater or even the $\sim 4.2 \mathrm{mg} / \mathrm{l}$ of $B$ in the Paradise fly ash pond water. It is quite possible that somewhat higher B levels than 1 to $4 \mathrm{mg} / \mathrm{l}$ in irrigation water can be tolerated without reducing growth significantly or killing the plants. Also, some B likely will leach out of the rooting zone during the winter months in Kentucky, more so than in drier areas where irrigation is widely practiced. This should facilitate using somewhat higher B concentrations in irrigation water than is possible in drier areas. The concentration of $B$ in irrigation water that trees can tolerate without adversely affecting growth likely will depend on how much B is applied per hectare per year as discussed in the next section. 


\subsubsection{Soil Boron Loading Rates and Tolerances}

The Boron Fact Sheet (2000) provides a good overview of soil and plant B. Of all the micronutrients, $B$ has the narrowest range between deficiency and toxicity. What may be an effective fertilizer rate for plants on one soil type (e.g., clay) may well lead to toxicity on another (e.g., sand). In order to correct B deficiencies, about 0.5 to $5 \mathrm{~kg} / \mathrm{ha}$ of boron normally is added. Up to $5 \mathrm{~kg} / \mathrm{ha}$ of boron is required to correct B deficiencies on pine trees. Soils with more than 5 $\mathrm{mg} / \mathrm{kg}$ soil of water soluble boron may supply toxic quantities of $B$ to plants; this corresponds to about $10 \mathrm{~kg} / \mathrm{ha}$ boron in the top $15 \mathrm{~cm}$ of soil, a typical depth to which B would be mixed in the soil by tillage. Adding $25 \mathrm{~cm}$ of water containing $70 \mathrm{mg} / \mathrm{l} \mathrm{B}$ would add about $170 \mathrm{~kg} / \mathrm{ha}$ B or 17 times more $B$ than generally required to induce B toxicity symptoms. Although visual B toxicity symptoms can be readily induced by excessive B application from fertilizers, significant yield reductions seldom are associated even with slight to moderate visual symptoms in the field. Most excessive fertilizer applications likely would be no more than twice the recommended rate. However, a 17X rate would be expected to cause a significant reduction in yields and ultimately kill the plants. Under Kentucky conditions, winter rainfall likely will leach some of the B below the rooting zone, but the Boron Fact Sheet (2000) strongly suggests that adding $170 \mathrm{~kg} / \mathrm{ha} \mathrm{B}$ every year during the growing season likely will cause severe B toxicity to trees and any cover crop that would be considered for the CCWESTRS field demonstration. In a study where fly ash was distributed over land, B concentrations increased to phytotoxic levels in the top $20 \mathrm{~cm}$ of soil. However, after $82 \mathrm{~cm}$ of accumulated rainfall, B levels fell to below $1 \mathrm{mg} / \mathrm{kg}$ (Gangloff et al. 1997).

On the other hand, adding $25 \mathrm{~cm}$ of water containing $4.2 \mathrm{mg} / \mathrm{l} \mathrm{B}$ would add about $10 \mathrm{~kg} / \mathrm{ha} \mathrm{B}$, enough to barely produce a borderline level of toxicity for many plants.

Boron toxicity data are limited for trees. Toxicity has been observed from native sources of B, but in forest trees $B$ toxicity has been observed most often from applications of borax used as a soil sterilizer, fire retardant, wood preservative, herbicide, or as a fertilizer on resistant crops (Stone 1967). Unwitting use of B-containing fertilizers intended for alfalfa or sugar beets (crops with a relatively high $B$ fertilizer requirement but less than $5 \mathrm{~kg} / \mathrm{ha} B$ ) have injured coniferous nursery stock on sandy soils; this indicates that even relatively low B loading rates that are beneficial to alfalfa or sugar beets can be detrimental to trees in some cases. Orchard pecan trees 20 to 30 years old showed leaf injury when excess B applications were made 8-11 m away from the trunk.

As a point of reference, 1 ha-cm of water with a concentration of $70 \mathrm{mg} / \mathrm{l} \mathrm{B}$ contains about 6.8 $\mathrm{kg} \mathrm{B}$. In order to significantly enhance tree growth and carbon sequestration via improved water supply, several centimeters of water will need to be applied during a given growing season. Application of $25 \mathrm{~cm}$ of FGD wastewater per year (a reasonable amount relative to irrigation water requirements) would provide about $170 \mathrm{~kg} / \mathrm{ha} /$ year $\mathrm{B}$. As indicated in the Boron Fact Sheet (2000), this is much more B than is generally required to correct B deficiencies and is also much more $B$ than is considered safe without causing phytotoxicity. Seventy $\mathrm{mg} / \mathrm{l}$ B of irrigation water is at least an order of magnitude too high to be used to enhance growth of any trees and/or cover crops proposed to be grown in the CCWESTRS project and that options are needed for removing or diluting $B$ in the wastewater before it is used for irrigation. The fly ash pond water $(\sim 4.2 \mathrm{mg} / \mathrm{l})$ appears to be more nearly in the range that plants can tolerate. However, more site-specific information than exists in the literature is needed as a basis for designing the CCWESTRS field demonstration. Laboratory-scale tree B tolerance and B leaching studies were conducted to provide more site-specific information about how to best 
use the FGD waste water and fly ash pond water for irrigating trees in the CCWESTRS field demonstration.

\subsection{Apparent Contradiction with Reeds and Cattails Growing in FGD Channel}

The Project Team observed that reeds, cattails, and other similar species grow in a ditch that conveys Paradise FGD wastewater containing high concentrations of $B$ to the fly ash pond. This could be interpreted as a contradiction to the literature cited above concerning the predicted phytotoxicity of $B$ in the FGD water.

A partial explanation is that reeds and cattails tolerate very high levels of $B$, higher levels than many upland plants appear to tolerate. Terry and Whiting (1999) reported in a microcosm wetland study that cattail survived for the duration of the study (54 days) in water containing approximately $45 \mathrm{mg} / \mathrm{l} \mathrm{B}$. Cattail dry matter was about $90 \%$ of that produced in water without B. Fourteen wetland species were tested. Cattail was one of seven that survived and one of three that produced dry matter comparable to that in the control without B. Some aquatic plants have necessarily developed mechanisms for tolerating constituents that tend to be harmful to upland plants. Some of these mechanisms are root avoidance, compartmentalization, chelation, and precipitation in the rhizosphere and/or within the plant itself. These mechanisms have not been developed as extensively by upland plants adapted to well-drained soils.

The mechanism of B tolerance for the existing plants growing in the FGD channel is unknown. Mechanisms for B tolerance and ecotype adaptation to ecosystems can involve more than the B plant physiology. It is possible that $B$ is being adsorbed at or just below the water-ditch interface at Paradise whereas the primary root activity is below the $\mathrm{B}$ adsorption zone. It is quite possible that various constituents from the wastewater have accumulated near the water-soil interface that in turn are capable of adsorbing B. Iron and aluminum hydroxides and finely divided lime can all adsorb B.

\subsection{Boron Treatment Literature Review}

The Project Team reviewed potential technologies to remove B from the irrigant. Because the amount of irrigant required for CCWESTRS is a large volume ( $>10$ million liters), and we require a low-maintenance, low-cost system in order to minimize cost impacts to the overall carbon sequestration economics, the literature review concentrated on passive treatment system potential for B removal. Numerous B removal technologies exist and include B exchange resins, reverse osmosis, the formation of anionic clay layers, polymer-assisted ultrafiltration, and remediation. However, no information on the successful use of passive treatment systems (e.g., constructed wetlands, rock or sand filters, bio-filters, etc.) was identified.

lon exchange is the most extensively used method of B removal from aqueous solutions (Badruck et al., 1999; Meyers et al. 2000). Ion exchange involves water flowing through a synthetic resin material such as Amberlite IRA 743, Diaion CRB 02, and Duolite ES 371. Ions in the water are exchanged for other ions fixed to the resin. Removal of ions such as $B$ can be achieved using ion exchange but once the resins become saturated and cannot bind the unwanted ion to be removed, it must be regenerated using a process called stripping to restore the ion-exchange ability to the resin. Although effective to purify water to very high standards, ion exchange regeneration uses strong acids and bases of which must be disposed. The resin beds can be permanently fouled and enhance bacterial growth, and capital and operation and maintenance costs are very high. Ion exchange is not practical or cost effective to remove $B$ for irrigation in a CCWESTRS-type scenario. 
Reverse osmosis is a membrane separation process in which feed water flows along the membrane surface under pressure. Purified water permeates the membrane and is collected, while the concentrated water, containing dissolved and undissolved material that does not flow through the membrane, is discharged to a drain. Reverse osmosis systems remove salts, microorganisms and many high molecular weight organics at nominal levels of $95-98 \%$. Physicochemical characteristics of B make its removal much less efficient, on the order of 80 $85 \%$ of the influent $B$. Reverse osmosis is less expensive than ion exchange, does not require much energy to operate the system, and the membranes last for long periods of time. However, operation and maintenance costs make reverse osmosis impractical for a CCWESTRS-type project.

The formation of anionic clay layers has proven effective in removing $\mathrm{B}$ from coal ash leachate (Reardon and Valle, 1997). Dolomite $\left(\mathrm{Ca}-\mathrm{Mg}\left(\mathrm{CO}_{3}\right)_{2}\right)$ and hydrated lime $\left(\mathrm{Ca}(\mathrm{OH})_{2}\right)$ are added to the coal ash. The addition of the two substances results in an anionic clay composed of double metal hydroxide layers consisting of net positive charges. The metal hydroxides result from the reaction:

$$
\mathrm{Ca}(\mathrm{OH})_{2}(\mathrm{~s})+\mathrm{CaMg}\left(\mathrm{CO}_{3}\right)_{2}(\mathrm{~s}) \rightarrow 2 \mathrm{CaCO}_{3}(\mathrm{~s})+\mathrm{Mg}(\mathrm{OH})_{2}(\mathrm{~s})
$$

The anionic elements in the fly ash water accumulate along the metal hydroxide layers. In water at $\mathrm{pH}>9$, B exists as a negatively charged oxyanion, borate, $\mathrm{BO}_{3}{ }^{-3}$. At lower $\mathrm{pH}$ the anionic clay is ineffective due to the fact that $\mathrm{B}$ exists as boric acid, $\mathrm{H}_{3} \mathrm{BO}_{3}$. The majority of $\mathrm{B}$ in a coal combustion stream, including the FGD water, exists as borate condensates on the surface of ash particles. In its aqueous borate form, B is best removed by the addition of both lime and dolomite. The addition of dolomite alone fails to produce the necessary $\mathrm{pH}$ levels to remove $\mathrm{B}$. However, the addition of lime alone results in hexagonal crystal structures composed of fly ash trace elements and lime called hydrocalumite $\left(\mathrm{Ca}_{4} \mathrm{Al}_{2} \mathrm{CO}_{3}(\mathrm{OH})_{12}{ }^{*} 5 \mathrm{H}_{2} \mathrm{O}\right)$ and hydrotalcite $\left(\mathrm{Mg}_{6} \mathrm{Al}_{2} \mathrm{CO}_{3}(\mathrm{OH})_{16}{ }^{*} 4 \mathrm{H}_{2} \mathrm{O}\right)$. The crystal layers in the anionic clay are separated by $\mathrm{H}_{2} \mathrm{O}$ and carbonate layers. Anions in the coal ash leachate are attracted to the positively charged $\mathrm{Al}^{+3}$, $\mathrm{Ca}^{+2}, \mathrm{Mg}^{+2}$ cations in the crystal structure. Aqueous borate concentrations may be even further reduced since borate may be substituted for carbonate in the intermediate anionic clay layers. One issue with the anionic clays is that they must be maintained at high $\mathrm{pH}$ levels. Hydrotalcite is stable to near neutral $\mathrm{pH}$ but hydrocalumite is only stable at alkaline $\mathrm{pH}$ levels.

In another related study, Goldberg and Forster (1991) found that B sorption on calcareous soils and calcite peaked at $\mathrm{pH}$ 9.5. They suggest that soil calcite acts as an important sink for $\mathrm{B}$ in calcareous soils that may play an important role in attenuating phytotoxic B concentrations from irrigation waters. The applicability of alkaline addition or treatment of the FGD water will be further investigated in this project.

Phytoremediation of B could occur through the use of hyperaccumulating plants at the CCWESTRS site. In a study conducted in microcosm wetlands with $13 \mathrm{~cm}$ of substrate and 6 $\mathrm{cm}$ of water column above the substrate, B was removed at a rate of $245 \mathrm{mg} / \mathrm{m}^{2} /$ day (Whiting and Terry, 1999). Although B was removed in these microcosms, in order to treat $\sim 27 \mathrm{I} / \mathrm{min}$ of water with a concentration of $58 \mathrm{mg} / \mathrm{l} \mathrm{B}$, a wetland with an area of about 3.8 ha would be required. Thalia, cattail, and rabbitfoot grass were the most tolerant plant species in the study that resulted in the highest B removal. Reed (1988) documents a Florida water hyacinth experiment in which the subtropical waterweed was successful in removing up to $36 \%$ of aqueous B. Phelps et al. (2002) suggests that B removal may be accomplished by the incorporation of $B$ with algal cells or by the formation of insoluble B precipitates mediated by mineral-precipitating bacteria. EPRI (1998) evaluated a constructed wetland facility to treat acid 
drainage from a coal ash disposal facility. Boron, a constituent in the acid drainage, was not removed to any degree by the wetland.

\subsection{Other Terrestrial C Sequestration Projects}

A complete review of terrestrial carbon sequestration projects is beyond the scope or need for this project. The CCWESTRS project is unique in that it proposes to integrate certain operational features of a fossil-fueled electric power generation plant with improved carbon sequestration, including using FGD byproducts for mulching and irrigation. The literature search uncovered no similar documented project anywhere in the world.

A related project is being conducted by the Oak Ridge National Laboratory and Pacific Northwest National Laboratory to study the use of soil enhancers made from coal plant fly ash, paper mills, and sewage treatment facilities to improve the natural carbon uptake of lands disturbed by mining, highway construction, or poor management practices (Palumbo, 2000). Class $\mathrm{C}$ and class $\mathrm{F}$ fly ash samples tested under column $\left.(5 \mathrm{mM} \mathrm{CaCl})_{2}\right)$ and batch leaching scenarios indicated variability in leachate composition between fly ash sources, especially with regard to lighter elements including boron (Palumbo et al. 2004). Fly ash mixed with soil from the TVA Paradise site and biosolid material or phosphate fertilizer showed a reduction in metal concentration recovered from column leachate, indicating that fly ash together with additional amendments, such as biosolids minimize leaching of metals. The primary goal is to identify and quantify key factors leading to successful carbon sequestration and reclamation of degraded lands. The results will be summarized in a set of guidelines containing practical information about matching amendment combinations to land types and optimum site-management practices. Long-term field studies will be designed and sites will be recommended for demonstration and optimization.

Another related project is being conducted by Allegheny Energy, Inc., in partnership with the DOE and the U.S. Office of Surface Mining, as well as several other local agencies and organizations. This pilot project was designed to demonstrate the technical and economic feasibility of revegetating strip-mined land for carbon sequestration, water quality enhancement, and environmental stewardship value. The Limestone Run Revegetation Project will involve planting more than 7,000 red and white pine seedlings and 0.2 ha of warm season, native grasses on an 8 ha former strip mine site purchased by Allegheny Energy after it had been mined and reclaimed. As part of the research, Allegheny Energy will mix fly ash from Armstrong Power Station with the revegetated soil to measure its effectiveness in stimulating plant growth. If proven effective, the application of fly ash could increase its marketability so that greater quantities can be used beneficially, reducing the amount that is deposited in landfills (Myers 2001).

Several NETL-sponsored projects are underway that deal with terrestrial carbon sequestration and power plant operations. Kronrad (2002) proposes to reclaim and reforest abandoned mine lands in the Appalachian region to store carbon in trees and forest ecosystems. Palumbo (2002) focuses on solid amendments from coal combustion, paper production, and biological wastetreatment, with the primary objective to identify and quantify key factors leading to successful carbon sequestration and reclamation of degraded lands. Roussopoulos (2002) proposes to investigate the use of forest biomass and various waste materials, including coal combustion byproducts, incorporated into the soil to restore its quality, increase long-term carbon sequestration, and enhance short- and long-term productivity and sustainability. 


\subsection{Task 2 - Site Assessment}

\subsection{Environmental Assessment and Permitting}

TVA is required to conduct environmental reviews of its proposed actions in accordance with the National Environmental Policy Act (NEPA). The Project Team completed an environmental review in the form of a TVA Environmental Decision Record (EDR) in accordance with TVA's September, 1996 "NEPA Guidance for Implementing Process Improvements for Environmental Review" (Tennessee Valley Authority, 2001). Additionally, the Project Manager contacted the Kentucky Department for Environmental Protection (KDEP) regarding any need for modifying or preparing environmental permits necessary for construction and operation of the CCWESTRS. Paradise Fossil Plant (PAF) currently operates under Kentucky Pollutant Discharge Elimination System permit KY0004201 which regulates discharge quality from the fly ash pond. Based on the project plans provided, the KDEP approved the CCWESTRS project without any additional permit or permit modification. Additionally, a Permit-By-Rule was obtained from the Kentucky Division of Solid Waste regarding the addition of FGD gypsum by-product to the CCWESTRS site. No additional permits or approvals have been identified, but if needed over the course of the project, they will be properly addressed. Irrigation water will be collected in the fly ash pond, and no permit modification was required from KDEP.

In December 2002 TVA completed the Installation of Flue Gas Desulfurization System on Paradise Fossil Plant Unit 3 Draft Environmental Assessment, (Tennessee Valley Authority, 2002). In January 1999, TVA completed the Environmental Assessment (EA) - Paradise Fossil Plant Units 1, 2, and 3 Selective Catalytic Reduction Systems for Nitrogen Oxide Control (Tennessee Valley Authority, 1999). Most of the general information, detailed site information, and conclusions contained in the January 1999 Environmental Assessment (EA) and in the December 2002 EA is applicable to the CCWESTRS project. Some of the information is referenced as support for the conclusions of the CCWESTRS EDR.

In 1996, TVA completed the Environmental Assessment (EA) - Development of Ash Disposal Capacity at Paradise Fossil Plant (Tennessee Valley Authority, 1996). Most of the general information and much of the detailed site information and conclusions contained in the 1996 EA is applicable to the CCWESTRS project and is referenced as support for the conclusions of the CCWESTRS EDR.

\subsection{Site Selection and Assessment}

The project Team conducted site technical assessments and preliminary engineering assessments related to the test design, irrigant distribution and collection, and various site characteristics. Project Team identified and reviewed existing data (internal TVA reports, topographic and land ownership maps, Paradise environmental reviews, aerial photography, and published reports for the site), identified data gaps, and collected additional data through field surveys. These data included soil surveys, topographic and slope data, photographic surveys, existing vegetation surveys, and baseline carbon budget.

\subsubsection{General site description}

The CCWESTRS site is located on the PAF reservation in Muhlenberg County, Kentucky. PAF is on the left (southwest) bank of the Green River. The plant site extends south beyond Hollmans Bend and the confluence of Jacobs Creek with the Green River. The plant is about $9.7 \mathrm{~km}$ northwest of Rochester and $2 \mathrm{~km}$ northeast of Drakesboro, KY. PAF is a 3-unit, 2558$\mathrm{Mw}$, power station that burns bituminous coal and uses flue gas desulfurization (FGD) in Units 1 $\& 2$, generating gypsum byproduct. In 2000, PAF began selective catalytic reduction (SCR) 
operations for nitrogen oxides $\left(\mathrm{NO}_{\mathrm{x}}\right)$ removal on Units 1 and 2, with future installation of SCR on Unit 3 planned for summer 2003. To convert $\mathrm{NO}_{\mathrm{X}}$, SCRs use ammonia to produce $\mathrm{N}_{2}$ gas and water; excess ammonia may slip through the airflow and be discharged with the FGD effluent. Therefore, ammonia discharge limits could be imposed on the ash pond discharge. The ash water also contains criteria metals that must be removed before discharge, including copper, nickel, zinc, chromium, and others

The site consists of about 40.5 ha of gently rolling, previously coal-mined land (pre-SMCRA) in the Interior Low Plateau physiographic province. Site slopes range from $0 \%$ to $12 \%$. The land is owned by TVA and is adjacent to land owned by Peabody Coal Company, Inc. Elevations range from $116 \mathrm{~m}$ to $146 \mathrm{~m}$ above mean sea level. Annual average rainfall is $114 \mathrm{~cm} /$ year, and 13 $\mathrm{cm} /$ day is the highest 24-hour rainfall intensity with an average 10-year recurrence interval (Choate, 1992). Mean annual temperature is $13.2^{\circ} \mathrm{C}$, with winter mean at $2.1^{\circ} \mathrm{C}$ and summer mean at $23.8^{\circ} \mathrm{C}$. The mean annual lake evaporation for Paradise is $89 \mathrm{~cm}$ (U.S. Dept. of Commerce, 1968). Figure 1 is an aerial photograph showing the CCWESTRS site and surrounding area before construction of the CCWESTRS.

\subsubsection{Surface water}

There are no named streams, perennial streams, or formally named impoundments on the site. Drainage occurs by overland flow through sheet flow, rills, gullies, and poorly defined channels, and by subsurface infiltration and migration through undifferentiated mine spoil to nearby surface impoundments, wetlands, and wet-weather seeps. Surface runoff is generally directed to the PAF Fly Ash Pond, to small surface impoundments informally called the Potato Pond and Pooh Bear ponds, or to an unnamed, enhanced marsh-type wetland (Figure 1). There were no sustained or perennial seeps or springs observed on or near the site during 2001-2003, although there are several wet weather seeps and moist areas that represent the interception of perched or unsaturated zone groundwater with the ground surface.

Water samples from several locations on or near the site were collected on May 31, 2001 and stored using EPA-approved grab-sampling techniques. Samples were shipped to the TVA Environmental Chemistry Laboratory in Chattanooga, Tennessee and analyzed for constituents described in the Groundwater section above. Surface water samples were taken from the FGD discharge, the upper FGD channel weir midway between the FGD discharge and the Fly Ash Pond, the lower FGD channel weir (where the FGD channel discharges into the Fly Ash Pond), from a location in the Fly Ash Pond adjacent to the CCWESTRS site, from the "Catfish Pond" west-southwest of the CCWESTRS site, from the "Catfish Pond" west-southwest of the CCWESTRS site, and in the surface impoundment south of the CCWESTRS site (see Figure 1). All samples were analyzed for aluminum, antimony, arsenic, beryllium, cadmium, chromium, copper, iron, manganese, lead, mercury, nickel, zinc, silver, thallium, molybdenum, B, fluoride, chloride, sulfate, acidity, alkalinity and total suspended and dissolved solids. Field measurements included temperature, conductivity, $\mathrm{pH}$, acidity, and alkalinity. Results of the water baseline analyses are contained in Appendix 2. These baseline samples will be compared to yearly samples taken at the same locations during or shortly after irrigation operation to determine if groundwater or surface water migration into nearby surface waters is causing any impact. It is not expected that any adverse impacts will occur due to the minor nature of the operation. In fact, an improvement in local groundwater quality is a more likely result since we will be irrigating with pretreated irrigant that will be of better quality than that present in the spoil aquifer (see subsequent section on groundwater-5.2.5). 


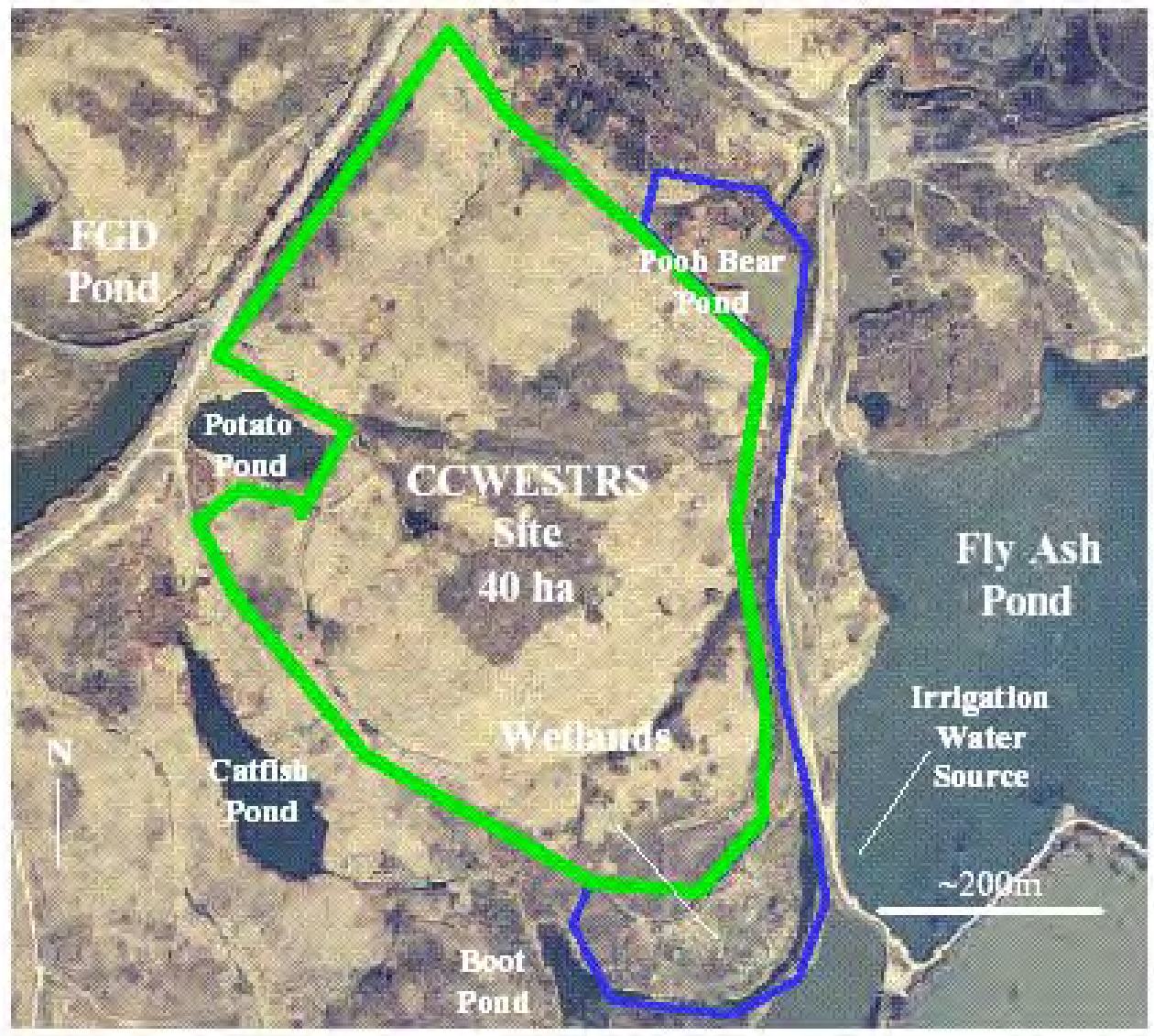

Figure 1. Aerial photograph showing pre-construction CCWESTRS site and adjacent areas.

\subsubsection{Soil}

The CCWESTRS site is located on a pre-SMCRA reclaimed coal mine, and as such, is overlain by undifferentiated mine spoil, characterized as having a large volume of fractured rock with little soil development. Project Team Soil Scientists surveyed and sampled site soils in 2001 for physical and chemical analyses. Three transects were established and sampled at $60.8 \mathrm{~m}$ intervals along each transect to a targeted depth of $100-120 \mathrm{~cm}$. A total of 28 locations were sampled along the three transects. Although the targeted sample depth was $100-120 \mathrm{~cm}$, coarse fragments and large stones and boulders limited our ability to sample to the desired depth at all sampling points. Coarse fragment (i.e., rock) content throughout the majority of soils ranged from $35 \%$ to $70 \%$ of the soil volume, with very few locations being fragment-free. These fragments consisted of relatively unweathered pieces of shale, sandstone, coal and limestone. The average depth to auger refusal was $75 \mathrm{~cm}$, with some locations being as shallow as $40 \mathrm{~cm}$. These shallow locations were sporadic and not consistent enough to map. With limited soil water holding capacity and shallow soil depths, moderate to severe water deficits could be common during much of the growing season without irrigation. The southern portion of the study site contained some areas which appeared to be comparatively wetter as evidenced by gleyed soils, hydrophilic vegetation and the presence of water at the time of sampling. It should be noted that, although our ability to auger was restricted by the coarse fragment content, the existence of continuous restrictive layers is rare and in most places there appears to be sufficient soil among the coarse fragments to allow exploration by plant roots to the depth of a meter or more. 
A subset of soil samples was analyzed at A\&L Agricultural Laboratories in Memphis, TN for all major nutrients (Table 2). Soil pH was more alkaline than expected, but was found to be typical for many of the reclaimed mine sites in the area. Less than $10 \%$ of the total samples were associated with the predominance of acid sandstone in some locations and highly leached hydric soils in others. Earlier reclamation efforts included the addition of excessive amounts of crushed limestone (inexpensive and locally available) in order to reverse the effects of acidic drainage. Local sources of limestone are known to be rather high in calcium. The relative high $\mathrm{pH}$ observed at all depths, would indicate that conifers will not perform well under these conditions since almost all pine species suffer severe micronutrient deficiencies (iron, copper, manganese, etc.) at these $\mathrm{pH}$ 's and may have difficulty extracting phosphorus. Hardwood species such as sycamore, Eastern cottonwood or hybrid poplar, red maple, sweet gum, and chestnut oak should respond better to the neutral to mildly alkaline conditions.

\begin{tabular}{|l|l|l|l|l|l|l|l|l|}
\hline Depth & & Soil pH & $\mathrm{P}\left(\mathrm{kg} \mathrm{ha}^{-1}\right)$ & $\mathrm{K}\left(\mathrm{kg} \mathrm{ha}^{-1}\right)$ & $\mathrm{Ca}\left(\mathrm{kg} \mathrm{ha}^{-1}\right)$ & $\mathrm{Mg}\left(\mathrm{kg} \mathrm{ha}^{-1}\right)$ & $\% \mathrm{OM}$ & $\mathrm{CEC}$ \\
\hline & & & & & & & & \\
\hline $0-30 \mathrm{~cm}$ & Mean & 7.3 & 122.1 & 345.5 & 12723 & 1179 & 1.4 & 33.4 \\
\hline $30-60 \mathrm{~cm}$ & Mean & 7.3 & 73.7 & 296.4 & 13824 & 1620 & 0.9 & 37.4 \\
\hline $60-90 \mathrm{~cm}$ & Mean & 7.7 & 64 & 291.2 & 13899 & 2099 & 0.8 & 39.2 \\
\hline
\end{tabular}

Table 2. Selected chemical analysis (by depth) for all soils at the CCWESTRS site.

Fertilizer recommendations (from A\&L Laboratories) were based on the nutritional requirements of hardwood species identified in the initial screening study. These recommendations are found in Table 3. Since the proposed planting densities may limit accessibility within the site in the near future (for broadcast fertilization), a double application of the less mobile elements ( $P$ and K) was applied in November 2001. Nitrogen will be applied to the trees through the drip irrigation system in 2003. An additional benefit of fertilization, is the possibility that soil pH may be lowered slightly, which may be beneficial to tree species such as sweet gum.

\begin{tabular}{|l|l|l|l|l|l|l|}
\hline Depth & & Lime & N & P2O5 & K2O & Mg \\
\hline $0-30 \mathrm{~cm}$ & Mean & 0.0 & 56 & 31.2 & 60.7 & 0.0 \\
\hline $30-60 \mathrm{~cm}$ & Mean & 0.0 & 56 & 49.7 & 72.1 & 0.0 \\
\hline
\end{tabular}

Table 3. Recommended yearly fertilization rates $\left(\mathrm{kg} \mathrm{ha}^{-1}\right)$ for CCWESTRS soils based on soil status/seedling requirements.

In 2002, selected physical parameters were characterized within the soil profile on the test site. The percentage of rock within the soil has a direct influence on the soil's ability to retain moisture, as well as providing areas for plant root exploration. A track-hoe excavated pits at four locations that were considered typical for the varying landforms found at the CCWESTRS site. Along opposing sides in each pit, a clear piece of 30 mil plastic was extended from the surface to a depth of $1.8 \mathrm{~m}$ and all areas of solid rock, coarse and finely fractured rock and soils were traced onto the plastic surface. The volume percentage of each fraction was then determined using a point intercept method. In areas considered to be soil (but still containing appreciable rock material), cylindrical areas $\left(500\right.$ to $1000 \mathrm{~cm}^{3}$ ) within the pit face were excavated at 30,60 , 90 and $120 \mathrm{~cm}$ depth and all materials (rock, soil and roots) were carefully collected for 
processing in the laboratory. The volume of each excavated area was determined by filling each with expanding foam. Once hardened, the foam was removed, cleaned of debris and its volume determined by displacement in water under laboratory conditions. All root materials (used for below ground carbon estimates) were removed from the soil by dry sieving, washed to remove adhering soil particles, dried and weighed.

Results of the study show that large pieces of solid rock (primarily sandstone and shale) can comprise as much as $29 \%$ of the entire soil profile, but averages as little as $5.5 \%$ (Table 4 ). Coarse and finely fractured rock dominated by shale is similar (though elevated), but unlike the solid rock, these areas can contain significant quantities of feeder roots (Figure 2). Within the areas designated as soil, rock fragments ( $>2 \mathrm{~mm}$ diameter) still can comprise as much as $51.6 \%$ of the total volume.

Although the focus of this exercise was to quantify the amount and distribution of roots throughout the soil profile for carbon estimates, it also documents how coarse-textured the soils are and gives some insight into expected moisture retention and release. Periodic sampling of soil moisture was conducted at random locations within the CCWESTRS site in 2002. Although moisture release curves have not been developed specifically for the CCWESTRS soils, the data collected from the pit study and gravimetric sampling during 2002 have helped construct a moisture evaluation guide with which moisture release can be evaluated at the CCWESTRS site.

Available water in the soil is that portion that can be absorbed by plant roots. It is the amount of water released between in situ field capacity (i.e., the maximum water content before gravity drainage starts) and the permanent wilting point (i.e., soil moisture content at which plants wilt and fail to recover their turgidity when placed in a dark, humid atmosphere), and is equivalent to soil matric potentials of -0.3 and $-1.5 \mathrm{MPa}$, respectively. Field capacity can be estimated by sampling the desired soil depth within two or three days preceding a sufficient rain event. Although soil textures (and consequently soil moisture) within the CCWESTRS site do vary, the field capacity of the top $40 \mathrm{~cm}$ of soil has been determined to be $15 \%$ (range 13 to $17 \%$ ) by weight. This value was determined by sampling in late October and early November 2002 when sufficient precipitation had fallen at the site (Figure 2). Using these data as indicators of ideal moisture conditions, sampling in early August revealed that soil moisture was limited with soil moisture percentages ranging between 6 and $9 \%$. Soil moisture percentages this low would indicate that the seedling roots were experiencing soil matric potentials at or near the permanent wilting point. These data also indicate a relatively low available water capacity, ranging from 6 to $11 \%$. 


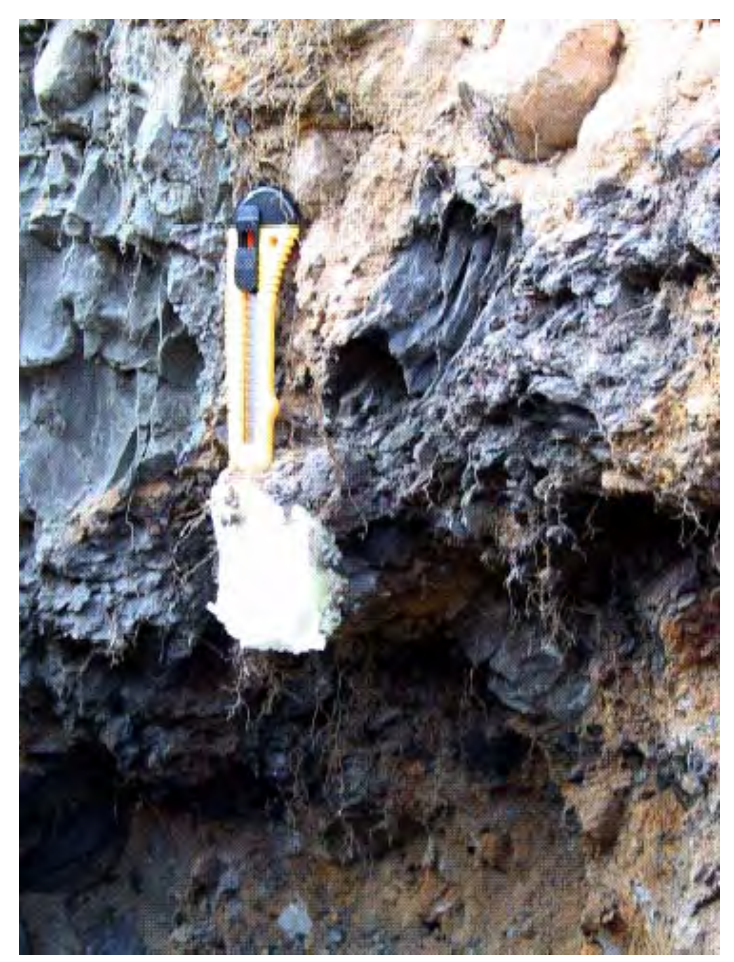

Figure 2. Photo of soil exploration pit face showing foam and feeder roots extending from adjoining area of finely fractured rock.

\begin{tabular}{|l|l|l|l|l|}
\hline $\begin{array}{l}\text { Fraction of } \\
\text { Profile }\end{array}$ & \% Solid Rock & $\begin{array}{c}\text { \% Coarse } \\
\text { Fractured } \\
\text { Rock }\end{array}$ & $\begin{array}{c}\text { \% Finely } \\
\text { Fractured Rock }\end{array}$ & $\begin{array}{c}\text { \% Soil } \\
\text { (and >2 mm } \\
\text { Fraction) }\end{array}$ \\
\hline Mean & 5.5 & 5.3 & 9.6 & $79.4(24.6)$ \\
\hline Minimum & 0 & 1.7 & 0 & $50.6(3.4)$ \\
\hline Maximum & 29.4 & 6.7 & 41.9 & $95.4(51.6)$ \\
\hline
\end{tabular}

Table 4. Mean, minimum and maximum percentages of rock and soil from excavated soil exploration pits at the CCWESTRS site.

\subsubsection{Vegetation}

A vegetative survey was conducted in May 2001 using 24 randomly selected plots $\left(\mathrm{m}^{2}\right)$ along five transects, including those established in our initial soil surveys. Species composition and percent total coverage were determined for all herbaceous species within each $\mathrm{m}^{2}$ sampling plot. The number of woody plant species within the sampling template was recorded and the contribution to the standing biomass was determined by prism count. In addition, the percent bare soil was noted. After the tally of all species within the sampling area was taken, all vegetation was clipped at ground level and surface litter collected and returned to the laboratory for total biomass determinations.

Thirteen herbaceous species were identified within the 28 sample plots and their relative abundance can be found in Table 5 . Only $0.1 \%$ of the CCWESTRS site is not covered in some form of vegetation. In terms of species composition, all plots fell within two distinct groups that 
were dominated by either tall fescue or lespedeza, both of which were the predominate species planted during reclamation of the site. The plots dominated by fescue rarely contained more than one or two additional species because of fescue's ability to out-compete most other vegetation, especially under conditions that are less than ideal. Plots dominated by lespedeza varied somewhat in their species composition and ranged from completely pure stands to ones quickly being overtaken by other species (pokeweed, thistle and prickly lettuce).

Although trees species like Eastern Red Cedar, Honey-Locust, Eastern Cottonwood, Eastern Redbud, and Box-Elder are observed at the site, their relative contribution to the surface vegetative cover is less than $0.01 \%$ percent.

\begin{tabular}{|l|l|l|}
\hline Species & Scientific Name & \multicolumn{1}{c|}{ \%of Total } \\
\cline { 2 - 3 } Cover \\
\hline Broom Sedge & Andropogon virginicus & 1.6 \\
\hline Carolina Geranium & Geranium carolianum & 0.3 \\
\hline Tall Fescue & Festuca arundinacea & 59.6 \\
\hline Prickly Lettuce & Lactuca scariola & 5.1 \\
\hline Sericea Lespedeza & Lespedeza sericea & 8.3 \\
\hline Korean Lespedeza & Lespedeza stipulacea & 12.6 \\
\hline Sour Clover & Melilotus indica & 9.3 \\
\hline Moss & Bryophytes & 6.1 \\
\hline Virginia Creeper & Parthenocissus & 3.4 \\
\hline Pokeweed & quinquefolia & \\
\hline Thistle & Phytolacca americana & 0.1 \\
\hline Venus' Looking Glass & Triodanis perfoliata & 1.2 \\
\hline Violet & Viola sp. & 0.3 \\
\hline
\end{tabular}

Table 5. Species identified within the 28 sample plots and their relative abundance.

\subsubsection{Geology and Geohydrology}

The site is located in the western Kentucky coal fields in the Shawnee section of the Interior Low Plateaus developed in the upland area. The CCWESTRS site is underlain by up to about $20 \mathrm{~m}$ of coal surface mining spoil consisting of sandy, silty, and gravelly clay mixed with coal and occasional limestone. The groundwater is generally poor quality (high acidity and hardness with elevated concentrations of metals, sulfate, and dissolved solids). Groundwater within the mine spoil flows generally toward the Fly Ash Pond. Irrigant will be applied periodically during the growing season via drip emitters at a rate of no more than about $25 \mathrm{~cm}$ per year. Detailed geologic and geohydrologic descriptions are found in Lindquist and Danzig (1998).

\subsubsection{Surveying}

\subsubsection{Plan layout}

The primary consideration for treatment layouts was to attempt to follow the topographic lay of the land so that rows were nearly level. Heavy equipment use for placement of FGD mulch and water pressure control after installation of irrigation lines generated the need for more level placement. In order to orient treatment tracts to accomplish nearly level ground placement, a 
spatially correct aerial orthophotograph was overlain with a 1-foot contour interval topographic map graphic. The FGD mulch and irrigation treatments were draft dimensioned and oriented parallel with contours on the photo.

\subsubsection{Draft dimensioning}

The treatments included three depths of mulching, three levels of irrigation, two tree species, and three replicates of each treatment for a total of 54 plots. The general site allowed 40 hectares to be divided into three large rectangles that would accommodate consistent levelcontour placement. These three rectangles constituted the first tier of treatments covering replication. The first tier rectangles were divided into three rectangles for the second tier of treatments covering mulch depth. The second tier rectangles were divided into three rectangles for the third tier of treatment covering irrigation level, and the third tier rectangles were divided into two squares for the fourth tier covering tree species. The size of a plot is 0.74 hectares. Latitudes and longitudes were generated for draft plot corners to the third tier level, i.e., corners for 27 rectangles from the geographic information system spatial layer associated with the orthophotograph. Numbers were assigned to the rectangles at each treatment tier level for use during randomization of treatment locations. One second tier rectangle, mulch depth, was divided in half and the halves were located on opposite sides of the site due to site topographic constraints.

\subsubsection{Random assignment}

The first tier division of the site into three larger rectangles was for replication only and did not require randomization. The second tier rectangles for three mulch depths were randomly located within each of the replication (first) tier rectangles by generating one of zero, eight, or fifteen centimeter depths from the Ferrara Pan ${ }^{\circledR}$ Atomic Fireball Random Number Generator (AFRNG) sequentially for the three second tier rectangles. If the $15 \mathrm{~cm}$ depth was generated first, that depth was assigned to the first rectangle, and if followed by zero, that depth was assigned to the second plot, and so on. The AFRNG was used in the same manner for the third tier rectangles for irrigation depth application. This division yielded nine smaller rectangles within the first tier. Zero, 13, and $25 \mathrm{~cm}$ annual depths of irrigation water were generated sequentially for the nine plots within each first tier rectangle and so on. The fourth tier locations for tree species were generated similarly by generating one species for one half of each third tier rectangle with the other half of the rectangle selected for the second species.

\subsubsection{Site survey control}

Property boundaries for the TVA PAF plant site provided outer limits for the study site. The property boundaries were available in latitude and longitude coordinates. The northwest corner of the general study site was near a property boundary corner marked with a steel T post. Two dirt roads known to lie within the TVA property boundaries originated at this corner and paralleled the proposed study boundary to the northwest and to the southwest. These roads (and the steel post) were used as the rough site survey control. A global positioning satellite (GPS) receiving unit was used to verify the positions of the steel post and the roads.

\subsubsection{Field layout}

The latitudes and longitudes generated during draft dimensioning for the draft plot corners were located in the field using the hand-held GPS unit. These points were roughly staked in the field using color-coded wire stake flags. The points were then checked and adjusted by direct measurement using a $30 \mathrm{~m}$ measuring tape. 


\subsubsection{Baseline Carbon Storage}

Changes in carbon storage on site will be carefully monitored throughout the study. Initial assessments of carbon stored on site, prior to the initiation of experimental treatments, were completed during this period and include measurements of (1) carbon stored in above-ground vegetation-mostly grasses and lespedeza, and (2) carbon stored below ground, both as soil carbon and as roots of the existing vegetation.

In the future, effects of treatments on above-ground carbon storage will be evaluated by measurements of tree survival, height, and basal diameters at both one and two years after planting. Amounts of woody biomass and carbon (C) sequestered will be estimated from these data using standard forest growth project models. Herbaceous biomass and litter will also be quantified after one and two years. Soils will be re-sampled for total $\mathrm{C}$ content (soil carbon plus roots) after two years. Combining the above data will provide an estimate of the amount $\mathrm{C}$ sequestered over the first two years. Additional funding will be sought to monitor these sites at subsequent five-year intervals following planting to get a much more complete picture of the $\mathrm{C}$ sequestration potential.

\subsubsection{Estimation of Baseline Aboveground C at CCWESTRS Site}

By the method described below, our site currently contains approximately 6.4 metric tons (T) of carbon per hectare (14.3 T dried organic matter) above ground. This amounts to $260 \mathrm{~T}$ of $\mathrm{C}$ for the entire 40.5 hectares. Note that this includes a considerable amount of plant litter above the mineral soil surface.

This calculation is based upon samples collected and oven-dried and weighed from 24 onemeter-square plots spaced along transects across the research site. On each plot both live and dead vegetation was clipped to the soil surface and plant litter was also collected. Of these 24 plots, $54 \%$ were dominated by fescue grass; $29 \%$ were dominated by species of lespedeza; $8 \%$ were dominated by sour clover, and $8 \%$ were about $50-50$ grass and lespedeza.

On average, using a typical $C$ fraction in organic matter of 0.45 , the lespedeza plots $(7.44 \mathrm{~T} / \mathrm{ha})$ contained about $60 \%$ more organic matter than the grass plots $(5.13 \mathrm{~T} / \mathrm{ha})$. Consequently an attempt was made to determine the surface area dominated by each type of vegetation. Using aerial photography, it was estimated, based upon the darkness of vegetative cover, approximately $60 \%$ of the area was dominated by grasses or clover, and $40 \%$ by other vegetation (mostly lespedeza). As can be seen from the above-described plot data, this is not inconsistent with a determination based on the 24 plots actually sampled. By stratifying the plots so as to place the clover-dominated and the grass-dominated together, it was determined that the 40.5 hectares contained approximately $578 \mathrm{~T}$ of oven-dried organic matter. This translates to $260 \mathrm{~T}$ of $\mathrm{C}$ for the entire 40.5 hectares or 6.42 metric tons of $\mathrm{C}$ per hectare.

\subsubsection{Estimation of Baseline Belowground C at CCWESTRS Site}

In contrast to aboveground carbon, the site is estimated to contain about 50.3 T of carbon per hectare belowground, or almost eight times the amount above ground. This amounts to about $2,040 \mathrm{~T}$ of $\mathrm{C}$ for the entire 40.5 hectares (100 acres). Based on the values for organic matter content of $0.8 \%$ as deep into the soil as $90 \mathrm{~cm}$, we suspect that more than half of this $\mathrm{C}$ is derived from fossil $\mathrm{C}$ mixed in with the buried spoil (Table 6). Small amounts of coal and coal shale were observed mixed throughout the spoil material. The fact that soil $\mathrm{C}$ declines very slowly with depth while coarse root material collected on sieves drops rapidly with depth also 
supports the contention that much of this $C$ is not of recent plant origin. At the 30 to $60 \mathrm{~cm}$ depth, root $C$ on average declines by more than $90 \%$ from its level in the 0 to $30 \mathrm{~cm}$ depth interval, yet soil $\mathrm{C}$ as a whole only declines by $35 \%$ over the same depth change.

Belowground carbon determinations were made from samples collected from soil cores taken with a bucket auger at 20 locations along transects representing $30-\mathrm{cm}$ depth intervals down to $90 \mathrm{~cm}$, and from four large pits dug with a backhoe at locations spaced across the site. Soil organic matter contents were determined by traditional methods using cored samples of soil and soft fractured rock that passed through a $2 \mathrm{~mm}$ sieve. Both faces of the backhoe-dug pits were used to determine, by $30-\mathrm{cm}$ depth intervals, (1) rock content, (2) coarse root content not passing a $2 \mathrm{~mm}$ sieve (Table 6), and (3) bulk density of the soil plus soft fractured rock fraction.

Rock content (excluding soft fractured material) averaged $30 \%$ to $40 \%$ across the three depth intervals, and bulk densities (including material from fractured rock) were quite high, ranging from 1.73 to 1.82 . Approximately half the $C$ total in the upper $90 \mathrm{~cm}$ was found in the upper 30 $\mathrm{cm}$. Unlike forest soils where coarse roots can compose a significant amount (up to $40 \%$ ) of the belowground $\mathrm{C}$, in these soils, coarse roots constituted less than $4 \%$ of the total, averaging only about $6 \%$ of the total in the upper $30 \mathrm{~cm}$ and about $1 \%$ of the total from $30 \mathrm{~cm}$ down to $90 \mathrm{~cm}$. Fine roots were not separated from the soil plus soft fractured rock fraction (due to labor intensity to do this), thus the fine root $C$ is included in the soil $C$ fraction shown in Table 6.

\begin{tabular}{|l|l|l|l|}
\hline $\begin{array}{l}\text { Soil Depth } \\
\text { Interval }(\mathbf{c m})\end{array}$ & $\begin{array}{l}\text { C as Coarse Roots } \\
\text { (T/ha) }\end{array}$ & $\begin{array}{l}\text { Soil Carbon } \\
\text { (T/ha) }\end{array}$ & $\begin{array}{l}\text { Total Belowground } \\
\text { Carbon (T/ha) }\end{array}$ \\
\hline $\mathbf{0}$ to $\mathbf{3 0}$ & 1.65 & 23.35 & 25.00 \\
\hline $\mathbf{3 0}$ to $\mathbf{6 0}$ & 0.15 & 13.25 & 13.40 \\
\hline $\mathbf{6 0}$ to $\mathbf{9 0}$ & 0.10 & 11.80 & 11.90 \\
\hline Total & 1.90 & 48.40 & 50.30 \\
\hline
\end{tabular}

Table 6. Belowground carbon by depth and type of carbon.

\subsection{Task 3 - Greenhouse and Field Studies}

The objectives of the greenhouse and field studies were to determine appropriate growth media, plant species, and amendment and irrigant application rates for the full-scale study by conducting short duration laboratory- and field-scale trials in TVA greenhouse facilities and at the CCWESTRS site. Technical areas requiring study included:

- $\quad$ Dealing with potential toxicity due to concentrated elements (particularly B) found in FGD gypsum and FGD water (i.e., the irrigant)

- $\quad$ Pre-testing for optimum plant species to grow in proposed soil media (FGD gypsum plus mine spoil)

- $\quad$ Experimenting with ideal methods for maintaining nutrients on site.

The sensitivity of target plant species (both tree seedlings and herbaceous cover crop seeds) to potential toxicity of FGD gypsum and FGD water was tested by examining selected plant responses to:

- $\quad$ Projected soil solution chemistry during active plant growth and during dormancy 
- $\quad$ Sensitivity to direct application to above-ground plant parts during both active growth and dormancy.

Other approaches to dealing with potential B toxicity were evaluated, including:

- $\quad$ Determining the concentration reductions necessary to avoid the above-determined sensitivities

- $\quad$ Lowering B concentration in pond water by various methods

- $\quad$ Leaching $B$ from soil solution with simulated rain water

Performance of various plant species in FGD gypsum was determined from a literature review. Surface applications of combinations of scrubber gypsum and short-term performance tests were conducted on target species to various combinations and amounts of FGD gypsum and organic material and fertilizer amendments.

\subsection{Boron Tolerance Study 6.1.1 Introduction}

Boron is one of seven essential elements in soil that is required in micronutrient quantities for proper plant growth. It has a narrow range of soil concentration for plant sufficiency and deficiency (Bergmann, 1992). It is normally not ionized in the $\mathrm{pH}$ range for plant growth and is absorbed by plants as the uncharged aqueous $\mathrm{B}(\mathrm{OH})_{3}{ }^{0}$ species (Goldberg, 1993; $\mathrm{Hu}$ and Brown, 1997). Little is known about the B tolerance or B requirement for fast growing hardwood timber trees that could be used to increase $C$ sequestration into woody tissue. The large volumes of water at fossil fuel plants to transport coal combustion byproducts are a potential source of water for tree irrigation. However, depending on the coal source and waste water handling techniques employed at selective power plants, the waste water concentration of $B$ can limit its use as a source of irrigation water (Sposito and Calderone, 1988).

A preliminary test was conducted in the greenhouse with white pine and white oak to help determine the range of soil B amendments that would be used on selected trees for potential field plantings in a follow-up greenhouse study.

\subsubsection{Preliminary Test \\ 6.1.2.1 Experimental Methods}

An available loam soil ( $\mathrm{pH} 5.34$ ) was used to establish 4 soil B levels of $0,10,35$, and $70 \mathrm{mg}$ $\mathrm{B} / \mathrm{kg}$ soil. The FGD waste water $(70 \mathrm{mg} \mathrm{B/l})$ was collected from TVA's PAF and used to establish a $5^{\text {th }}$ treatment by irrigating the waste water to meet the evapotranspiration demand of the growing trees. A single one-year-old tree seedling was planted into $2 \mathrm{~kg}$ of soil per pot for white oak and $1 \mathrm{~kg}$ of soil for white pine. Four pots (replications) were prepared for each species-treatment combination. White oak seedlings were partially dormant when planted with few green leaves and were root pruned to a length of about 6-8 cm to fit the planting soil depth in the pots. Both plant species were planted with the remaining root ball and artificial media intact as much as possible.

Soil moisture was maintained at $50 \%$ field capacity with deionized water (167 $\mathrm{g} \mathrm{H}_{2} \mathrm{O} / \mathrm{kg}$ soil). Boron $\left(\mathrm{Na}_{2} \mathrm{~B}_{4} \mathrm{O}_{7} \bullet 10 \mathrm{H}_{2} \mathrm{O} ; \mathrm{FW}=381.37 \mathrm{~g} /\right.$ mole; $\left.11.34 \% \mathrm{~B}\right)$ was mixed throughout the potted dry soil with a V-cone mixer for 5 minutes. Trees were planted on November 22, 2000, and grown in a glasshouse. Boron irrigation was limited to $25.4 \mathrm{~cm}$ (10 in) or less as tolerated by the tree seedlings. 


\subsubsection{Results and Discussion}

White oak early growth at 40 days after planting (DAP) was observed to be better with FGD waste water, possibly due to a small amount of nitrogen and other nutrients in the waste water. At 55 DAP, white pine needle tips were observed to be scorched (necrosis) with the highest rate of soil B $(70 \mathrm{mg} / \mathrm{kg}$ soil), but scorching was not observed on the other treatments of either species. Soluble fertilizer (30N-10P-10K) was applied to achieve $400 \mathrm{mg} \mathrm{N} / \mathrm{kg}$ soil. At 70 DAP, the necrosis on pine needles was observed on the $35 \mathrm{mg} \mathrm{B}$ soil treatment and the pale yellow discoloration (chlorosis) of the needles was clearly correlated with the increasing rates of soil B (Figure 3). White pine was severely damaged by all levels of $B$ in this test, and controls grew very little in this test. It was concluded that white pine is an unsuitable test species under the conditions of this tolerance screening test.

White oak took much longer to demonstrate the chlorosis and necrosis due to the B uptake and did not begin to show these general effects until 100 DAP (Figure 4). However, the leaf damage to white oak leaves due to irrigated FGD waste water was evident shortly after initiating irrigation during leaf emergence. Fifty percent were killed by less than half of the planned irrigation $(<12.5 \mathrm{~cm})$ and were replanted once. Since soil applied B did not increase the plant mortality, it is presumed that FGD water salinity was partially responsible for the plant toxicity due to other dissolved solids. Salinity develops more readily in greenhouse pots than in a field environment and would not be expected to be as severe in the field. It is also possible that the plant available B in the FGD waste water is higher than similar levels of B amended to soil prior to plant growth due to soil adsorption. The growth trend of white oak as measured by accumulated dry matter into leaf, stem, and root biomass after 230 DAP was similar or higher with the $10 \mathrm{mg} \mathrm{B} / \mathrm{kg}$ soil than with the controls. Growth was depressed relatively little compared by the higher soil treatments (Figure 5). Analyses of white oak tissue concentrations of B were incomplete at the time of this writing.

It was concluded that: 1) white oak could be a candidate for more detailed study for tolerance testing, as could other oak species, 2) white pine is not suitable for further screening, 3) the range of $B$ amendments used in this test seemed reasonable for main screening tests that would follow, and 4) FGD wastewater was more toxic than comparable soil amended with B. FGD wastewater salinity due to other dissolved solids may be partially responsible. It was decided to use simulated waste water in the main screening test by adding only $B$ as boric acid to avoid salinity effects. 


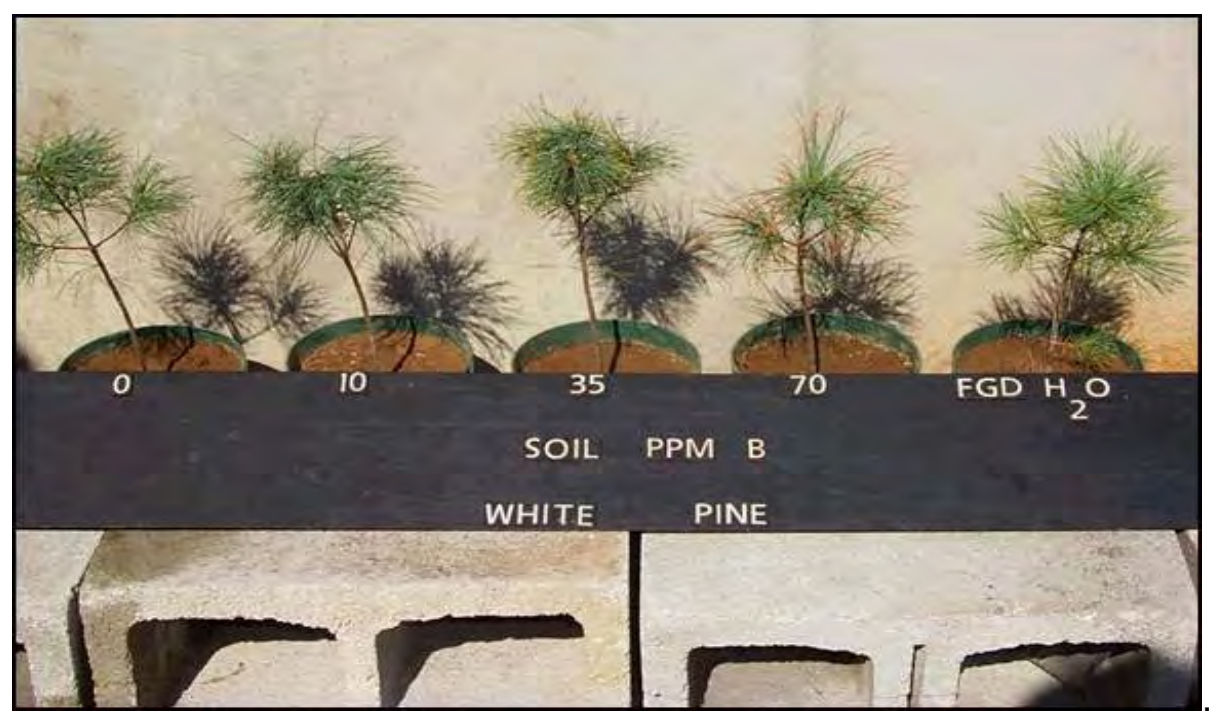

Figure 3. Comparison of greenhouse seedling morphology of white pine grown in soil amended with (left to right) $0,10,35$, and $70 \mathrm{mg} \mathrm{B} / \mathrm{kg}$ soil and irrigated with FGD wastewater containing $70 \mathrm{mg} / \mathrm{L}$ boron.

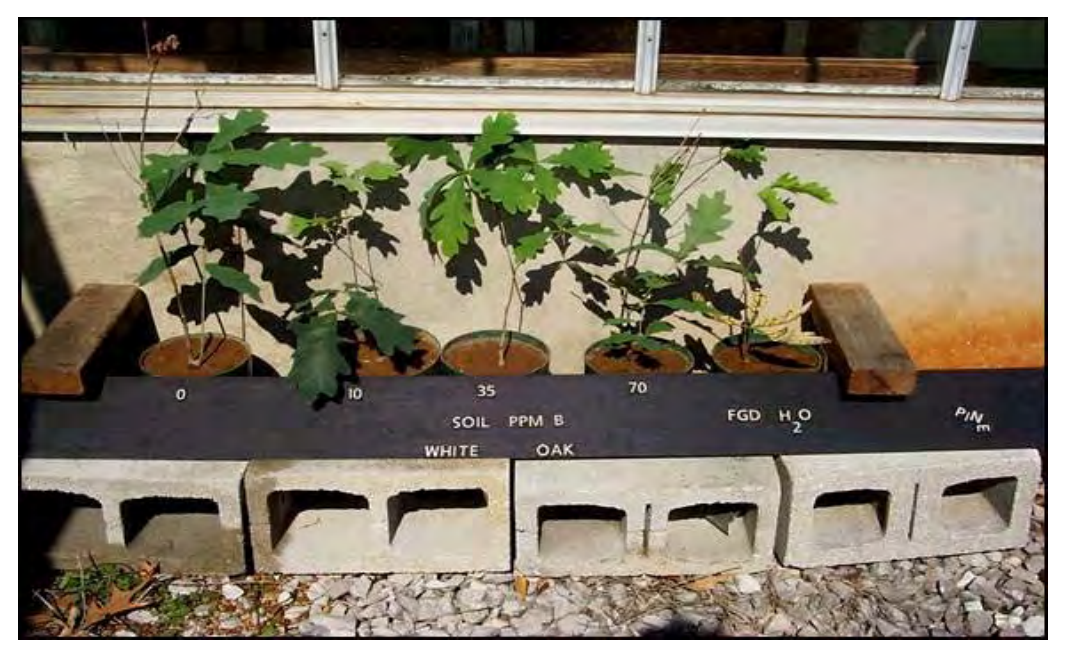

Figure 4. Comparison of greenhouse seedling morphology of white oak grown in soil amended to contain (left to right) $0,10,35$, and $70 \mathrm{mg} \mathrm{B} / \mathrm{kg}$ soil and irrigated with FGD wastewater containing $70 \mathrm{mg} / \mathrm{l}$ boron. 


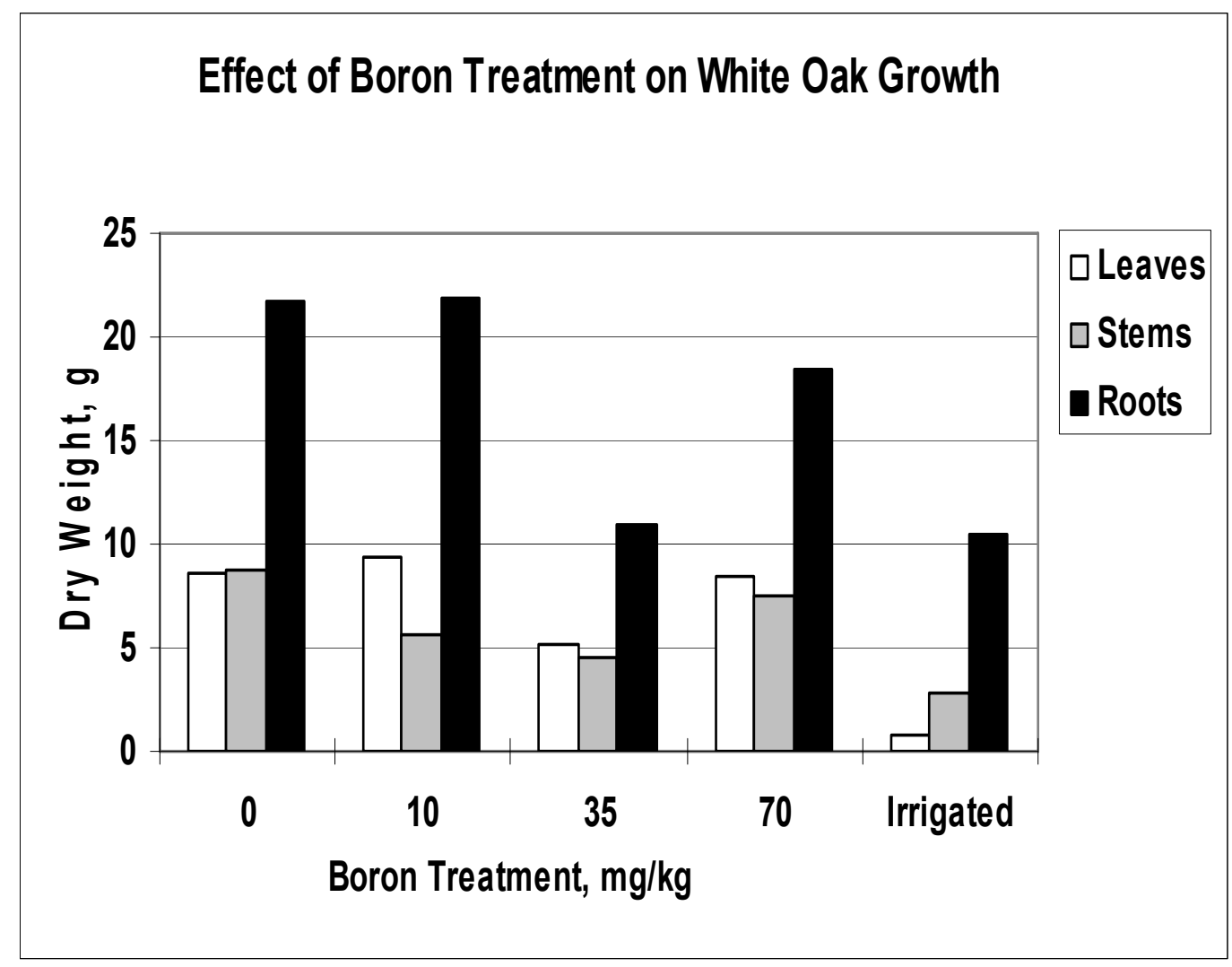

Figure 5. Growth of white oak in response to soil B treatments and irrigated FGD waste water at 230 DAP.

\subsection{Plant Screening Studies}

This phase of the greenhouse research investigated the effects of soil applied B and irrigated B on sycamore, sweet gum, red maple, eastern cottonwood, and tulip poplar tree seedlings in mine reclamation soil from the CCWESTRS site

\subsubsection{Materials and Methods}

Soil was collected from the top $15 \mathrm{~cm}$ (6 in) of a selected site of the CCWESTRS field site on March 1, 2001. The root crown and grass foliage was first removed from the soil surface. The vegetation was mostly fescue (Festuca arundinacea). The soil was air dried, rocks $>5-10 \mathrm{~cm}(2-$ 4 in) were removed, and the remaining soil was processed through a soil chopper without screening to homogenize the soil. Soil inclusions $>0.6-1.2 \mathrm{~cm}(0.24-0.47 \mathrm{in})$ comprised about $10.2 \%$ by weight. Soil moisture at field capacity was approximately $41.1 \%$ and soil $\mathrm{pH}=6.6$. Boron $\left(\mathrm{Na}_{2} \mathrm{~B}_{4} \mathrm{O}_{7} \bullet 10 \mathrm{H}_{2} \mathrm{O} ; \mathrm{FW}=381.37 \mathrm{~g} / \mathrm{mole} ; 11.34 \% \mathrm{~B}\right)$ and soluble fertilizer $(30 \mathrm{~N}-10 \mathrm{P}-10 \mathrm{~K}$; $400 \mathrm{mg} \mathrm{N} / \mathrm{kg}$ soil) with micronutrients was amended and mixed into dry soil in a V-cone soil mixer for 2 minutes per $8 \mathrm{~kg}$ soil/pot. Four soil B treatments consisted of $0,10,35$, and 70 $\mathrm{mg} / \mathrm{kg}$ soil and a $5^{\text {th }}$ treatment was irrigated with simulated waste water containing $35 \mathrm{mg} \mathrm{B/l}$. Simulated water was used to avoid possible salinity effects of actual FGD waste water that tend to be problematic in greenhouse tests.

One-year-old dormant bare-rooted plants were purchased from the Warren County Nursery in Tennessee and sized into 2 or 3 classes by height, stem diameter, and root structure. Four 
species [sycamore (Platanus occidentalis), sweet gum (Liquidambar styraciflua), red maple (Acer rubrum), and eastern cottonwood (Populus deltoides)] were planted on March 16, 2001 and tulip poplar (Liriodendron tulipifera) was planted on March 26, 2001. For each species, three plants per pot were planted. Four pots (replications) per species were planted. All species were planted within one or two days after receipt by next day shipment. Pots were kept watered to $66 \%$ of the field capacity with deionized water and transplants were acclimated in shade for 10 days before being placed in the glasshouse. Plants scheduled to receive irrigation with boronated water were watered with only deionized water until they had initiated growth. Sand (1000 g/pot) was added to the surface of each pot to reduce evaporation from the soil and to maintain more uniform soil moisture throughout the potted soil.

\subsubsection{Results}

Slow and poor seedling leaf initiation of all species was attributed to heavy nursery root pruning and soil that was slow to consolidate after re-wetting. Sweet gum and tulip poplar were replanted on June 1 due to poor survival. Evidence of a twig dieback syndrome from the nursery slowed the leaf initiation of sweet gum, and tulip poplar was plagued with powdery mildew that was treated with captan and benomyl fungicides twice during the study.

Boron-induced leaf necrosis and chlorosis was observed during leaf emergence for cottonwood, sycamore, and red maple in the $70 \mathrm{mg} \mathrm{B} / \mathrm{kg}$ treatment 37 days after transplanting (DAP). Boron leaf damage was clearly evident on all plants receiving B soil amendments at 47 DAP. For all four species, leaves of plants growing in $70 \mathrm{mg} \mathrm{B} / \mathrm{kg}$ soil were completely scorched off at 77 DAP, and this treatment was abandoned.

The irrigation schedule with boronated water and harvest dates are shown in Table 7. Accumulated amounts of boronated irrigation water could not be standardized for all tree species due to the species variation in growth rates, water use, planting dates, and species tolerance to the added B. Sweet gum and tulip poplar initiated growth much slower than the other species and, combined with the late season replanting date, did not require as much water as the other three species. The faster growing sycamore, cottonwood, and red maple received $800 \mathrm{ml}$ of boronated water on 40 DAP and 41 DAP and were using about $400 \mathrm{ml}$ of water per pot per day at this time. The irrigation of the boronated water was temporarily interrupted until 108 DAP in hopes that the other two species, sweet gum and tulip poplar, would catch up in physiological growth, but these two species had to be replanted on June 1 due to poor survival of the transplants. Since these two species, sweet gum and tulip poplar, were replanted about 2.5 months after the other species were planted, they were allowed to grow later and were harvested later in the season (9/13 vs. 7/10 harvest dates, Table 7 ). Only red maple was allowed to grow significantly longer (214 days) than the other species because it initiated growth so slowly after being transplanted, and it developed leaf damage at a slower rate than sycamore or cottonwood. 


\begin{tabular}{|c|c|c|c|c|c|c|}
\hline $\begin{array}{l}\text { Tree } \\
\text { Species } \\
\text { (Planting } \\
\text { Date) }\end{array}$ & $\begin{array}{l}\text { Begin } \\
\text { DAP* } \\
\text { (Date) }\end{array}$ & $\begin{array}{l}\text { Cease } \\
\text { DAP } \\
\text { (Date) }\end{array}$ & $\begin{array}{l}\text { Inclusive } \\
\text { Days** }\end{array}$ & $\begin{array}{l}\text { Accumulated } \\
\text { B Water, cm } \\
\text { (in) }\end{array}$ & $\begin{array}{l}\text { Accumulated } \\
\text { B mg/pot } \\
\text { (mg/kg soil) }\end{array}$ & $\begin{array}{l}\text { Harvest } \\
\text { Date } \\
\text { (DAP) }\end{array}$ \\
\hline $\begin{array}{l}\text { Sycamore } \\
(3 / 16 / 01)\end{array}$ & $\begin{array}{l}108 \\
(7 / 2)\end{array}$ & $\begin{array}{l}149 \\
(8 / 12)\end{array}$ & 41 & 25.4 (9.99) & $\begin{array}{l}473 \\
(59.1)\end{array}$ & $\begin{array}{l}8 / 21 / 01 \\
(158)\end{array}$ \\
\hline $\begin{array}{c}\text { Cottonwood } \\
(3 / 16 / 01)\end{array}$ & $\begin{array}{l}108 \\
(7 / 2)\end{array}$ & $\begin{array}{l}149 \\
(8 / 12)\end{array}$ & 41 & $22.5(8.87)$ & $\begin{array}{l}414 \\
(51.7)\end{array}$ & $\begin{array}{l}8 / 21 / 01 \\
(158)\end{array}$ \\
\hline $\begin{array}{r}\text { Red Maple } \\
(3 / 16 / 01)\end{array}$ & $\begin{array}{l}108 \\
(7 / 2)\end{array}$ & $\begin{array}{l}175 \\
(9 / 7) \\
\end{array}$ & 67 & $10.1(3.97)$ & $\begin{array}{l}188 \\
(23.5) \\
\end{array}$ & $\begin{array}{l}10 / 16 / 01 \\
(214)\end{array}$ \\
\hline $\begin{array}{r}\text { Sweet gum } \\
(6 / 01 / 01)\end{array}$ & $\begin{array}{l}43 \\
(7 / 14) \\
\end{array}$ & $\begin{array}{l}98 \\
(9 / 7)\end{array}$ & 55 & $4.14(1.63)$ & $\begin{array}{l}77.5 \\
(9.7) \\
\end{array}$ & $\begin{array}{l}10 / 16 / 01 \\
(137)\end{array}$ \\
\hline $\begin{array}{c}\text { Tulip Poplar } \\
(6 / 01 / 01)\end{array}$ & $\begin{array}{l}43 \\
(7 / 14) \\
\end{array}$ & $\begin{array}{l}98 \\
(9 / 7)\end{array}$ & 55 & $3.58(1.41)$ & $\begin{array}{l}66.9 \\
(8.4) \\
\end{array}$ & $\begin{array}{l}10 / 16 / 01 \\
(137)\end{array}$ \\
\hline
\end{tabular}

${ }^{*}$ DAP $=$ Days after planting.

** Inclusive Days = Number of days water demand was met by irrigating with $B$ water.

Table 7. Schedule of B Water Irrigation and Harvest Dates

A leaf damage index (LDI) was used to compare the five tree species as an indicator of their tolerance to soil amended with $B$ or irrigated $B$ as a simulated waste water containing $35 \mathrm{mg}$ $B / L$. Measurements were scored as 0 , without visual evidence of damage, to 5 , having the greatest amount of leaf chlorosis (yellow) and necrotic tissue (scorched brown), and the results are shown in Table 8.

\begin{tabular}{|c|c|c|c|c|c|c|c|}
\hline \multicolumn{8}{|c|}{ Boron Treatment } \\
\hline & & \multicolumn{4}{|c|}{ Soil Applied, mg/kg } & \multirow{2}{*}{\multicolumn{2}{|c|}{$\begin{array}{l}\text { Irrigated, } \\
35 \text { mg B/L }\end{array}$}} \\
\hline & & 0 & 10 & 35 & 70 & & \\
\hline Tree Species & 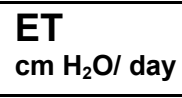 & \multicolumn{5}{|c|}{ Leaf Damage Index } & cm H $\mathrm{H}_{2} \mathrm{O}$ applied \\
\hline Sycamore & 0.68 & 0 & 1.0 & $\mathrm{X}$ & $\mathrm{X}$ & 5.0 & 25.4 \\
\hline Cottonwood & 0.61 & 2.0 & 1.7 & 4.0 & $\mathrm{X}$ & 5.0 & 25.4 \\
\hline Red Maple & 0.23 & 0 & 3.0 & 4.7 & $\mathrm{X}$ & 2.0 & 3.0 \\
\hline Sweet gum & 0.08 & 0 & 0.3 & 4.0 & $\mathrm{X}$ & 0 & 0.8 \\
\hline Tulip Poplar & 0.05 & 0 & 0.7 & 3.0 & $\mathrm{X}$ & 1.0 & 0.5 \\
\hline
\end{tabular}

$\mathrm{ET}=$ evapotranspiration; $\mathrm{X}=$ No leaves; 0 to $5=$ Leaf damage index, 5 greatest damage

Table 8. Leaf damage index as an indicator of B tolerance $(8 / 13 / 01)$ 
Note that transplants of red maple, sweet gum, and tulip poplar were in their lag phase of growth after transplanting at the time of the LDI measurement. The comparison of the LDI was made at 73 DAP for sweet gum and tulip poplar which were replanted eleven weeks after sycamore, cottonwood, and red maple. The latter three species were scored for their LDI at 150 DAP and had been growing 64 days longer than sweet gum and tulip poplar before starting irrigation with boronated water (see Table 7, 108 DAP vs. 44 DAP). Cottonwood and sycamore grew faster and had accumulated more biomass prior to initiating the $B$ irrigation, hence this may partially account for the apparent tolerance to a higher amount of irrigated B. Additionally, the greater water demand due to faster growth could result in a higher amount of B uptake and a slower manifestation of visual leaf damage. We conclude that red maple is initially a slower growing species than cottonwood and sycamore as evidenced by its height and use of B-water. Red maple may expend more energy in lateral stem growth than stem elongation (height), and along with a higher density of wood could account for the observed differences in the species at this stage of growth. With adequate moisture and fertilizer, sycamore and cottonwood could initially grow taller and exhibit a greater stem diameter in soil from the CWESTERS site. This early and quick growth response could dilute $B$ in plant tissue and result in a higher tolerance in the amount of B applied in the irrigation water over short periods of time.

Timing of B application in the irrigation water relative to size of plants, B application rates, physiological water demand, concentration of the B in the water, and tree species along with rainfall patterns and leaching rates are some of the factors that can determine the amounts of $B$ that can be applied in the irrigation water.

From the early LDI scores we concluded:

- None of the five species tested will avoid severe leaf damage with the two highest rates of $B$ (35 and $70 \mathrm{mg} \mathrm{B/kg} \mathrm{soil).}$

- Red maple, sweet gum, and yellow poplar had not grown rapidly enough to provide a good indication of $B$ tolerance at the $10 \mathrm{mg} \mathrm{B} / \mathrm{kg}$ soil applied rate at the time of the LDI scoring. Even with a low growth rate, red maple leaves were moderately damaged with $10 \mathrm{mg} \mathrm{B} / \mathrm{kg}$ soil applied treatment.

- Both sycamore and cottonwood sustained relatively little leaf damage with the $10 \mathrm{mg} \mathrm{B} / \mathrm{kg}$ soil applied treatment, even though both of these species grew relatively rapidly with relatively high rates of water use.

Based on early plant height and LDI of the five species tested, sycamore and cottonwood appeared to be the best candidates for our field study because they were fairly tolerant of $10 \mathrm{mg}$ $\mathrm{B} / \mathrm{kg}$ soil (low LDI) while growing rapidly, and they grew taller much faster than the other three species. However, sweet gum performance was deemed adequate by the team and, because of its superior commercial value over cottonwood, it was selected as one of the test species along with sycamore.

\subsubsection{Water Use}

The LDI results need to be interpreted relative to average water use (i.e., evapotranspiration, $\mathrm{ET}$ ) as compared to the trees in the control treatment (no B added). Evapotranspiration is the combined water loss from the soil due to evaporation and plant transpiration. Transpiration of water is an active transport of water from roots and through the stomata openings in the leaves for the dual purpose of transporting nutrients and cooling the leaves. Some water loss also occurs through the epidermal layers of the leaves. The relative amount of water loss by these passive and active transport mechanisms is highly variable due to many factors including soil, plant species, ambient temperature, relative humidity, solar radiation, stage of growth, plant 
nutrient status, etc. Plants that use water efficiently can accumulate large amounts of dry matter with small amounts of water use. Sweet gum and tulip poplar slowly developed relatively low leaf damage in the $10 \mathrm{mg} \mathrm{B} / \mathrm{kg}$ soil treatment, but these two species did not use much water at early stages of growth. As sweet gum and tulip poplar grow and use water more rapidly, they likely will show more leaf damage from increased B uptake. Even with low growth rate and water use, these two species had obvious leaf damage from the $35 \mathrm{mg} \mathrm{B} / \mathrm{kg}$ soil treatment (Table 8).

The leaf damage results from the $B$ irrigation treatment need to be interpreted relative to the amount of boronated irrigation water that had been applied at the time of the LDI scores (Table 8). Since, the sycamore and cottonwood species had been growing rapidly and using a lot of water, the planned $25.4 \mathrm{~cm}$ (10 inches) of boronated irrigation water was achieved early in the growing season for these two species. Only $7.5 \mathrm{~cm}$ (3 inches) of boronated irrigation water had been applied to the red maple species when LDI scores were taken even though red maple was planted at the same time as sycamore and cottonwood. Less than $0.5 \mathrm{~cm}$ ( $1 \mathrm{inch}$ ) of boronated water had been applied to the sweet gum and yellow poplar species, partly because these species were planted later (replanted) and partly because they were growing more slowly as a result of being replanted.

It should also be noted that cottonwood sustained some leaf damage (damage rating of 2) with no $B$ applied. We don't know what caused this leaf damage that looks like B damage in the 10 $\mathrm{mg} \mathrm{B} / \mathrm{kg}$ soil treatment. This result suggests that cottonwood may not be very well adapted to the soil used in the experiment.

Irrigation with $35 \mathrm{mg} \mathrm{B/L}$ water severely damaged the leaves of the sycamore and cottonwood species. This damage started to appear two weeks after irrigating with about $11.4 \mathrm{~cm}(4.5$ inches) of boronated water (26.6 mg B/kg soil) for sycamore and about $10.2 \mathrm{~cm}$ (4.0 inches) of boronated water $(23.4 \mathrm{mg} \mathrm{B} / \mathrm{kg}$ soil) for cottonwood. Sycamore and cottonwood were growing rapidly and using water at a relatively high rate after two weeks of boronated water application and likely were taking up $B$ at a high rate. The full $25.4 \mathrm{~cm}$ (10-inch) application of boronated water corresponded to $60 \mathrm{mg} \mathrm{B} / \mathrm{kg}$ soil. Severe leaf damage after applying $25.4 \mathrm{~cm}$ (10 inches) of boronated water is similar to damage in the soil-applied treatments of 35 and $70 \mathrm{mg} \mathrm{B} / \mathrm{kg}$ soil.

Evapotranspiration was measured over a 24-hour period near the stage of maximal seasonal growth prior to the harvest date for each species and is graphically shown in Figure 5 . The growing pots did not drain and sand was added to the soil surface at the beginning of the screening test to reduce the water loss by soil surface evaporation. Pots were watered daily to $66 \%$ field capacity and the gravimetric change in 24-hour moisture was measured as an estimate of the evapotranspiration water loss.

Comparing B treatments (Figure 5) with the control treatment (no B added) for each species indicates that nearly all species had reduced levels of evapotranspiration rates due to the $B$ treatment whether applied as a soil amendment or irrigation. However, one exception was found with the $\mathrm{B}$ irrigated red maple which had an apparent higher evapotranspiration rate than the controls. This result is difficult to explain since accumulated soil B application due to irrigation at harvest time was $23.5 \mathrm{mg} \mathrm{B} / \mathrm{kg}$ soil (Table 7). Red maple was permitted to grow nearly $40 \%$ longer than the other species before harvesting. Boron irrigated red maple had a higher evapotranspiration rate at this stage of growth than red maple with lower levels of soil amended $B$ and their controls. This is consistent with the observation that the LDI for irrigated red maple was lower (less leaf damage) than for red maple with soil amended B (Table 8). These results suggest that some species transplanted into soil amended B will sustain more leaf damage than plants that were allowed to grow and initiate new roots prior to exposing them to $B$ irrigation. It 
is concluded that these test species' tolerance to B exposure, as measured by their evapotranspiration, can depend not only on the amount of $B$ but also on the duration of the $B$ exposure, physiological timing of the $B$ exposure, and possibly the method of $B$ application. More than one mechanism of physiological damage to the plant integrity is probably responsible for the delayed response to B plant exposure.

\subsubsection{Visual Toxicity Symptoms}

Visual comparisons of the effect of soil amended B and irrigated B on leaf and stem damage are shown in Figure 7 through Figure 11. Severe leaf necrosis can be seen in the B irrigated sycamore plants after 132 DAP (Figure 7). Only one sycamore plant out of 12 survived in the 35 $\mathrm{mg} \mathrm{B} / \mathrm{kg}$ of soil and it was a basal sprout (Table 9 ). The damage to the trees occurred early and maximum leaf expansion was never achieved, possibly due to root damage in the higher level of soil B. Sycamore trees growing in the $10 \mathrm{mg} \mathrm{B} / \mathrm{kg}$ treatment were $16.5 \%$ taller than controls and had about $25 \%$ more dry weight in both leaf and stem dry weight (Figure 12A). Dry weight of sycamore irrigated with B water was equivalent to only $75 \%$ of the controls when harvested. This species grew rapidly after transplanting and required large amounts of water to maintain soil moisture. When B irrigation was initiated, the effect of B uptake was fast and damage occurred through out the plant.

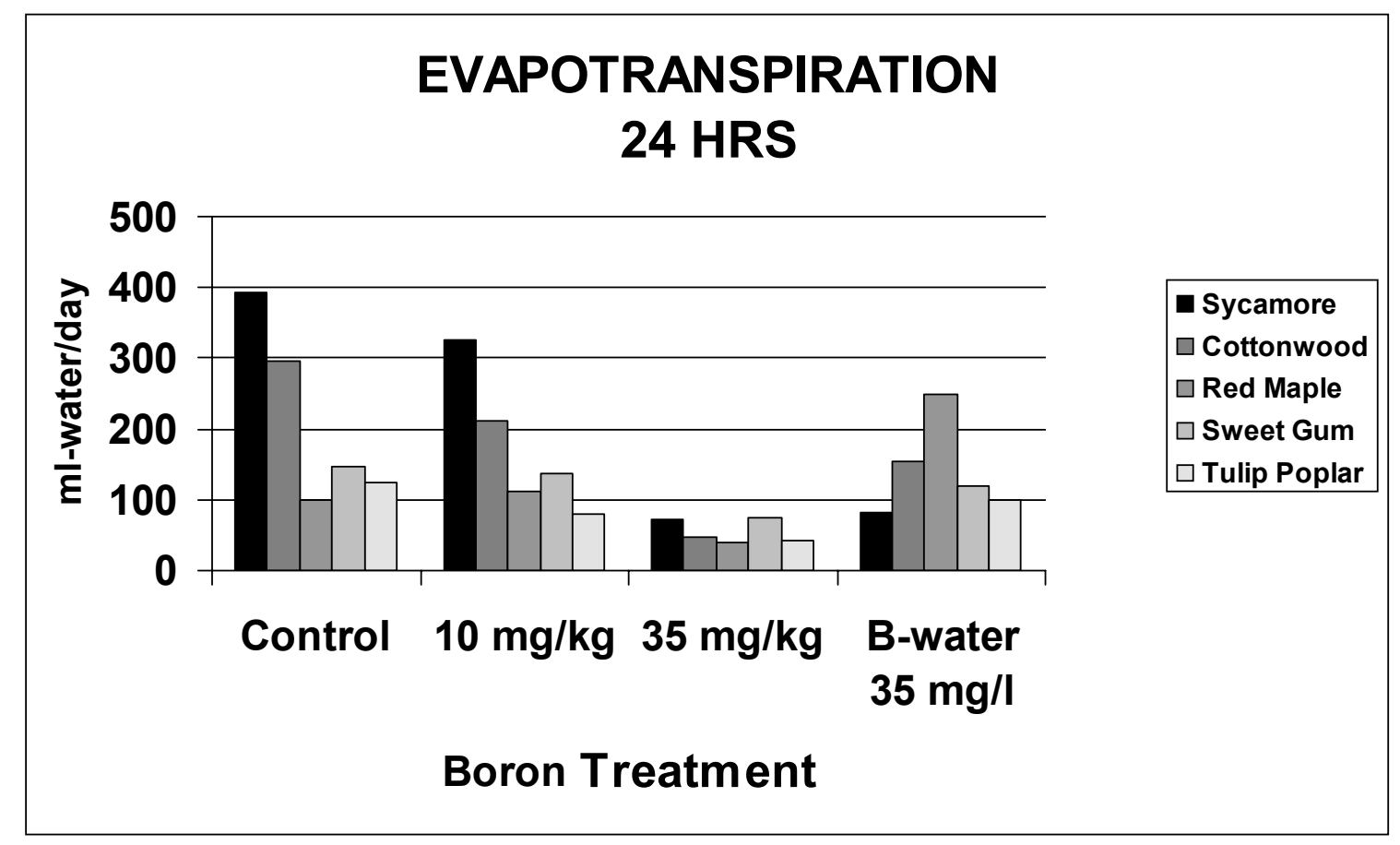

Figure 6. Effect of B soil treatments and B irrigation on the 24 hour gravimetric water loss of tree test species at specified days after planting (DAP). Sycamore and cottonwood $=154$ DAP, red maple $=180 \mathrm{DAP}$, and sweet gum and tulip poplar $=104 \mathrm{DAP}$. 


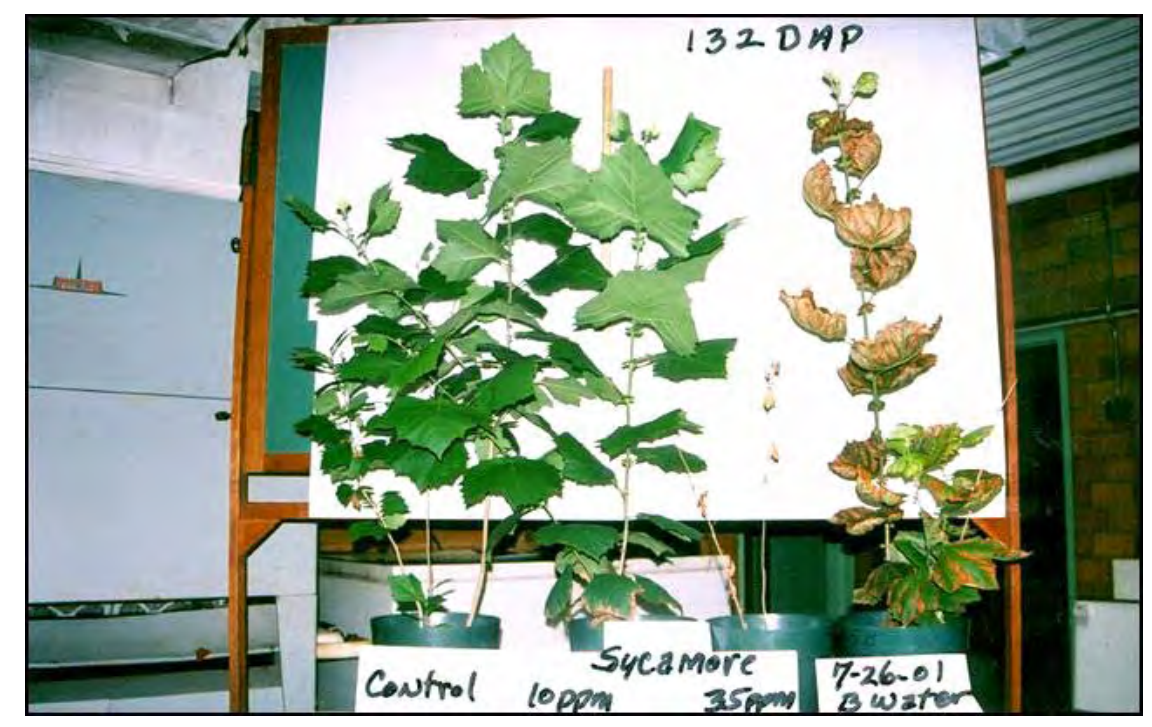

Figure 7. Seedling morphology of sycamore grown in soil amended to contain (left to right) 0 , 10 , and $35 \mathrm{mg} \mathrm{B} / \mathrm{kg}$ soil and irrigated with water containing $35 \mathrm{mg} \mathrm{B} / \mathrm{L}$.

Cottonwood leaf damage due to $B$ treatments is shown in Figure 8. Damage was characteristically chlorosis with marginal leaf splotches of necrosis. There was not as much interveinal necrosis as observed with sycamore and abscission of older leaves was frequent with a moderate amount of $B$ damage. Younger leaves were crenately puckered, with necrotic spots that penetrated both leaf surfaces. Survival in all treatments was generally poor but somewhat better than for sycamore at the higher soil B treatment; however, height was severely stunted in the higher soil B treatment (Table 9). There was a trend for the surviving trees to be slightly taller than the controls when grown in the lowest level of soil amended B. Harvested dry weight was reduced by both soil B treatments and irrigated B (Figure $12 \mathrm{~B}$ ).

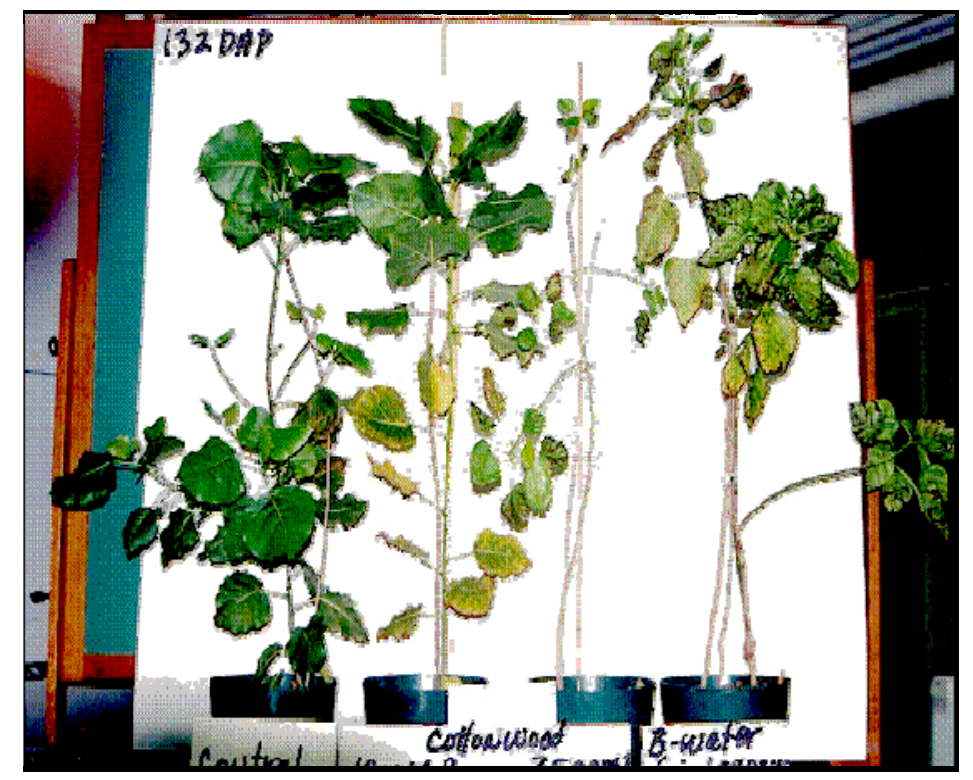

Figure 8. Seedling morphology of Eastern cottonwood grown in soil amended to contain (left to right) 0,10 , and $35 \mathrm{mg} \mathrm{B} / \mathrm{kg}$ soil and irrigated with water containing $35 \mathrm{mg} \mathrm{B} / \mathrm{l}$. 
As previously discussed, red maple was much slower to show leaf damage due to B exposure, and that result is presumed to be due to its much lower water uptake. Leaf chlorosis and necrosis is more pronounced in the leaf margins and unlike cottonwood, its progression is not splotchy but continuous and resembles drought damage (Figure 9). Red maple had excellent survival $(94 \%)$ when averaged over all treatments. There was a trend for B irrigated trees to be $17 \%$ taller than controls (Table 9 ). Boron irrigated trees also had about $30 \%$ more stem weight and almost twice as much leaf dry weight at harvest time (Figure 12-C). The accumulative B added by irrigation was $188 \mathrm{mg} /$ pot and equivalent to $23.5 \mathrm{mg} / \mathrm{kg}$ of dry soil (Table 5). Due to its low rate of water use and slow growth, its exposure to B was over 214 days of growth. This exposure to $B$ was $35 \%$ longer than sycamore and cottonwood and the maximum exposure concentration was only about $40 \%$ of the faster growing trees. Choosing this species as a candidate for waste water irrigation as compared to sycamore could prove be a case of the tortoise vs. the hare. Slow growth and low water use reduces its exposure to B and increases its chances for survival. Transplant seedlings had a much more fibrous and intact root system than the other species.

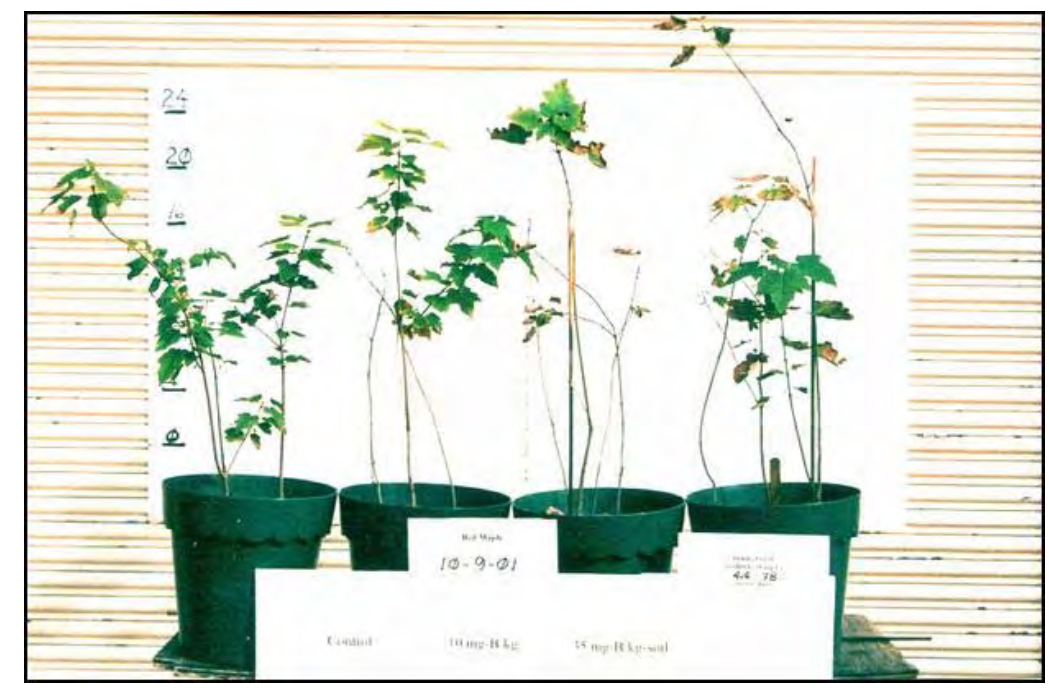

Figure 9. Seedling morphology of red maple grown in soil amended to contain (left to right) 0 , 10 , and $35 \mathrm{mg} \mathrm{B} / \mathrm{kg}$ soil and irrigated with water containing $35 \mathrm{mg} \mathrm{B} / \mathrm{L}$.

Sweet gum exposure to B occurred at a much lower level of water use than for sycamore or cottonwood. Only $77.5 \mathrm{mg}$ of B/pot was irrigated in 55 days for sweet gum compared to 473 $\mathrm{mg} / \mathrm{pot}$ of B irrigated in 41 days on sycamore. Sweet gum leaf damage initially looked similar to red maple but eventually resembled cottonwood because of its severe puckered characteristic (Figure 10). Slow leaf initiation (a characteristic of the species) and replanting may have greatly reduced the seasonal impact of $B$ exposure. Survival averaged only $50 \%$ over all treatments (similar to other species except for red maple) and little change in plant height due to B treatments was noted at harvest (Table 9). Very little stem growth difference was found between treated plants and the controls, but leaf dry matter was reduced $50 \%$ by the $35 \mathrm{mg} \mathrm{B} / \mathrm{kg}$ soil treatment (Figure $12 \mathrm{D}$ ). 


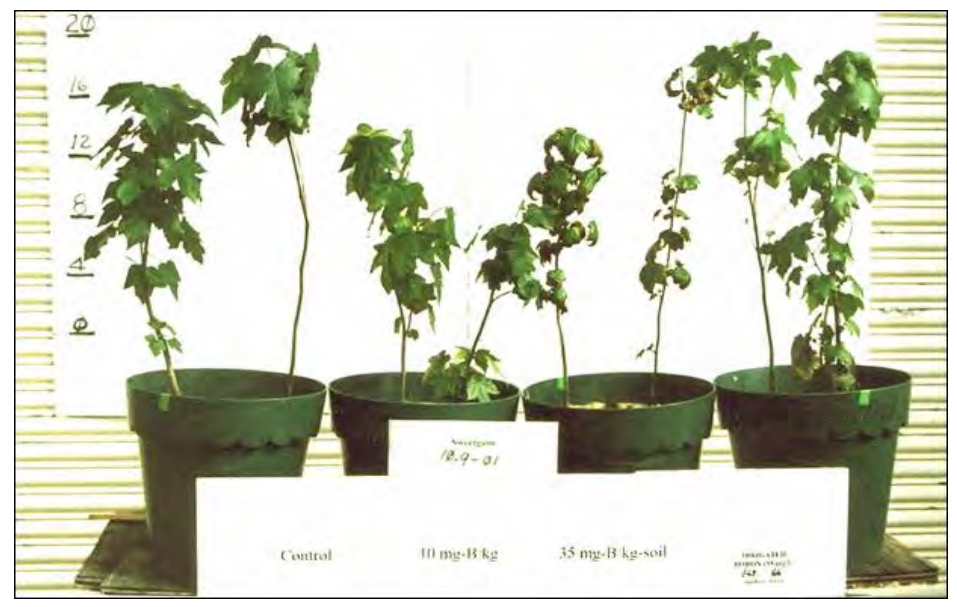

Figure 10. Seedling morphology of sweet gum grown in soil amended to contain (left to right) 0 , $10,35 \mathrm{mg} \mathrm{B} / \mathrm{kg}$ soil and irrigated with water containing $35 \mathrm{mg} \mathrm{B} / \mathrm{L}$.

Tulip poplar exposure to B was similar to sweet gum due to the late replanting and slow initial growth, but leaf response to B damage was very different from sweet gum and was similar to sycamore (manifested severe chlorosis and necrosis from both soil and irrigated B). Leaves curled upwards and were readily aborted due to the B damage (Figure 11). Therefore, the leaf dry matter loss shown in Figure 12-E is largely due to aborted leaves that were not included in the harvest. The stem dry matter increases relative to controls are positively correlated with the B treatments. This growth response could be explained in one of two ways: 1) stem growth occurred before the leaves aborted (implies fast growth) or 2) a small amount of surviving leaf area is very efficient in increasing stem dry matter in the presence of added B. No appreciable increase in plant height was detected. Surviving plants that were irrigated with $B$ tended to be slightly taller than controls (Table 9). Stem diameter was not measured as an indication of stem volume but could have partially accounted for this growth response. The threshold for leaf damage by B appears to be very low and severe. Significant leaf losses were recorded after 137 days when exposed to only $8.4 \mathrm{mg} \mathrm{B} / \mathrm{kg}$ of soil in the irrigation water.

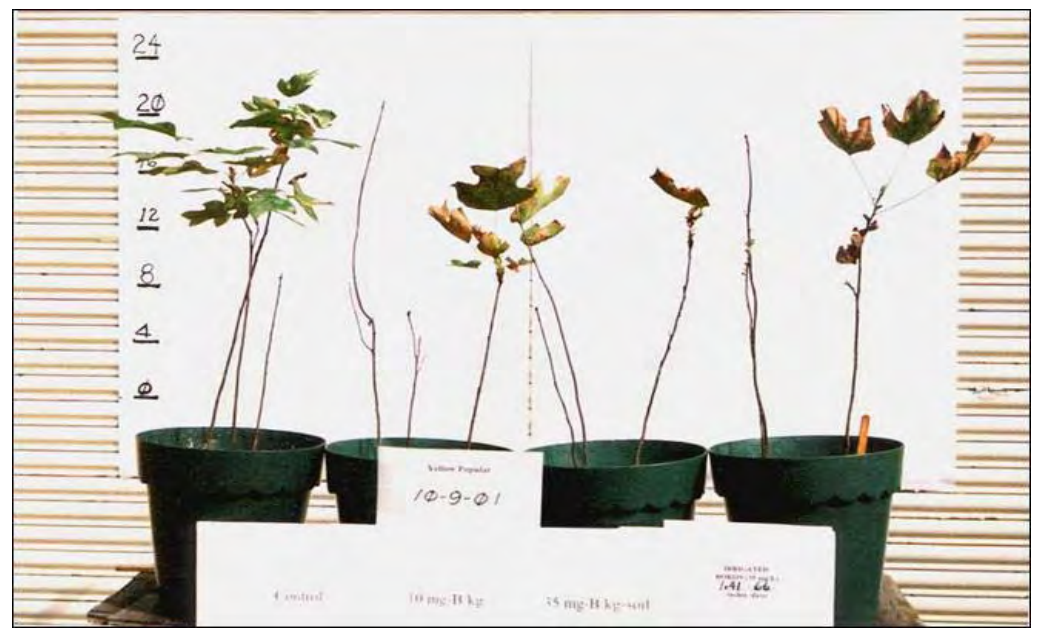

Figure 11. Seedling morphology of tulip poplar grown in soil amended to contain (left to right) 0,10 , and $35 \mathrm{mg} \mathrm{B} / \mathrm{kg}$ soil and irrigated with water containing $35 \mathrm{mg} / \mathrm{kg}$. 


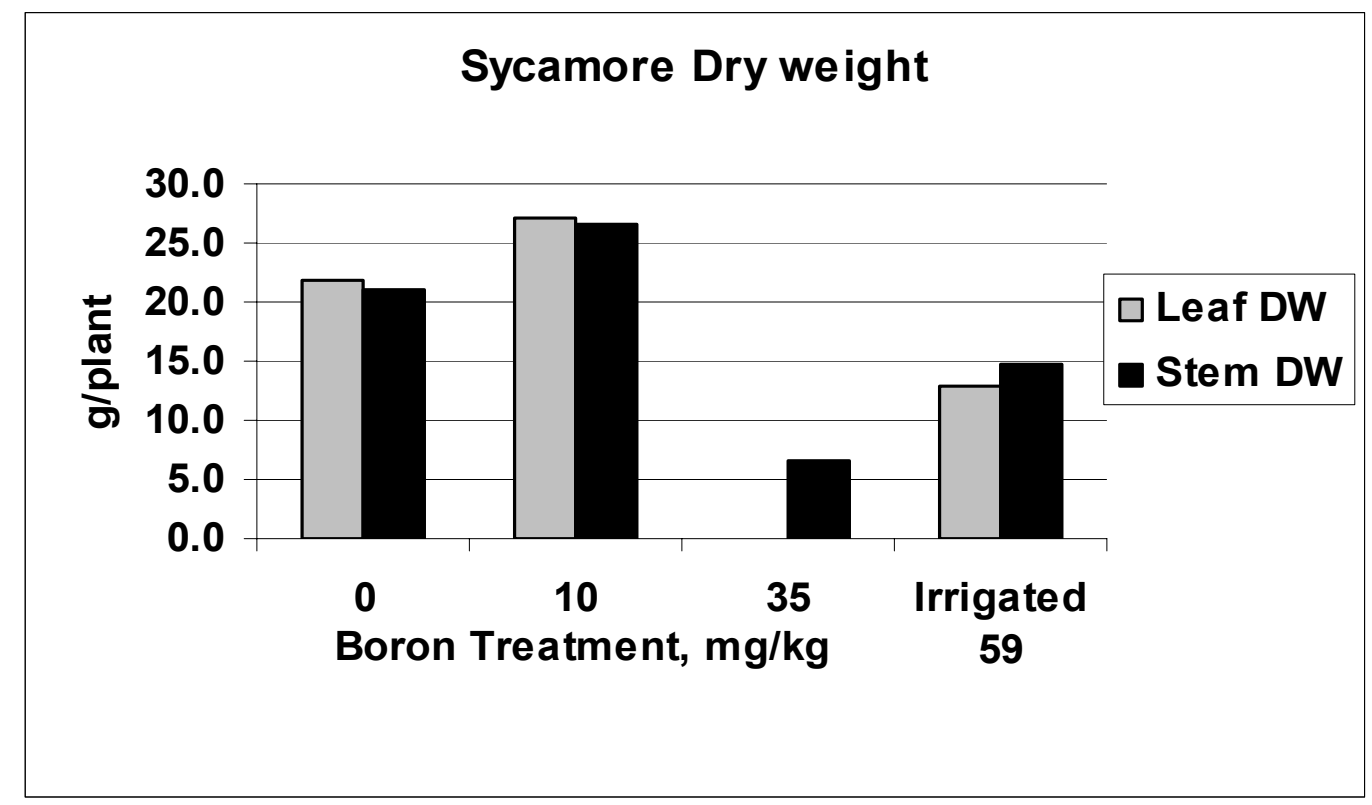

A

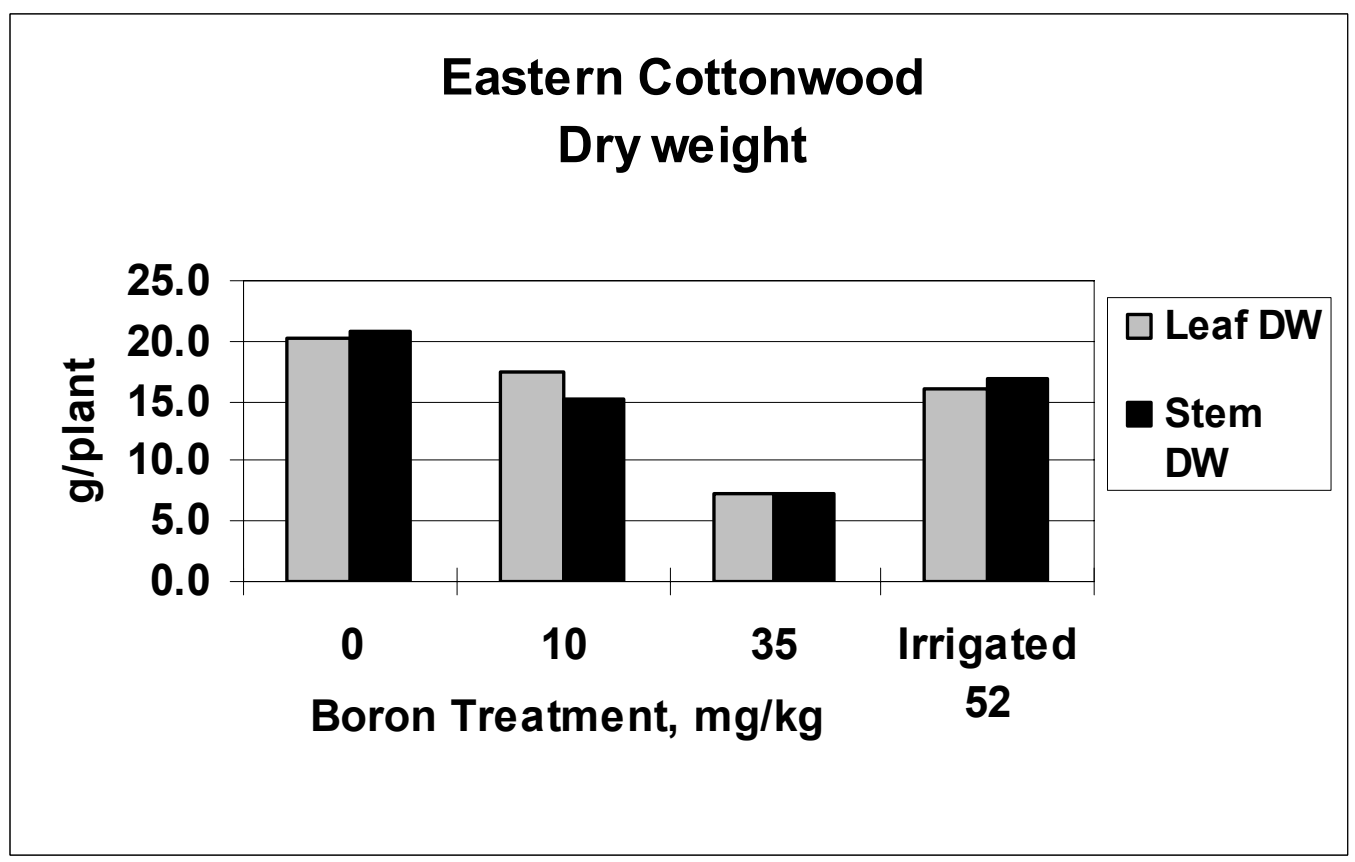

B 

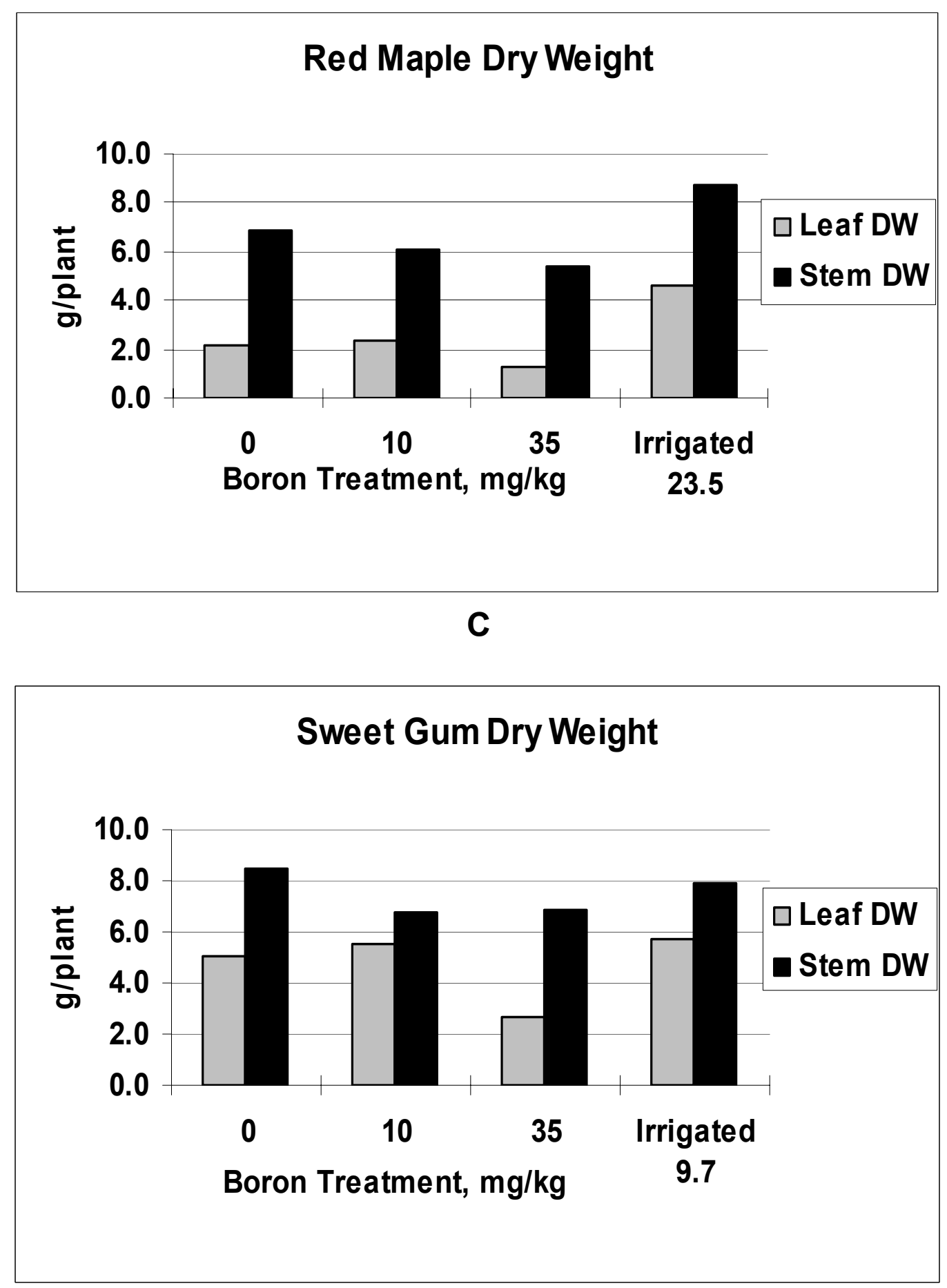

D 


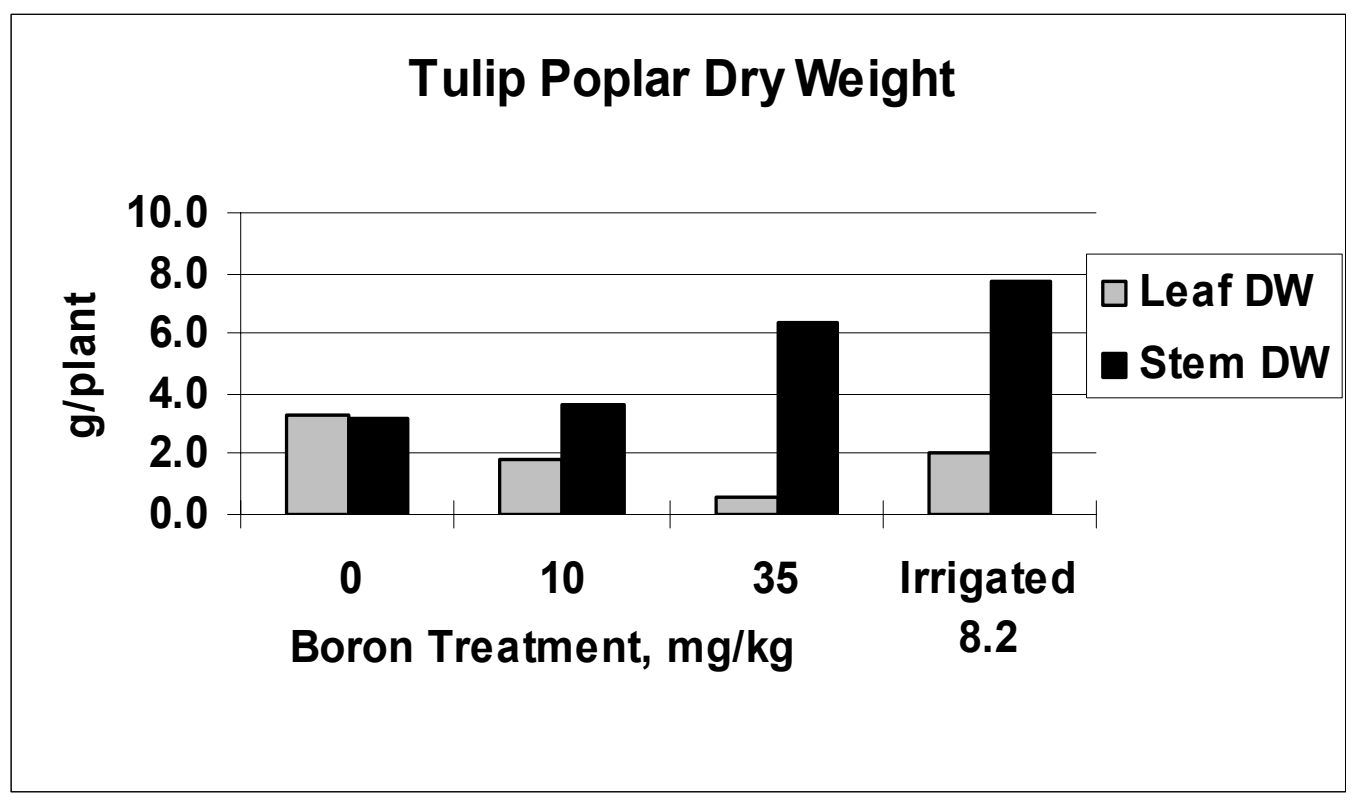

E

Figure 12A-E. Effect of soil amended $B$ and irrigated $B$ on dry weight of attached tree leaves and stems of sycamore (A), cottonwood (B), red maple (C), sweet gum (D), and tulip poplar (E) at designated harvest days after planting (DAP).

\begin{tabular}{|c|c|c|c|c|c|}
\hline & \multicolumn{5}{|c|}{ Number of Surviving Trees at harvest date $(\mathrm{N}=12)$} \\
\hline $\begin{array}{l}\text { Boron } \\
\text { Treatment }\end{array}$ & Sycamore & Cottonwood & \begin{tabular}{|l} 
Red \\
Maple \\
\end{tabular} & Sweetgum & Tulip Poplar \\
\hline 0 & 8 & 5 & 12 & 6 & 8 \\
\hline 10 & 5 & 5 & 11 & 6 & 6 \\
\hline 35 & 1 & 2 & 10 & 4 & 5 \\
\hline \multirow[t]{2}{*}{ Irrigated } & 8 & 7 & 12 & 8 & 5 \\
\hline & \multicolumn{4}{|c|}{ Average Height / Plant (cm) } & \\
\hline 0 & 109 & 112 & 54 & 49 & 42 \\
\hline 10 & 127 & 114 & 56 & 42 & 39 \\
\hline 35 & Sprout & 80 & 55 & 48 & 45 \\
\hline Irrigated & 102 & 105 & 65 & 40 & 48 \\
\hline
\end{tabular}

Table 9. Effect of soil amended B and irrigated B on tree survival and surviving tree height.

Red maple stem dry weight increased during its longer growing season when irrigated with $B$ water (Figure 12-C). In an effort to explain this increase in growth due to irrigated B, plant height growth rates at 144 DAP were compared with plant height growth rates at 209 DAP (Figure 13). Plants were harvested for leaf and stem dry matter determinations at 214 DAP and B irrigation was initiated at 108 DAP (Table 6). The rates of growth in plant heights at 144 DAP were generally higher in the $B$ treated plants than the controls (Figure 13). The rates of growth in plant height at 214 DAP in the B treated plants were again generally higher than the controls but tended to be less than at 144 DAP. The differences in plant height growth rate between 144 days and 209 days suggest that the growth rates of $B$ treated plants were declining relative to 
the controls. The data suggest that much of the plant height differences due to B occurred early in the growing season, before $B$ excess uptake was achieved. Decreases in dry matter due to the longer exposure times in the higher soil amended B treatment, supports this conclusion (Figure $12 \mathrm{C}$ ).

Several native and local species of trees were arbitrarily selected and transplanted into pots with high levels of soil $B$ in hopes that some species would show more tolerance than the initially selected species used in this study. Red mulberry (Morus rubra), black willow (Salix nigra), American chestnut (Castanea dentata), hybrid chestnut (Castanea sp.), and green ash (Fraxinus pennsylvanica) seedlings were planted in the $70 \mathrm{mg} \mathrm{B} / \mathrm{kg}$ soil treatment. Seedlings of sycamore, poplar, and sweet gum of the same purchased lot were allowed to develop in artificial media. These plants with fully expanded leaves were replanted into the high B soil treatment. After 30 DAP, only the red mulberry survived and continued to live with poor growth. Its' older leaves exhibited the worst damage at 250 DAP. Figure 14 shows the type of leaf damage seen in red mulberry after 28 days of exposure to the highest rate of soil amended B, $70 \mathrm{mg} \mathrm{B} / \mathrm{kg}$ soil.

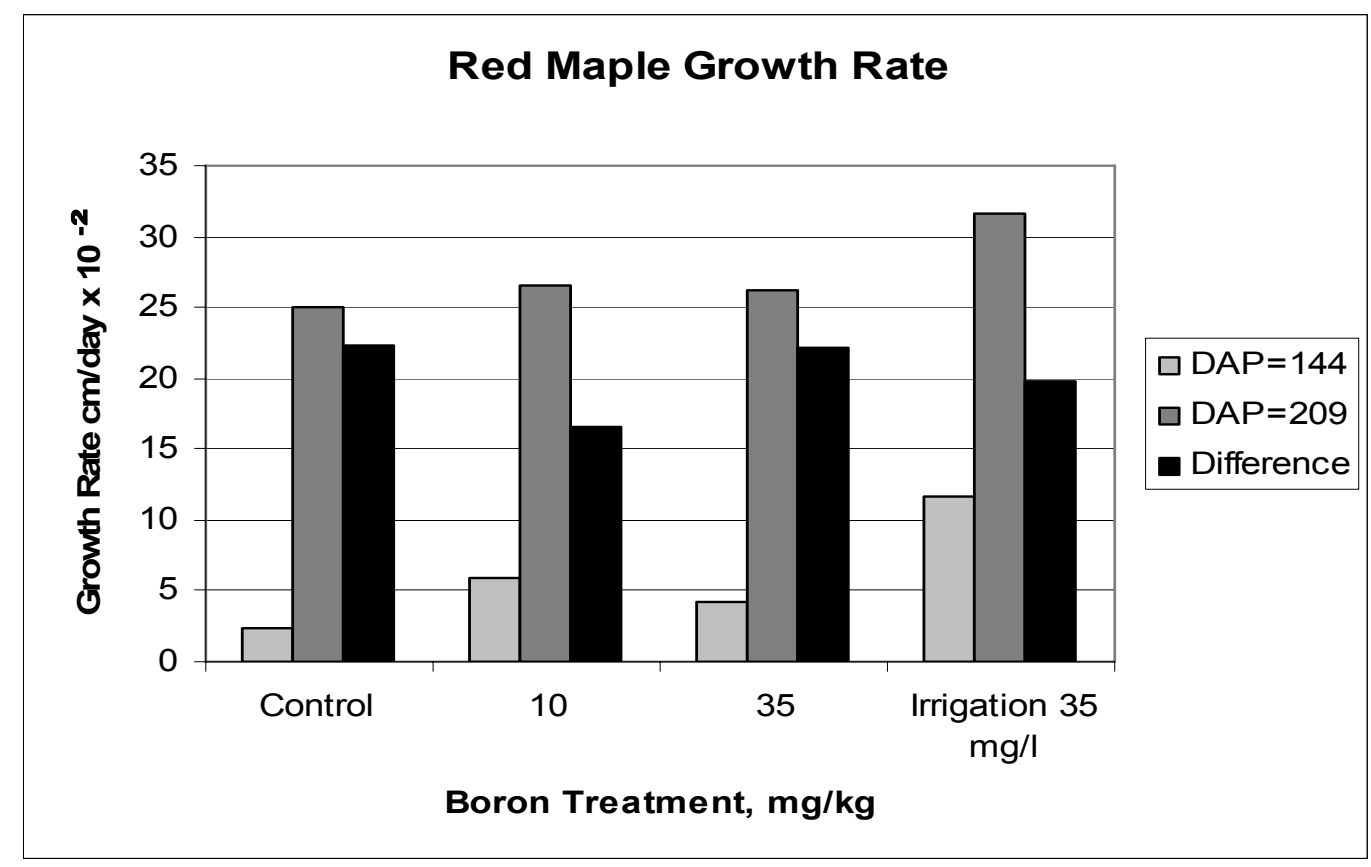

Figure 13. Effect of soil amended B and irrigated $B$ on red maple stem growth rate $(\mathrm{cm})$ between 144 DAP and 209 DAP.

\subsubsection{Plant Tissue Boron Concentrations}

Stem concentrations of $B$ were proportional to the exposure to the amount of $B$ amended into the soil or B applied in the irrigation water (Table 10). Generally, the stem concentration of B in all tree species was 1.5 to 2.0 times the control when grown in the $10 \mathrm{mg} / \mathrm{kg}$ soil treatment. However the stem concentration of the B in the irrigated plants was generally 4 to 10 times higher than the controls. Stems of irrigated plants had a higher B concentration than stems growing in the soil amended with $35 \mathrm{mg} / \mathrm{kg}$ of B with the exception of tulip poplar. However, tulip poplar survival in the $35 \mathrm{mg} / \mathrm{kg}$ soil treatment was poor and enough tissue from only one tree was available to analyze for $B$ content. 


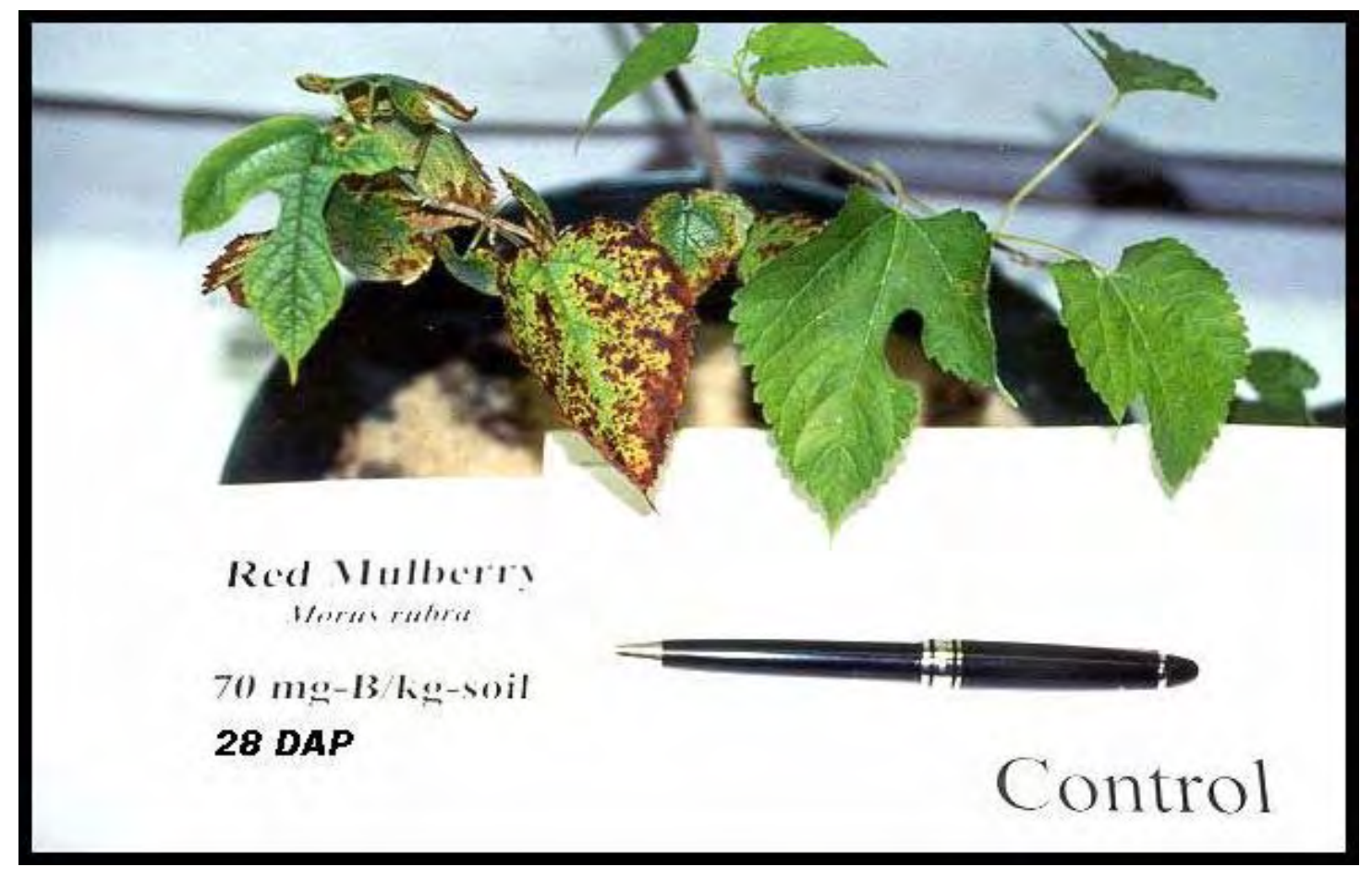

Figure 14. Effect of soil amended B (70 mg/kg soil) on red mulberry leaves.

Leaf B concentrations were generally much higher than their stems in this screening test. The higher concentrations of tissue $B$ were much higher than previously reported in many tree species (Sposito and Calderone, 1988). Leaves of the trees irrigated with B were about 25-40 times higher in B than the controls and most were much higher than plants growing in the 35 $\mathrm{mg} / \mathrm{kg}$ soil treatment. The exception was sweet gum, probably due to its slow growth and low demand for water. Boron concentration in the leaves was very similar in all species when grown in soil amended with $10 \mathrm{mg} / \mathrm{kg}$ of B. Differences in B concentration in the leaf tissue between species were more evident when plants were grown in the higher soil concentration of $B$, or irrigated with water containing $35 \mathrm{mg} / \mathrm{L}$ of $\mathrm{B}$.

It is concluded that $B$ uptake from irrigation will be greater than $B$ uptake from soil amended with a similar concentration of $B$. These results were obtained when $B$ irrigation is used to meet the total plant demand for water for a period of time in juvenile trees. Plants growing in the field would obtain a portion of their water needs from rainfall and a portion from irrigation. The replacement rate of water during periods of drought and the concentration of $B$ in the irrigation water will be the major factors to consider for irrigation management. Additionally, larger and older trees will have different water demands and different size sinks for B accumulation. It can be assumed that larger and older plants could tolerate more exposure to $B$ as measured by growth and changes in biomass accumulation rate. It can also be assumed that B uptake will have early effects on flowering, fertilization of ovules, pollen tube development, etc before changes in biomass accumulation are detected but these effects are largely unknown.

\subsubsection{Summary Discussion of Boron Tolerance Testing}

All tree species tested were damaged by the high level of B in water used in this test. Two types of B mobility are exhibited by plants: 1) immobile and 2) mobile. Plants with immobile physiology exhibit tip/edge burn on older leaves, while those in which $B$ is mobile, meristematic 
dieback of young shoots is a primary symptom (Brown and Barry, 1997; Brown and Hu, 1998). All species tested demonstrated symptoms of immobile physiology when exposed to B by irrigation. In these species, the $B$ is brought to the leaves in the transpiration stream and tends to concentrate due to lack of a simple sugar complex (polyol-B-polyol) to transport B into the phloem tissue of the plant species (Brown et al, 1999). However, when the one year-old transplants were exposed to soil amended with $B$, differences in plant species responses were found. These differences suggest that the B toxicity in four of these species also exhibits some characteristics of mobile physiology, and seedling survival was poor in these species. The exception to this response was red maple, and seedling survival was generally good. This species had slow stem growth, but growth remained positive with increasing seasonal exposure to $B$. Growth rate of this species appeared to be slowing during the growing season due an increased exposure to $B$ in soil as a result of accumulated $B$ from irrigation and duration of exposure. Red maple seedlings were probably protected from rapid onset of $B$ damage due to both partial immobile physiology and its low requirement for water.

\begin{tabular}{|c|c|c|c|c|c|c|c|c|c|c|}
\hline \multicolumn{11}{|c|}{ STEMS (Avg. \pm std) } \\
\hline \multirow[t]{2}{*}{$\begin{array}{l}\text { Soil Treatment } \\
(\mathrm{B}, \mathrm{mg} / \mathrm{kg})\end{array}$} & \multicolumn{2}{|c|}{ Sycamore } & \multicolumn{2}{|c|}{ Sweet Gum } & \multicolumn{2}{|c|}{$\begin{array}{l}\text { Red } \\
\text { Maple }\end{array}$} & \multicolumn{2}{|c|}{$\begin{array}{c}\text { Eastern } \\
\text { Cottonwood }\end{array}$} & \multicolumn{2}{|c|}{$\begin{array}{l}\text { Tulip } \\
\text { Poplar }\end{array}$} \\
\hline & Avg. & Std & Avg. & Std & Avg & Std & Avg. & Std & Avg. & Std \\
\hline Control & 11.2 & 1.8 & 12.6 & 1.1 & 16.8 & 2.7 & 18.0 & 2.9 & 18.3 & 3.8 \\
\hline 10 & 19.3 & 13.6 & 31.4 & 8.8 & 27.5 & 6.0 & 27.9 & 6.5 & 29.1 & 5.6 \\
\hline 35 & 87.7 & 0 & 71.8 & 15.6 & 60.0 & 22.5 & 43.3 & 20.0 & 110.7 & 24.0 \\
\hline Irrigated & 131.3 & 30.1 & 86.3 & 7.0 & 75.2 & 30.4 & 120.1 & 32.8 & 80.7 & 37.2 \\
\hline
\end{tabular}

Leaves (Avg. \pm std)

\begin{tabular}{|l|l|l|l|l|l|l|l|l|l|l|}
\hline $\begin{array}{l}\text { Soil Treatment } \\
\text { (B, mg/kg) }\end{array}$ & \multicolumn{2}{|l|}{ Sycamore } & \multicolumn{2}{|c|}{ Sweet Gum } & \multicolumn{2}{|c|}{$\begin{array}{l}\text { Red } \\
\text { Maple }\end{array}$} & \multicolumn{2}{|c|}{$\begin{array}{l}\text { Eastern } \\
\text { Cottonwood }\end{array}$} & \multicolumn{2}{|c|}{$\begin{array}{c}\text { Tulip } \\
\text { Poplar }\end{array}$} \\
\hline & Avg. & Std & Avg. & Std & Avg. & Std & Avg. & Std & Avg. & Std \\
\hline Control & $\mathbf{2 9}$ & 5.1 & $\mathbf{1 5}$ & 3.5 & $\mathbf{3 6}$ & 4.4 & $\mathbf{7 8 . 1}$ & 40.1 & $\mathbf{2 4 . 3}$ & 5.3 \\
\hline $\mathbf{1 0}$ & $\mathbf{2 3 7}$ & 21.7 & $\mathbf{2 2 6}$ & 30.0 & $\mathbf{2 9 5}$ & 29.2 & $\mathbf{2 2 6}$ & 105 & $\mathbf{2 1 9}$ & 18.2 \\
\hline $\mathbf{3 5}$ & $\mathbf{4 7 4}$ & 158 & $\mathbf{1 2 7 3}$ & 155 & $\mathbf{9 8 9}$ & 231 & $\mathbf{7 3 9}$ & 56.0 & $\mathbf{1 6 1}$ & 0 \\
\hline Irrigated & $\mathbf{1 1 4 9}$ & $\mathbf{7 7 1}$ & $\mathbf{4 2 3}$ & 135 & $\mathbf{1 1 8 5}$ & 394 & $\mathbf{2 7 7 0}$ & 671 & $\mathbf{1 0 4 2}$ & $\begin{array}{l}450 . \\
\mathbf{4}\end{array}$ \\
\hline
\end{tabular}

Table 10. Effect of soil amended B and simulated FGD wastewater (35 mg B/L) on B concentrations $(\mathrm{mg} \mathrm{B} / \mathrm{kg}$ ) in stems and leaves of harvested trees.

In trees with mobile physiology, B would be able to redistribute from older leaves into younger leaves, stems, and fruit. This type of physiology tends to dilute the B into a larger amount of biomass and protects the plant from excessive tissue damage. Some nut (walnut - immobile) and fruit (apples - mobile) trees can accumulate relatively large amounts for nut and fruit dry matter and exhibit intolerant characteristics to water B concentrations higher than $0.3-1.0 \mathrm{mg} / \mathrm{l}$. Leaf tissue analyses to assess B sufficiency (or toxicity) levels for these types of species must be collected differently (Brown and Uriu, 1996). Following the progressive uptake of B in plant 
leaves would require collecting older fully expanded leaves and younger not fully expanded leaves separately over several times and analyzing them for B.

Irrigation guidelines to avoid B toxicity suggest that a plant's tolerance level to soil solution B should be divided by a factor of 2.4 to estimate the $B$ water concentration that can be used for irrigation (Leyshon and Jame, 1993). Tolerance level of plants to B is usually determined in sand/solution culture to avoid soil clay adsorption which can confound the results. The use of the actual soil from the CCWESTRS site in this greenhouse test should provide sufficiently accurate results if trees are field planted on the same soil type. Assuming tolerance to $10 \mathrm{mg}$ $\mathrm{B} / \mathrm{kg}$ soil, then a water concentration of $4.1 \mathrm{mg} / \mathrm{L}$ would be suitable $(10 / 2.4=4.1)$. The rapid response of sycamore and cottonwood due to heavy water usage suggests short irrigation periods of only 40 days should be utilized if rainfall is not anticipated. Plants with significantly less water demand could be exposed to a higher level of soil solution B or a longer period of irrigation. Sweet gum and red maple may be grown at a lower risk of B toxicity if low growth rates can be tolerated.

\subsubsection{Conclusions of Boron Tolerance Testing}

Using the Paradise power plant FGD waste water as a source of irrigation on tree seedlings without first diluting the $B$ concentration would require careful planning and management. It was suggested:

(1) The FGD water should be blended to $4 \mathrm{mg} \mathrm{B/L}$ or less prior to use.

(2) Allow trees to become fully established before applying diluted water.

(3) Do not saturate the soil with boronated waste water.

(4) Initially monitor $B$ and $N$ in leaves to help schedule irrigation and fertilization.

(5) Monitor the accumulation of B in the soil profile.

(6) Schedule leaching irrigation with low B water to prevent B accumulation in the soil.

(7) Continue to search for more tolerant trees and crop management techniques to reduce the risk of irrigating with boronated waste water.

\subsection{Boron Leaching from Drip-Irrigated FGD Wastewater at the CCWESTRS Field Site 6.3.1 Background}

The amount of B that can be safely applied in the irrigation water without reducing tree growth will depend partly on how much B will leach below the rooting zone. Significant quantities of soil water will move below the rooting zone during the winter months when precipitation exceeds evapotranspiration. Some soil water may also move below the rooting zone following rainy periods during the growing season or when significant rainfall occurs immediately after irrigation. Information is needed concerning the extent that B will move with excess soil water and ultimately be leached out of the rooting zone.

Two factors will determine the extent that B moves with soil water. One factor is how strongly B is adsorbed on the surfaces of soil particles. If $B$ is strongly adsorbed, then little $B$ will move with soil water in micropores. A second factor is how much B is carried with water that moves in macropores resulting from soil cracks, old root channels, earthworm holes, etc. Boron moving with water in macropores doesn't come into intimate contact with soil surfaces and may move significant distances with soil water before finally being adsorbed on soil surfaces. The soil at the CCWESTRS site may have a lot of macropores because it has been in a perennial crop (fescue/lespedeza mixture) for several years and hasn't been tilled and as a result of the skeletal (rocky) nature of the soil. Macropore flow likely will be greatest near the irrigation system drip emitters where the soil routinely becomes saturated and water can freely move from 
micropores into any macropores that may exist near the emitters. Rainfall likely will not result in much macropore flow, especially with FGD gypsum mulch, except perhaps during winter months. Significant macropores likely won't develop in the mulch, and rainwater will be dispersed in micropores in the mulch before entering the original soil. Rainwater that does enter macropores in the original soil won't contain much B (assuming B is strongly adsorbed by the soil) and is not expected to result in much $B$ leaching.

A field leaching study was conducted to simulate drip irrigation of Paradise FGD wastewater and associated movement of wastewater $B$ below the emitters. This study was designed to reflect maximum potential for $B$ leaching. If $B$ leaching is significant in the field experiment, somewhat higher levels of $B$ in the irrigation water can be tolerated in the field study without causing soil $B$ buildup and resulting $B$ phytotoxicity problems.

\subsubsection{Experimental Methods}

The field B leaching study was designed to simulate the anticipated CCWESTRS field-scale drip irrigation system with the following characteristics:

- One tree occupies $3.6 \mathrm{~m} \times 1.8 \mathrm{~m}$ (3.6 m between tree rows, $1.8 \mathrm{~m}$ between trees)

- One drip line runs parallel to each tree row $30 \mathrm{~cm}$ (11.8 in) to the side of tree rows

- Emitter spacing on drip lines is $60 \mathrm{~cm}$ (23.6 in); this implies 3 emitters/tree [3 emitters $/ 6.6 \mathrm{~m}^{2}$ $\left(71 \mathrm{ft}^{2}\right)$ of field area or 1 emitter/2.2 $\mathrm{m}^{2}\left(23.7 \mathrm{ft}^{2}\right)$ of field area]

- Each emitter wets soil beneath a $60 \mathrm{~cm} \times 60 \mathrm{~cm}=0.36 \mathrm{~m}^{2}\left(23.6 \mathrm{in} \times 23.6 \mathrm{in}=3.87 \mathrm{ft}^{2}\right)$ area of land (i.e., the emitters will wet approximately $(0.36 / 2.2) \times 100=16.4 \%$ of the field area)

- A $2.54 \mathrm{~cm}$ (1 in) application of irrigation water on a total field basis will be equivalent to a 15 $\mathrm{cm}$ (5.9 in) application over the land area actually wetted

- The estimated maximum evapotranspiration (ET) rate on hot, dry days will be about 0.65 $\mathrm{cm} /$ day ( 0.25 in/day) on a field basis; maximum ET rates will probably be lower than this until the canopy closes in the third or fourth growing season

- During periods with maximum ET and no rain, apply $2.54 \mathrm{~cm}$ ( 1 in) on a field basis of irrigation water every fourth day (assumes capacity to irrigate one-fourth of the field on a given day)—this irrigation rate corresponds to approximately $2.3 \mathrm{l} / \mathrm{emitter} / \mathrm{hr} \quad(0.61$ gal/emitter/hr) for 24 hours every fourth day

Experimental procedures were as follows:

1. Mowed the cover crop in a $1.2 \mathrm{~m} \times 4.6 \mathrm{~m}(3.9 \times 15.1 \mathrm{ft})$ strip to facilitate installation of drip emitters

2. Calibrated five drip emitters and associated delivery tubes and wastewater tanks with proper head pressure for the desired rate and volume of water application

3. Placed drip emitters $60 \mathrm{~cm}$ (23.6 in) apart on the longitudinal axis in the center of the strip where the cover crop was mowed

4. Collected sub-sample of wastewater used for irrigation and saved for B analysis; the wastewater contained $80 \mathrm{mg} \mathrm{B/l}$

5. Ammonium nitrate was added to the FGD wastewater to provide $100 \mathrm{mg} \mathrm{NH}_{4}-\mathrm{N} / \mathrm{l}$ and 100 $\mathrm{mg} \mathrm{NO}_{3}-\mathrm{N} / \mathrm{l}$ to be monitored relative to $\mathrm{B}$ movement

6. Applied a $2.54 \mathrm{~cm}$ (1 in) application of FGD wastewater on a field basis [15-cm (5.9 in) application over the wetted area] over a $24 \mathrm{hr}$ period; this corresponded to $55 \mathrm{l} / \mathrm{emitter} / 24 \mathrm{hr}$ (14.5 gal/emitter/24hr)

7. Allowed soil moisture to redistribute for $24 \mathrm{hrs}$

8. Sampled soil immediately below each of the center three emitters in 15-cm (6 in) increments to a depth of $1 \mathrm{~m}(3.28 \mathrm{ft})$ using a bucket auger 
9. Sampled soil just beyond the wetted area (for background B measurement) in $15 \mathrm{~cm}$ (6 in increments to a depth of $1 \mathrm{~m}(3.28 \mathrm{ft})$

10. Determined B distribution by depth. Boron in soil from each depth was extracted with hot water (Wear, 1965) and with calcium chloride (Matsi and Keramidas, 2001) and the extracts were analyzed for $B$

\subsubsection{Results}

Soil moisture levels 24 hours after irrigation are presented in Figure 15. The soil moistures levels were lower than normally expected for medium-textured soils at field capacity (i.e., after draining for 24 hours). The low soil moisture levels at field capacity are apparently due to the large fraction of rock in the soil. The rock holds very little water, thereby reducing the waterholding capacity per unit mass of rock-soil mixture. Irrigation increased the soil moisture content at all depths sampled.

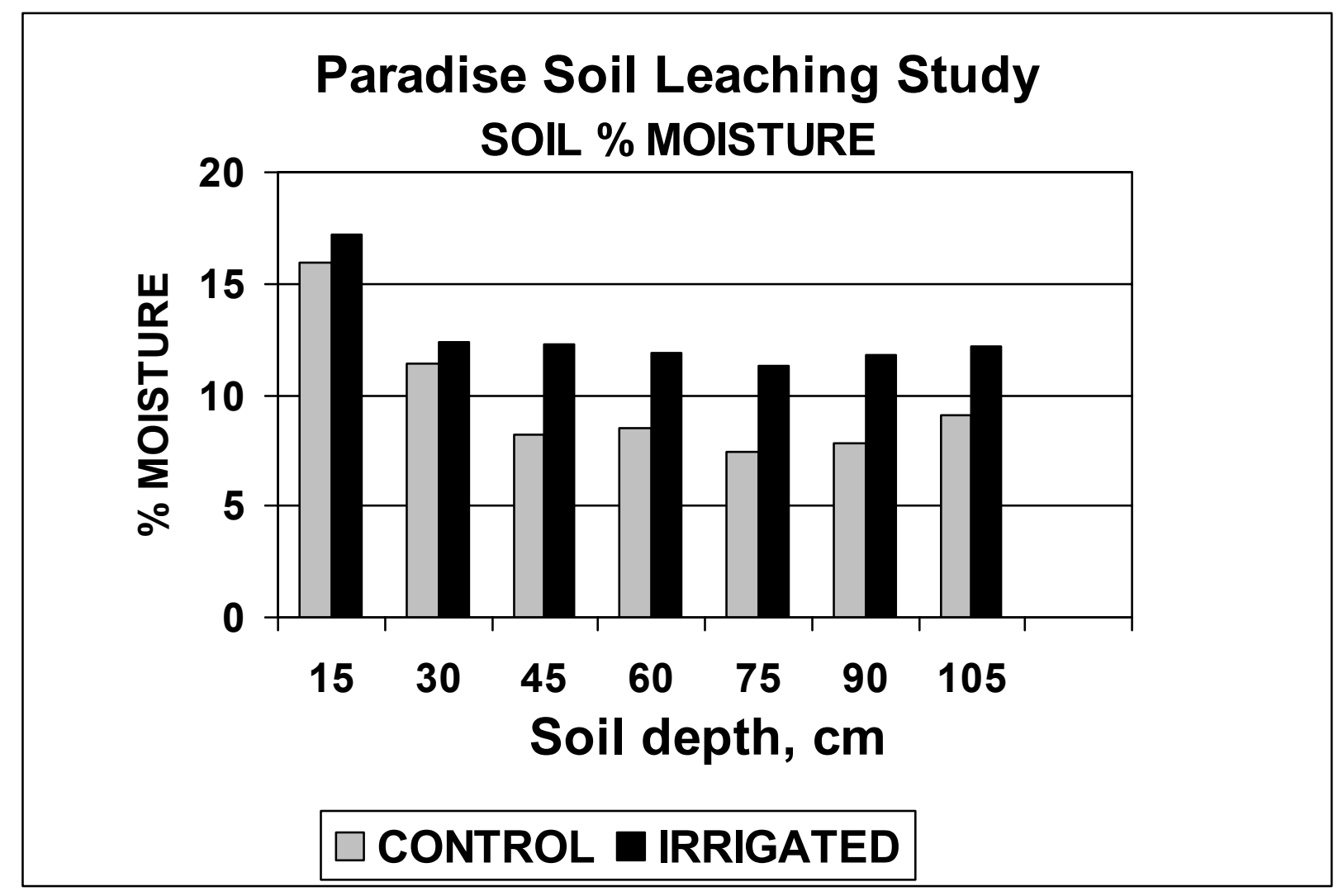

Figure 15. Soil moisture content as affected by drip irrigation.

Hot-water extractable $B$ is often used as an index of plant-available $B$ and is presented in Figure 16. Significant quantities of $B$ moved to a $60-\mathrm{cm}$ (23.6 in) depth, but the highest $B$ concentration occurred in the top $15 \mathrm{~cm}$ (6 in) of soil. The soil clearly adsorbed B to a significant degree because more $B$ was retained near the soil surface than at lower depths. These data indicate that most of the B applied in FGD wastewater will be retained in the rooting zone during the growing season. However, $B$ is somewhat mobile in this soil, suggesting that B will leach out of the rooting zone to some extent during the winter when precipitation exceeds evapotranspiration. 


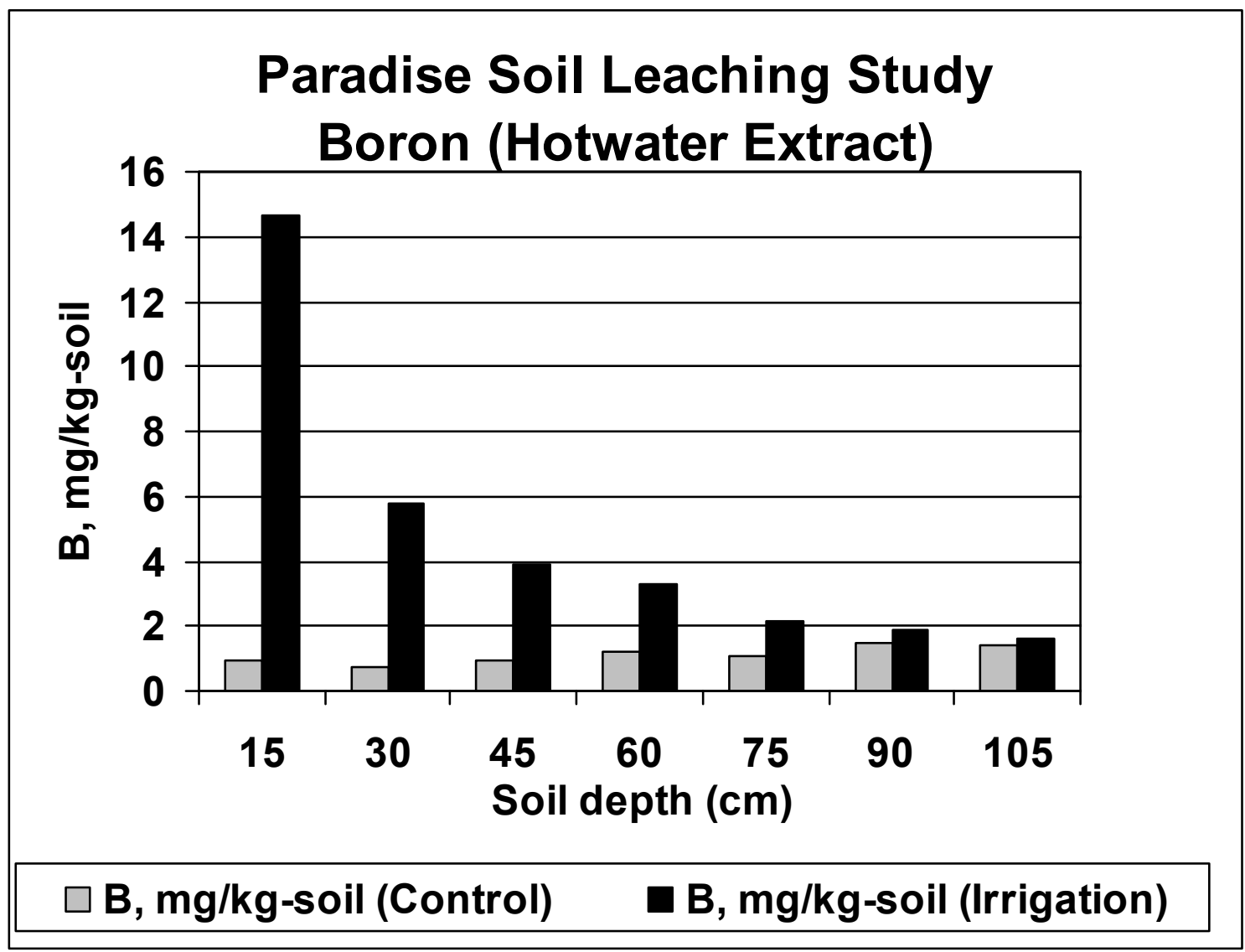

Figure 16. Hot water-extractable B as affected by drip irrigation.

The general distribution of $\mathrm{Ca}(\mathrm{Cl})_{2}$-extractable $\mathrm{B}$ with depth (Figure 17) was similar to the $\mathrm{B}$ distribution as indicated by extraction with hot water (Figure 16). About $64 \%$ of total B extracted with $\mathrm{Ca}(\mathrm{Cl})_{2}$ was removed in the first extract, indicating that the soil had some affinity for the irrigated $\mathrm{B}$. The distribution of $\mathrm{NH}_{4}$ with depth is presented in Figure 18. Some of the $\mathrm{NH}_{4}$ added to the irrigation water moved to about $45 \mathrm{~cm}(17.7 \mathrm{in})$, but most of the $\mathrm{NH}_{4}$ was retained in the top $15 \mathrm{~cm}$. Ammonium (Figure 18) didn't move downward quite as much as B (Figure 16), but $\mathrm{NH}_{4}$ and $\mathrm{B}$ moved similarly. It is generally considered that significant quantities of $\mathrm{NH}_{4}$ will not leach below the rooting zone in most situations. The distribution of $\mathrm{NO}_{3}$ with depth is presented in Figure 19. Although some $\mathrm{NO}_{3}$ moved to a depth of $90 \mathrm{~cm}$, much of the $\mathrm{NO}_{3}$ was retained in the top $15 \mathrm{~cm}$. Significant retention of $\mathrm{NO}_{3}$ in the top $15 \mathrm{~cm}$ is surprising, given that $\mathrm{NO}_{3}$ generally is very mobile in soils and readily moves below the rooting zone with excess soil moisture; the reason for the unusual $\mathrm{NO}_{3}$ retention near the soil surface in this study is not clear. It is possible that fescue plant roots could have partially accounted for the $\mathrm{NO}_{3}$ retention in this surface sample. 


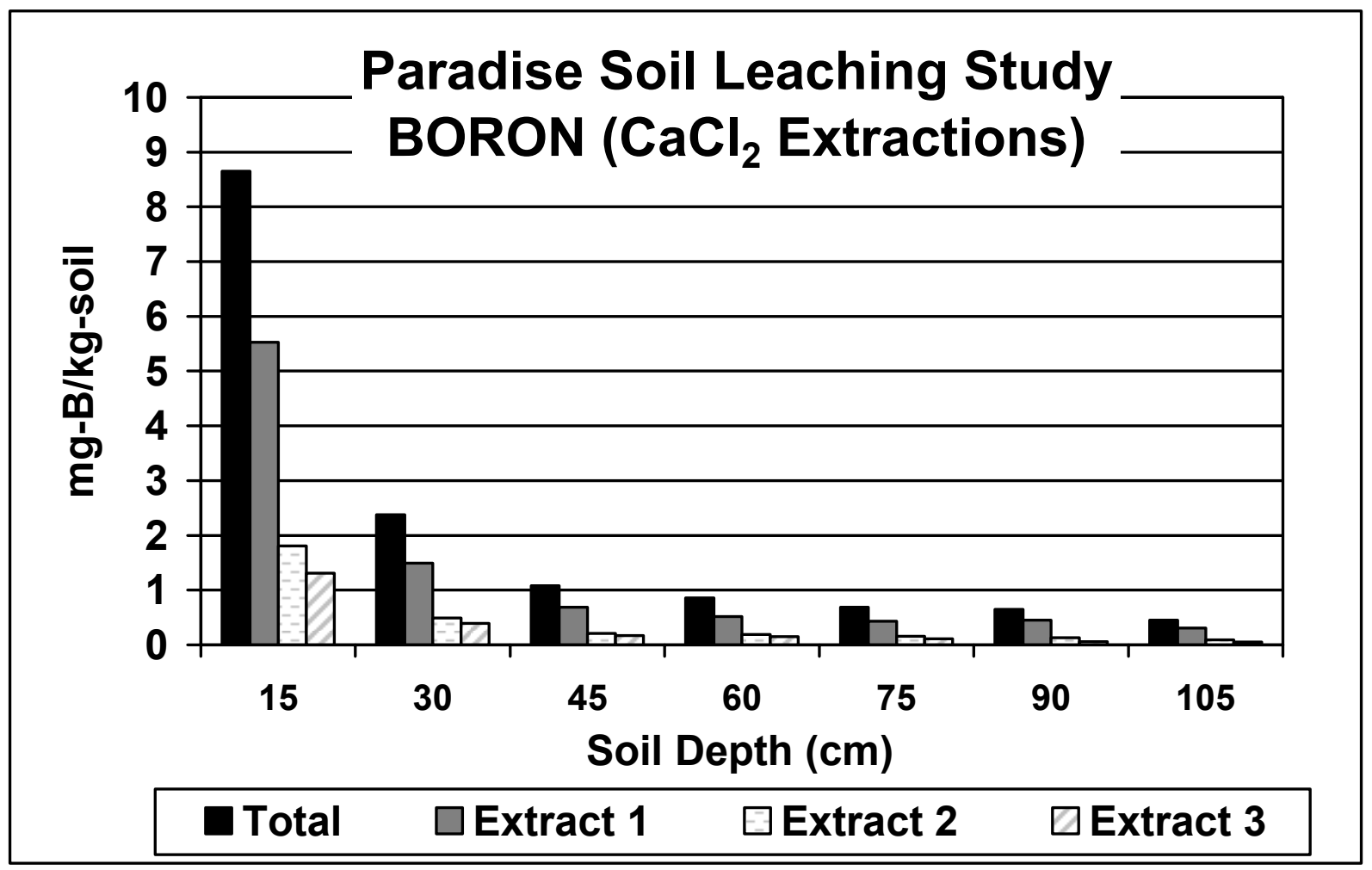

Figure 17. Calcium chloride-extractable $B$ as affected by drip irrigation.

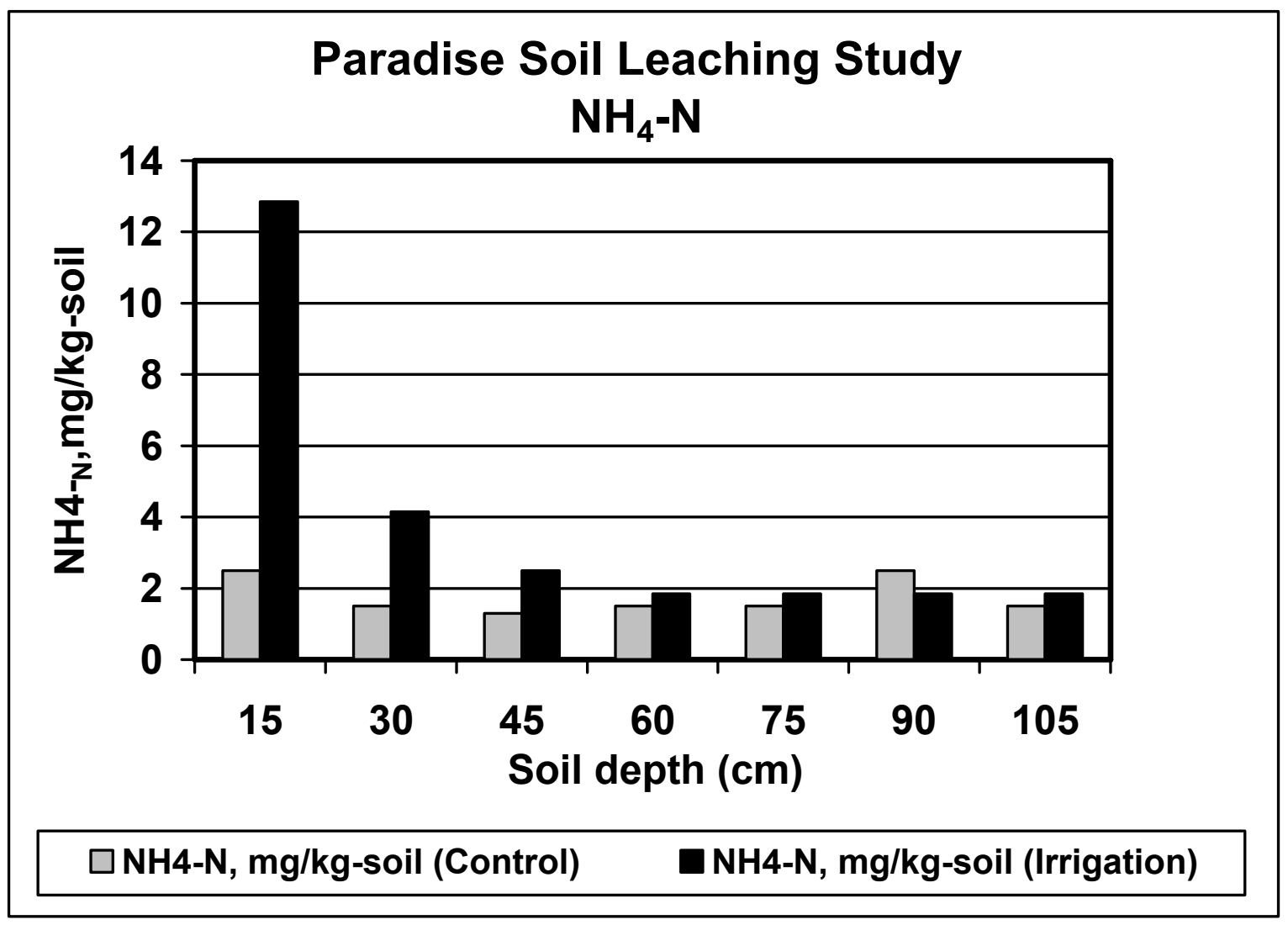

Figure 18. $\mathrm{KCl}$-extractable $\mathrm{NH}_{4}$ as affected by drip irrigation. 


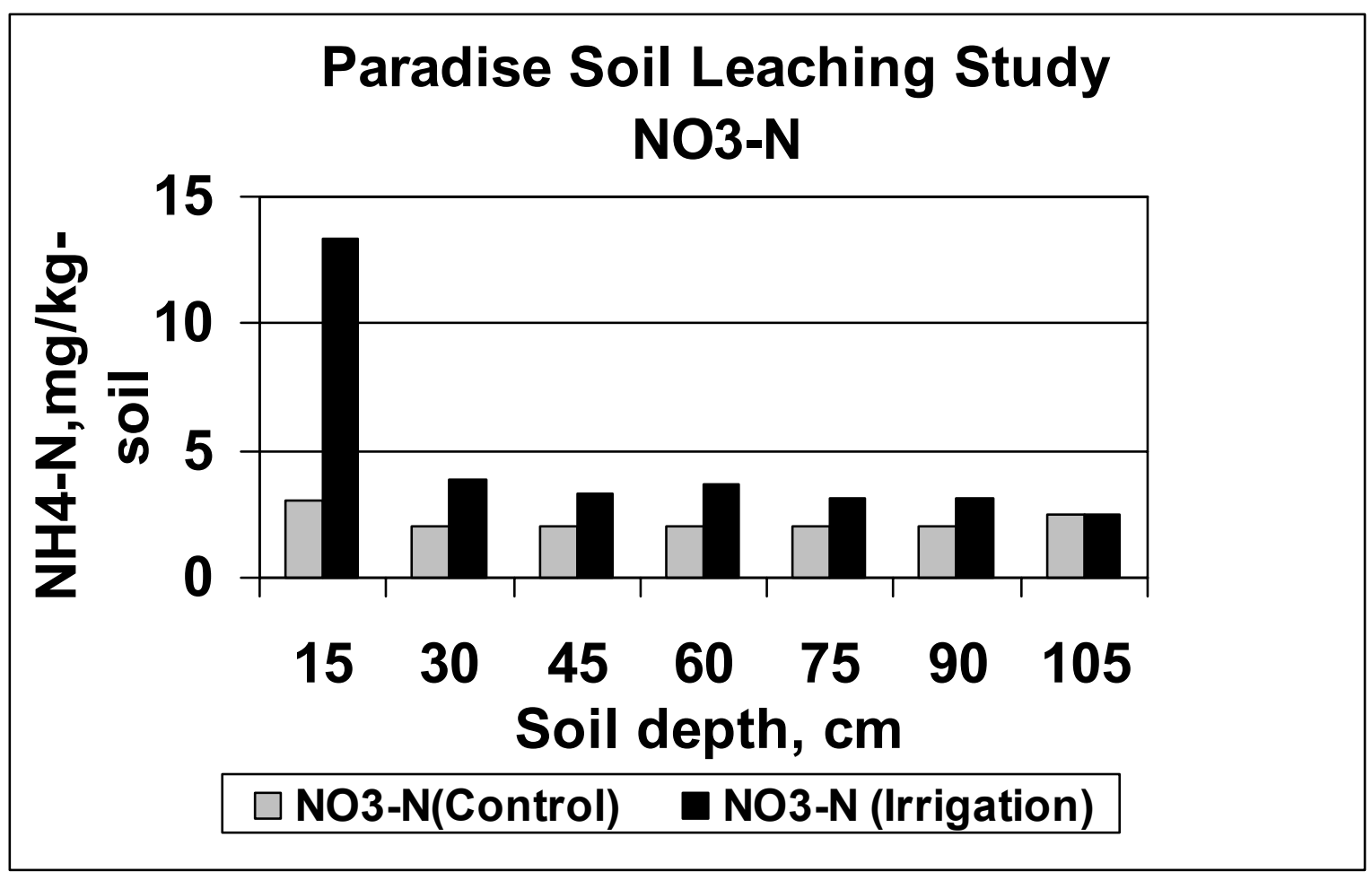

Figure 19. $\mathrm{KCl}$-extractable $\mathrm{NO}_{3}$ as affected by drip irrigation.

\subsubsection{Conclusions for Boron Leaching Study}

Overall, results from this B leaching study indicate that if wastewater containing B is dripirrigated to match evapotranspiration during the growing season, most of the applied B will be retained in the upper part of the rooting zone during the growing season. Since B is somewhat mobile at our study site, winter precipitation likely will leach much of the B out of the rooting zone, resulting in lower levels of soil B at the beginning of each growing season. With this type of pattern, application of $25 \mathrm{~cm}$ ( $9.84 \mathrm{in}$ ) of water containing $7 \mathrm{mg} \mathrm{B/l}$ irrigation water (e.g., the fly ash pond water) would result in an accumulation of about $7 \mathrm{mg} \mathrm{B} / \mathrm{kg}$ soil in the rooting zone by the end of each growing season. During the first part of each growing season, significantly less than an additional $7 \mathrm{mg} \mathrm{B} / \mathrm{kg}$ soil will have accumulated. The greenhouse B tolerance study indicated that sycamore, cottonwood, sweet gum, and red maple will tolerate $10 \mathrm{mg} \mathrm{B} / \mathrm{kg}$ soil reasonably well for about one growing season or less. Some B leaf damage would probably occur during the last part of the growing season and concentrate in the autumn leaf litter to be leached out by rainfall. The combined results of the greenhouse B tolerance study and the field B leaching study suggest that sycamore, cottonwood, sweet gum, and red maple will tolerate an annual application of $25 \mathrm{~cm}$ fly ash pond water reasonably well, but that $25 \mathrm{~cm}$ of FGD wastewater ( $70 \mathrm{mg} \mathrm{B} / \mathrm{l})$ would be very damaging to the trees.

\subsection{FGD Mulch Depth Field Study}

A small field study was initiated at the CCWESTRS site in March 2001 to determine possible impacts that varying depths of FGD-gypsum depth might have on fescue survival and growth. $2 \mathrm{~m} \times 2 \mathrm{~m}$ sub-plots were established with FGD gypsum depths at $5,10,15$, and $20 \mathrm{~cm}$ (one 30 $\mathrm{cm}$ application was established, but abandoned as too extreme) and a control (zero FGD). These treatments were replicated four times and all sub-plots were observed over the 2001 
growing season. In the spring, the fescue began to penetrate the $5 \mathrm{~cm}$ applications of FGD materials throughout the plot. Some fescue also began to penetrate the $10 \mathrm{~cm}$ applications, but this was limited to the sub-plot margins were erosion had decreased the depths of the material. None of the 15 and $20 \mathrm{~cm}$ applications (or the single $30 \mathrm{~cm}$ ) has been penetrated by fescue or any other plant species to date. Left undisturbed, the FGD gypsum settles by as much as 15$20 \%$, becomes denser and forms a superficial crust which may limit plant penetration. When dry, this crust may also initially act as an impediment to water infiltration during intense summer storms; however, the gypsum has a moderate hydraulic conductivity when moistened (measured in the laboratory at $3.9 \mathrm{~cm} / \mathrm{hr}$ ). Visual observations of fescue health both inside of the sub-plots (5 cm depth) and along the edges of the FGD material in all sub-plots, would suggest that the FGD gypsum is certainly effectively conserving soil water when much of the surrounding site is experiencing droughty conditions.

Based on the field study, the Project Team determined that the full-scale demonstration should be tested with zero, $10 \mathrm{~cm}$, and $20 \mathrm{~cm}$ depths of the FGD gypsum for mulch.

\subsection{Task 4 - Engineering Design of CCWESTRS 7.1 Silvicultural Plan}

In 2001, the Project Team developed a preliminary test plan. This research project involved the application of three levels each of two types of power plant byproducts-three levels of FGD gypsum mulch, and three levels of FGD pond irrigation water. This design produced nine treatment levels $(3 \times 3)$, which will be tested, with two species of hardwood trees (i.e., sweet gum and sycamore). Each treatment combination will be replicated three times, resulting in a total of 54 treatment plots ( 3 FGD gypsum levels $X 3$ irrigation water levels $\times 2$ tree species $\times 3$ replicates). Survival and growth response of plant species in terms of sequestering of carbon in plant material and soil will be the primary measure of effectiveness of each treatment

FGD gypsum was applied (see section 9.0) at mulch at three levels: (1) control = no mulch; (2) Low = $10 \mathrm{~cm}$ depth; and (3) High $=20 \mathrm{~cm}$ depth. Irrigation water is being applied at three levels-(1) control = zero irrigation; (2) Low; and (High). The 40.5-hectare research area is subdivided into nine zones, each covered with one of the three levels of FGD gypsum mulch ( 0 , $10 \mathrm{~cm}$, and $20 \mathrm{~cm}$ ), replicated three times. Exact application levels applied to each zone were randomly chosen. Figure 18 shows the location and variable information of the test plots. Gypsum was applied in 3.7-m wide strips, separated by $1.2-\mathrm{m}$ wide strips of existing grass (fescue plus lespedeza) cover crop. The cover crop rows were retained for erosion control purposes, particularly with respect to the gypsum being applied.

Soil analyses revealed that the $\mathrm{pH}$ of soils on site was circum-neutral $(7.0+/-0.5)$, implying that hardwood tree species would generally perform considerably better than coniferous species. After extensive greenhouse testing of a number of tree species for tolerance to $B$, and consideration of other factors such as drought tolerance, growth rate, and commercial value, sycamore and sweet gum were chosen as the optimum species for planting.

Two rows of two-year-old tree seedlings were planted in February-March 2002 in each 3.7-m wide row of gypsum treatment (except in plots with zero gypsum treatment) at 2.44-m X 2.44-m spacing. This planting pattern resulted in a 2.4-m wide strip of gypsum between rows of trees on one side of a row and $0.6-\mathrm{m}$ wide strip of mulch plus $1.2-\mathrm{m}$ of grass plus a second $0.6 \mathrm{~m}$ of mulch between rows on the opposite side.

Within each of the nine zones of FGD gypsum treatment, the three irrigation treatments are replicated randomly. Figure 20 shows the location of the 27 irrigation areas $(Z e=$ no irrigation 
control) within the nine FGD gypsum treatment zones. Within each of the 27 irrigation areas (3 replicates of the nine possible gypsum-irrigation level combinations), half of the area will be planted to sycamore and half to sweet gum, in a split-plot design. This will result in 54 treatment plots of approximately 0.75 hectares each.

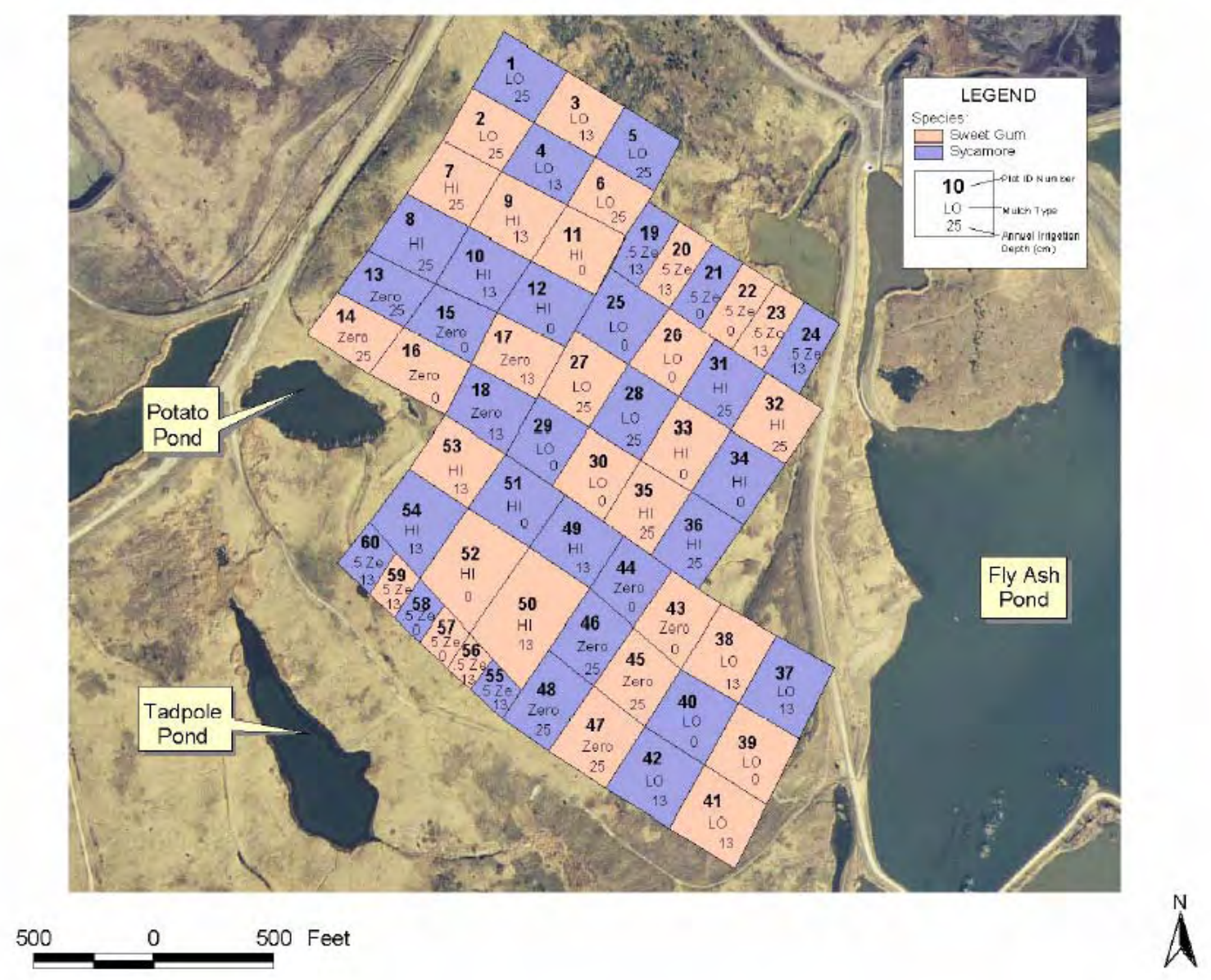

Figure 20. Schematic of CCWESTRS test plan showing FGD mulch depth (colored) and irrigation levels $(\mathrm{Hi}=25 \mathrm{~cm} / \mathrm{yr}$, Lo $=12.5 \mathrm{~cm} / \mathrm{yr}, \mathrm{Ze}=$ zero irrigation).

Because poor seedling survival over the 2002 growing season was partially attributed to weed competition for moisture (Figure 21), a decision was made to use herbicide to kill the living vegetation over the entire plot. In late October 2002, the entire site was sprayed with a mixture of Roundup Pro (glyphosate 41\%) and Oust (sulfometuron methyl 75\%) at a rate of 7.0 I Roundup Pro plus 0.1 I of Oust herbicide per hectare. These contact herbicides were used to kill the live plants --largely fescue and, to some extent, lespedeza. A low rate of Oust was used because the activity of Oust may result in residual herbicide activity that could damage newly planted tree seedlings if planting occurred too soon after herbicide application. Approximately $85 \%$ of the area was successfully impacted. A corrective follow-up spraying was carried out in December 2002 for those areas that were missed or received inadequate treatment. 


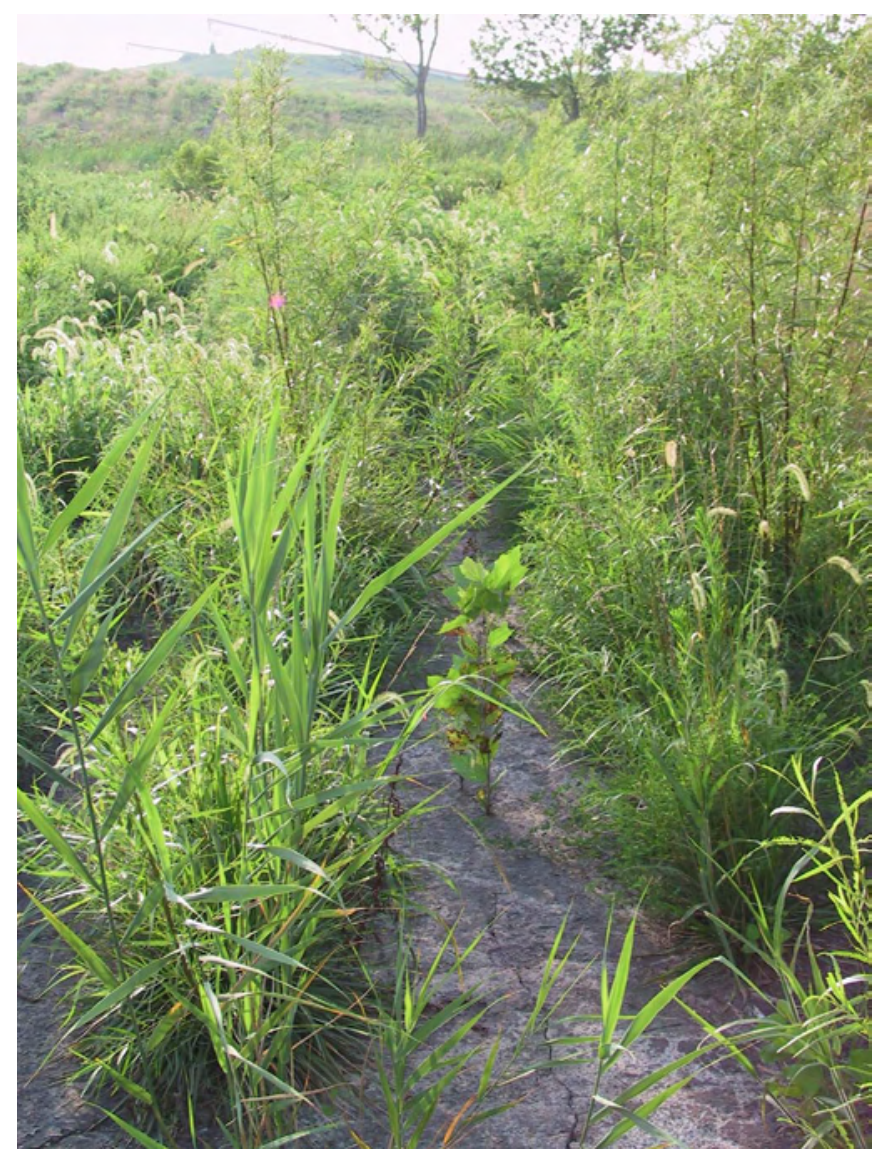

Figure 21. Photo of intensive vegetative competition impacting seedlings in some areas of the CCWESTRS site.

In January 2003, the entire site was bush-hogged in order to facilitate mechanical planting. Two-year-old sycamore and sweet gum seedlings were planted in late February and early March following the previous plot layout. Subsequent to planting, the irrigation system was installed adjacent to the trees lines.

\subsection{Irrigation system}

During the report period, the Project Team developed a preliminary approach to irrigating the CCWESTRS. Plans were to draw water from the FGD discharge channel using diesel, electric or hydraulic ram pumps or windmills to pump water to a head tank located centrally to the CCWESTRS. Distribution pipes would direct water to several other smaller head tanks designed to spill at rates determined to provide the specified amount of irrigant on the test plots via drip emitters.

Due to various reasons and decisions, the irrigation system was not installed in 2002 as planned. One of the reasons was the initial poor performance of the seedlings, which showed significant leaf damage and symptoms of boron toxicity and heat stress, presumably from the FGD gypsum mulch. Rather than subject the trees to additional B stress from irrigation with water from the FGD pond, it was decided to allow the trees to adapt to conditions in a slower manner. Although rainfall was adequate through June 2002, July and August rainfall was below normal and temperatures were above normal. In late August, we initiated a modified plan for the irrigation of the CCWESTRS test site. A temporary irrigation system was used to supply fresh 
water from a nearby, non-industrial surface impoundment, instead of using the FGD wastewater. This would allow the trees to adapt to the harsh conditions to which they have been subjected (i.e., drought, high heat, FGD gypsum as planting medium and insect infestations). Based on the results of the 2002 growing season (i.e., poor tree survival and boron toxicity), the team decided to use, in 2003, water obtained from the fly ash pond as the irrigation source.

A Request for Proposal (RFP) to install a drip irrigation system for trees at the CCWESTRS site was sent to four companies on November 12, 2002. The three companies that responded and their total cost estimates for design, delivery, installation, testing, and operator training of the drip irrigation system are shown below:

Irrigation-Mart, Inc.

Tuckasee Irrigation

East Coast Irrigation Services
Ruston, Louisiana Russellville, Kentucky Darlington, South Carolina
$\$ 106,150$

$\$ 107,200$

$\$ 135,000$

After a technical evaluation of the three proposals was performed, the contract was awarded to Irrigation-Mart. The primary reasons for Irrigation-Mart being awarded the contract were:

- all three designs were very similar

- Irrigation-Mart was the lowest bidder

- Irrigation-Mart provided a 1-year any/all services and materials needed to make the system operate as planned.

\section{Design}

The drip irrigation system is designed to irrigate 27.8 hectares $(2 / 3$ of the site since $1 / 3$ is not irrigated) in two zones (Figure 22). This fully automated system is designed to irrigate trees that have been planted in a $2.43 \times 2.43$ meter (8 ft.) arrangement. One $16 \mathrm{~mm}$ drip line with 1.58 liter per hour (Iph) (0.42 gallons per hour) fully pressure compensated emitters spaced 1.06 meters ( 3.5 feet) apart is to be placed along each row on the surface. The drip irrigation system has the capacity to allow the application of up to $5.08 \mathrm{~cm}$ per week. The system is divided into two zones and is shown in Figure 22. Zone 1 consists of nine plots (13.0 ha total) that are to receive the most irrigation. The pumping rate for zone 1 is about 1,323 liters per minute (lpm). Zone 2 consists of nine (or eleven if splits are counted) plots (14.82 ha total) that are to receive one-half of the amount of irrigation that the plots in zone 1 receive. The pumping rate for zone 2 is about $1,512 \mathrm{lpm}$.

Design features of the drip irrigation system include the following:

- Approximately 104,880 meters (65 miles) of $16 \mathrm{~mm}$ drip line with 1.58 liter per hour (Iph) pressure compensating emitters (Figure 23) spaced 1.06 meters apart. This is Toro Ag's Drip in Blue Strip, PC. 


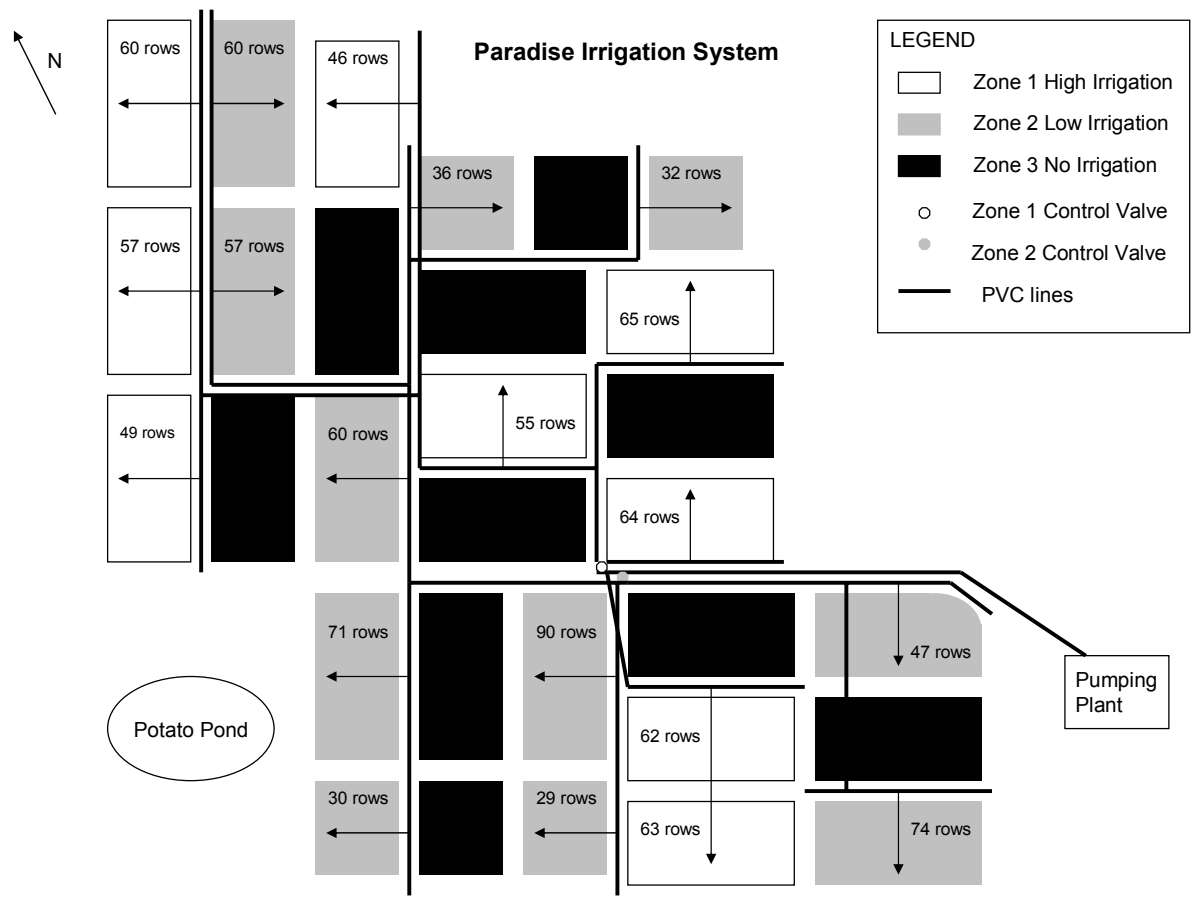

Figure 22. Schematic diagram of the CCWESTRS irrigation system.

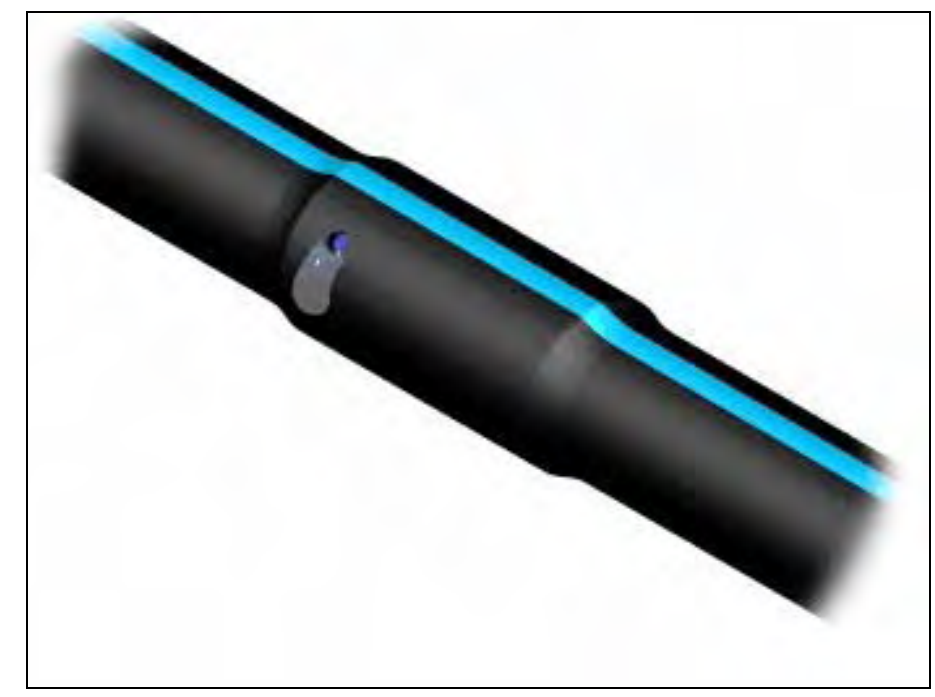

Figure 23. Photo of Toro Ag's $16 \mathrm{~mm}$ drip emitter used in the study.

- Approximately 1,107 drip lines, each beginning with a shut-off valve and terminating with an automatic flush valve.

- Approximately 1,107 one-half inch flex PVC risers from the PVC headers to the drip lines.

- PVC mainlines and headers, sized to maintain flow velocities, friction losses and pressures. The pipe will be gasketed (allowing installation during cold weather) and thrust blocked to secure in place. 
- 5.08 centimeter PVC flush valves at the ends of the PVC pipelines.

- Controller-to-valve wire and PVC pipe installed 0.608 meters below the soil surface, with wires placed below the pipe.

- Air/Vacuum relief valves placed in the PVC pipelines both before and after the zone valves.

- Two Toro Ag control valves (one for each zone).

- Irritrol IBOC, 24-volt battery powered controller to completely automate the system including signaling the engine's control panel to start/stop the pumping plant. Controller sets the current time, current day, watering day schedule, station watering time, and watering start time.

- McCrometer flow meter with instantaneous gpm and cumulative gallon readout.

- Pressure gauges/check-points throughout the system to assist in monitoring for proper performance/operation.

- $\quad$ Check valve to prevent back flow into water source.

- Fresno pressure relief valve.

- 15.2 centimeter Sure-Flo, foot valve.

- Fresno automatic, two 1.14 meter (45 inch) stainless steel tanks, for the sand media filter system rated at 2,097.9 lpm (555 gpm), placed on a pad.

- Alex-tronix filter backwash controller. Controller sets backwash interval, backwash time, and dwell time between each filters time to flush.

- Pumping plant consists of a VM (Detroit) SUN-2105 air-cooled, 2-cylinder, industrial diesel engine and a Berkeley B4EQM pump. The engine is equipped with a full feature control panel (Murphy automatic engine controller, ASM150) that protects the engine and pump, and makes the pumping plant operate automatically in response to the system controller. The controller includes selectable crank and rest cycles, sensing circuit for crank disconnect and overspeed, overcrank, and re-crank protection on false starts. Four LEDs indicate first-out shutdown for: low oil pressure, high temperature, overcrank and overspeed. A fifth LED indicates engine running.

- A 12-volt car battery for starting the engine.

- A 1,134 liters (300 gallons) diesel fuel storage tank.

\subsection{Task 5 - Construction of CCWESTRS 8.1 FGD Mulch Application}

Fluidized gas desulfurization (FGD) byproduct was selected for use as mulch to demonstrate a beneficial use of this material. Mulch placement width was arbitrarily selected at a minimum of $0.6 \mathrm{~m}$ on both sides of the tree row for a total of 1.2-m width of material. It was also determined 
that grass strips should be left between strips of mulch to stabilize fugitive material transported by storm water runoff. No economically attractive method of placement in 1.2-m strips over large areas was discovered. Heavy equipment was available with the ability to place the material in $3.7-\mathrm{m}$ rows. Placing the material in $3.7-\mathrm{m}$ wide rows with a $1.2-\mathrm{m}$ wide grass strip between was accepted as the best placement scenario. Two rows of trees could be planted in the 3.7-m mulch row.

Placement of the FGD mulch was accomplished by using heavy equipment capable of loading and spreading the material. Caterpillar 621 pan scrapers capable of moving 16 cubic meters per load were used meeting the need to move large amounts of material economically and placing in 3.7-m wide rows. Material was loaded directly from the FGD dry stack by the loader and hauled one kilometer to the placement site. The pan scrapers were capable of placing the material to the 10 - and $20-\mathrm{cm}$ depths selected by the study. Some smoothing and dressing of the material was done after placement using a Caterpillar D6 dozer.

Placement of the material was conducted over a three month period. Actual placement time was approximately one month. The three month period was required due to weather constraints. Placement was started in the first week of December.

The total amount of FGD material placed was 34,500 cubic meters. The material was divided into 11,500 cubic meters for the $10-\mathrm{cm}$ depth portion of the site and 23,000 cubic meters for the $20-\mathrm{cm}$ depth. Placement occurred at the rate of 11,500 cubic meters per month during December, January, and February.

The total cost for placing the material was $\$ 159,000$. The unit cost for placement was $\$ 4.61$ per cubic meter. It is thought that the total cost is approximately one third higher than a "best case" estimate due to weather delays.

\subsection{Tree planting \\ 8.2.1 2002 Tree Planting}

Tree planting preparations began in the middle of February with the receiving, inspection, and proper storage of all nursery stock. The bulk of sycamore and sweet gum seedlings were kept in cold storage facilities near Rochester, KY until they were transported to a temporary nursery established on-site. This nursery served as a holding facility to insure that an adequate supply of seedlings was always present to supply the mechanical planter and to afford protection for the seedling roots during times of inclement weather. Planting was interrupted twice by cold fronts moving through the area that produced snow and very low air temperatures.

Planting began on 2-23-02 and was completed 3-7-02. Stutts Forestry Services (Martin, TN) was the planting contractor and used a Caterpillar DC3 LGP Bulldozer/C\&G Tree Planter arrangement to plant seedlings. Although the bulldozer had a gross weight of $8,164 \mathrm{~kg}$, special "Pyramid Pads" (63 cm in width) gave the bulldozer a lower ground pressure and facilitated planting in the wetter portions of the site. It also provided better traction in those areas cover in FGD materials. The C\&G Planter had a gross weight of $2,721 \mathrm{~kg}$ and, with a new coulter, can make a vertical cut of $35 \mathrm{~cm}$ in most soils. This was normally the case at the CCWESTRS site, except in areas compacted by machinery transporting FGD materials and the chance encounter with large sandstone rocks. Sprockets were adjusted on the planter to deliver a seedling every eight feet and this distance was checked periodically using a standard tape measure. Guides mounted on the front of the bulldozer were used to determine the proper distance between rows. Supporting personnel routinely followed the planter to check this distance between rows 
and to hand plant seedlings any missing seedlings (rare occasion). Throughout the planting process, all seedling roots were protected from desiccation and very low temperatures.

On 5-5-02, a survivorship survey was conducted in all plots for both tree species. Rows and starting locations within rows were selected randomly within each major treatment (two for each species) and the first ten plants (or plant locations) from each row location were categorized as 1 ) seedlings being fully flushed, 2) seedlings experiencing tip dieback and resprouting from its base, 3) dead, or 4) missing. Results of the survey indicated that the percent survivorship for both species was greater than $85 \%$ (Fig. 24). One distinct difference between the tree species noted during the survey was sycamore's inherent trait of resprouting after tip dieback. The number of missing seedlings was more an artifact of erosion in some FGD locations, rather than planter error. To combat further erosion (and reduce further seedling lost), bare spots (access roads used for FGD application) were seeded with spring oats and Kobe lespedeza and approximately 700 bales of hale were stalked in strategic locations. Finally, all plot boundaries were marked with 1.5-m steel posts for future location.

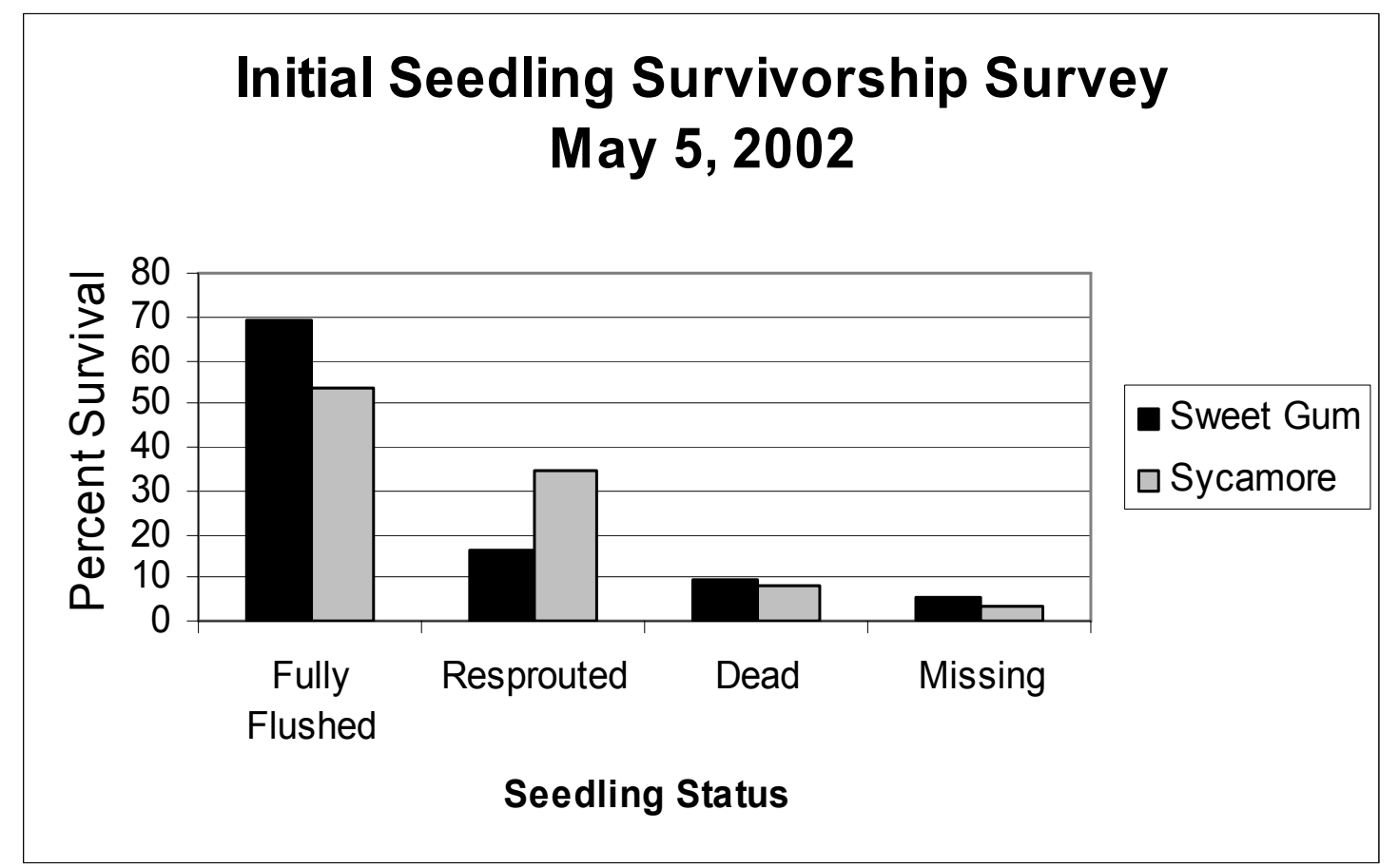

Figure 24. Initial survivorship of all seedlings planted in February and March 2002.

\subsubsection{Tree Planting}

The decision to replant all trees was made in October 2002. Poor tree survival was partially attributed to weed competition and drought. The weed competition was primarily fescue and lespedeza originally planted during the re-vegetation stage of land restoration of the strip mine. A decision was made to herbicide the entire site. The site was mowed in order to stimulate new growth and insure herbicide effectiveness. The entire site was sprayed with a mixture of contact and soil herbicides (3 quarts of Roundup Pro (41\% Glyphosate plus surfactant) +1.5 oz Oust (75\% Sulfometuron (Dupont) per acre) on 22 October, 2002 to kill perennial vegetation and control early season weed germination in the early part of spring and summer of 2003 (Figure 25). Tree planting preparations began in November 2002 with calls and visits to state nurseries in Kentucky and Tennessee in order to access planting stock for 2003. All sycamore seedlings were obtained from the Kentucky state nursery system, while the majority of sweet gums were 
purchased from the state of Tennessee. An additional 6,000 sweet gum seedlings (20\% of the total planted) were purchased from Warren County Nursery in McMinnville, TN.

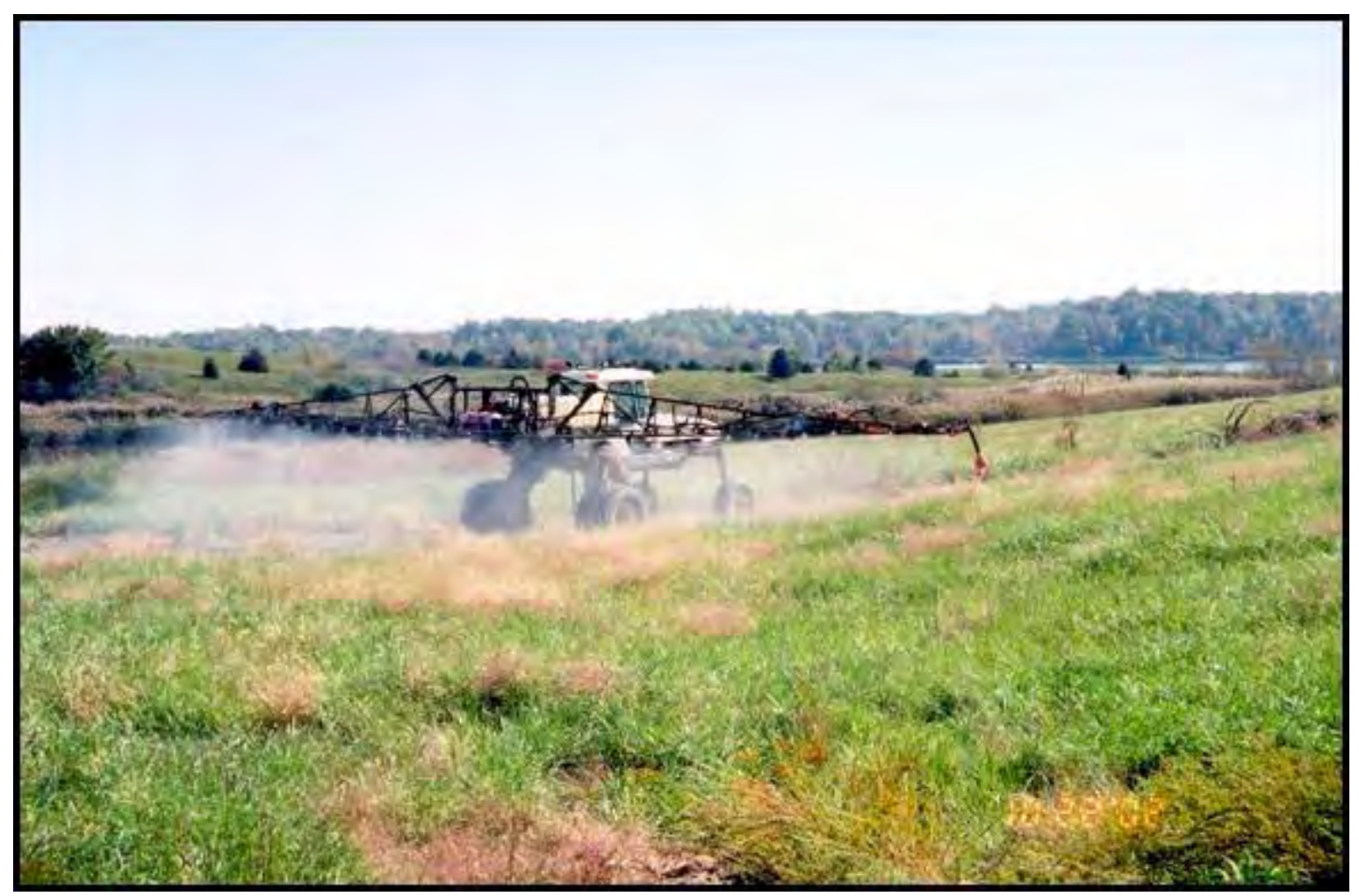

Figure 25. Ground application equipment used to apply a mixture of herbicides to the CWESTERS field site on October 22, 2002.

Upon the receipt of sweet gum seedlings from both sources in early February 2003, a complete integration of seedlings was carried out in order to insure that the additional seedlings from Warren County nursery were spread throughout the study and was included in all treatments. All seedlings were kept in cold storage facilities near the site. To complete the pre-planting activities, the entire CCWESTRS site was bush hogged to remove the excessive weed growth that had occurred the following season and to remove the few surviving sycamores and sweet gums seedlings that may have been missed by herbicide treatments in late 2002 .

Planting began on 2-11-03 and was completed by 3-12-03. Weather conditions changed quickly during early February and resulted in a few planting delays. Excessive soil moisture and very low air temperatures were of concern and considered before planted began after a delay. Seedlings transported from cold storage and waiting to be planted were held on-site in a temporary enclosure. Stutts Forestry Services was selected as the planting contractor again due to their familiarity of the site, planting conditions and plot arrangements. Equipment and operational/QA protocols remained the same as in 2002.

After-planting activities included plot boundary verification and selective erosion control. Erosion at the time of planting was much less than that seen in the previous year, especially in the FGD mulch plots. Settling, compaction and hydration of the FGD mulch material resulted in reduced movement of the materials. Plant stems and litter also inhibited less erosion on many plots. The 
majority of erosion was due to rill development (observed adjacent to ditches and drainage ways) with little sheet runoff observed. Costs for the planting are shown in Table 11.

\begin{tabular}{|l|l|r|}
\hline Task & Source & Cost \\
\hline Bush Hogging & Two Rivers & 2,000 \\
\hline Tree Planting & Stutts Forestry Services & 7,000 \\
\hline Sycamore Seedlings & KY State Treasurer & 6,570 \\
\hline Sweet Gum Seedlings & TN State Treasurer & 4,050 \\
\hline Sweet Gum Seedlings & Warren County Nursery & 2,649 \\
\hline Seedling Storage & East of Eden & 290 \\
\hline Trailer Rental & TVA & 50 \\
\hline Straw for Nursery & East of Eden & $\mathbf{4 5}$ \\
\hline Total & & $\mathbf{\$ 2 2 , 6 5 4}$ \\
\hline
\end{tabular}

Table 11. Costs for tree planting in 2003.

\subsection{Irrigation System Installation}

Installation of the drip irrigation system began in mid-March 2003 just prior to the completion of tree planting. Six days were required to trench the $4,023 \mathrm{~m}$ of $0.609-\mathrm{m}$ deep trench using a Case trencher with backhoe and blade attachment. This task took considerably longer than planned due to all of the large rocks encountered in the soil. These had to be removed and the trench manually cleaned out to insure proper placement of the PVC piping. The PVC pipe (15, $10,7.6$ and $5 \mathrm{~cm}$ diameter) was transported within the site by a tractor/trailer arrangement. Once the main and secondary lines were installed from the pump house to the various plot locations, the 1,107 connections for the $1.27 \mathrm{~cm}$ diameter drip lines were connected to the PVC through control valves and flex risers. All controller-to-value wiring was secured to the mainline PVC in the trenches before the trenches were back-filled.

The next step in the installation of the irrigation system was the placement of $104,880 \mathrm{~m}$ of drip line. Since each drip line came in 304-m rolls, a two-reel delivery system was designed and mounted on the back of a four-wheeler to insure proper placement and safe delivery (avoid crimping of the line). Couplings were used to attach the drip line together after each 304-m roll. After the 1,107 rows of drip line were installed, each drip line was attached to a shut-off valve which was attached to a 1.27-cm PVC flex riser. At the other end of each drip line, the automatic flush valves were installed.

While the drip line was being installed, work on installing the pumping plant got underway. Although delayed initially by vandalism to the engine, pump, and various system components, replacement parts $(\$ 2,075)$ were quickly obtained and construction continued. Three different concrete pads were formed for the construction of the pumping plant. One for the two filter tanks, one for the diesel engine pump, and one for the diesel fuel storage tank. After the diesel engine/pump was set into place, the 15-cm PVC suction line with check valve to prevent back flow into the ash pond and the 15-cm Sure-Flo foot valve were installed. Two $114 \mathrm{~cm}$ diameter stainless steel sand filters were installed and plumbed from the pump to the filters. The sand filters were plumbed so that each tank could be periodically backwashed with the backwash water going back to the fly ash pond. From the sand filters, the water flows through the flow meter (instantaneous and cumulative gallon readout) and up the hill to the two control valves. The two control valves are used to control the flow to either zone 1 or zone 2. 
After the pumping plant was assembled, the automatic controllers for the irrigation system were installed and wired for operation. Three controllers are used to control the irrigation system. An Irritrol IBOC, 24-volt battery powered controller completely automates the system including signaling the engine's control panel to start/stop the diesel engine. A Murphy automatic engine controller, ASM150, protects the engine and pump, and makes the engine operate automatically in response to the system controller. The third controller is an Alex-tronix filter backwash controller that controls the backwash interval, backwash time, and dwell time between each filters time to flush.

After the pumping plant was complete, a wood frame building with metal siding and roof (approximately $8 \mathrm{ft} \times 18 \mathrm{ft}$ ) was built around the pumping plant. The design includes a large ventilation area in the front of the building (covered with hardware cloth) to remove excess heat generated by the motor and pump. For security, a 6-ft chain link fence with 3 strands of barbed wire at the top was installed. The fence included a 10-ft locking gate.

The cost for design, delivery, installation, testing, and training on the drip irrigation system was $\$ 106,150$. The building for the pumping plant and also any repairs to the system for the first year was included in this price. The cost for the chain link fence surrounding the building was $\$ 1,985$. The total charge for Two Rivers Inc. (daily checks, switching zone valves, routine maintenance such as oil changes, end of year shutdown, etc.) was $\$ 4,182.50$ (May to November). Approximately 3,200 gallons of diesel fuel $(\sim 4,000)$ was used by the system during 2003.

\section{0- Task 6 Monitoring 9.1 Soils Monitoring}

\section{1 .12002}

Soil monitoring during 2002 focused on characterizing selected physical parameters within the soil profile. The percentage of rock within the soil has a direct influence on the soil's ability to retain moisture, as well as, provide areas for plant root exploration. A track-hoe was used to excavate pits at four locations that were considered typical for the varying landforms found at the CCWESTRS site. Along opposing sides in each pit, a clear piece of 30 mil plastic was extended from the surface to a depth of $1.8 \mathrm{~m}$ and all areas of solid rock, coarse and finely fractured rock, and soils were traced onto the plastic surface. The volume percentage of each fraction was then determined using a point intercept method. In areas considered to be soil (but still containing appreciable rock material), cylindrical areas $\left(500\right.$ to $\left.1000 \mathrm{~cm}^{3}\right)$ within the pit face were excavated at 30,60,90 and $120 \mathrm{~cm}$ depth and all materials (rock, soil and roots) were careful collected for processing in the laboratory. The volume of each excavated area was determined by filling each with expanding foam. Once hardened, the foam was removed, cleaned of debris and its volume determined by displacement in water under laboratory conditions. All root materials (used for below ground carbon estimates) were removed form the soil by dry sieving, washed to remove adhering soil particles, dried and weighed.

Results of the study show that large pieces of solid rock (primarily sandstone and shale) can comprise as much as $29 \%$ of the entire soil profile, but average as little as $5.5 \%$ (Table 12 ). Coarse and finely fractured rock dominated by shale is similar (though elevated), but unlike the solid rock, these areas can contain significant quantities of feeder roots (Figure 2). Within the areas designated as soil, rock fragments ( $>2 \mathrm{~mm}$ diameter) still can comprise as much as $51.6 \%$ of the total volume. 


\begin{tabular}{|l|l|l|l|l|}
\hline $\begin{array}{l}\text { Profile } \\
\text { Fraction }\end{array}$ & $\begin{array}{l}\text { \% Solid } \\
\text { Rock }\end{array}$ & $\begin{array}{l}\text { \% Coarse } \\
\text { Fractured Rock }\end{array}$ & $\begin{array}{l}\text { \% Fractured Rock } \\
\text { Fra }\end{array}$ & $\begin{array}{l}\text { \% Soil } \\
\text { (and >2mm Fraction) }\end{array}$ \\
\hline Mean & 5.5 & 5.3 & 9.6 & $79.4(24.6)$ \\
\hline Minimum & 0 & 1.7 & 0 & $50.6(3.4)$ \\
\hline Maximum & 29.4 & 6.7 & 41.9 & $95.4(51.6)$ \\
\hline
\end{tabular}

Table 12. Mean, minimum and maximum percentages of rock and soil from excavated soil pits at the CCWESTRS site.

Although the focus of this exercise was to quantify the amount and distribution of roots throughout the soil profile (for carbon estimates), it also documents how coarse-textured the soils are and gives some insight into expected moisture retention and release. Periodic sampling of soil moisture was conducted at random locations within the CCWESTRS site in 2002. Although moisture release curves have not been developed specifically for the CCWESTRS soils, the data collected from the pit study and gravimetric sampling during 2002 have help construct a moisture evaluation guide with which moisture release can be evaluated at the CCWESTRS site.

Available water in the soil is that portion that can be absorbed by plant roots. It is the amount of water released between in situ field capacity and the permanent wilting point (soil matric potentials of -0.3 and $-1.5 \mathrm{MPa}$, respectively). Field capacity can be estimated by sampling the desired soil depth within two or three days preceding a sufficient rain event. Although soil textures (and consequently soil moisture) within the CCWESTRS site do vary, the field capacity of the top $40 \mathrm{~cm}$ of soil has been determined to be 15\% (range 13 to 17\%). This value was determined by sampling in late October and early November 2002 when sufficient precipitation had fallen at the site. Using these data as indicators of ideal moisture conditions, sampling in early August revealed that soil moisture was limited with soil moisture percentages ranging between $6-9 \%$. Soil moisture percentages this low would indicate that the seedling roots were experiencing soil matric potentials at or near the permanent wilting point.

During FGD application, planting and shortly after planting, some of the FGD material immediately eroded from the site. The site experienced a couple of very heavy rains during this time. FGD material was deposited in three locations: 1) in a low area between the CCWESTRS site and a conveyor belt due north of the site; 2 ) behind a berm in the $1 / 2$ zero mulch area on the northeast side of the CCWESTRS site and 3) near the Potato pond adjacent to the road that separates the CCWESTRS site and the large ash pond. In the large fan-shaped deposition area near site 1, erosion pins were placed in the FGD to see if additional FGD was still being deposited there. Subsequent inspections suggested that most of the FGD movement occurred during application and continued until shortly after planting and that very little moved after pins were placed. Where slopes were fairly level, the FGD was in place.

Several measurements of length, width, and depth of the FGD were done to get a good estimate of the volume of FGD that migrated to locations 1 and 2 (location 3 was inaccessible). Several samples of FGD were collected to determine specific gravity, which was determined to be about $1.1 \mathrm{~g} / \mathrm{cm}^{3}$. These measurements showed that site 1 contains 1,060 metric tons of FGD with a volume of $964 \mathrm{~m}^{3}$. Site 2 contains 518 metric tons of FGD with a volume of $471 \mathrm{~m}^{3}$. This material left its intended location, but not the site. Only the material in site 3 left the site.

The drainage areas for both depositional sites 1 and 2 are in either a high and/or low FGD mulch thickness treatment. In order to estimate the FGD in each drainage area, we calculated the total weight of FGD that would be in an average hectare using $15 \mathrm{~cm}$ as the average depth of FGD (found to be the case in most areas where samples for soil moisture were obtained). 
Assuming that the pan applied FGD in rows that were $4.3 \mathrm{~m}$ wide, with $1.4 \mathrm{~m}$ vegetation buffers, we calculated that there are 1,515 metric tons of FGD per hectare. Contributing drainage areas for each site were site $1=5.0$ ha, and site $2=4.15$ ha. Therefore, site 1 contained 7,573 metric tons, or about $14 \%$ of the FGD eroded into site 1 . For site 2 , the figure was $8 \%$.

\section{1 .22003}

In 2003, soil fertility was assumed to be sufficient for both tree species (based on 2002 plant nutrient analysis) therefore; the soil was not analyzed for routine chemical determinations. However, a subset of soils was sampled after irrigation ended in order to measure the possible buildup of trace metals in the soil surface. 30 subplots (including all levels of FGD mulch and irrigation) were sampled in $15-\mathrm{cm}$ increments to a depth of $45 \mathrm{~cm}$. These profiles were duplicated at each location and marked for re-sampling in May 2004.

\section{1 .32004}

In May 2004, samples were collected again adjacent to the 2003 sampling points and both samples were submitted for chemical analysis at that time. From these comparative data, trends can be established as to which elements are likely to accumulate in the soil surface during those periods of prolonged irrigation and which are likely to be flushed from the system by precipitation during the winter/early spring season.

Between autumn 2003 and spring 2004, the mulch treatments had major effects on changes in soil concentrations of $\mathrm{B}, \mathrm{Ca}$, and $\mathrm{S}$ during this time period. The patterns of change interacted with soil depth in most cases, and at times, with irrigation treatment.

\section{Effect of Mulch on B Change over Time by Depth}

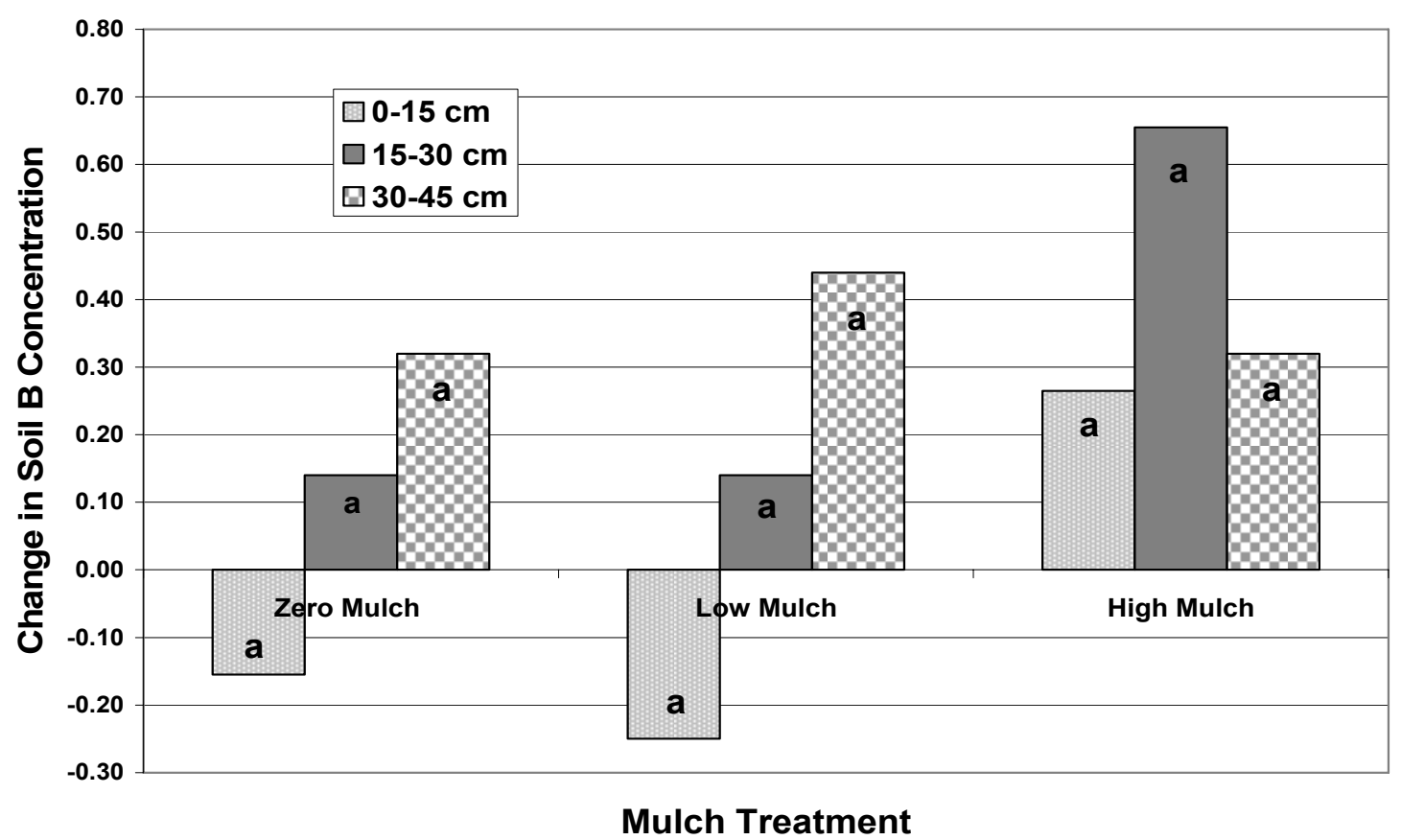

Figure 26. Effect of mulching on changes in soil boron concentrations over time and by depth. Different letters within each bar indicates significant differences $(P<0.05)$ between mulch treatments. 
Mulching in general, when compared with the Zero Mulch (control) treatment, resulted in an overall increase in $\mathrm{Ca}, \mathrm{S}$, and $\mathrm{B}$ throughout the profile over the dormant season. Although not significantly different, statistically, the effect of mulching on B levels tends to show up most strongly at the deeper depths, i.e., $15-30 \mathrm{~cm}$ and 30-45 cm (Figure 26). In the Zero Mulch control, B declined in the surface slightly and increased slightly at the $15-45 \mathrm{~cm}$ depths, thus appearing to demonstrate a downward leaching of B from the surface $15 \mathrm{~cm}$ of soil, without the presence of mulch. This was facilitated by the fact that the surface soil was already wet when autumn precipitation began, thus allowing more effective time and water for downward leaching. This downward movement of B under zero mulch was most dramatic in the High Irrigation treatment.

\section{Soil B Concentrations by Irrigation Treatment}

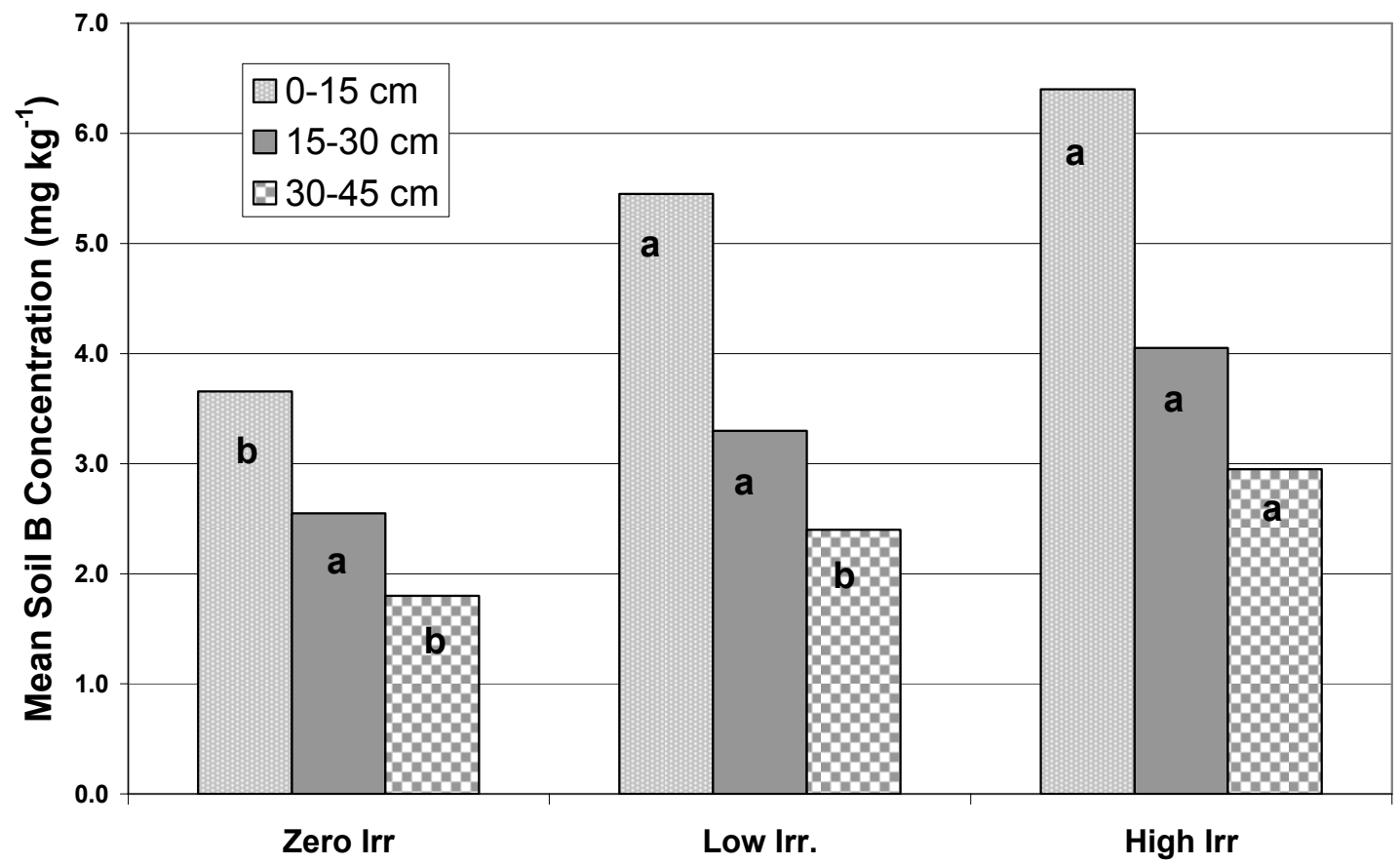

Irrigation Treatment

Figure 27. Soil boron concentrations as a function of depth and irrigation treatment. Comparisons are across irrigation treatments by depth. Different letters within each bar indicates significant differences $(P<0.05)$ between treatments.

The two irrigation treatments have resulted in a continued accumulation of $B$ within the soil profile, with the greatest accumulation seen in the top $15 \mathrm{~cm}$ of soil (Figure 27). Although the accumulation at the two deeper depths is higher when compared to the Zero Irrigation treatments, only the increases seen at the $30-45 \mathrm{~cm}$ increment in the High Irrigation treatments is significant.

The two mulch treatments resulted in significant increases in $\mathrm{Ca}$ and $\mathrm{S}$ within the soil profile over the fall-winter dormant period (Figure 28). This was apparently the result of these two elements leaching out of the mulching material, which is high in $\mathrm{CaSO}_{4}$. The distribution of the 
increase in these two elements with depth was variable across mulching treatments, but was generally deeper (not statistically significant) in the two irrigation treatments than in the Zero Irrigation Control (Figure 29). As with B, the prior wetting of the surface horizons prior to autumn/winter precipitation apparently resulted in deeper leaching of these two elements.

Accumulation of Calcium and Sulfur in Upper $45 \mathrm{~cm}$ of Soil by Mulch Treatment

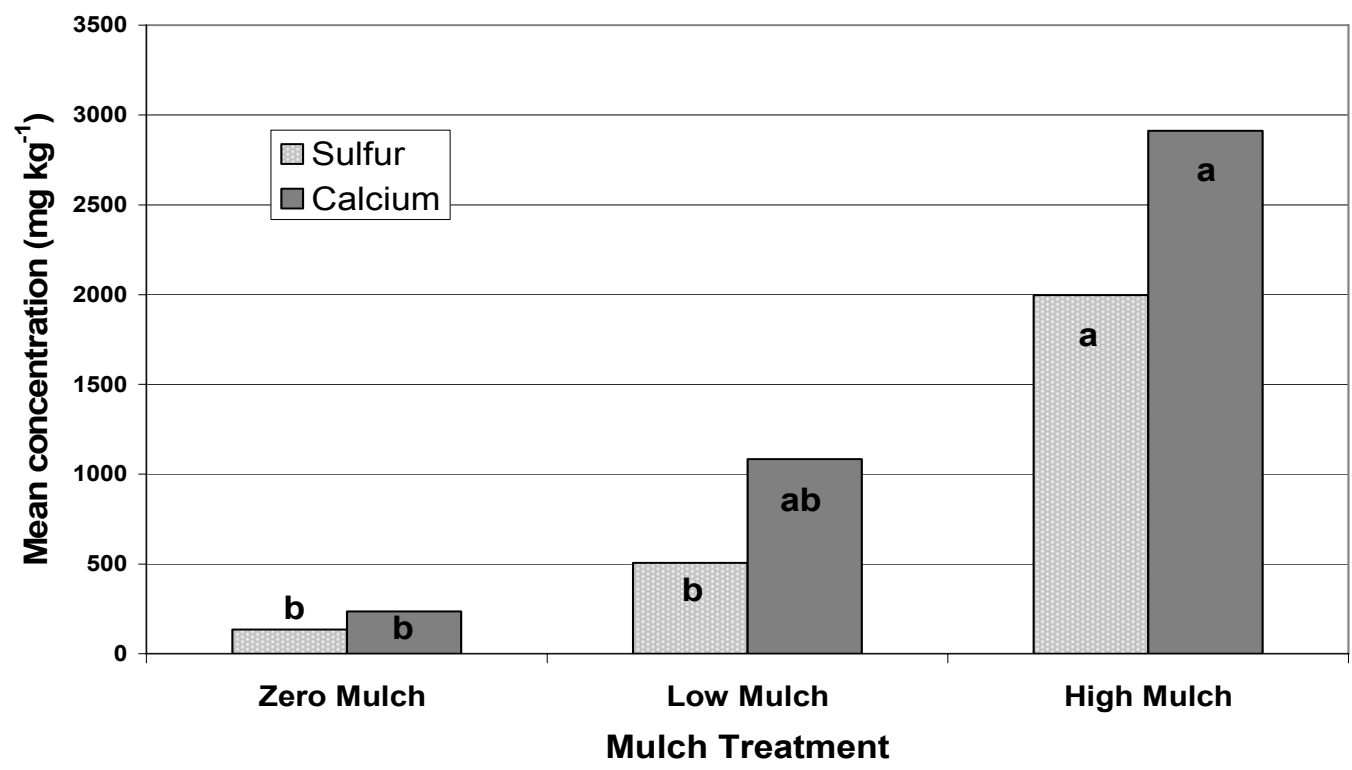

Figure 28. Accumulation of $\mathrm{Ca}$ and $\mathrm{S}$ in the upper $45 \mathrm{~cm}$ of soils as a function of mulch treatment. Different letters within each bar indicates significant differences $(P<0.05)$ between treatments.

\section{Impact of Irrigation on Soil S Change by Depth}

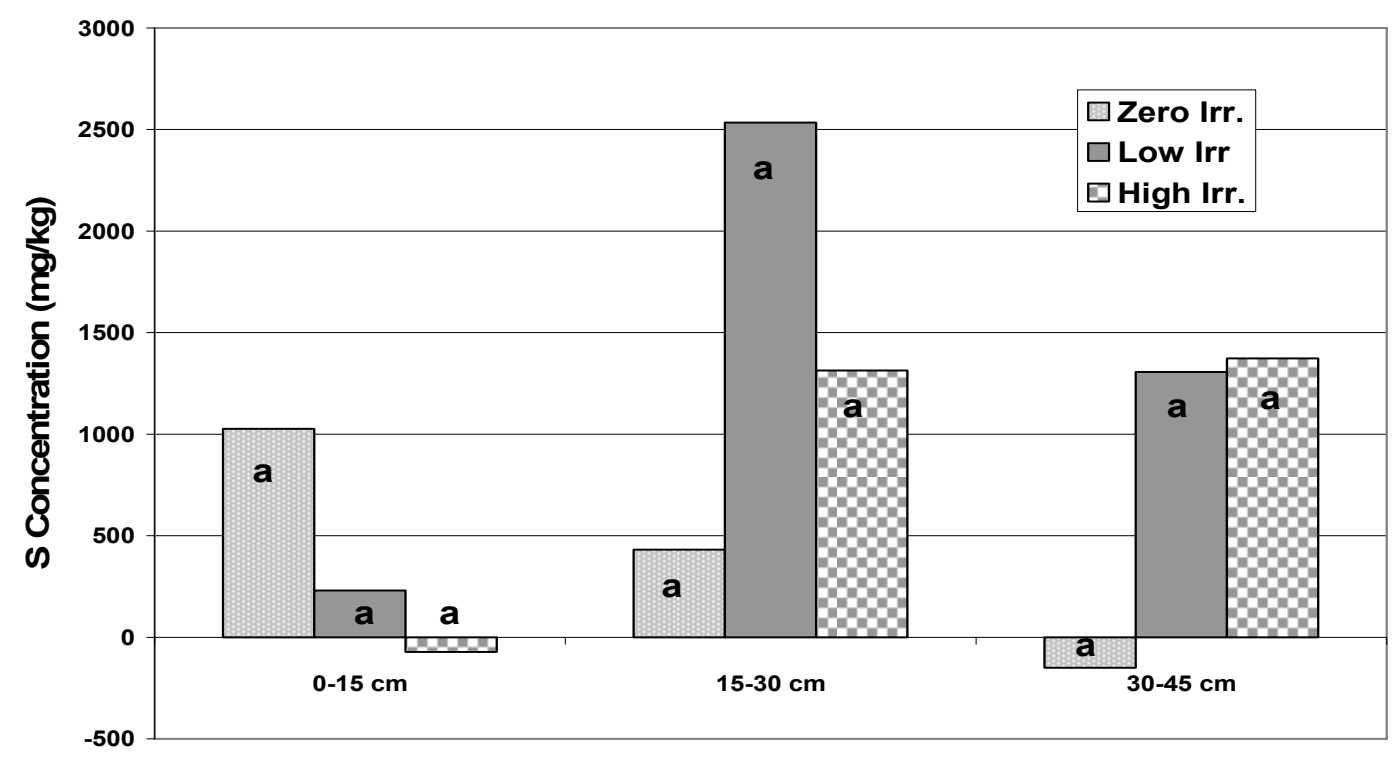

Soil Depth Interval

Figure 29. Impact of irrigation on soil $S$ changes at various depths. Different letters within each bar indicates significant differences $(P<0.05)$ between treatments. 
Irrigation treatments had virtually no effect on soil organic matter in the surface $(0-30 \mathrm{~cm})$ during the autumn-to-spring interval (Figure 30). However, a decrease in soil organic matter occurred below $30 \mathrm{~cm}$ in the High Irrigation treatment.

\section{Effect of Irrigation on Soil Organic Matter by Depth}

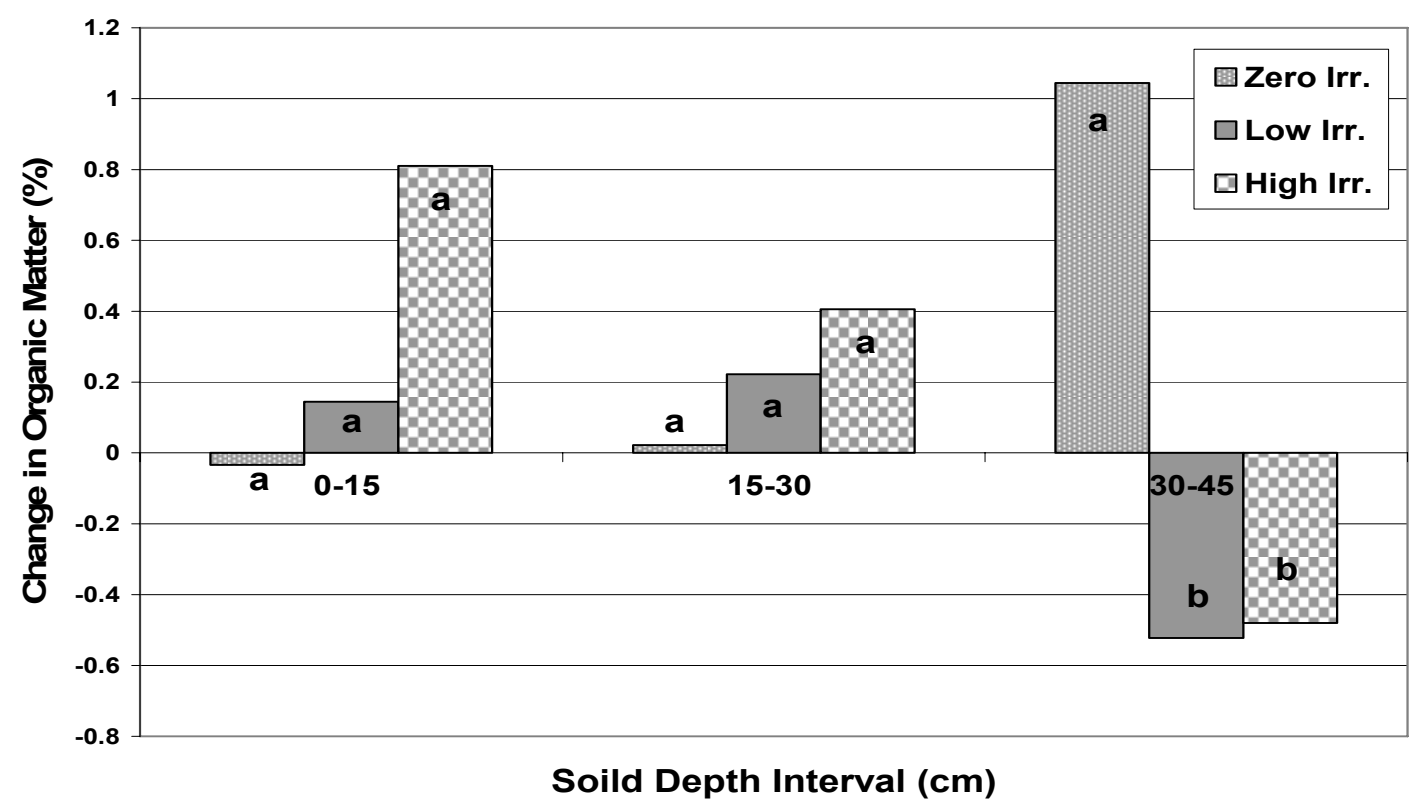

Figure 30. Effects of irrigation on changes to the percentages of soil organic matter by depth. Different letters within each bar indicates significant differences $(P<0.05)$ between treatments.

These increases and decreases in soil organic matter at different depths under different treatments are most likely the result of differences in rooting patterns. If this is true, it would appear that plants are concentrating their rooting in the upper $15 \mathrm{~cm}$ under the mulch treatments (data not shown) and under high irrigation, at the expense of deeper rooting. Conversely, under zero or low levels of irrigation, and under zero mulch, plants are concentrating their rooting below $15 \mathrm{~cm}$ and especially below $30 \mathrm{~cm}$. A second possible impact of irrigation and/or mulching could be upon decomposition rates of soil organic matter.

Such hypothesized changing rooting patterns-yet to be verified by direct measurements of roots- or changing decomposition patterns, could be explained by any of several hypotheses, or some combination thereof: (1) Roots are concentrating near the surface under mulched plots and under High Irrigation plots because of the ready availability of water at this depth. (2) Roots in these same treatments are avoiding deeper depths because of excess water and a shortage of soil air (reducing conditions, i.e., high Eh). (3) Roots in these treatments are "avoiding" the deeper depths because of higher concentrations of B below $15 \mathrm{~cm}$. (4) Roots in these treatments are "avoiding" the deeper depths because of higher concentrations of $\mathrm{SO}_{4}^{-2}$ (high salinity?) below $15 \mathrm{~cm}$. (5) High Irrigation and/or mulching treatments may be causing increased death of roots and/or higher rates of organic matter decomposition at the $30-45 \mathrm{~cm}$ depth. (6) Roots are concentrating at the deeper depths under the Zero Mulch control and in the Zero Irrigation and Low Irrigation treatments because there is a shortage of available moisture in the upper $15 \mathrm{~cm}$ (at least during part of the year) and more water available at deeper depths. (7) Roots in these treatments are better able to grow at these depths because they are exposed to lower levels of $B$ than the mulched treatments or the High Irrigation 
treatment. (8) Roots in these treatments are better able to grow at these depths because they are exposed to lower levels of $\mathrm{SO}_{4}^{-2}$ than the mulched treatments or the High Irrigation treatment.

The actual soil chemistry data do not lend much support to hypotheses $3,4,7$, and 8 . Soil B and $S$ levels are higher in the upper $15 \mathrm{~cm}$ of both the mulched plots and High Irrigation plots than they are at the deeper depths where rooting in these treatments appears to be declining. Furthermore, the highest B levels in any of the plots are at the $10 \mathrm{mg} \mathrm{kg}-1$ used in preliminary greenhouse studies, wherein both sycamore and sweet gum showed virtually no leaf damage at this soil concentration. Otherwise, it appears that any or all of the remaining four hypotheses could be valid.

\section{1 .42005}

At the end of the 2005 growing season, soils in all plots were sampled at two depths $(0-25 \mathrm{~cm}$ and $26-50 \mathrm{~cm}$ ) in conjunction with below-ground biomass determinations. In addition, the FGD gypsum in mulched plots was sampled separately and analyzed for the same parameters determined for soils. The sampling of the FGD gypsum was in response to the observation that plants (primarily in the herbaceous layer, but includes trees) are rooting directly in the mulch in many plots. Note: Care should be taken when comparing soil chemical analysis from 20032004 with that determined in 2005. In the 2003-2004 analysis, our goal was to determine possible changes in soil chemistry as a result of leaching by winter/spring precipitation. Our 15 $\mathrm{cm}$ increments began at the surface and included FGD material in some plots. In contrast, the 2005 exercise sampled the FGD and the two soil depths separately.

In the two soil depths analyzed, most nutrients were at acceptable levels for plant growth. However, soil potassium and phosphorous in all plots were considered to be at deficient levels for optimum growth (data not shown). These deficiencies were observed during the previous soil analysis in 2003-2004, but were few in number and sporadic across all treatments. Although the entire CCWESTRS site was fertilized earlier in the study, uptake (and leaching) appears to have exceeded inputs (rain, irrigation and weathering) of these to elements. It is interesting to note that yearly analysis of foliage from selected plots does not indicate that potassium or phosphorous are limited.

Boron, calcium and sulfur concentrations in the FGD and soil are presented in Figures 31-33. Boron, calcium and sulfur concentrations are all higher in the FGD than the mineral soil, but do not differ significantly by either mulch or irrigation treatment as in the soil. As observed in 20032004, boron concentrations are significantly impacted by irrigation treatments, while calcium and sulfur concentrations are tied directly to mulch treatments. The results of the higher irrigation treatment is the continued accumulation of $B$ in the top $50 \mathrm{~cm}$ of the soil profile that is significantly higher than in either the zero or low irrigation treatments (Figure 31). Calcium and sulfur continue to leach from the FGD mulch as indicated by the significant difference between their concentrations in the mulched and non-mulched plots (Figure 32 and 33). 


\section{Boron Concentrations in FGD and Soil by Irrigation Treatment}

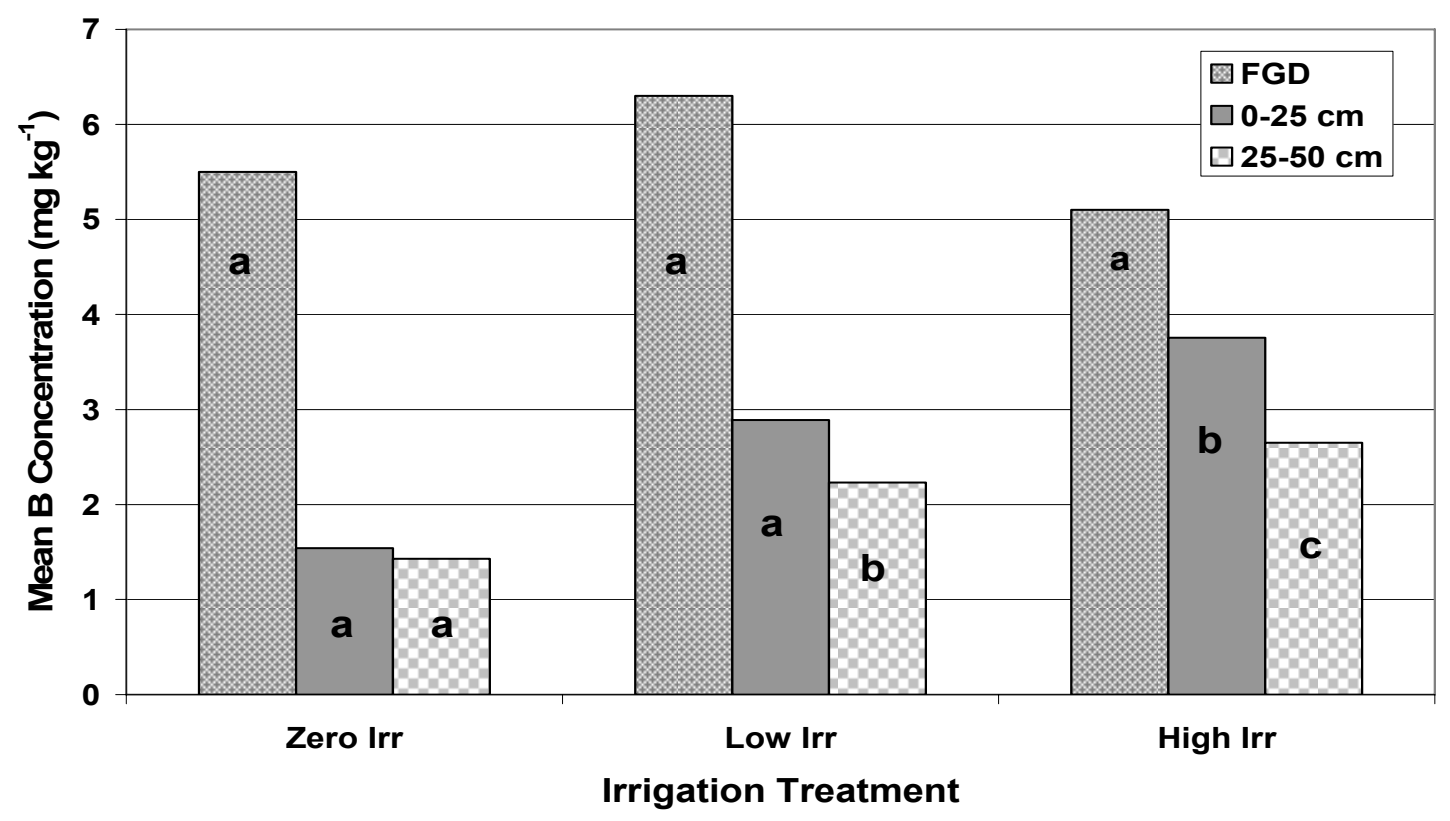

Figure 31. Effect of irrigation treatment on mean boron concentrations in FGD and soil by depth. Different letters within each bar indicates significant differences $(P<0.05)$ within each depth by irrigation treatment.

\section{Calcium Concentration in FGD and Soil by Mulch Treatment}

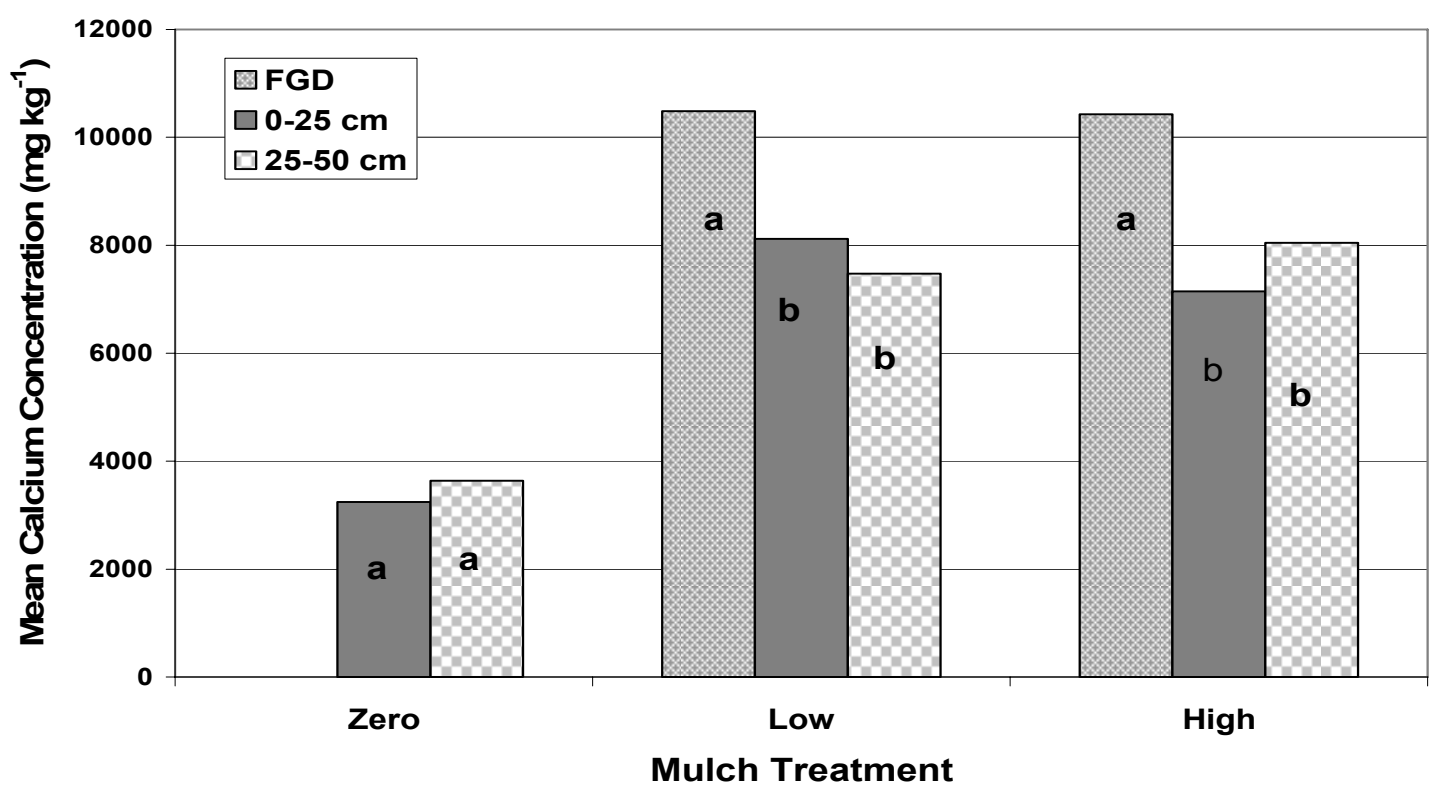

Figure 32. Effect of mulch treatment on mean calcium concentrations in FGD and soil by depth. Different letters within each bar indicates significant differences $(P<0.05)$ within each depth by mulch treatment. 


\section{Sulfur Concentration in FGD and Soil by Mulch Treatment}

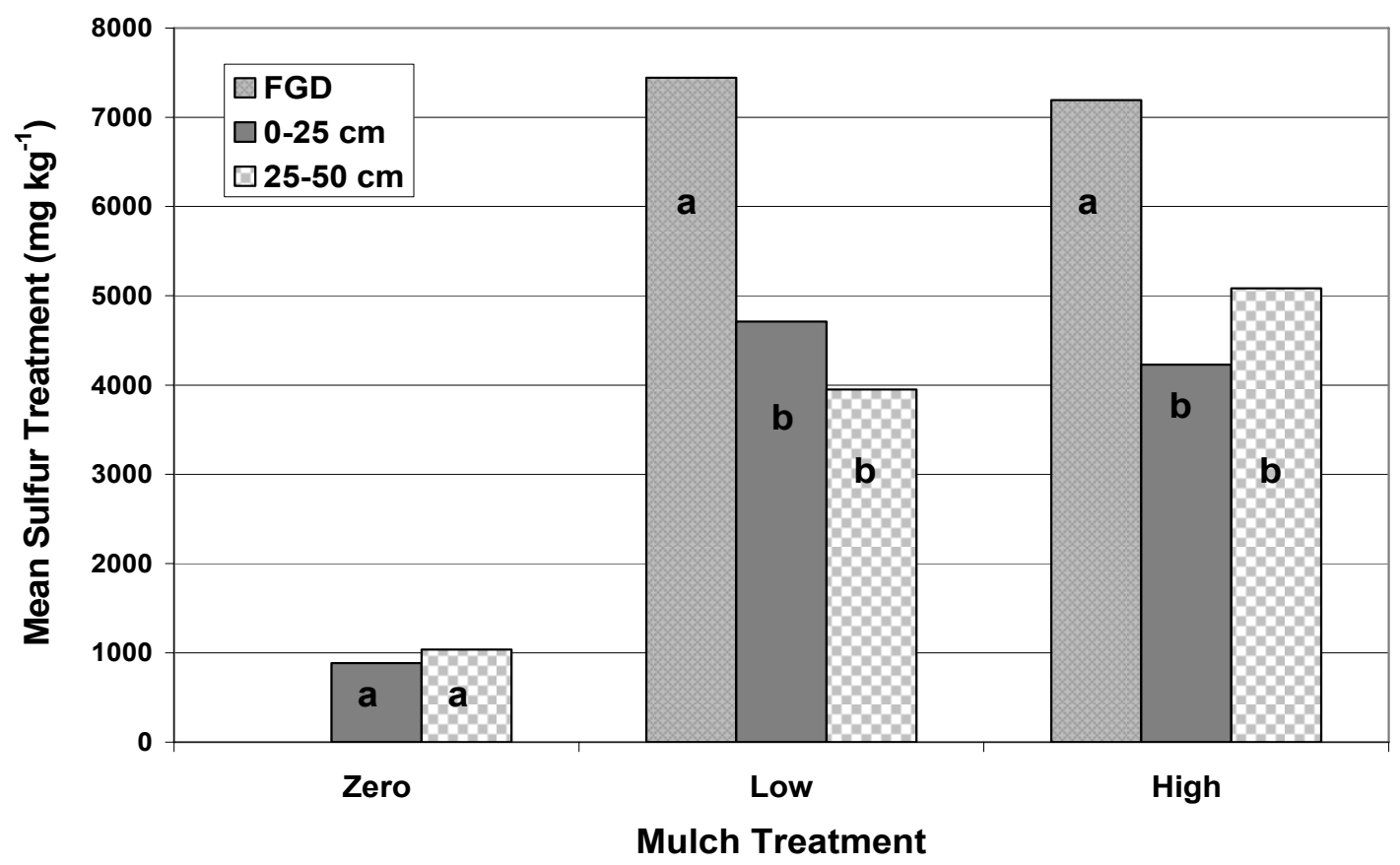

Figure 33. Effect of mulch treatment on mean sulfur concentrations in FGD and soil by depth. Different letters within each bar indicates significant differences $(P<0.05)$ within each depth by mulch treatment.

\subsection{Carbon Sequestration Monitoring}

\subsubsection{2}

August 2002 measurements (after bush hogging, FGD gypsum application, fertilization, and first tree planting) indicated that on the untreated (zero Mulch) plots, the above-ground biomass had been reduced considerably from the baseline levels (from $6.45 \mathrm{~T} / \mathrm{ha}$ to an average of $2.82 \mathrm{~T} / \mathrm{ha}$ ) (Figure 34 ). This $56 \%$ reduction was probably largely the result of bush-hogging the entire study area in late spring 2002. Subsequent trafficking over the site for fertilizer application and tree planting may have also had an impact, and some areas on lower slope positions have been partly covered with FGD gypsum deposited following gypsum erosion from upslope plots. For example, "zero Mulch" plots 21 and 22 had the highest level of bare ground of any plots. Areas receiving the "low mulch" application have also experienced a similar reduction in average biomass, and are not significantly different from the zero sludge plots (Figure 34). The "high mulch" plots experienced a considerably greater reduction in aboveground biomass compared to the two other treatments. By August 2002, their biomass averaged approximately half that of the two other gypsum treatments and about one-fourth that of the initial aboveground biomass. 


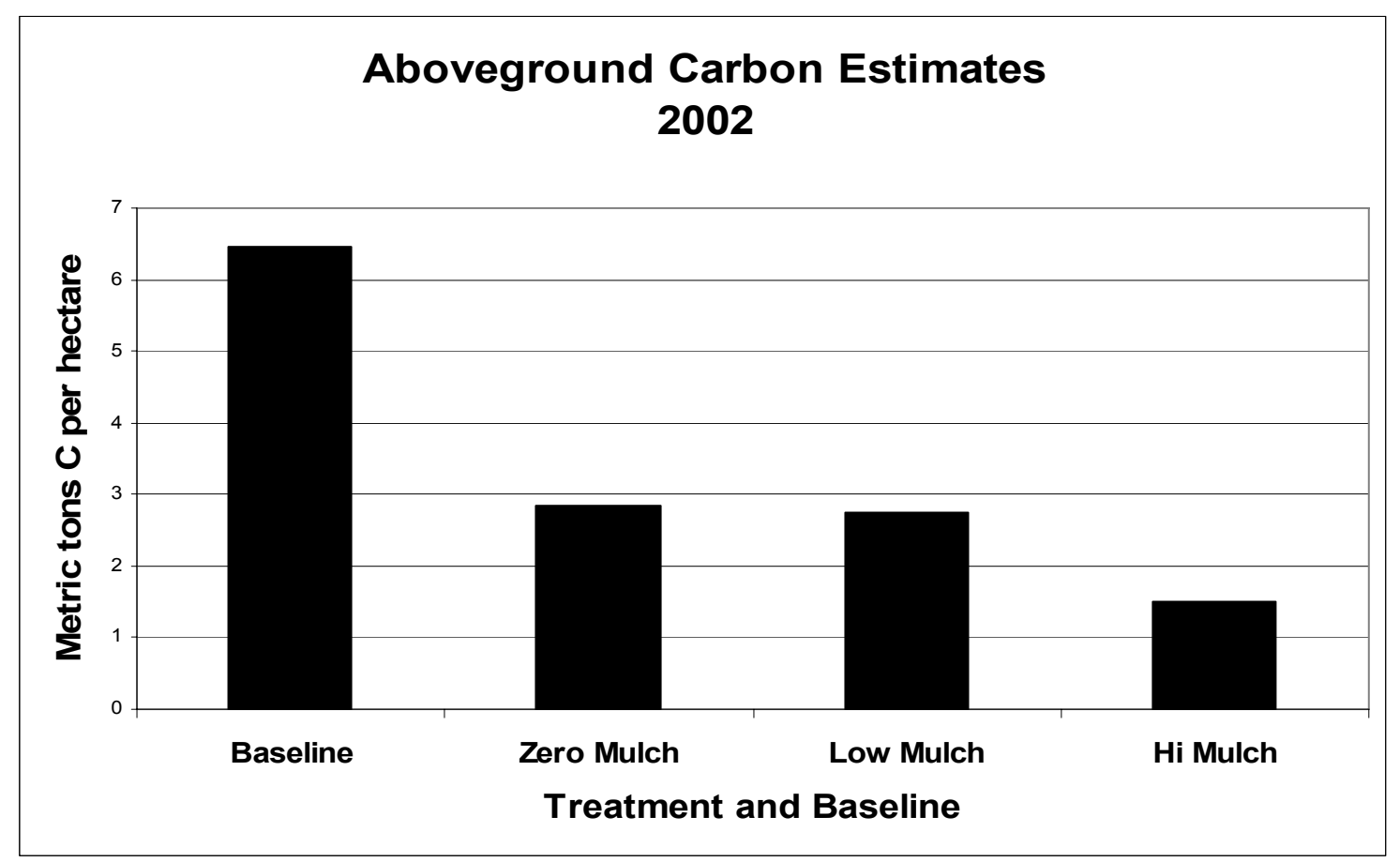

Figure 34. Effect of Treatments on Aboveground Carbon after First Growing Season

\subsubsection{3}

In August 2003 measurements of aboveground biomass were taken following herbicidal treatments applied the previous fall and spring, and following replanting. This above ground biomass consisted almost entirely of weed cover, since the tree seedlings planted earlier in the year are still quite small and widely spaced. For all plots, the above ground biomass has been reduced considerably from the baseline levels (2001) (from $6.45 \mathrm{~T} / \mathrm{ha}$ baseline mean to an average of $0.99 \mathrm{~T} / \mathrm{ha}$ ) (Figure 35). There was also a considerable reduction as a result of the herbicidal treatments from the previous year (2002) (from a mean of $2.40 \mathrm{~T} /$ ha to $0.99 \mathrm{~T} / \mathrm{ha}$ ). In 2002, bush-hogging was used to control weeds rather than herbicides.

As in the previous year, the zero mulch plots had the highest average amount of aboveground biomass (Figure 35). Levels under zero mulch were about twice as high as under high mulch, a significant difference at the 0.05 level of probability. Low mulch plots were intermediate and not significantly different from either of the other mulch treatments (Figure 35). 


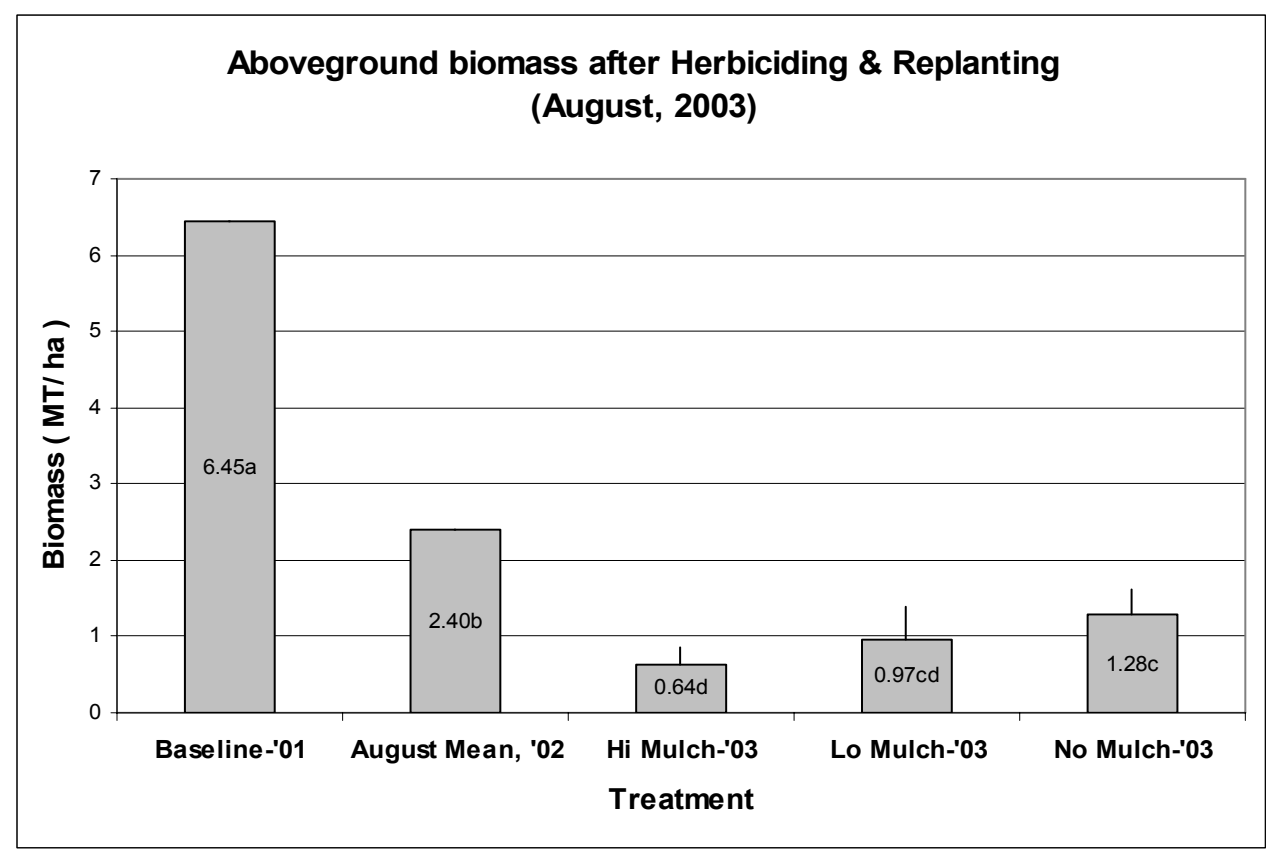

Figure 35. Above ground biomass by mulch treatment for 2003 compared to mean aboveground biomass in 2002 and pre-treatment baseline levels in 2001.

\subsubsection{4}

By the end of 2004, the average amount of carbon being stored in the above ground portions of seedlings and vegetation at the site had returned to near pre-study levels at $5.42 \mathrm{MT} \mathrm{C} / \mathrm{ha}$. Seedling growth in 2004 had accelerated following the first year of establishment with sweet gums and sycamores reaching average heights of 0.76 and 1.5 meters, respectively, with some sycamores reaching a height in excess of 3.0 meters. Seedling biomass was determined through regression analysis using height/diameters obtained from a subset of representative seedlings throughout the site. Although the contribution of each tree species to the total biomass of the site varied, the average contribution of both species was less than $2 \%$ of the total. Differences in the contribution were affected by treatments and individual species (Figure 36). 


\section{Seedling/Sapling Biomass (Above Ground) by Treatment}

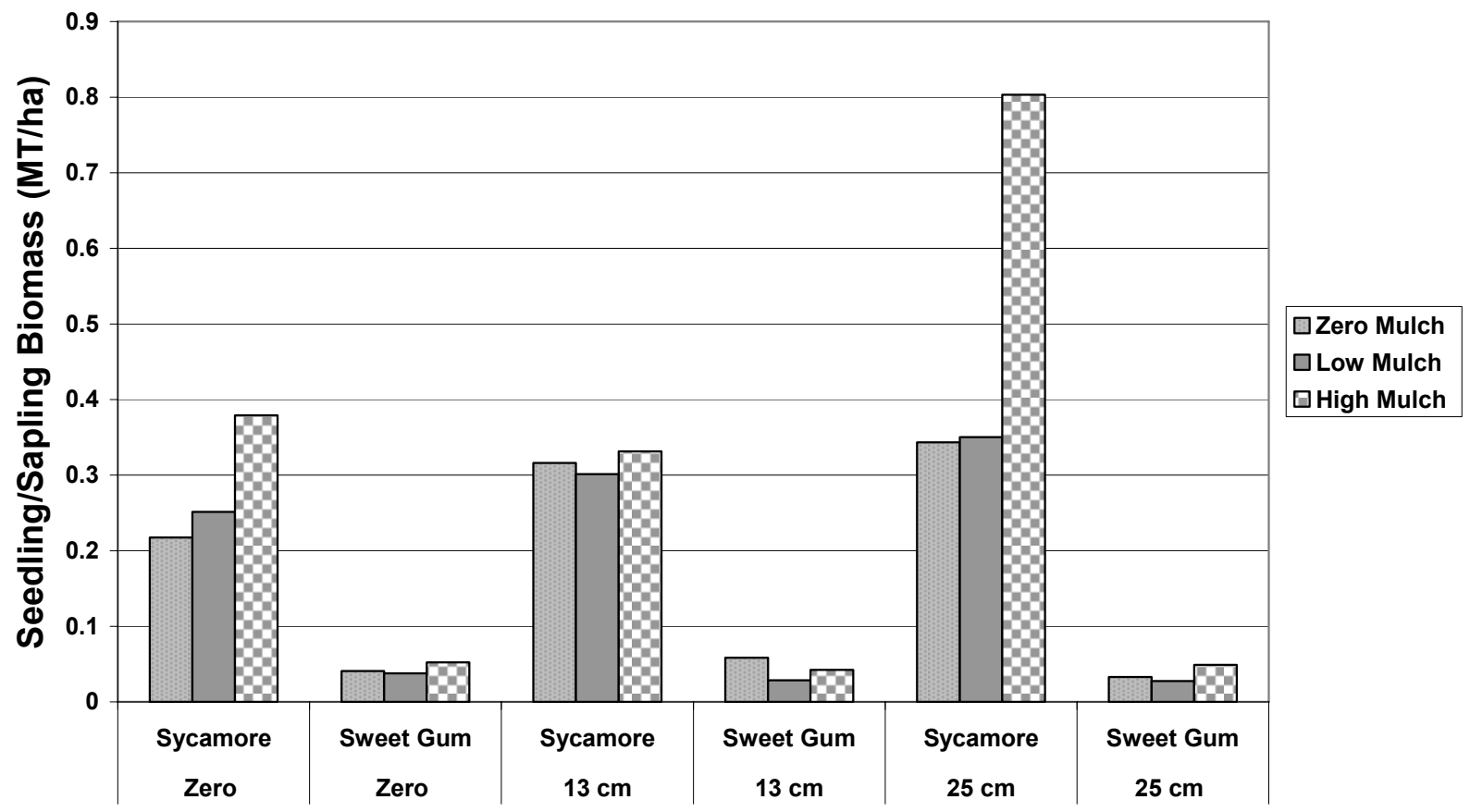

Irrigation Level

Figure 36. Seedling/sapling standing biomass in 2004 as a function of treatments.

\subsubsection{5}

In 2005, both above and below ground carbon was determined in all treatment plots. The above ground sampling was based on the remeasurements of trees in previously established (2003) locations in all plots. The below ground estimates were made in conjunction with soils collected for chemical analysis and were obtained from all treatment plots. It is important to note that baseline and 2005 carbon estimates were obtained by slightly different techniques with the number of observations in 2005 being greater.

The average above ground carbon being stored at the site had increased by $16.9 \%$ over the preceding year to 6.34 metric tons/hectare (Figure 37). As in 2004, the average contribution of each tree species to the total above ground carbon storage varied with sweet gum and sycamores averaging 0.5 and $3 \%$, respectively. The 6.34 metric tons/hectare translates to 256 MT of $\mathrm{C}$ for the entire 40.5 hectares. In terms of our initial baseline measurements, this is a reduction of less than $2 \%$. However, a more appropriate evaluation of carbon accumulation in the above ground pool might be a comparison between 2002 or 2003 and 2005. During the period 2002-2003, above ground biomass was significantly altered by FGD application, herbicide application and the second planting of the selected seedlings. The increases in above ground carbon from 2002 and 2003 to 2005 were $164 \%$ and $535 \%$, respectively.

The average amount of carbon being stored below ground (roots and soil by depth increment across all treatments) in 2005 is shown in Table 13. Below ground biomass sampling in 2005 
had indicated a shift in carbon distribution with depth, as well as an overall decline in root carbon as compared to baseline estimates made in 2001. Baseline $C$ in coarse roots in the 0 to $30 \mathrm{~cm}$ interval was estimated at $1.65 \mathrm{~T} / \mathrm{ha}$ in 2001. 2005 estimates of the same root fraction (including some fine roots) indicated a $67 \%$ decrease or $0.545 \mathrm{~T} / \mathrm{ha}$. Similar declines in root $\mathrm{C}$ were observed in the 30 to $60 \mathrm{~cm}$ and 60 to $90 \mathrm{~cm}$ depth intervals as well. This decline in the carbon stored in the roots may be due to shifts in the vegetation type (from a fescue dominated system to one dominated by Lespedeza and planted trees) or possibly affected as a result of herbicide treatments to remove vegetation prior to mulching and planting trees. In the base line estimates made in $2001,90 \%$ of the root carbon was found in the 0 to $30 \mathrm{~cm}$ depth interval. In 2005 , carbon measurements revealed that only $63 \%$ of root carbon is in the surface representing a shift in depth distribution that may also be attributed to vegetation changes.

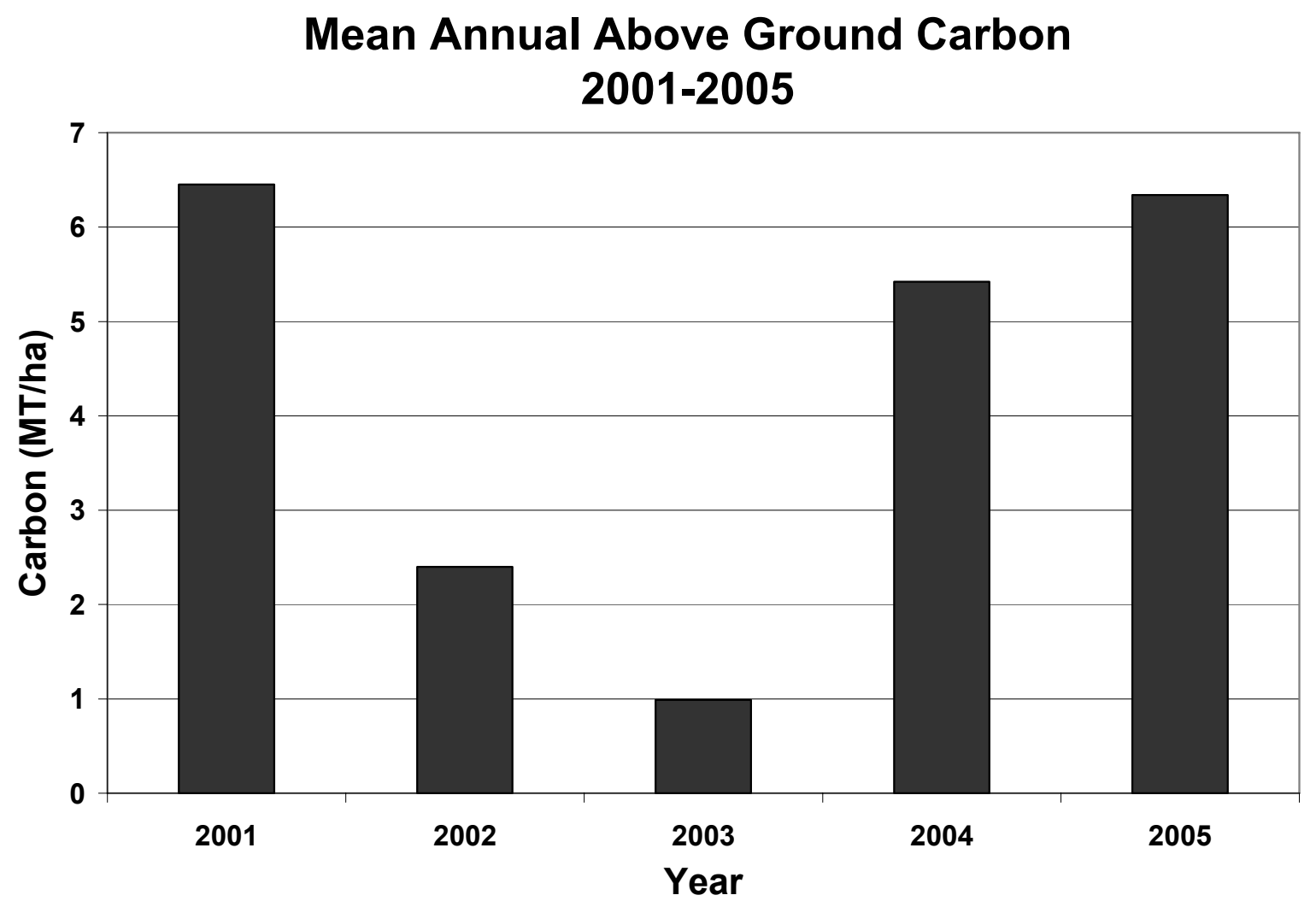

Figure 37. Average carbon being stored in the above ground biomass from 2001-2005.

In contrast to root $\mathrm{C}$, average soil $\mathrm{C}$ and consequently total belowground $\mathrm{C}$ have increased from the baseline estimates made at all depth increments in 2001 (Table 13). Soil carbon in the 0 to $30 \mathrm{~cm}$ depth increment increased $30 \%$ from 23.35 to $30.27 \mathrm{~T} / \mathrm{ha}$. Soil $\mathrm{C}$ in the 30 to 60 and 60 to $90 \mathrm{~cm}$ depth increments also increased, $60 \%$ and $12 \%$ respectively, over baseline values.

As mentioned earlier, the baseline sampling scheme for determining below ground carbon employed a different sampling technique than in 2005 which makes direct comparisons of root $\mathrm{C}$ and soil $\mathrm{C}$ uncertain. Future sampling using the same methods used in 2005 will allow more robust comparisons. 


\begin{tabular}{|l|l|l|l|}
\hline & C Total $^{*}$ Roots (T/ha) & Soil C (T/ha) & Total Below Ground C (T/ha) \\
\hline $0-30$ & 0.545 & 30.27 & 30.82 \\
\hline $30-60$ & 0.20 & 21.42 & 21.62 \\
\hline $60-90$ & 0.15 & 13.27 & 13.42 \\
\hline Total & 0.895 & 64.96 & 65.86 \\
\hline
\end{tabular}

${ }^{*}$ Includes Fine $(\leq 1 \mathrm{~mm})$ plus Coarse $(>1 \mathrm{~mm})$ roots.

Table 13. Below ground carbon by depth in 2005.

\subsection{Vegetation monitoring}

\subsubsection{Seedlings - Survival and Vigor}

\subsubsection{2}

Near the end of the first growing season (September 2002), seedling survival and vigor was poor across the entire study area. Sycamore average survival rate $(27 \%)$ was over twice that of sweet gum (12\%), and the percentage of healthy sycamore seedlings was considerably higher $(17 \%$ vs. $4 \%)$. Both species performed best under the high mulch treatment and worst under the zero mulch treatment. Low mulch treatments averaged intermediate for both species. Distribution and survival of healthy seedlings across the site in August 2002 are depicted in Figure 38-40.

In order to further assess seedling health and ascertain the need to apply additional fertilizer before the growing season, foliage was collected in June 2002 from all plots at the CCWESTRS site. A total of 36 composite samples (Table 14) of sweet gum and sycamore were collected and analyzed for nitrogen $(\mathrm{N})$, sulfur $(\mathrm{S})$, phosphorous $(\mathrm{P})$, potassium $(\mathrm{K})$, magnesium $(\mathrm{Mg})$, calcium $(\mathrm{Ca})$, sodium $(\mathrm{Na})$, boron $(\mathrm{B})$, zinc $(\mathrm{Zn})$, manganese $(\mathrm{Mn})$, iron $(\mathrm{Fe})$, copper $(\mathrm{Cu})$, and aluminum (Al). Only recently-produced, but almost fully-developed foliage was sampled. Each composite was composed of leaves from 20 to 30 seedlings.

The 36 composites samples were taken in the following configuration:

\begin{tabular}{|l|l|l|}
\hline Treatment & Sweet Gum & Sycamore \\
\hline High FGD & 3 plots $\times 2$ reps & 3 plots $\times 2$ reps \\
\hline Low FGD & 3 plots $\times 2$ reps & 3 plots $\times 2$ reps \\
\hline Control & 3 plots $\times 2$ reps & 3 plots $\times 2$ reps \\
\hline
\end{tabular}

Table 14. Foliage sampling configuration for June 2002. 


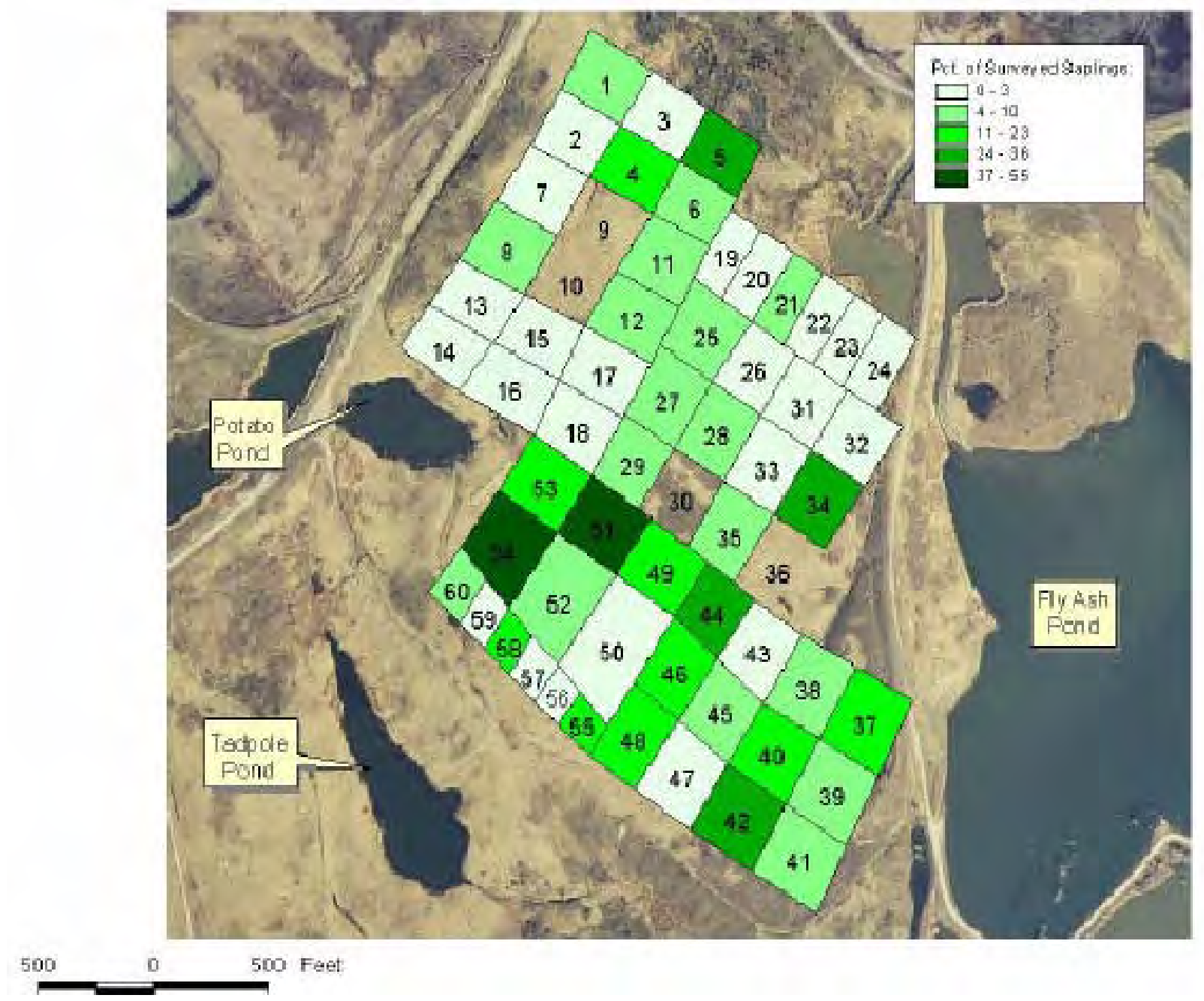

Figure 38. Distribution of healthy seedlings by plot on CCWESTRS site August 2002. 


\section{Survivorship - First Growing Season (2002)}

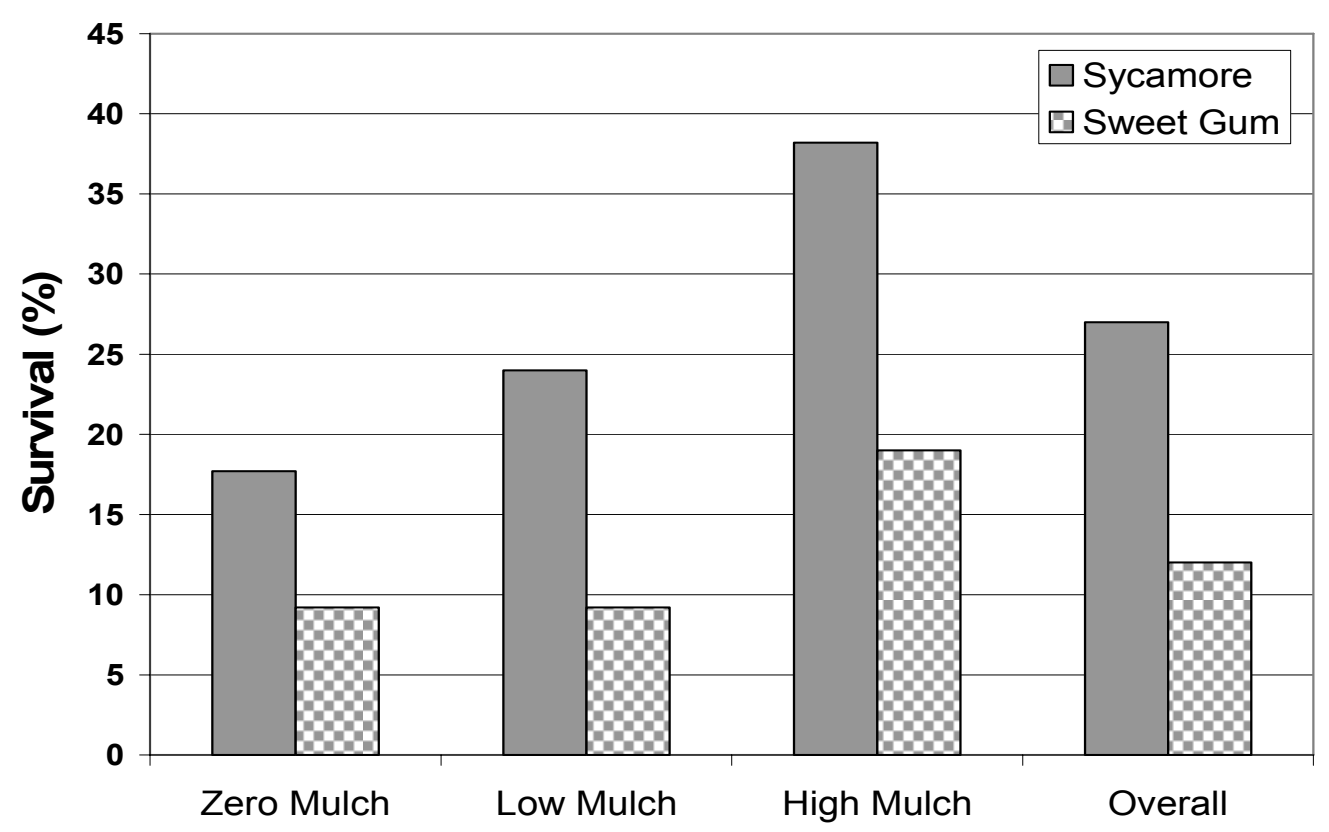

Figure 39. Survival by Species and Mulch Treatment after First Growing Season (2002)

\section{Percentage of Healthy Seedlings}

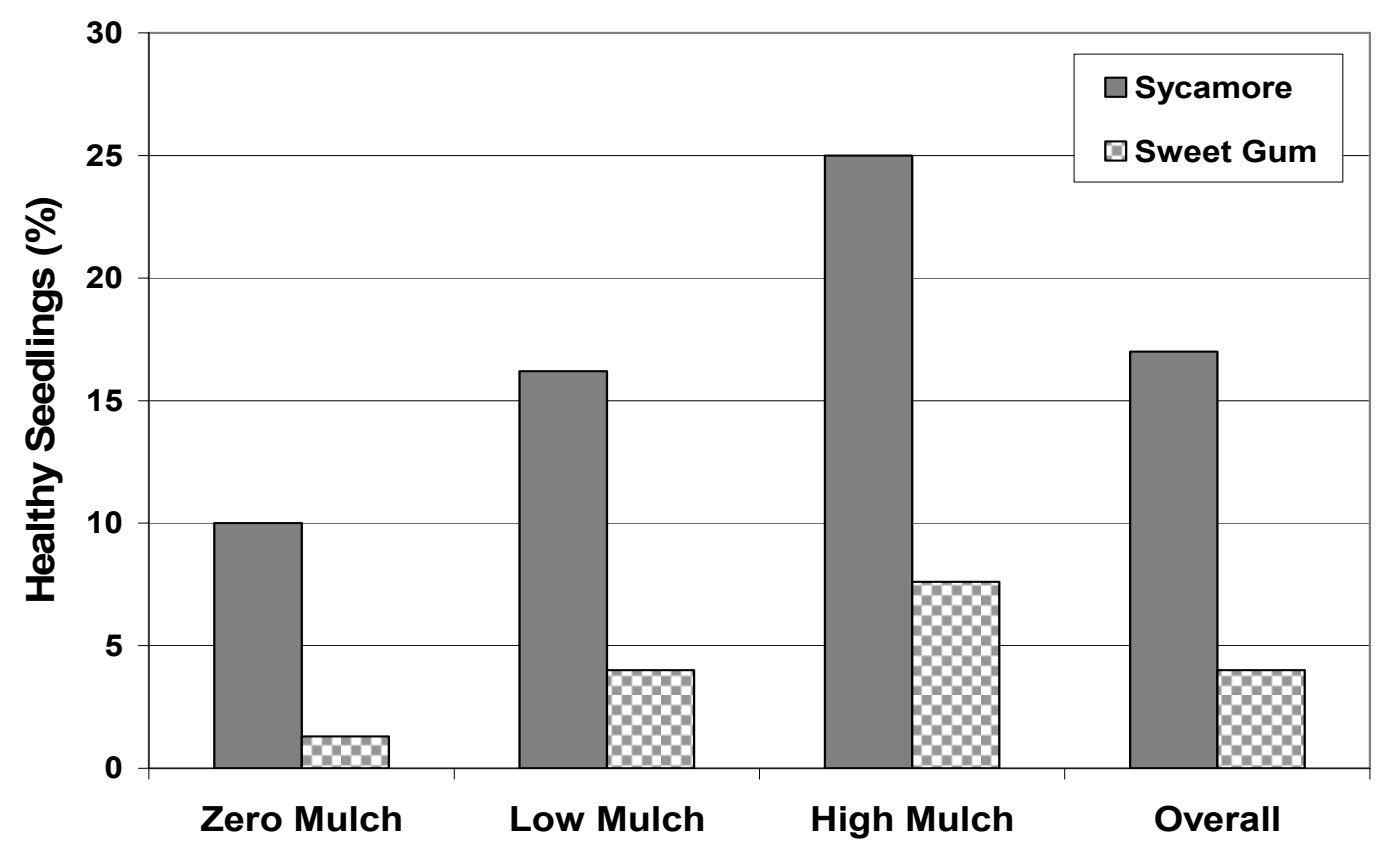

Figure 40. Percentage of Healthy Seedlings after One Growing Season (2002) 


\section{Nitrogen, Phosphorous and Potassium}

Results of the analysis indicated that $\mathrm{N}, \mathrm{P}$, and $\mathrm{K}$ in all of the sycamores sampled were considered sufficient for proper plant growth. In sweet gum seedlings, the same trend was true for $\mathrm{P}$ and $\mathrm{K}$, but over $60 \%$ of the sweet gums sampled were considered to have low or deficient levels of $\mathrm{N}$. These sampling points were scattered across the entire site, but were most common in areas on the western fringe of the study site. In addition, there was a clear trend for $\mathrm{N}$ to be generally sufficient on all the high mulch plots, indicating that the FGD material was probably actually supplying some $\mathrm{N}$ to the sweet gum. The same trend was observed in samples of fescue collected adjacent to the FGD Mulch Depth Field Study (Section 9.6). Since the sweet gum indicated some $\mathrm{N}$ problems, but the sycamore never did, it was possible that the manner of sampling (inclusion of young foliage) may have contributed to this result.

\section{Calcium and Magnesium}

Trends in calcium and magnesium levels were similar for both species although differed greatly between each other. Mg was considered sufficient in all samples of both species. $\mathrm{Ca}$, on the other hand, was reported as being deficient to very low in $58 \%$ of all samples. The apparent problem was again greatest in areas along the western fringe of the study site. These low levels of foliar $\mathrm{Ca}$ were particularly surprising given the near neutral $\mathrm{pH}$ of the soil, and the complete absence of Mg deficiencies or Mg excesses (which could have indicated competition for uptake, but did not). Again, it was possible that the sampling technique may have influenced the results.

\section{Micronutrients}

Sycamore was apparently sufficient in all of the micronutrients with the exception of $\mathrm{Zn}$. $\mathrm{Zn}$ turned up deficient in $30 \%$ of the samples and tended to be slightly worse in the treatments with FGD sludge as compared to the control plots. While sweet gum had no problems with $\mathrm{Zn}$, it consistently had deficiencies of both $\mathrm{Fe}$ and $\mathrm{Mn}$ in areas along the western fringe of the study site. Sweet gum may have been having a problem extracting sufficient $\mathrm{Fe}$ and $\mathrm{Mn}$ under these moderately high $\mathrm{pH}$ conditions. Fe and $\mathrm{Mn}$ are classic examples of nutrients that are more plant-available in more acid soils.

\section{Recommendations}

After reviewing all of the data, it was decided that the application of more fertilizer to the CCWESTRS site was neither critical nor practical at this time. The most serious concernscattered $\mathrm{N}$ deficiency in sweet gum, would be difficult to deal with. The fact that $\mathrm{N}$ was not a problem with sycamore also may have indicated that the sweet gum results were an artifact of our sampling method. Still it appeared that it may be important to administer additional nitrogen in the future. While $\mathrm{Ca}$ was frequently low, it was rarely deficient. Micronutrient deficiencies of $\mathrm{Fe}$ and $\mathrm{Mn}$ are probably real in sycamore (and perhaps with $\mathrm{Zn}$ in sweet gum). These however would be very difficult to correct.

Since B toxicity had been a concern expressed earlier in the study, B analysis of the plant stem was conducted on sycamore and sweet gum seedlings that suffered mortality during the 2002 planting season. These were compared to unplanted seedlings from the same stock (held in the TVA nursery at Norris, TN and considered as control samples). Woody tissue samples were digested according to EPA (1995) SW846 method 3050B (Acid Digestion of Soils, Sediments, and Sludges) using $70 \%$ nitric acid and $30 \%$ hydrogen peroxide and analyzed on a Perkin Elmer 9000 Elan ICP-MS. The results of this analysis are presented in Table 15. 
Analysis of Variance (SAS, 1996) conducted for the FGD mulch determined that the amount of mulch applied to the plots had significant effects on boron concentration levels $(F=2.74, p=0.10)$ in recovered tree tissue. However, the amount of irrigation applied to test plots ( $F=0.191$, $p=0.669$ ) had no significant effect on boron concentration levels. Boron concentrations recovered from the tree samples on treated plots were lower on average than concentrations recovered from control site soil $(0.7 \mathrm{mg} \mathrm{B} / \mathrm{kg}$ soil, $\mathrm{n}=5)$ using hot water extracted boron.

\begin{tabular}{|l|l|l|l|l|}
\hline Plot & $\begin{array}{l}\text { Boron } \\
(\mathbf{m g} / \mathbf{k g})\end{array}$ & Species & $\begin{array}{l}\text { FGD Mulch } \\
\text { Level }\end{array}$ & $\begin{array}{l}\text { Irrigation } \\
\text { Level }\end{array}$ \\
\hline 5 & 0.410 & SY & low & high \\
\hline 20 & 0.307 & SG & zero & low \\
\hline 21 & 0.070 & SY & zero & zero \\
\hline 23 & 0.146 & SG & zero & low \\
\hline 40 & 0.213 & SY & low & zero \\
\hline 42 & 0.065 & SY & low & low \\
\hline 50 & 0.208 & SY & high & low \\
\hline 51 & 0.104 & SY & high & zero \\
\hline 52 & 0.609 & SG & high & zero \\
\hline 53 & 0.391 & SG & high & low \\
\hline 55 & 0.168 & SG & zero & low \\
\hline 57 & 0.062 & SY & zero & zero \\
\hline 58 & 0.004 & SY & zero & zero \\
\hline 60 & 0.138 & SG & zero & low \\
\hline $\begin{array}{l}\text { Unplanted } \\
\text { Seedlings }\end{array}$ & 0.126 & SY & & \\
\hline $\begin{array}{l}\text { Unplanted } \\
\text { Seedlings }\end{array}$ & 0.152 & SG & zero & zero \\
\hline
\end{tabular}

Table 15. Boron analysis of sweet gum (SG), sycamore (SY), and control (unplanted) seedlings taken from the CCWESTRS site in 2002.

\subsubsection{2003}

Seedlings were replanted in late February/early March of 2003 and a cursory survivorship estimate in early spring indicated that greater than $90 \%$ of the seedlings had broken dormancy. On August 13 and 14, overall survivorship and health were determined on a subset of seedlings in all 50 plots at the CCWESTRS site. 60 seedlings were chosen at random in each plot (10 consecutive seedlings in portions of six rows spread out across the plots). Each seedling was assessed and placed in categories that ranged from missing or dead, to live (either healthy or stressed). The results are summarized in the following five figures (Figures 41-45).

Results indicated that overall survival rates were similar for sweet gum (81\%) and sycamore (82\%), but sycamore seedlings appeared to be healthier (64\% vs. 47\%) (Figure 41$)$. Though not rated, sycamore was clearly on average much taller and had a much greater leaf mass than sweet gum.

Irrigation improved survival (Figure 42) and health (Figure 43) noticeably for both species, with the greatest differences generally between zero irrigation and low irrigation. Mulching had a 
noticeable negative effect on survival in sweet gum seedlings only (Figure 44). It had a mixed effect on sweet gum health (Figure 45). Mulching had no measurable impact on either survival or health of sycamore.

In August 2003, foliage samples were collected from randomly-selected seedlings for chemical analysis. Although every plot was not sampled as in 2002, the randomly-selected samples represented all mulch and irrigation treatments for each species. In general, macronutrient levels were sufficient except for $\mathrm{Ca}$ in non-FGD mulched plots. In the high irrigation plots (both zero mulch and high mulch), B levels were high to very high (Figure 46). Even in those plots with very high B concentrations, sycamore seedlings showed no signs of toxicity. In general, sweet gum seedlings did not look as healthy, but their appearance did not point to any particular nutrient limitation or excess.

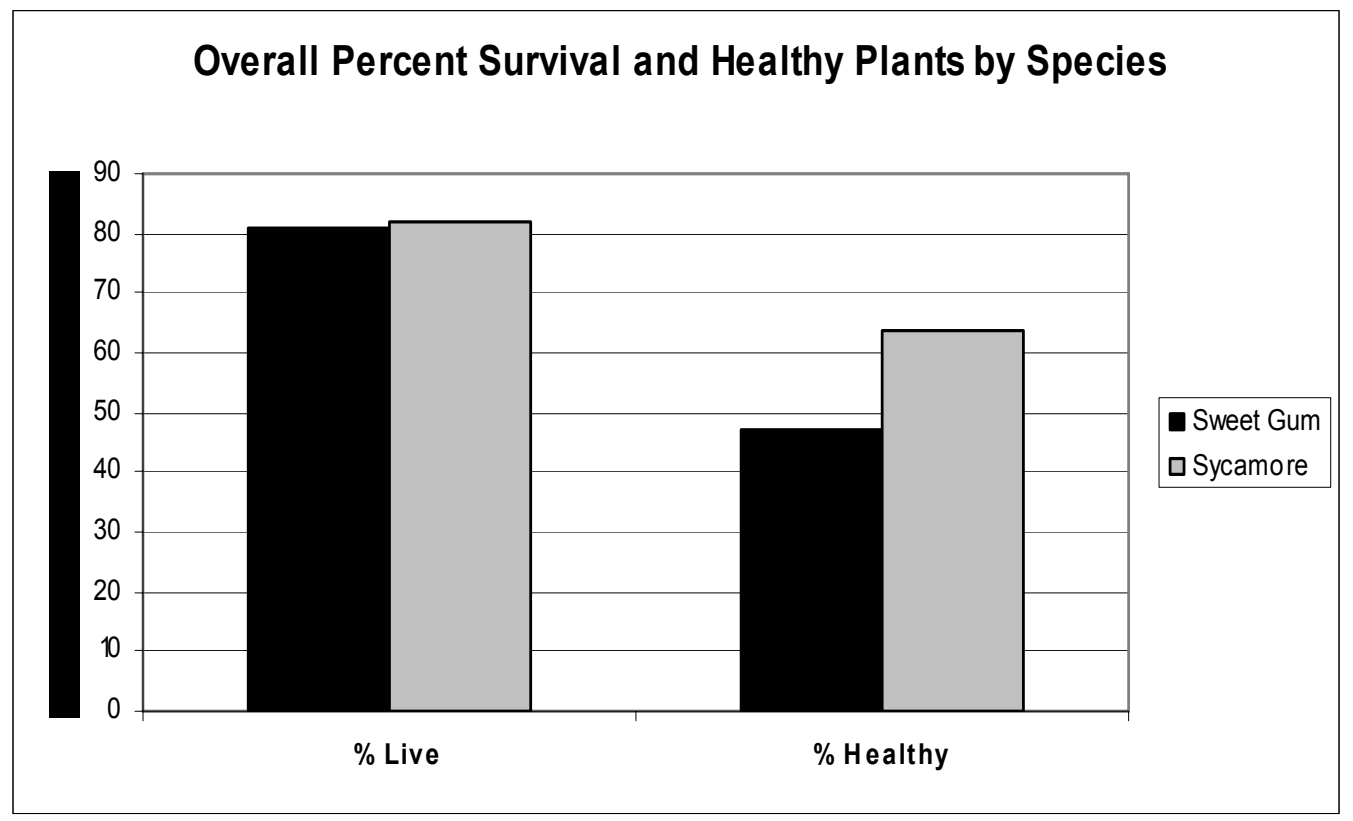

Figure 41. Overall percentages of live seedlings and seedlings considered healthy in 2003.

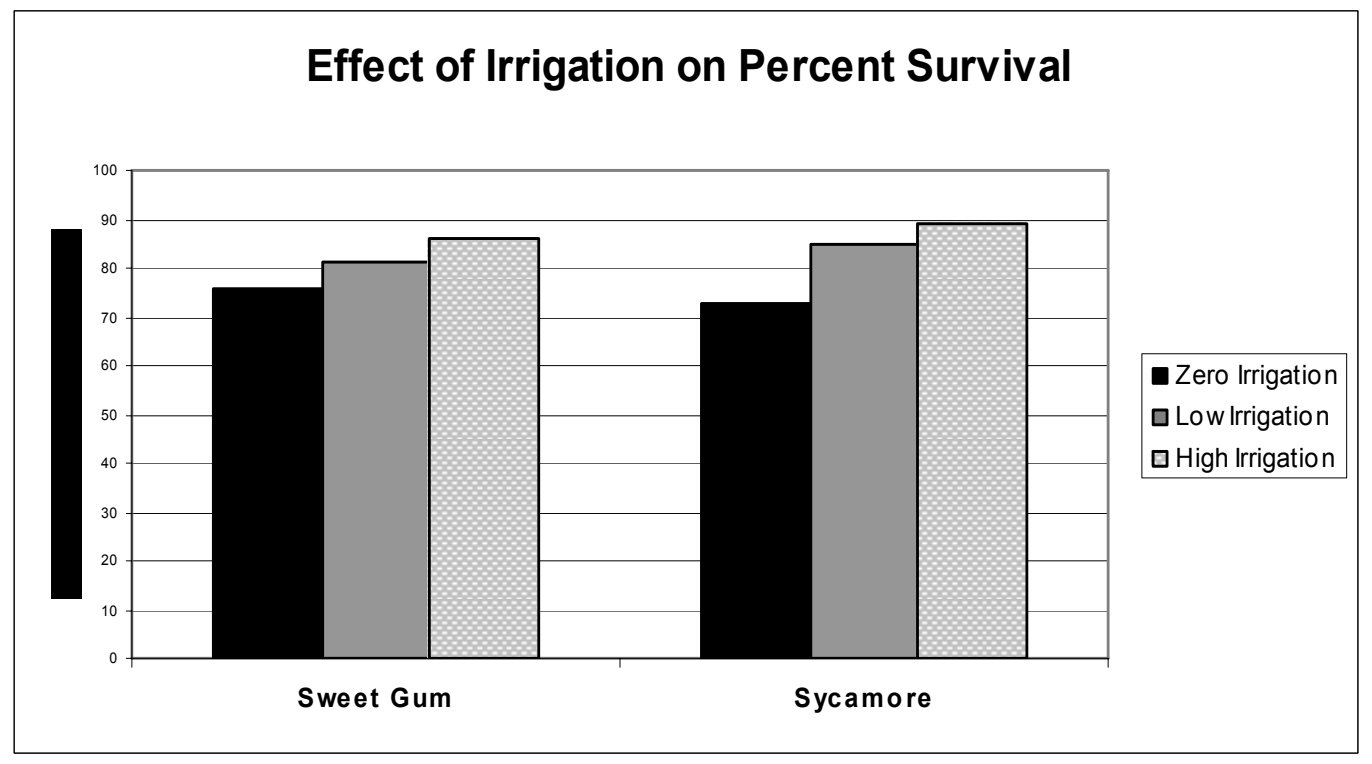

Figure 42. Effect of Irrigation on percent survival of sycamore and sweet gum seedlings in 2003. 


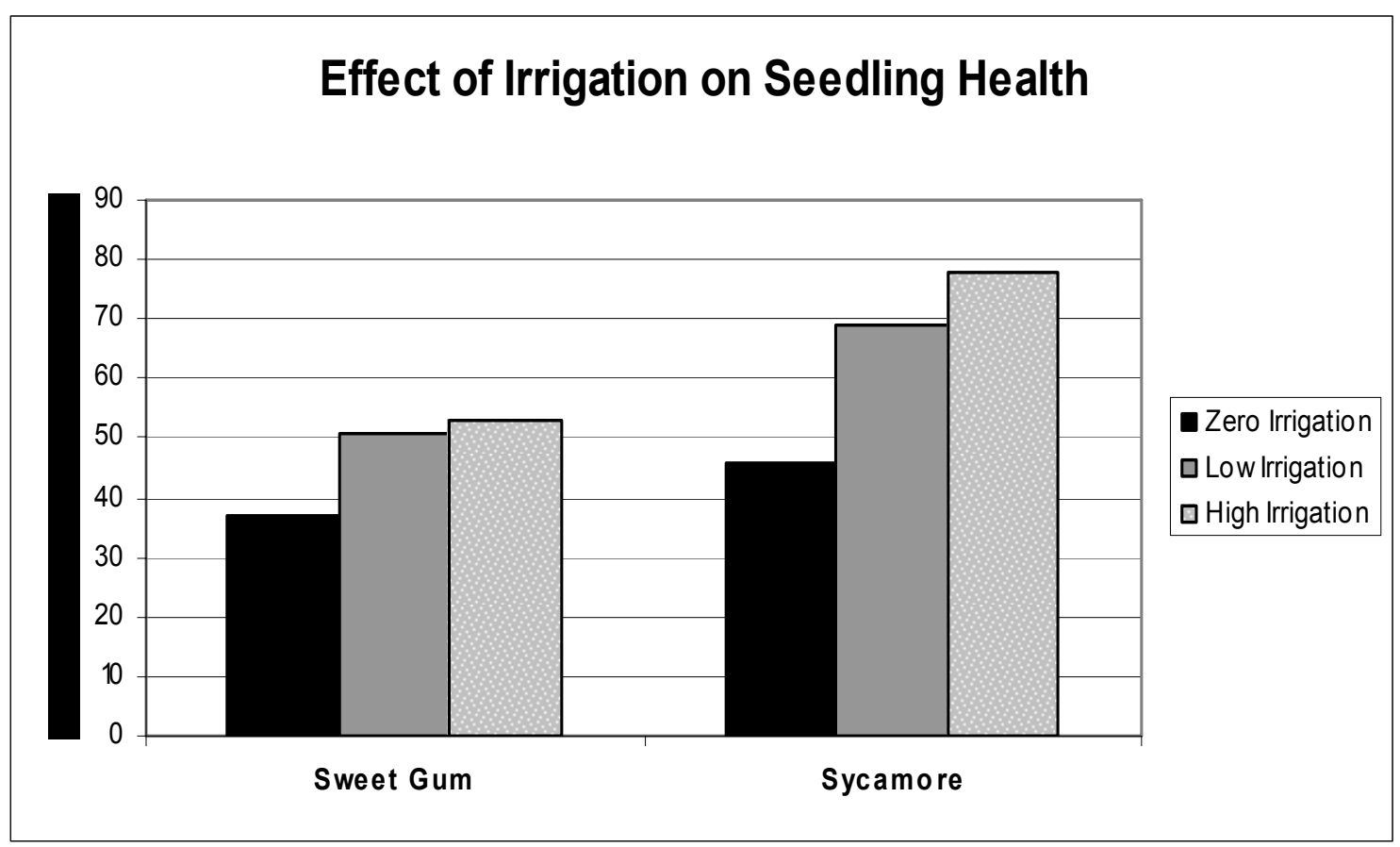

Figure 43. The effect of irrigation on seedling health on sycamore and sweet gum seedlings in 2003.

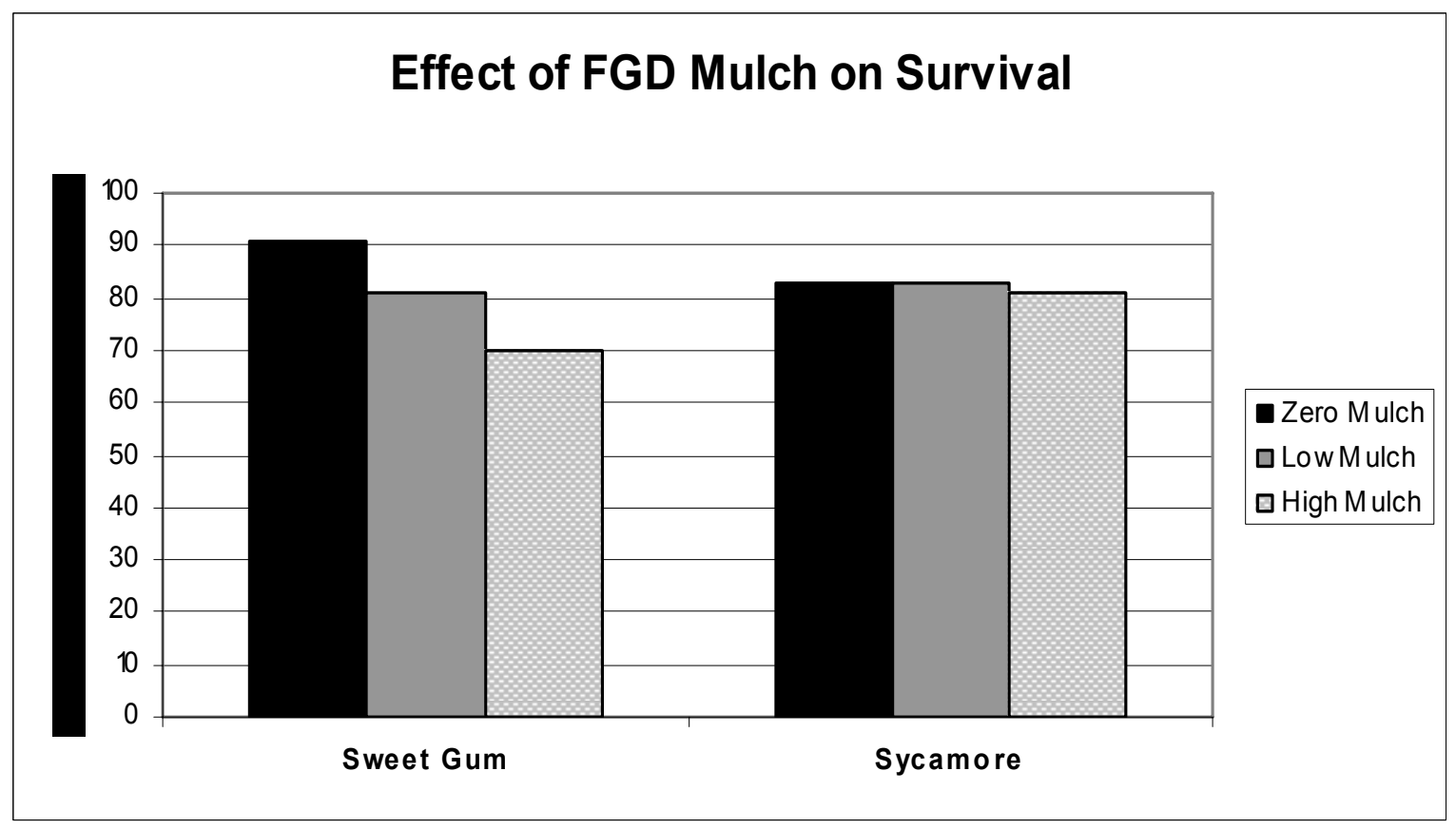

Figure 44. Effect of FGD mulch on survival of sycamore and sweet gum seedlings in 2003. 


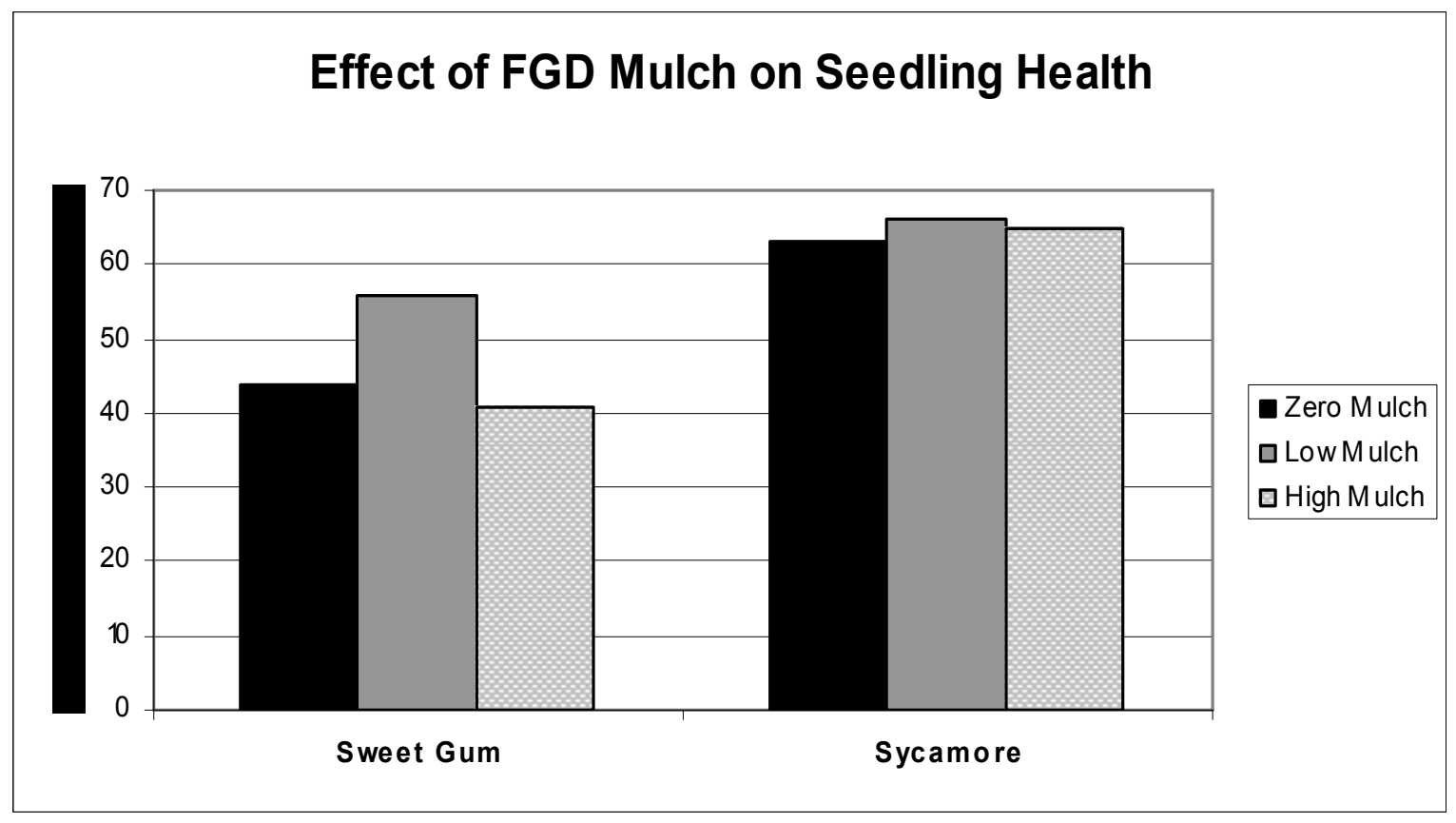

Figure 45. Effect of FGD mulch on seedling health in 2003.

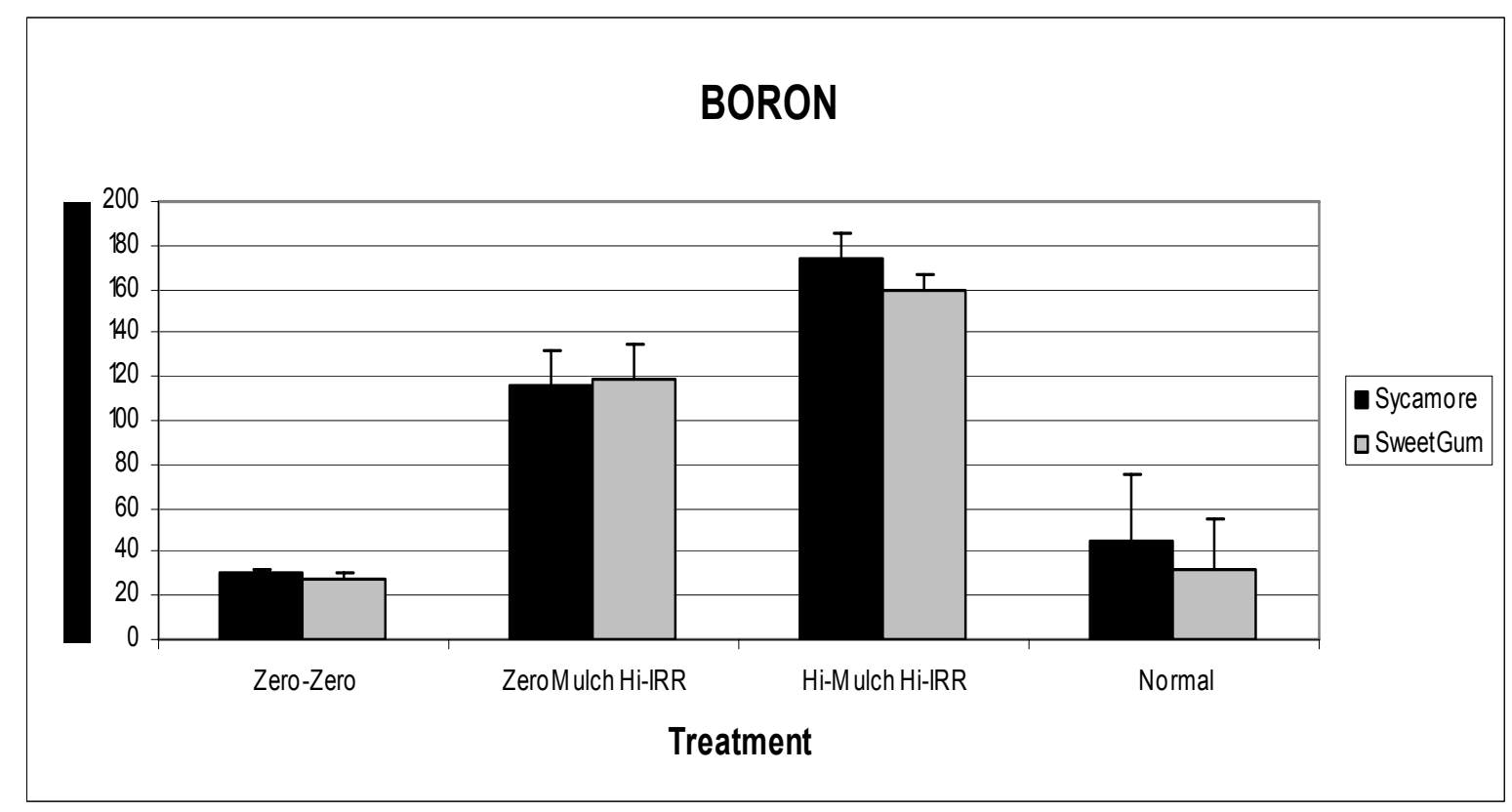

Figure 46. Boron concentrations in sycamore and sweet gum foliage for three treatment combinations and compared to normal healthy concentration ranges. Error bars depict standard errors for treatments. 


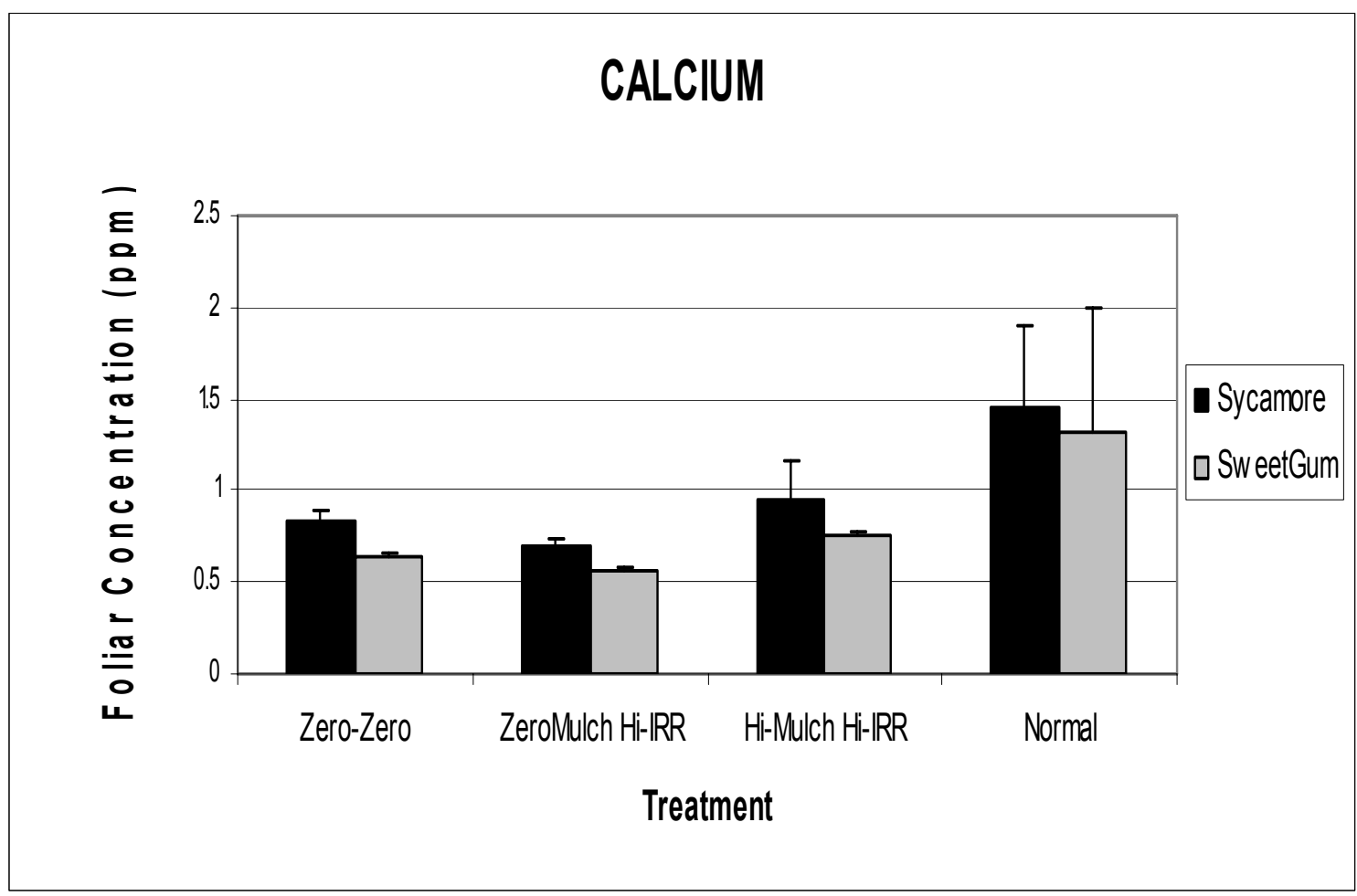

Figure 47. Calcium concentrations in sycamore and sweet gum foliage for three treatment combinations and compared to normal healthy concentration ranges. Error bars depict standard errors for treatments.

As in 2002, calcium was low for all treatments, but not significantly different from the normal range for sweet gum in any treatment (Figure 47). Calcium levels were significantly $(p<0.05)$ below normal for sycamore in the two treatments that received no mulching. For both species, Ca seemed to be slightly improved by mulching but not by irrigation. These Ca results were quite unexpected since the $\mathrm{pH}$ of these soils are near neutral and the soils were limed at the beginning of the study.

\subsubsection{2004}

Foliage sampling was conducted from the same selected plots in 2004. As in 2003, calcium concentrations were slightly low in both species and across all treatments. This is particularly surprising since soil Ca levels were generally high, especially under mulching treatments where foliar Ca was the lowest. Excess soil potassium (and subsequent uptake) is the most likely reason for low calcium within the foliage up. This may prove likely since almost all of the vegetation that was sampled had high levels of $\mathrm{K}$. Also, mulching generally raises foliar $\mathrm{K}$ levels (significant in sweet gum) while at the same time lowering foliar Ca levels (but not significantly). Manganese was low in both species and treatments. Low manganese availability could be caused by the high soil $\mathrm{pH}$, poor drainage (possible in some plots, but many of the plots are close to excessively drained), and high soil iron. The poor soil drainage explanation is supported by the fact that sweet gum foliar manganese levels drop from sufficient to deficient under high irrigation treatments.

Boron levels are very high in both species across all mulch and irrigation treatments. The 2004 levels are even higher than those seen in 2003, especially for sweet gums (Figure 48). Both 
species exhibited increased growth in 2004, resulting in increased uptake of boron. There is no visual evidence that either species of trees are having a problem with this. It is interesting to see that the boron concentration in sycamores seems to have peaked at approximately 170 ppm while sweet gums are able to exceed this level. Soil levels of B support the contention that $B$ is not a major factor limiting growth, though it could be a minor one. Among the mulching treatments, the highest $B$ levels are found in the upper $15 \mathrm{~cm}$ of soil where mean B levels average between $6.2 \mathrm{mg} \mathrm{kg}^{-1}$ (high mulch) and 5.6 (low mulch). These levels are close to the $10 \mathrm{mg} \mathrm{kg}-1$ used in preliminary greenhouse studies, wherein both sycamore and sweet gum showed virtually no leaf damage at this soil concentration. Major leaf damage in both species in greenhouse studies was observed at 35 mg kg-1 (2002 CCWESTRS Annual Report). Between $15 \mathrm{~cm}$ and $45 \mathrm{~cm}$ depth, soil $B$ levels for both species remain below 4 (mulching treatment means range from 2.3 to 3.7). No mulch controls have mean soil B levels below 1.7. In fact, the highest soil B concentrations values are found in the upper $15 \mathrm{~cm}$ of the high mulch/high irrigation treatments (mean $=8 \mathrm{mg} \mathrm{kg}^{-1}$ ). In spite of these moderately high $\mathrm{B}$ levels, biomass production (in these treatments) was equal to or better than 6 of the 8 treatments with lower soil B levels for both species.

Copper levels in the sweet gums are considered high, even though their concentrations are less than those seen in the sycamores, but do not appear to be an issue at this time.

\section{Boron Concentrations in Leaves by Species, Treatment, and Year}

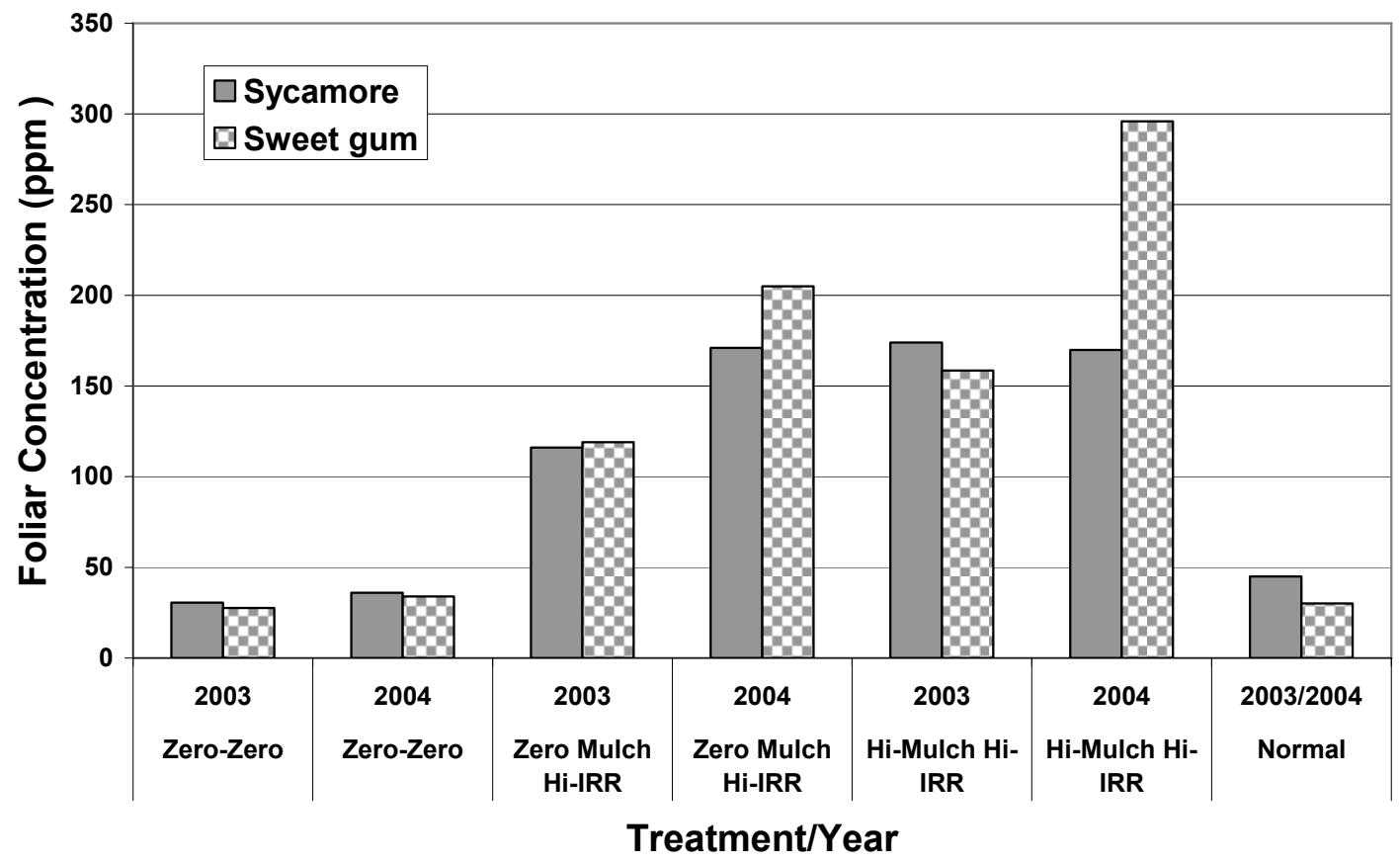

Figure 48. Boron concentrations in both species by treatment and year.

\subsubsection{2005}

In 2005, differences between the two tree species became apparent as the sycamores (in most plots) appeared to have adapted to site conditions and are thriving. Sycamore growth continues 
to be enhanced by the high mulch and high irrigation treatments (Figure 49 and 50). Sweet gums have not faired as well. There are no significant differences in sweet gum biomass across all mulch or irrigation treatments. It is assumed that the lack of establishment and growth of the sweet gums can be attributed primarily to the intense competition for water, nutrients and light from the ground cover species (primarily lespedeza). Possible detrimental effects of elevated boron levels in the plant tissue can not be dismissed as a contributing factor, but some of the healthiest (vigor) sweet gums were observed in high mulch/high irrigation treatment plots. In all plots (both species) not receiving supplemental irrigation, tree survival and growth have been severely impacted.

As in the two previous years, plant foliage was sampled in the summer of 2005 from the same selected plots. Foliage samples taken in mid-summer revealed sufficient macronutrient levels in both species except for calcium which was low in most treatments. Calcium (Ca) concentration seems to be slightly improved by mulching but not by irrigation. Manganese (Mn) concentrations were slightly deficient in some plots and may be attributed to its low availability in soils with a high soil $\mathrm{pH}$, high organic matter or poor drainage. The assumption made in 2004 that sycamores may have reached a peak boron concentration within the foliage was dispelled as boron concentrations in high irrigation plots exceeded $210 \mathrm{ppm}$ (Figure 51). Boron was within normal range for zero mulch/zero irrigation treatments, but very high for both treatments with high irrigation (mulching also seems to increase B levels even further). Although boron levels were higher than in previous years, sycamore seedlings showed no signs of boron toxicity. Boron levels in sweet gum seedlings were lower than in 2004 and could possibly be attributed to the overall stagnation in growth and lower plant uptake.

The reestablishment of two tree species previously observed in our preliminary site surveys should be noted. American cottonwood and black willows have invaded the wetter areas of the study (especially those covered by FGD gypsum) and have attained heights equal to our most aggressive study species, American sycamore. Their success under the conditions provided at the CCWESTRS site should be considered in future carbon sequestration or possible phytoremediation studies. 


\section{Tree Biomass by Mulch Treatment}

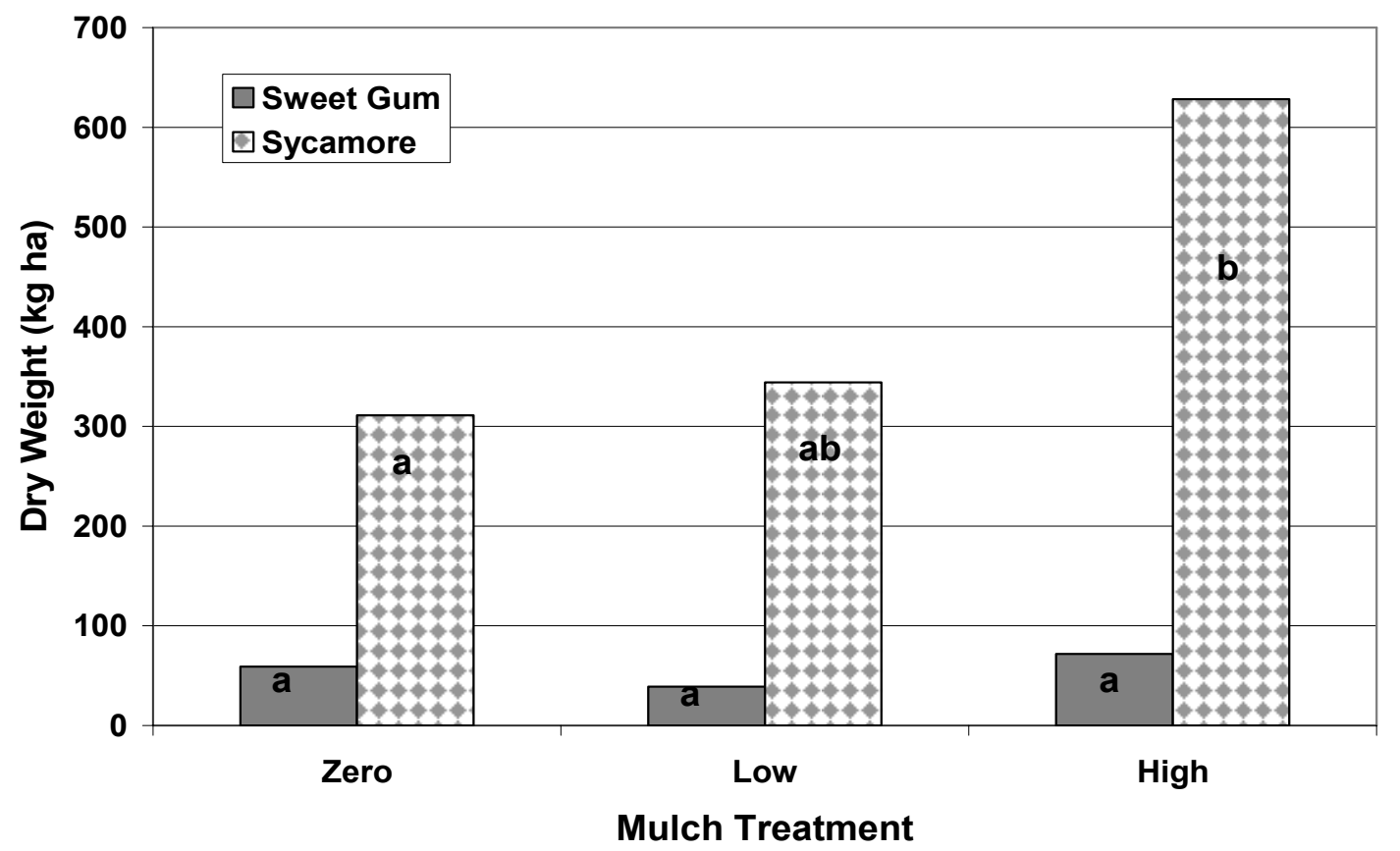

Figure 49. Tree biomass (dry weight) in 2005 by species and mulch treatment. Different letters within each bar indicates significant differences $(P<0.05)$ between treatments effects for each species.

\section{Tree Biomass by Irrigation Treatment}

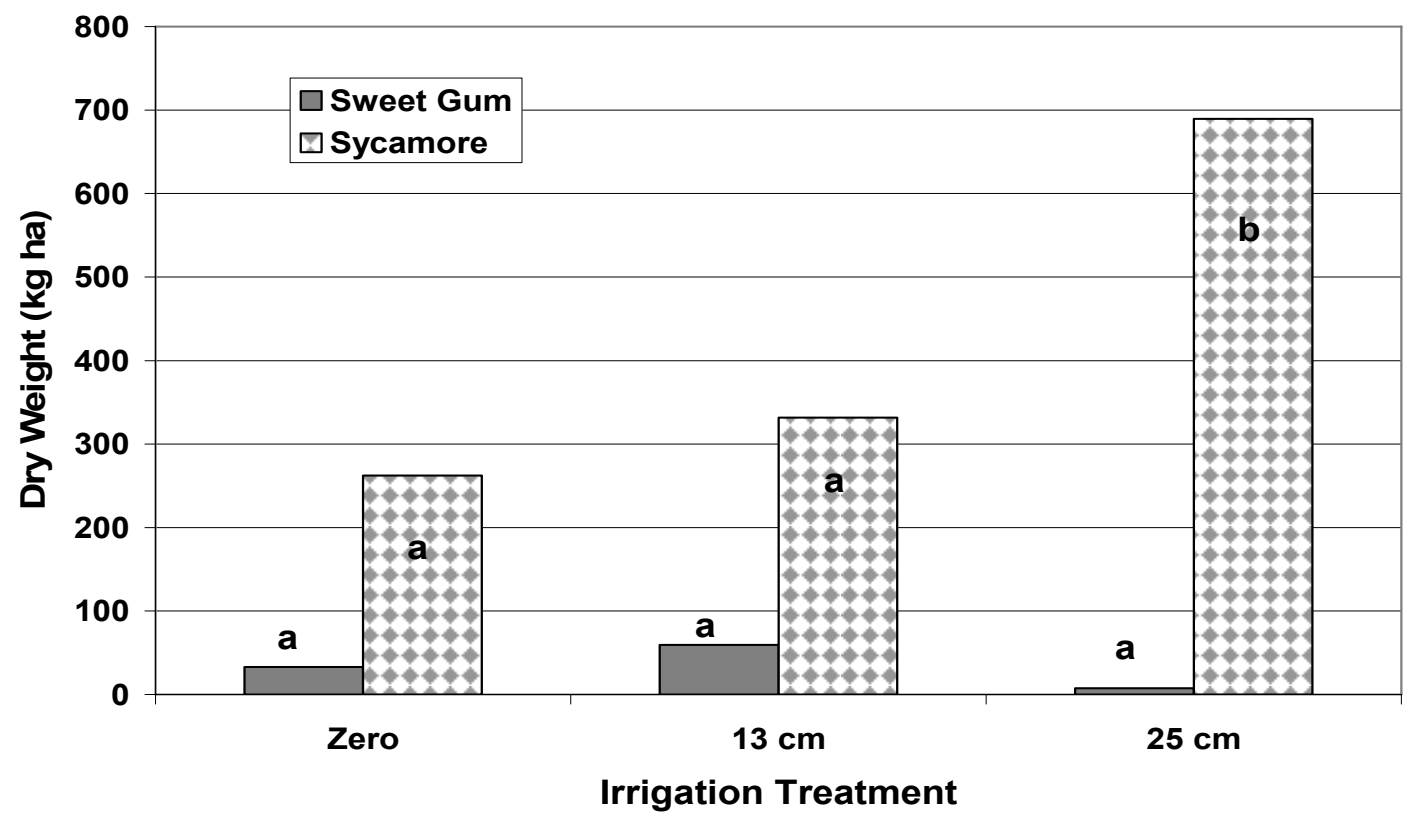

Figure 50. Tree biomass (dry weight) in 2005 by species and irrigation treatment. Different 
letters within each bar indicates significant differences $(P<0.05)$ between treatments effects for each species.

\section{Boron}

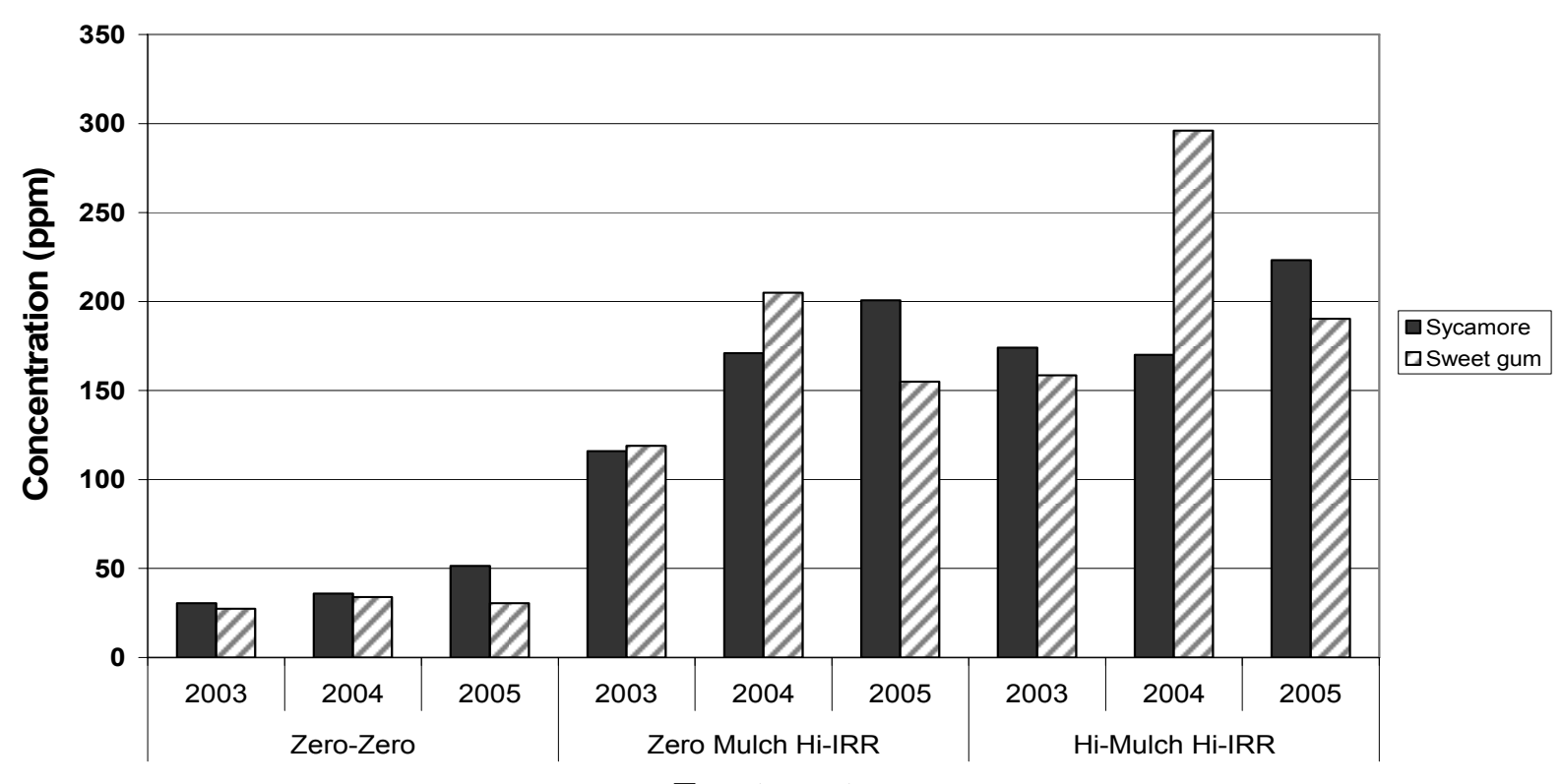

Figure 51. Leaf boron concentrations in both species by treatment and year from 2003-2005.

\subsubsection{Ground cover}

\subsubsection{2}

A vegetative survey was conducted in 2002 using randomly selected plots $\left(\mathrm{m}^{2}\right)$ as described in the initial vegetative survey of the site (see section 5.2.4). In 2001, thirteen herbaceous species were identified within the sample plots and their relative abundance can be found in Table 5 . Only $0.1 \%$ of the CCWESTRS site was not covered in some form of vegetation. In terms of species composition, all plots fell within two distinct groups that were dominated by either tall fescue or lespedeza, both of which were the predominate species planted during reclamation of the site. The plots dominated by fescue rarely contained more than one or two additional species because of fescue's ability to out-compete most other vegetation, especially under conditions that are less than ideal. Plots dominated by lespedeza varied somewhat in their species composition and ranged from completely pure stands to ones quickly being overtaken by other species (pokeweed, thistle and prickly lettuce). Although trees species like Eastern Red Cedar, Honey-Locust, Eastern Cottonwood, Eastern Redbud, and Box-Elder were observed at the site, their relative contribution to the surface vegetative cover was less than $0.01 \%$ percent.

In 2002, tall fescue continued to dominate most of the zero mulch plots, with $89 \%$ having at least $70 \%$ fescue cover. However, $22 \%$ of the plots also had at least $40 \%$ coverage by lespedeza species. These "high lespedeza" plots, as in baseline measurements, had considerably higher aboveground biomass, averaging $0.99 \mathrm{~kg}$ organic matter $\mathrm{m}^{-2}$ (4.45 metric tons $\left.\mathrm{C} \mathrm{ha}{ }^{-1}\right)$ compared to the remaining zero mulch plots $(0.52 \mathrm{~kg}$ organic matter $\mathrm{m}-2$ or $2.35 \mathrm{~T}$ $\mathrm{ha}^{-1}$ of $\mathrm{C}$ ). 
The low mulch application was effective in reducing the cover by tall fescue, with only $11 \%$ of the plots having greater than $70 \%$ fescue, compared to $89 \%$ of the zero mulch plots. However, no difference between zero mulch and low mulch was observed in the percentage of plots having at least $40 \%$ cover by lespedeza species (22\% of the plots). In place of the reduced fescue cover, numerous other weed species such as ragweed and pigweed became common on many plots. For example, $38 \%$ of the low mulch plots had at least $80 \%$ cover by a variety of weed species.

The high mulch application was more effective in reducing weed competition, especially from tall fescue and lespedeza species. Only $11 \%$ of these plots had at least $70 \%$ fescue coverage and none had as much as $40 \%$ lespedeza coverage. However, weed species coverage exceeded 30 percent on $67 \%$ of these plots. Bare FGD gypsum occupied at least $20 \%$ of the ground cover on $89 \%$ of these plots.

Figure 52 depicts the distribution of aboveground biomass across the experimental site. The highest concentration of organic matter was found in four zero mulch plots (Plots 57-60) that are currently dominated by sericea lespedeza. The ten plots in the second highest biomass category consist of four zero mulch plots dominated by tall fescue $(17,18,45,46)$, four low mulch plots dominated by sericea lespedeza $(25,26,41,42)$, and two low mulch plots dominated by tall ragweed $(3,4)$. Of the 14 plots with highest aboveground biomass, none were high mulch plots.

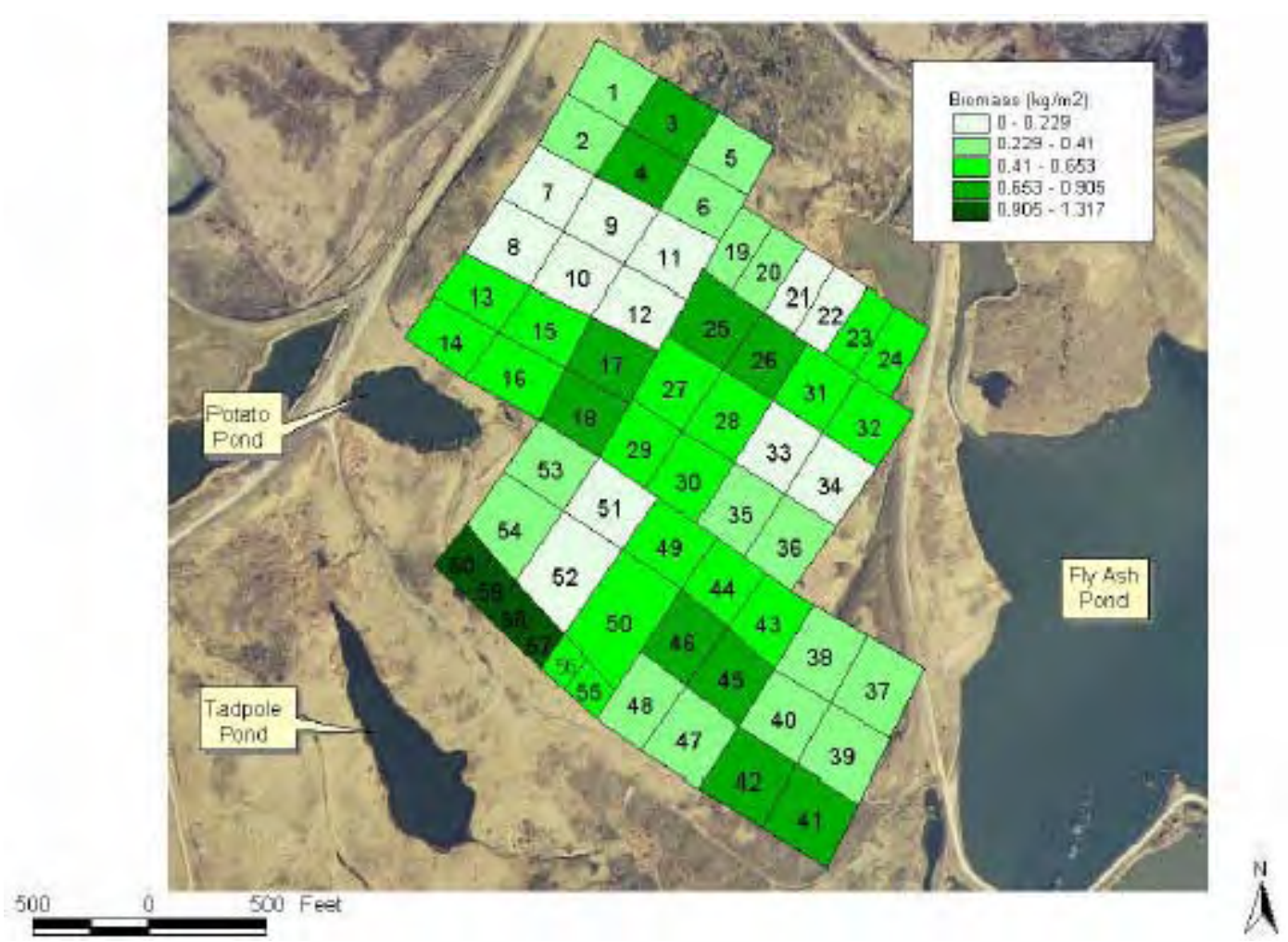

Figure 52. Distribution of aboveground biomass across the experimental site.

\subsubsection{3}


Overall, herbicidal treatments in 2003 appeared quite effective in minimizing the weed competition, through mid-August. On average across all treatments, less than $50 \%$ of the ground surface was occupied by weeds at this time (Figure 53). The two FGD mulch treatments resulted in only a slight suppression of weeds relative to the zero mulch treatment. Fifty to sixty percent of the surface was covered by bare FGD sludge in these treatments, with little discernable difference between the high and the low mulch treatments. Whereas there was minimal exposure of bare soil under the two mulch treatments, in the zero mulch treatment about $50 \%$ of the surface cover was bare soil. There was also slightly more thistle and lespedeza under zero mulch, the two most noxious weeds on the site.

The irrigation treatments seemed to have had minimal impact on weed cover by August, 2003 (Figure 54). The two irrigation treatments seemed to have stimulated weeds slightly compared to no irrigation, resulting in somewhat less bare soil or bare FGD mulch. Lespedeza was the only weed that seemed to be responding positively to irrigation in any consistent manner.

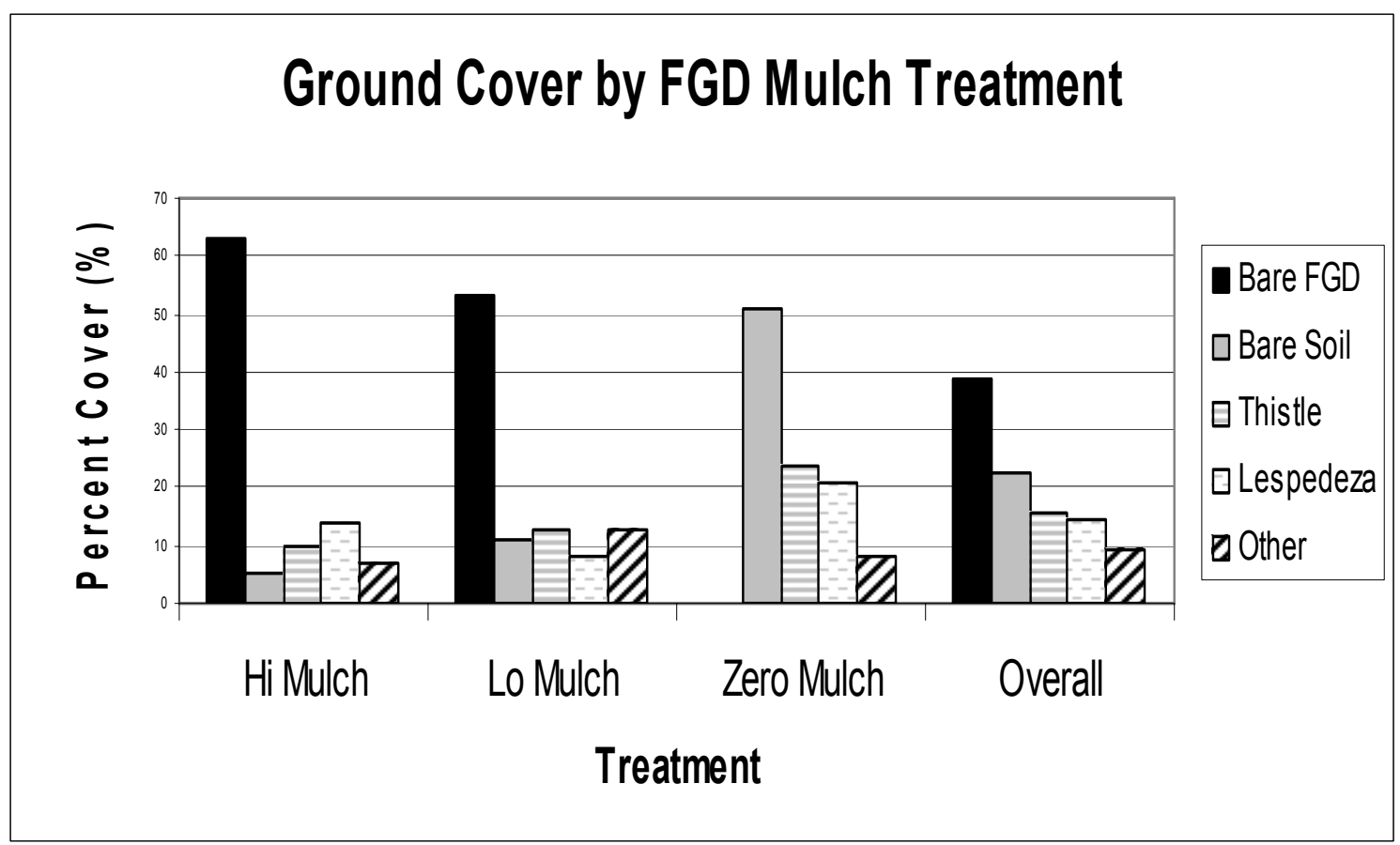

Figure 53. Ground Cover by weed species, FGD mulch, and bare soil by mulch treatment. Total may be greater than $100 \%$ due to layering of vegetation. Moss cover has been omitted from the chart. 


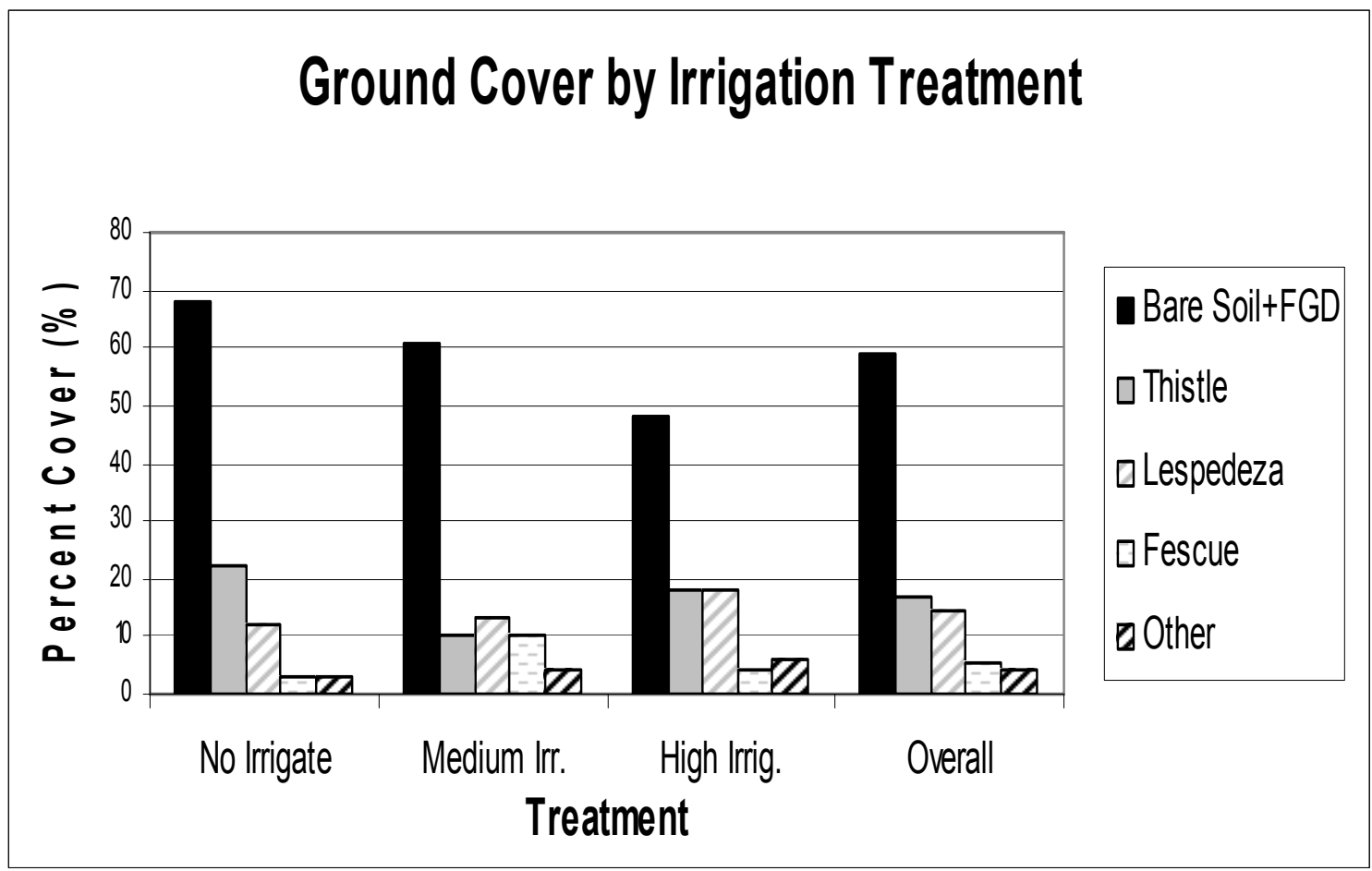

Figure 54. Ground Cover by weed species, irrigation treatment, and bare soil by mulch treatment. Total may be greater than $100 \%$ due to layering of vegetation. Moss cover has been omitted from the chart.

\subsubsection{2004}

In 2004, lespedeza's dominance of the vegetative cover became more evident across practically all mulch (Figure 55) and irrigation treatments (Figure 56). Three factors contribute to the enhanced growth of lespedeza (and other weed species) - sufficient area for seedling establishment, irrigation and the removal of competition. The mean percentage of cover area (overall) occupied by bare soil and FGD in 2003 was approximately $50 \%$. After colonization by numerous weed species, this average dropped to $14 \%$ in 2004 (Figure 55). Irrigation level effects varied among species, but generally showed an increase in percent cover with increases in irrigation (especially true for grasses) (Figure 56). 


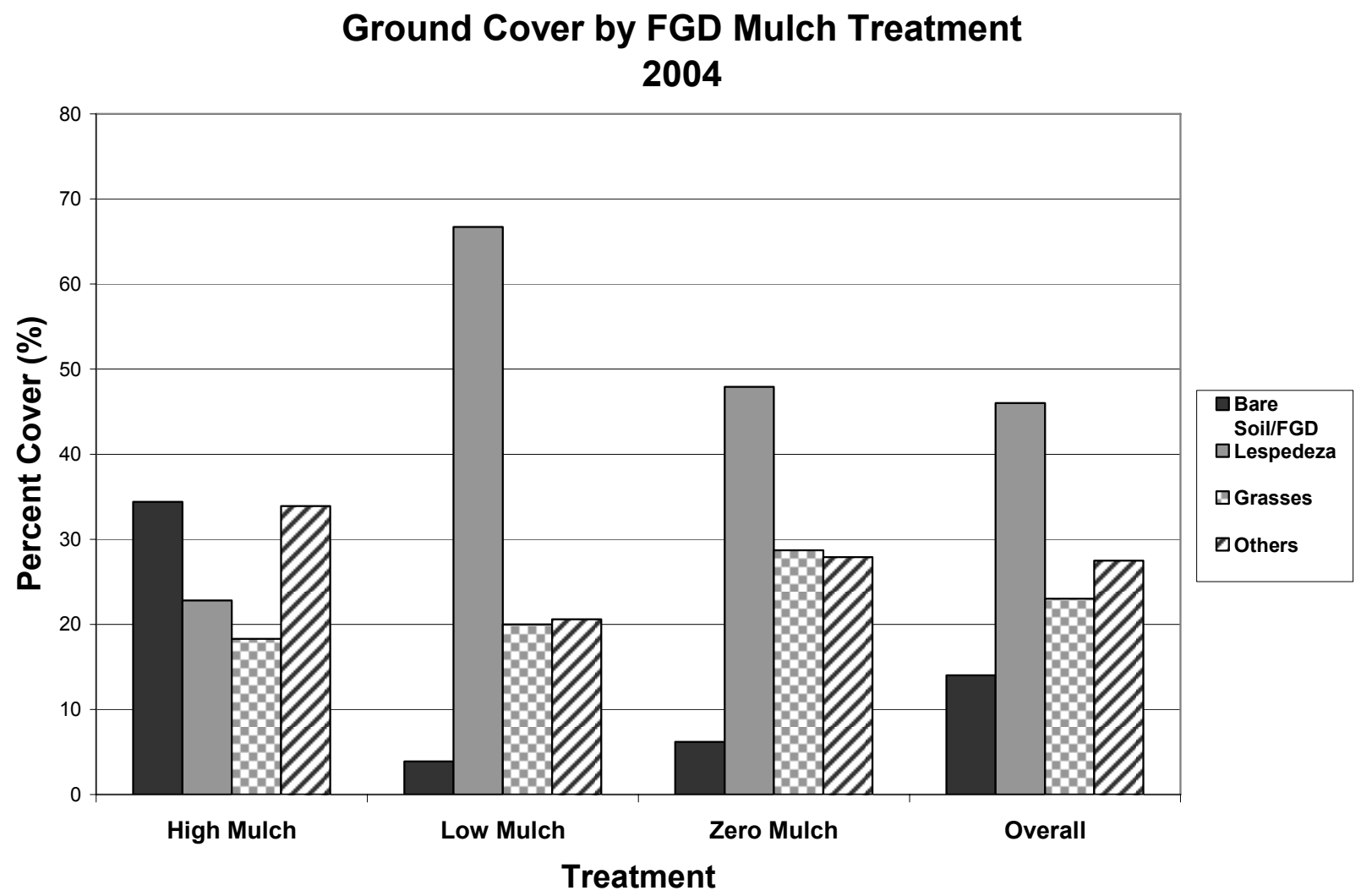

Figure 55. Ground cover percentages as a function of mulch treatment in 2004.

Ground Cover by Irrigation Treatment 2004

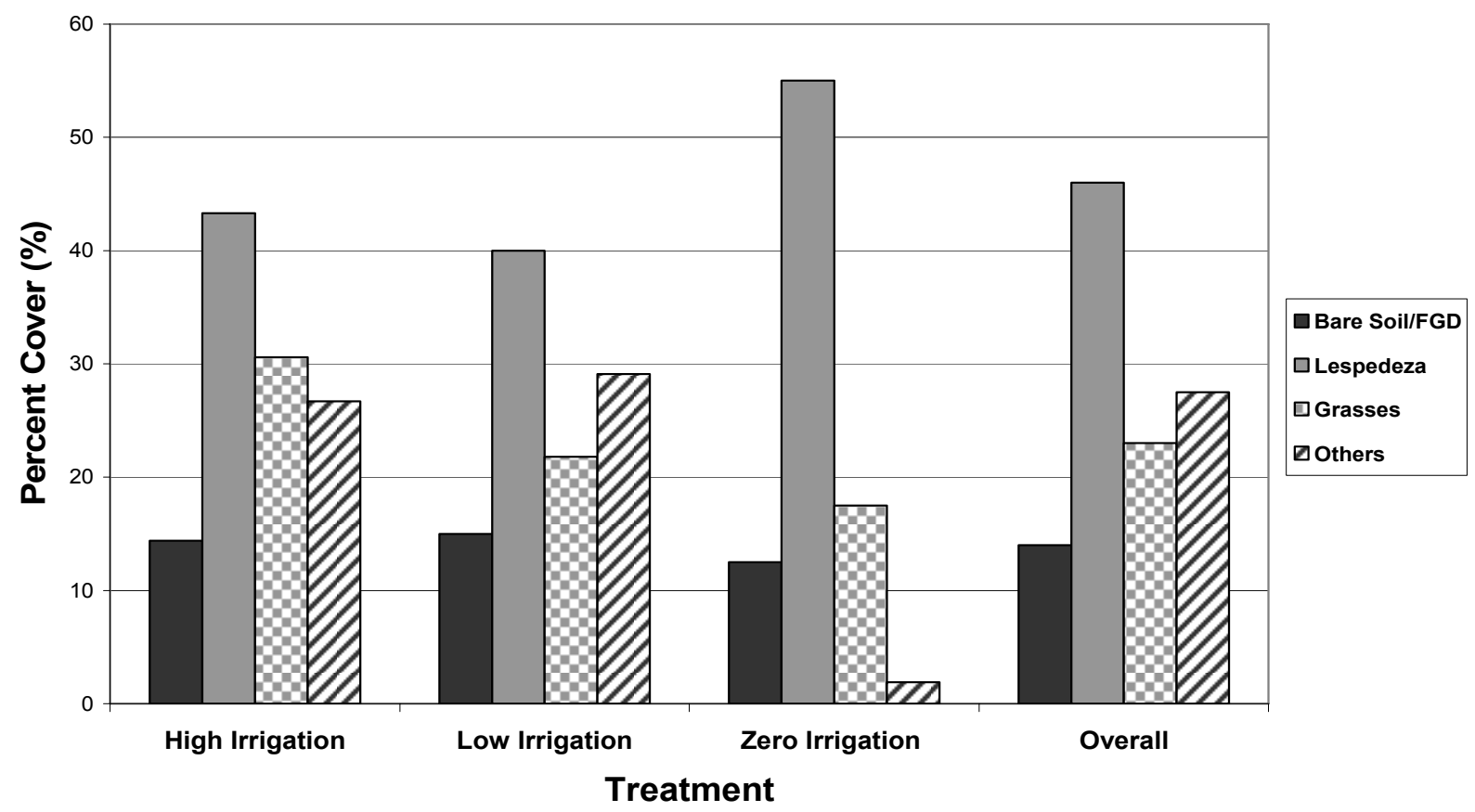

Figure 56. Ground cover percentages as a function of irrigation treatment in 2004. 


\subsubsection{2005}

In 2005, the dominance of lespedeza in the ground cover increased across all treatments. This was achieved primarily at the expense of the remaining herbaceous vegetation through competition and as the bare soil/FGD surfaces were colonized (Figure 57).

\section{Ground Cover by FGD Mulch Treatment 2005}

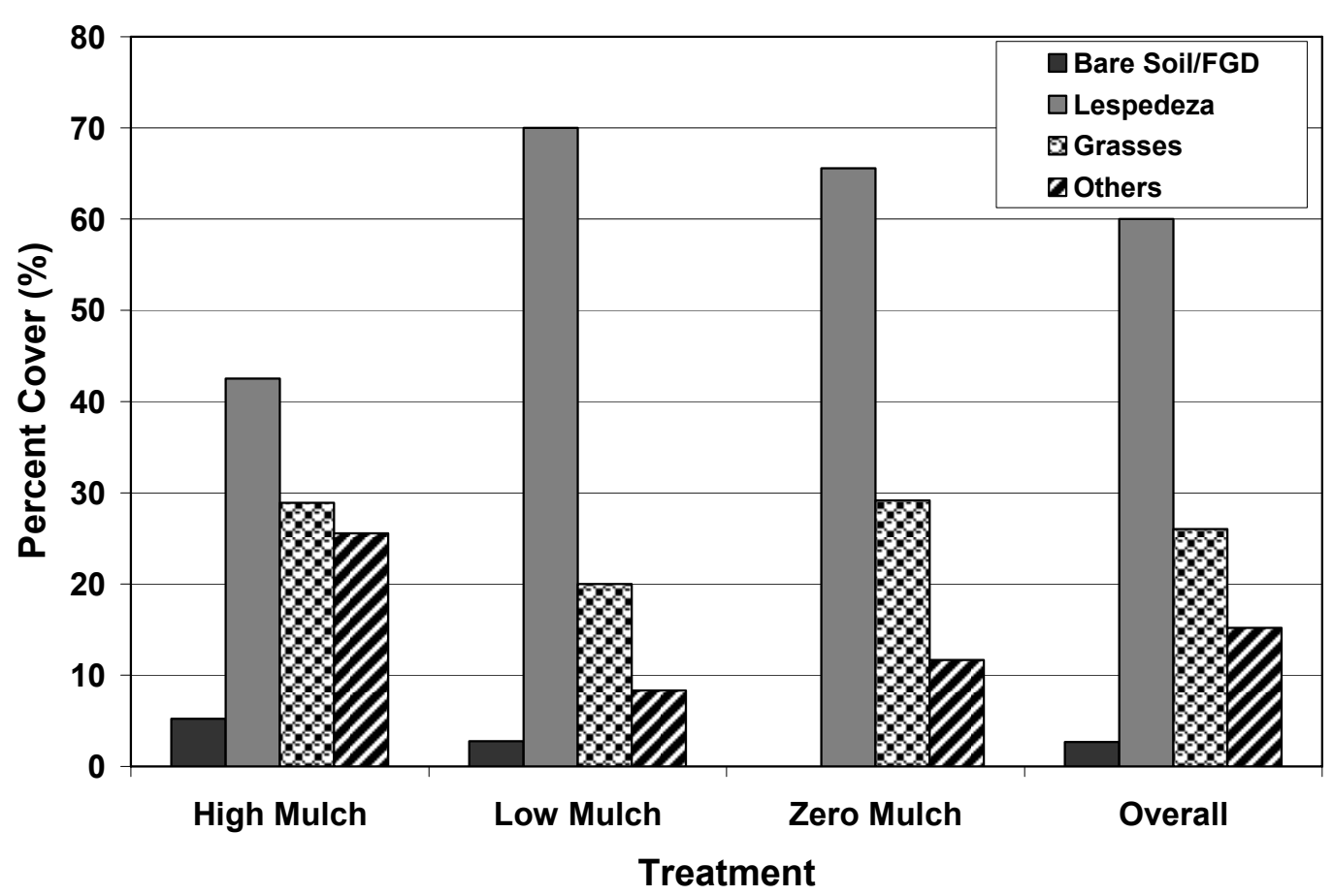

Figure 57. Ground cover percentages as a function of irrigation treatment in 2005.

\subsubsection{Potato Pond Sub-Experimental Tree Planting}

In addition to the plantings on the 54 test plots, the Team decided to plant an experimental test cell in a variety of trees that were tested in laboratory experiments for B tolerance but did not perform adequately to be selected as test species. The trees were planted in late March to late April, 2002. The primary reason for this plot was to evaluate potential survival of the species under actual field conditions. Table 16 shows the various species planted and the results of a survival survey conducted in August, 2002. The test area occupies about 0.5 ha with 1.2-m grass strips between the 3.7-m strips of FGD gypsum, and is just southwest of the Potato Pond. Trees were planted on 2.4-m centers. The planned irrigation treatment was split between no FGD water and high FGD water; however, the irrigation system was not installed in time to initiate irrigation on the trees, so this aspect of the test was not included.

The tulip poplar, cottonwood, red maple, (Warren County Nursery) and white oak (Greenwood Nursery) are all one-year-old seedlings from Tennessee nursery stocks. 
The 2-year-old sycamore and sweet gum are from the same nursery stock used last year in the greenhouse study and a very limited number were planted into beds of artificial media. One half were grown in artificial media with Pisolithus tinctorius $(\mathrm{Pt})$ ectomycorrhiza (beneficial root fungi). The purpose of this test planting was to estimate: 1) the initial survival and potential growth benefits of using trees reared with mycorrhizae, and 2) compare two-year-old trees with one-year-old commercial seedlings used in the main field planting. The native red mulberry and American chestnut, are additional species being subjected to the screening process in search for tolerate species. The native red mulberry demonstrated high survival tolerance to soil amended B in our greenhouse trial.

\begin{tabular}{|l|l|l|l|}
\hline Tree Species & Total Planted (n) & No. Living (N) & \% Living \\
\hline American Chestnut & 58 & 0 & 0 \\
\hline Tulip Poplar & 152 & 0 & 0 \\
\hline Sweetgum & 56 & 3 & 5 \\
\hline Black Walnut & 56 & 5 & 9 \\
\hline Red Maple & 152 & 22 & 14 \\
\hline White Oak & 152 & 24 & 16 \\
\hline Sycamore & 56 & 17 & 30 \\
\hline Cottonwood & 96 & 41 & 43 \\
\hline Red Mulberry & 56 & 30 & 54 \\
\hline
\end{tabular}

Table 16. Survival Counts on Potato Pond Plot as of August 1, 2002

Several observations were made related to these experiments that are significant and relevant to the main test plots experiment. Erosion segregated the FGD gypsum into a light, sandy component and a heavier, darker component. Survival was generally better in the lighter component. The darker component is very hard and difficult to break through. Deer browsing was significant and many seedlings were missing completely. Some were washed out and covered up with the lighter component of the FGD gypsum. American chestnuts were all fully leafed out in late May after planting on March, 26. The American chestnut died with leaves attached as with a sudden toxicity or severe drought during June and July. Although deer browsing occurred, it is believed that some American chestnut may sprout from their base later. Many black walnut seeds floated out of position and deposited on top of the ground. The few living walnut trees were planted as seedlings. Sycamore seedlings that were 2 years old had poorer survival than 1-year-old seedlings. Surviving sweet gum had largely sprouted from their base and had dead tops. Cottonwood cuttings grew profusely. Cottonwood stem plantings, without roots, may have avoided early root damage due to solute leaching from gypsum and also due to late planting (April, 29). Cottonwood is naturally prevalent on the site and seems to be well adapted to the radically disturbed soil at the strip mine reclamation site. No difference was found in survival of 1-year-old and 2-year-old red mulberry seedlings. Mulberry seedlings appear to be very tolerant of the site conditions. Common reeds (Phragmites australis) were aggressively invading the site from the adjacent Potato Pond drainage. The potential for $\mathrm{C}$ accumulation due to the growth rate of this reed species appears to be significant.

A visual survey of the seedlings at the Potato Pond Sub-Experiment site was conducted in the spring of 2003, at which time five species were observed to be breaking dormancy (red mulberry, cottonwood, sycamore, red maple and white oak). The arid conditions experienced throughout 2002 continued into the summer of 2003 and resulted in the complete decimation of all but three tree species. In order of decreasing survivorship, those species were red mulberry, cottonwood and sycamore. This same trend in survivorship had been noted in August 2002 (Table 16) and was attributed to $B$ tolerance, acclimation to the site (based on native 
abundance), and the deferential conditions of the FGD material and soil. In the case of deferential conditions within the site, cottonwood had flourished in the moist areas adjacent to the Potato Pond discharge. The added moisture not only benefited the plant directly through uptake, but also made the FGD/soil more friable for root penetration.

In 2004, the red mulberry, cottonwood and sycamore seedlings that were able to adjust to site conditions in 2003 were still thriving. Surveys of the seedlings at the Potato Pond SubExperiment site ended in 2004.

\subsection{Water monitoring}

\subsubsection{Irrigation system monitoring}

\subsubsection{Operation - Start-Up}

The start-up of the irrigation system began in early May 2003. The 5-cm flush valves were opened allowing all of the main lines and headers to be flushed, at which time, about half of the fourteen $5-\mathrm{cm}$ flush valve sections came loose at the last gasketed connection before the flush valve. The initial thought was that the rocky soil was sufficient to hold them in place. All of the flush valves were thrust-blocked using rocks and concrete to secure them in place. Additional gasketed connections leaked due to the PVC pipe not being properly inserted deep enough into the gasketed section of the pipe. The leaks were fixed by digging up the pipe and reinserting the pipe.

One elbow fitting at the road where the pipe turns toward the pumping plant came loose twice and had to be repaired with a new fitting and solvent each time. One grommet, nipple, riser had to be repaired after it blew out of a $15 \mathrm{~cm}$ line sending a jet of water 15 meters into the air.

It was noticed that several leaks were occurring at the shut-off valves at the beginning of each drip line. The valve top would blow off the valve crack or pinhole leaks would form spewing water. After about 60 had failed and it was speculated that others would probably continue to fail in time, it was decided to replace all of them with elbows. This alleviated the problem, as no leaks occurred from the elbows.

Occasionally, a flush valve at the end of a drip line would come off or a coupling would come loose. The flush valves and couplings had initially been installed in $50^{\circ} \mathrm{F}$ weather and it was difficult to fasten the connections properly. All of the flush valves were retightened. The flush valves and couplings detachment continued to be a problem over the irrigation season. When this occurred, flush valves that came off were retightened. Subsequently, a different type of coupling was used throughout the remaining portion of the irrigation season.

It was noticed that about $608 \mathrm{~m}$ of drip line (approximately 6 drip lines) were defective (no holes punched into the emitters). These sections of the drip line were replaced. It was also discovered that about $912 \mathrm{~m}$ of the drip line only had one hole punched in the emitter instead of the usual two. After discussion, it was decided that this was acceptable since only one hole was needed and that most drip lines contained only one hole.

\subsubsection{Operation - Seasonal 2003}

The seasonal operation of the drip irrigation system began on May 23, 2003 and ended on November 10, 2003. A total of 148,728 cubic meters of irrigation water was applied during this time. The pumping plant totaled 1,921 hours of operation. During this time approximately 70.76 $\mathrm{cm}$ of irrigation water was placed on zone 1 and $35.61 \mathrm{~cm}$ of irrigation water was placed on zone 2. During the months of May through November, the site received approximately $59.64 \mathrm{~cm}$ 
of rainfall. Figure 58 shows the monthly precipitation and precipitation plus irrigation water total applied to each zone.

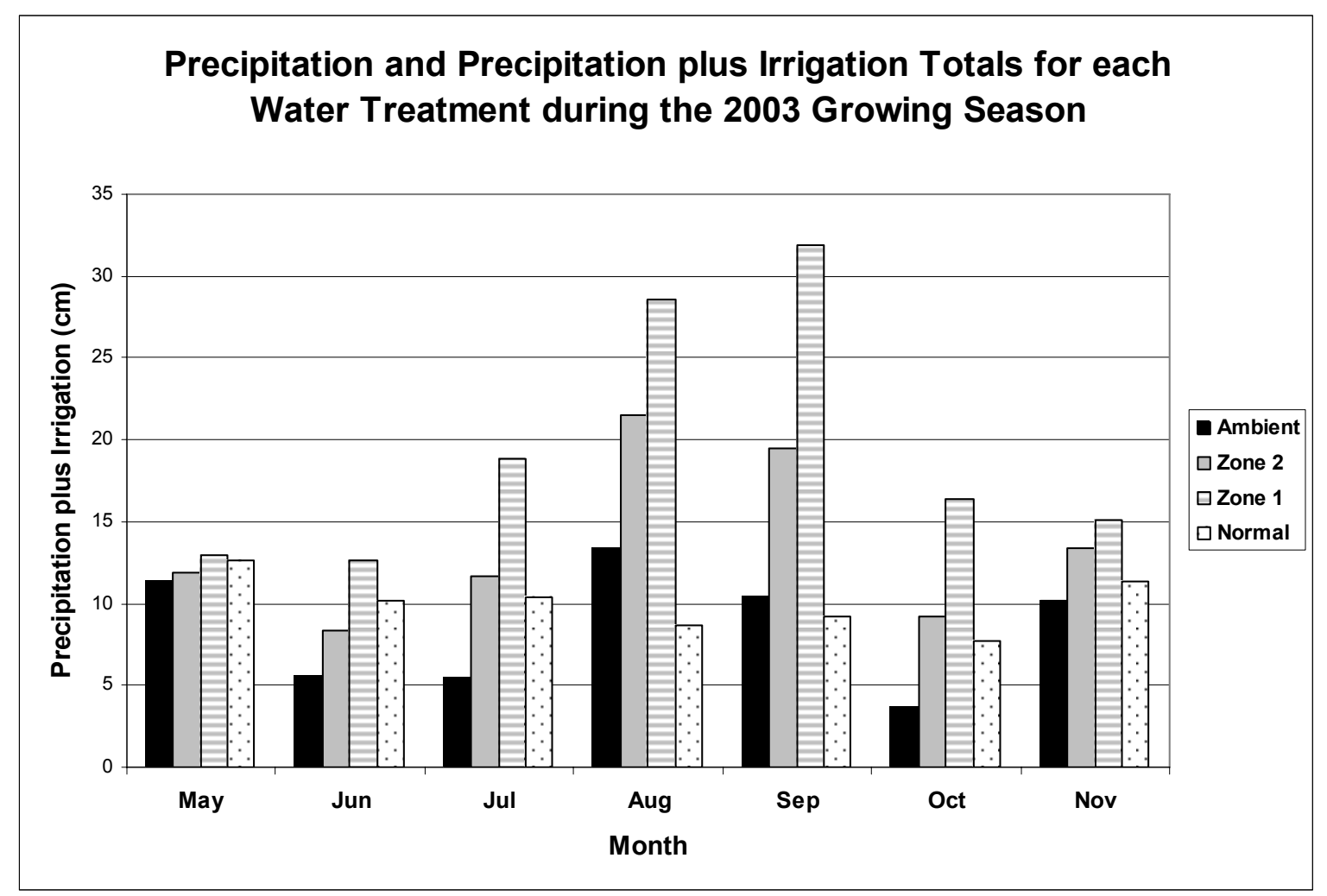

Figure 58. Precipitation and precipitation plus irrigation totals for the three water treatment levels used in the CCWESTRS study during 2003.

\section{May}

Irrigation rates for May were planned for $2.54 \mathrm{~cm}$ per week on zone 1 and $1.27 \mathrm{~cm}$ per week on zone 2. During the last 9 days of May, the system ran a total of 50 hours supplying zone 1 with $1.60 \mathrm{~cm}$ and zone 2 with $0.60 \mathrm{~cm}$ of irrigation water.

Operation of the irrigation system during the last part of May, although successful, experienced problems. It was noticed that the 2-cylinder diesel engine had excessive vibration and consumed an excessive amount of oil in both the crankcase and the oil bath air cleaner. The battery had to be replaced since the system initially was not recharging the battery. It was discovered that the zone valves were often not opening and closing correctly (especially the zone 2 valve). This pump continued to run and the system would overheat because both valves were closed. Eventually the $10-\mathrm{cm}$ valve used to prime the pump was blown off and the line from the pump to the filters collapsed. The system was re-plumbed and operation continued in June.

June

Irrigation rates for June were planned for $2.54 \mathrm{~cm}$ per week on zone 1 and $1.27 \mathrm{~cm}$ per week on zone 2. During June, the system ran a total of 184 hours supplying zone 1 with $7.01 \mathrm{~cm}$ and zone 2 with $2.74 \mathrm{~cm}$ of irrigation water. 
Irrigation in June was successful throughout the first several weeks of operation, until the excessive vibration of the engine caused the engine mounting brackets to break. The engine was re-stabilized, however, within a week the brackets broke again. Excessive vibration of the engine and the zone valves not opening properly causing the system to overheat also caused the Murphy controller to fail. The valve used to prime the pump again came off. At this time it was decided to replace the engine and install a new Murphy controller. The option of using an electric motor was seriously reconsidered but the cost of running electricity to the site was too high.

The new engine was a 4-cylinder, water-cooled, Isuzu engine. It was speculated that the excessive vibration and failure of the 2-cylinder diesel engine might be contributed to the fact that the engine had been turned on its side for a few days during the vandalism.

\section{July}

Irrigation rates for July were planned for $5.08 \mathrm{~cm}$ per week on zone 1 and $2.54 \mathrm{~cm}$ per week on zone 2. During July, the system ran a total of 319 hours supplying zone 1 with $13.31 \mathrm{~cm}$ and zone 2 with $6.17 \mathrm{~cm}$ of irrigation water.

Operations in July went well except for a few days of down time due to a bad fuel solenoid and engine thermostat that had to be replaced. The new engine was performing well. It was decided to operate the zone valves manually to make sure the correct one was open and the correct one was closed. Also a kill-switch to stop the engine was installed to keep the system from overheating if the pump water temperature became too high due to both zone valves accidentally being closed.

\section{August}

Irrigation rates for August were planned for $5.08 \mathrm{~cm}$ per week on zone 1 and $2.54 \mathrm{~cm}$ per week on zone 2. During August, the system ran a total of 393 hours supplying zone 1 with $15.24 \mathrm{~cm}$ and zone 2 with $8.23 \mathrm{~cm}$ of irrigation water.

Operations in August were successful. The system ran the whole month as planned, except was shut down for 8 days for lysimeter installation. The system was totally walked finding six couplings and one flush valve off on zone 2 and fifteen couplings and three flush valves off on zone 1.

\section{September}

Irrigation rates for September were planned for $5.08 \mathrm{~cm}$ per week on zone 1 and $2.54 \mathrm{~cm}$ per week on zone 2. During September, the system ran a total of 554 hours supplying zone 1 with $21.43 \mathrm{~cm}$ and zone 2 with $9.09 \mathrm{~cm}$ irrigation water.

Operations in September went well, essentially running the whole month as planned. The level and condition of the sand in the filters were checked and both were in good shape. The system was inspected for operation maintenance and the 2 inch flush valves were opened to flush out the lines.

It was noticed that the controller failed to shut down the system after 21 hours of operation. This problem, which initially Two Rivers, Inc. employees resolved, continued for the rest of the season; however, this occurrence was seen as a minor problem since the system would run for 
an extra 3 hours each day. The shut down failure was speculated to occur due to a power malfunction caused by the batteries in the controller becoming weak at the end of the season.

\section{October}

Irrigation rates for October were planned for $5.08 \mathrm{~cm}$ per week on zone 1 and $2.54 \mathrm{~cm}$ per week on zone 2. During October, the system ran a total of 218 hours supplying zone 1 with $7.26 \mathrm{~cm}$ and zone 2 with $5.53 \mathrm{~cm}$ of irrigation water.

Two minor water leaks occurred in the pumping plant over the course of several months. It was decided to continue operation and resolve the water leaks at the season end. However, on October 4, one of the leaks became too severe and caused the site glass on the backwash outlet to break. The system remained in shutdown mode for 17 days, due to incorrect equipment replacement and shipping delay. In addition to the leak and subsequent malfunction, the Murphy controller experienced problems and was replaced. The system ran for another week after the site glass repair before it was shut down to fix a leak in the pump discharge line prior to the filters.

\section{November}

Irrigation rates for the early part of November were planned for $5.08 \mathrm{~cm}$ per week on zone 1 and $2.54 \mathrm{~cm}$ per week on zone 2. During the first 10 days of November, the system ran a total of 162 hours supplying zone 1 with $4.92 \mathrm{~cm}$ and zone 2 with $3.20 \mathrm{~cm}$ of irrigation water.

After 10 days of operation in November, it was decided to shut down the system for the winter. Winterizing the system included placing stabilizer in the diesel fuel storage tank and operating the system for a few minutes, draining all water lines including pump and filters, and changing the oil and oil filter.

\section{Routine Maintenance}

Daily routine maintenance, performed by Two Rivers, Inc. employees, were conducted for oil level in crankcase, coolant level, fan belt tension, oil pressure and temperature, fuel/oil leaks, diesel fuel storage tank level, fence and building security, and battery and alternator condition. Total engine operating hours and total gallons of water pumped measured by the flow meter were recorded each day.

The oil and oil filter were changed approximately every 300 hours of operation. The air cleaner was also inspected periodically, and the level and condition of the sand in the filters was periodically checked.

It was determined that the 5-cm flush valves should be flushed biweekly for each zone, as well as checking for leaks from couplings blown apart, drip line flush valves that have come off, and damage due to animals

\subsubsection{Operation - Seasonal 2004}

The seasonal operation of the drip irrigation system began on May 3, 2004 and ended on November 22, 2004. A total of 139,304 cubic meters of irrigation water was applied during this time. The pumping plant totaled 2,087 hours of operation. During this time, approximately 67.1 $\mathrm{cm}$ of irrigation water was placed on zone 1 and $35.0 \mathrm{~cm}$ of irrigation water was placed on zone 2. During the months of May through November, the site received approximately $79.0 \mathrm{~cm}$ of 
rainfall. Figure 59 shows the monthly precipitation and precipitation plus irrigation water total applied to each zone.

\section{Precipitation, Precipitation plus Irrigation Totals for 2004 Growing Season}

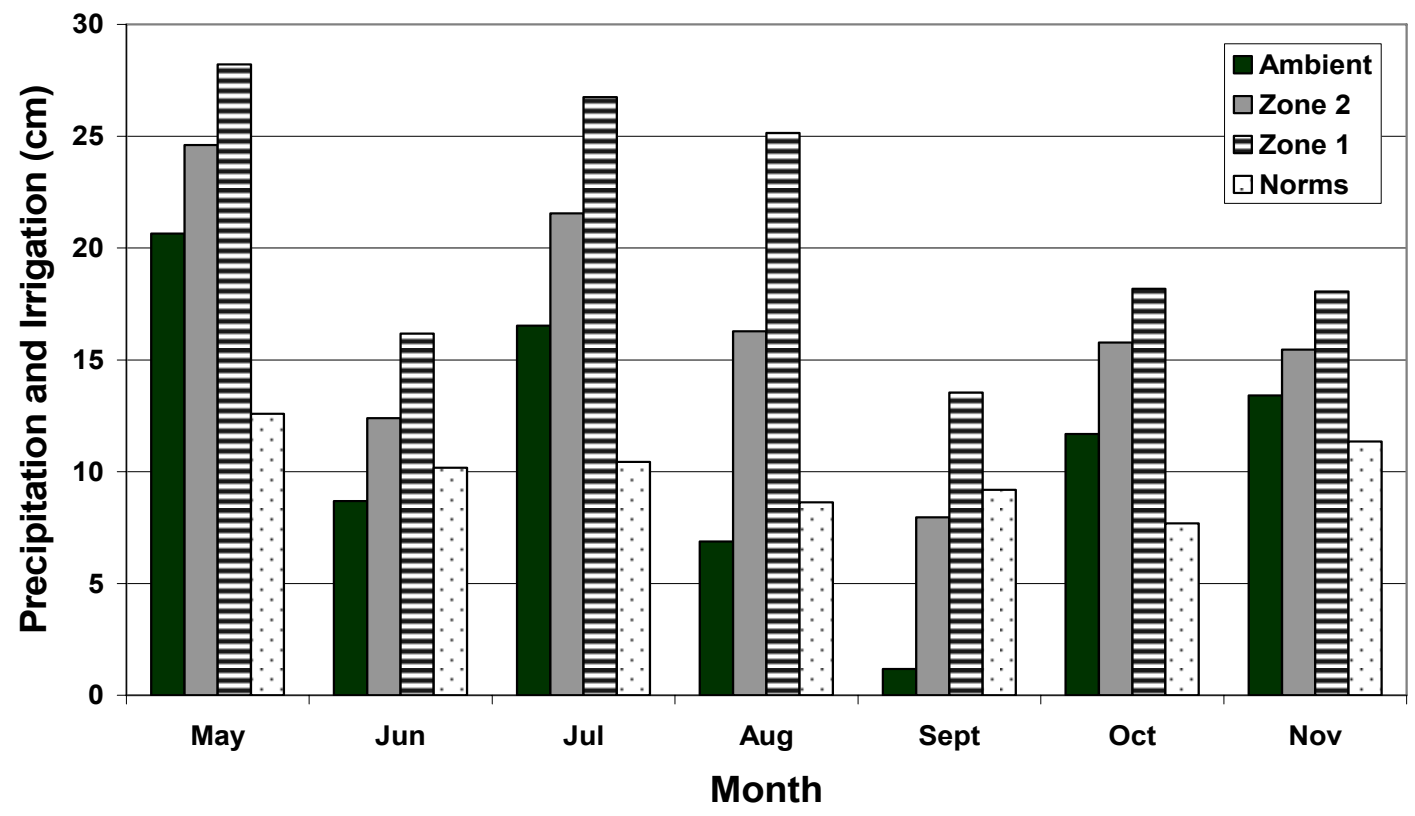

Figure 59. Precipitation and precipitation plus irrigation totals for the three water treatment levels used in the CCWESTRS study during 2004.

Operation of the drip irrigation system was similar to that of the 2003 season. Overall, less operational problems were encountered as compared to the previous season. The main operational problems occurred at start up in early May. Over the winter, wildlife had bitten into the driplines. Repairs were made to the driplines in about 140 places. Cold weather had also caused five of the fourteen 2" flush valves to crack. Other maintenance items required during start up included adding additional sand to the sand filters, replacing the batteries in the controller, and securing the float to the pump suction line in the ash pond.

\subsubsection{Operation - Seasonal 2005}

The seasonal operation of the drip irrigation system began in early May and ended in midOctober (five weeks earlier than in previous years) due to a complete pump engine failure. Due to the degree of senesce observed in both tree species and the assumed adequacy of the existing soil moisture levels, a decision was made to forego obtaining a new engine until the 2006 growing season. A total of 103,829 cubic meters of irrigation water was applied from May to October. During this time, approximately $51.0 \mathrm{~cm}$ of irrigation water was placed on zone 1 and $25.1 \mathrm{~cm}$ of irrigation water was placed on zone 2. During the months of May through November, the site received approximately $26.5 \mathrm{~cm}$ of rainfall. Figure 60 shows the monthly precipitation and precipitation plus irrigation water total applied to each zone. 


\section{Precipitation and Precipitation plus Irrigation Totals for each Water Treatment during the 2005 Growing Season}

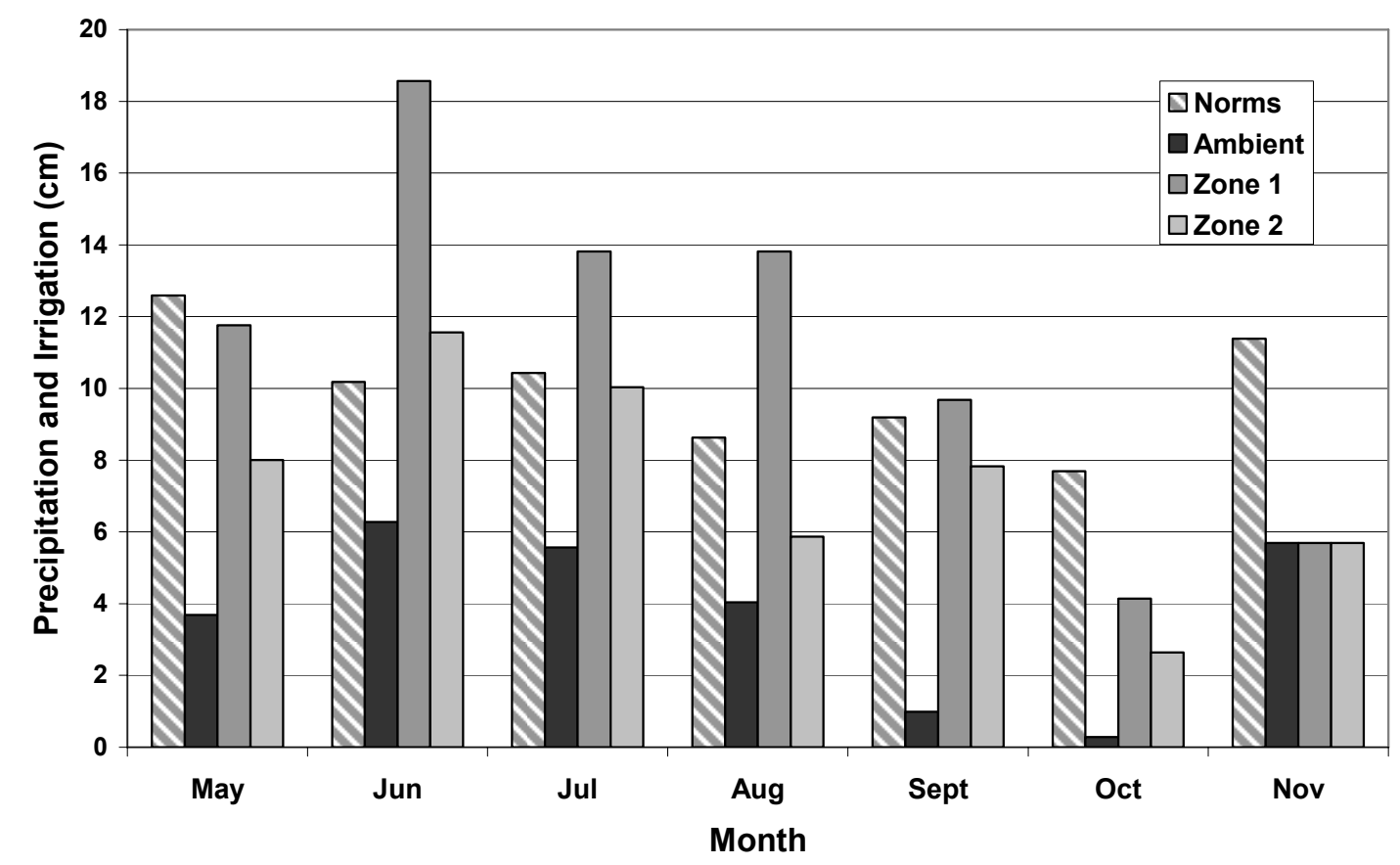

Figure 60. Precipitation and precipitation plus irrigation totals for the three water treatment levels used in the CCWESTRS study during 2005.

It is apparent from Figure 60, that 2005 was a much drier year for the herbaceous vegetation, as well as the sycamores and sweet gums. Precipitation totals during the 2005 growing season were $55.8 \%$ and $66.4 \%$ below those in 2003 and 2004, respectively. In addition, irrigation totals dropped by $28 \%$ from the previous two seasons.

\subsubsection{Surface and pore water monitoring}

Baseline water monitoring was performed in 2002 as described in Section 5.2.2 at the CCWESTRS site. Additional surface water samples were collected in September 2003, August 2004 and September 2005 at the locations described in Section 5.2.2, plus at two additional locations where surface runoff was flowing offsite. Ash pond water used for irrigation was routinely sampled at the ash pond discharge under the Paradise Fossil Plant NPDES permit.

An important aspect of the CCWESTRS project is to characterize the treatment capacity of the underlying soils and geologic materials in the unsaturated zone. Porous cup lysimeters were selected as the best method for collecting samples of unsaturated zone flow-through as the irrigation water migrated vertically through the soil column. Test plots were selected to evaluate soil pore moisture in zero, low, and high mulch levels, and zero, low, and high irrigation rates, resulting in 7 sampling locations. Locations of the lysimeters were selected based on the likelihood that surface water influence would be minimized at the site in order to test irrigation water treatment with minimal impact from infiltration. The type of trees should have minimal impact on the water treatment capacity of the soil during the first several years of growth, and 
that future sampling could be done in 5-10 years to determine if differences in water treatment ability exist between the tree species. The sampling ports of the lysimeters were set at two depths-approximately $1.5 \mathrm{~m}$ and $5.0 \mathrm{~m}$-in the mine spoil and above any permanent water table.

Model 1990F1L24 pressure vacuum lysimeters from Soil Moisture Equipment, Inc. were selected for installation at $1.5 \mathrm{~m}$ to $5.0 \mathrm{~m}$ depth. Prior to on-site installation, each lysimeter was pressure tested to insure all parts were working properly and that adequate vacuum seals could be established.

S\&ME, Inc. (Knoxville, TN) were contracted for lysimeter installation. On August 112003 , equipment and S\&ME personnel for this project were mobilized from Louisville, Tennessee. On August 12 through 14 2003, S\&ME completed the drilling and installation of fourteen lysimeters in accordance with TVA and the instrument manufactures' guidelines. The lysimeter pairs were installed to depths of either $1.5 \mathrm{~m}$ or $5 \mathrm{~m}$. Bore holes required for the lysimeter installations were completed by advancing $8.25-\mathrm{cm}$ (inside-diameter) hollow-stem augers with an all-terrain CME 550-X drill rig. Bore holes were advanced into the mine-spoil deposits approximately $30 \mathrm{~cm}$ beyond the desired lysimeter depths. The additional depth was completed to account for potential material cave-in during auger removal.

Upon completion of the drilling, loose material that caved into the hole was tamped with a weight attached to a rope. Bentonite pellets were used to fill the remainder of the over-drilled bore hole depth. As instructed by the manufactures' guidelines, silica flour slurry was mixed to the consistency of mortar. A tremie pipe used to convey the silica slurry was trimmed to the depth of the bore hole to insure proper deposition. The lysimeter was attached to a PVC riser was then lowered into the bore hole. The porous ceramic cup of the lysimeter was submerged into the silica slurry and stabilized for the remainder of the back-filling activities. The drill cuttings were sieved to remove rock with a particle size greater than $0.64 \mathrm{~cm}$ in diameter. The sieved soil was used as backfill material. Sieved material was tamped with the weight attached to the rope to prevent settling. Additional layer(s) of bentonite pellets and/or powder were used to isolate the lysimeter and prevent direct surface water intrusion. Boring/lysimeter installation logs have been completed for each of the lysimeters and are attached in Appendix 3.

Five sets of samples were collected from the lysimeters in August and September of 2003, April, July and August of 2004, and April and September Of 2005.. Collection was performed in accordance with EPA Region IV Environmental Investigations Standard Operating Procedures and Quality Assurance Manual. Sample analyses were not performed during this reporting period. The samples will be analyzed for constituents shown in Table 16.

$\begin{array}{lll}\text { Acidity } & \text { Filterable Residue } & \text { Selenium, Total } \\ \text { Alkalinity } & \text { Fluoride, Total } & \text { Silica Calculation } \\ \text { Aluminum, Total } & \text { Inorganic Carbon, Total } & \text { Silicon, Total } \\ \text { Ammonia as N } & \text { Iron, Total } & \text { Silicon, Total } \\ \text { Antimony, Total } & \text { Lead, Total } & \text { Silver, Total } \\ \text { Arsenic, Total } & \text { Magnesium, Total } & \text { Silver, Total } \\ \text { Barium, Total } & \text { Manganese, Total } & \text { Sodium, Total } \\ \text { Beryllium, Total } & \text { Mercury, Total } & \text { Strontium, Total } \\ \text { Boron, Total } & \text { Molybdenum, Total } & \text { Sulfate, Total } \\ \text { Ca \& Mg Calculated Hardness } & \text { Nickel, Total } & \text { Thallium, Total }\end{array}$




Cadmium, Total
Calcium, Total
Chemical Oxygen Demand
Chloride, Total
Chromium, Total
Cobalt, Total
Copper, Total

\author{
Nitrate-Nitrite as $\mathrm{N}$ \\ Nitrite as $\mathrm{N}$ \\ Non-Filterable Residue \\ Organic Carbon, Total \\ $\mathrm{pH}$ \\ Phosphorus, Total \\ Potassium, Total
}

\author{
Tin, Total \\ Titanium, Total \\ Total Kjeldahl Nitrogen \\ TSS Initial Weight \\ Vanadium, Total \\ Zinc, Total
}

Table 17. Constituents analyzed in lysimeter water samples.

Surface and soil pore water were examined for relationships as well as spatial and temporal patterns using SPSS ${ }^{\mathrm{TM}}$, Surfer ${ }^{\mathrm{TM}}$ and Arc/Info GIS software packages. The quality of process water varies and changes as it moves through the CCWESTERS site. The purpose of the following discuss is to address these changes, particularly in relation to metals and nutrients, as water moves from the irrigation source into the irrigation line for application to the surface and then into surface waters via runoff and groundwater flow. These changes are presented for selected analytes in Figures 61-67. All waters moving into, thorough and from the CCWESTRES site were below limits set by NPDES standards.

The irrigation source for the CCWESTRS site is the adjacent coal ash pond. The $\mathrm{pH}$ of the irrigation water is normally in the 7.5 to 8.4 range. The concentrations of antimony, arsenic, cadmium, cobalt, chromium, copper, lead, mercury, nickel, selenium, and thallium were consistently at or below the Minimum Detection Limit during the study. Prior to intake into the irrigation system, water in this pond has elevated levels of boron (mean $=4.7 \mathrm{mg} / \mathrm{l}$ ), sulfate $($ mean $=387.5 \mathrm{mg} / \mathrm{l})$ and magnesium $($ mean $=33.0 \mathrm{mg} / \mathrm{l})$. Levels of these constituents remain fairly constant as the water moves through the irrigation system, with only slight increases in sulfate and magnesium.

After on-site application as irrigation water and subsequent percolation through the FGD mulch and upper soil horizons, levels of nitrogen, iron, magnesium, and sulfate increase, while boron decreases. Leaching of constituents from the FGD mulch is evident when comparing groundwater and irrigation water samples. The $\mathrm{pH}$ of ground and surface water sample range from 6.8 to 7.5. Mean nitrogen levels increase from $0.55 \mathrm{mg} / \mathrm{l}$ in the ash pond, to groundwater levels of $3.3 \mathrm{mg} / \mathrm{l}$ at a 5 foot depth and $1.17 \mathrm{mg} / \mathrm{l}$ at the 15 foot level. Mean iron levels increase from $0.65 \mathrm{mg} / \mathrm{l}$ in the ash pond to $27.22 \mathrm{mg} / \mathrm{l}$ in the groundwater at 5 feet and $4.74 \mathrm{mg} / \mathrm{l}$ at the 15 foot depth. Mean magnesium levels increase from $33.0 \mathrm{mg} / \mathrm{l}$ in the ash pond to $243.81 \mathrm{mg} / \mathrm{l}$ at the 5 foot depth and $303.26 \mathrm{mg} / \mathrm{l}$ at the 15 foot depth. Sulfate levels also increase upon movement through the FGD mulch, with mean levels increasing from $387.5 \mathrm{mg} / \mathrm{l}$ in the ash pond to $2,687.24 \mathrm{mg} / \mathrm{l}$ at the 5 foot depth and $3,167.74 \mathrm{mg} / \mathrm{l}$ at the 15 foot depth. Boron levels exhibit a reverse trend, with mean levels decreasing from $4.7 \mathrm{mg} / \mathrm{l}$ in the ash pond to $0.65 \mathrm{mg} / \mathrm{l}$ at the 5 foot depth and $0.47 \mathrm{mg} / \mathrm{l}$ at the 15 foot depth. This indicates that boron, at least initially, is being removed from the water and is potentially accumulating in the FGD mulch and upper horizons soil horizons.

Surface and groundwater flow from the CCWESTRS site is towards Boot Pond and Pooh Bear Pond. Water samples from these ponds are designated as "Surface Water" in the following graphs. Boron levels in the ponds are similar to levels found in the ash pond (irrigation source) and are much higher than groundwater levels. This may indicate the existence of surface runoff of the irrigation water or shallow lateral movement (via the upper layers of mulch and soil) of boron into the ponds. Iron and manganese levels in the ponds are similar to levels found in the 
irrigation water and are lower than groundwater levels. Surface water levels of magnesium, sulfate, ammonia and calcium are roughly midway between irrigation source and groundwater levels.

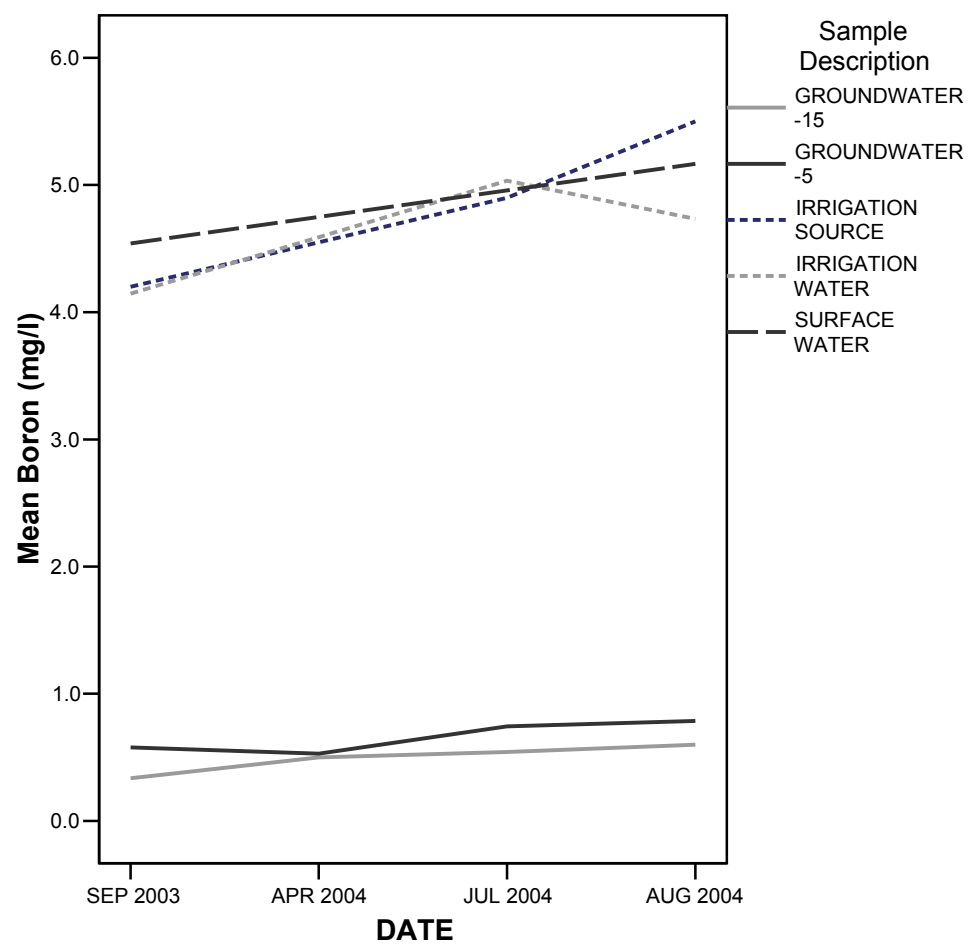

Figure 61. Boron in surface and pore waters from April 2003 - August 2004.

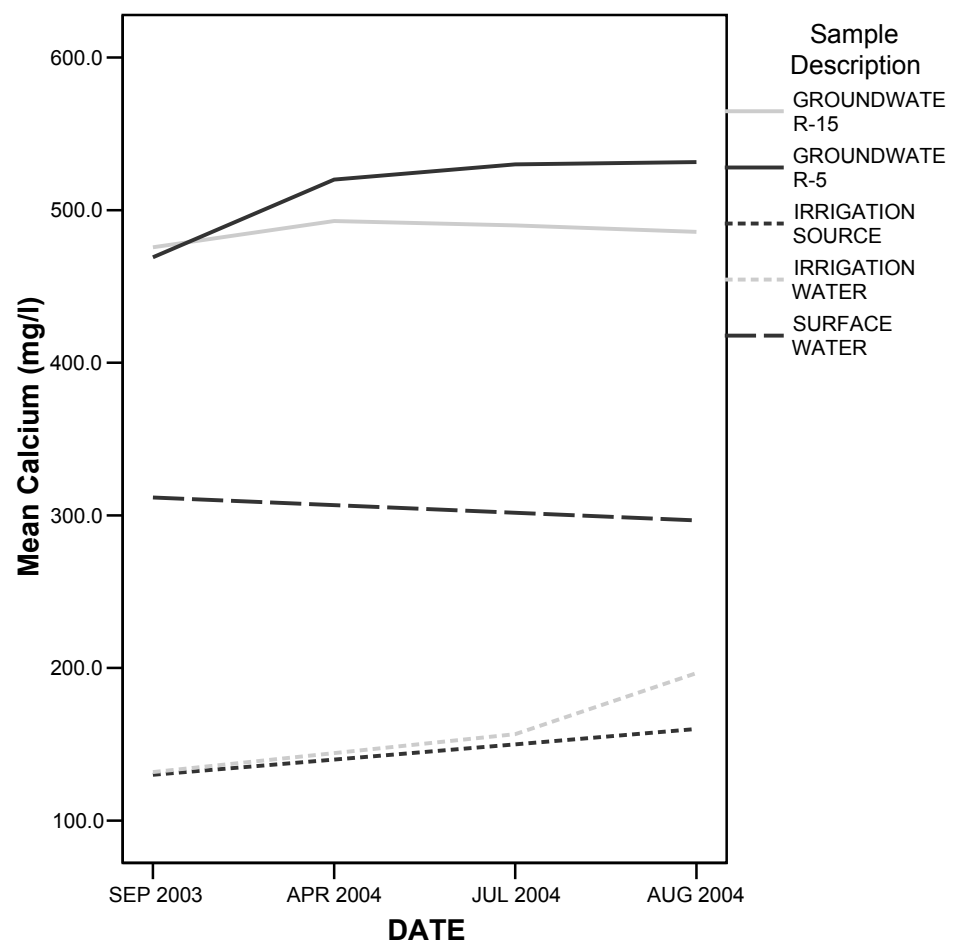

Figure 62. Calcium in surface and pore waters from April 2003 - August 2004. 


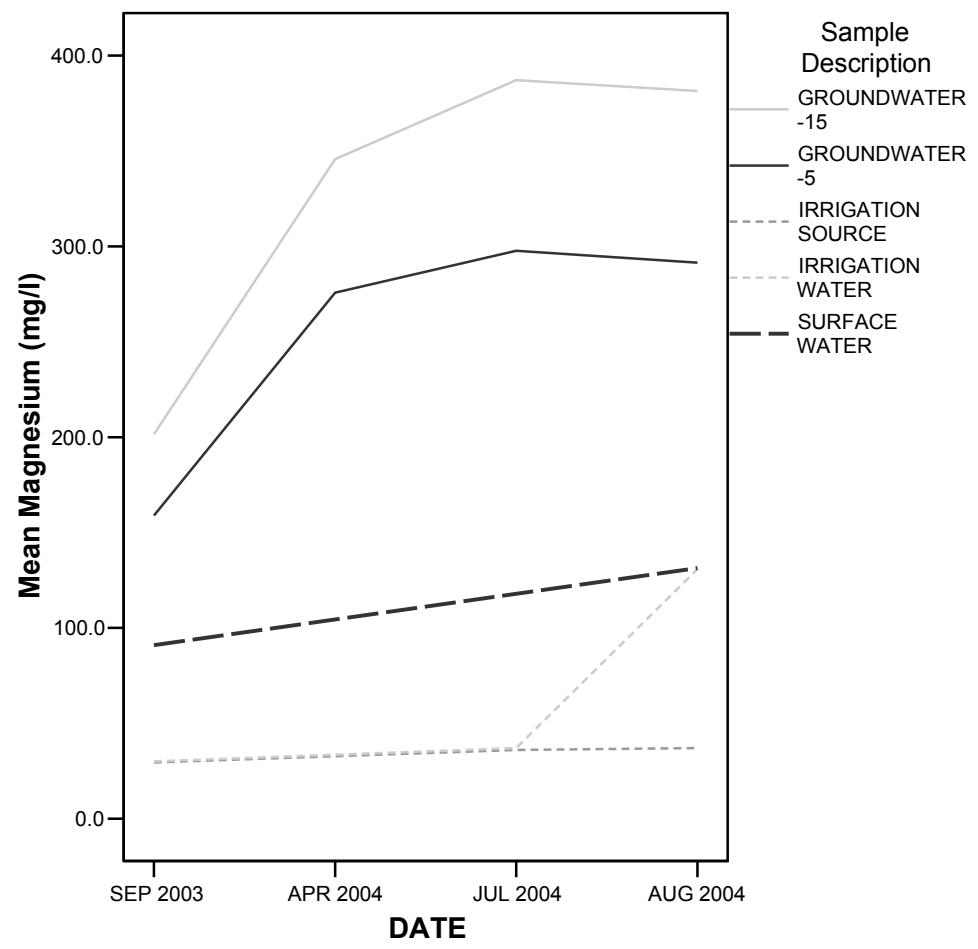

Figure 63. Magnesium in surface and pore waters from April 2003 - August 2004.

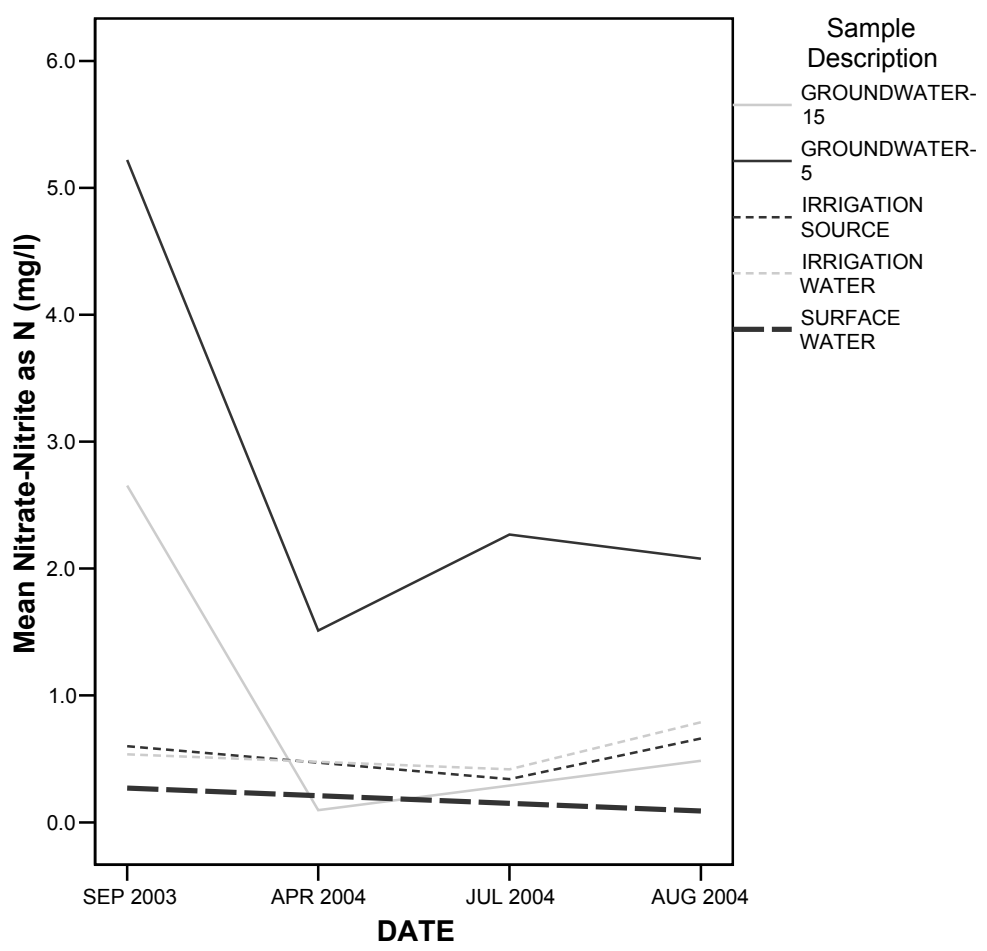

Figure 64. Nitrogen (nitrate-nitrite) in surface and pore waters from April 2003 - August 2004. 


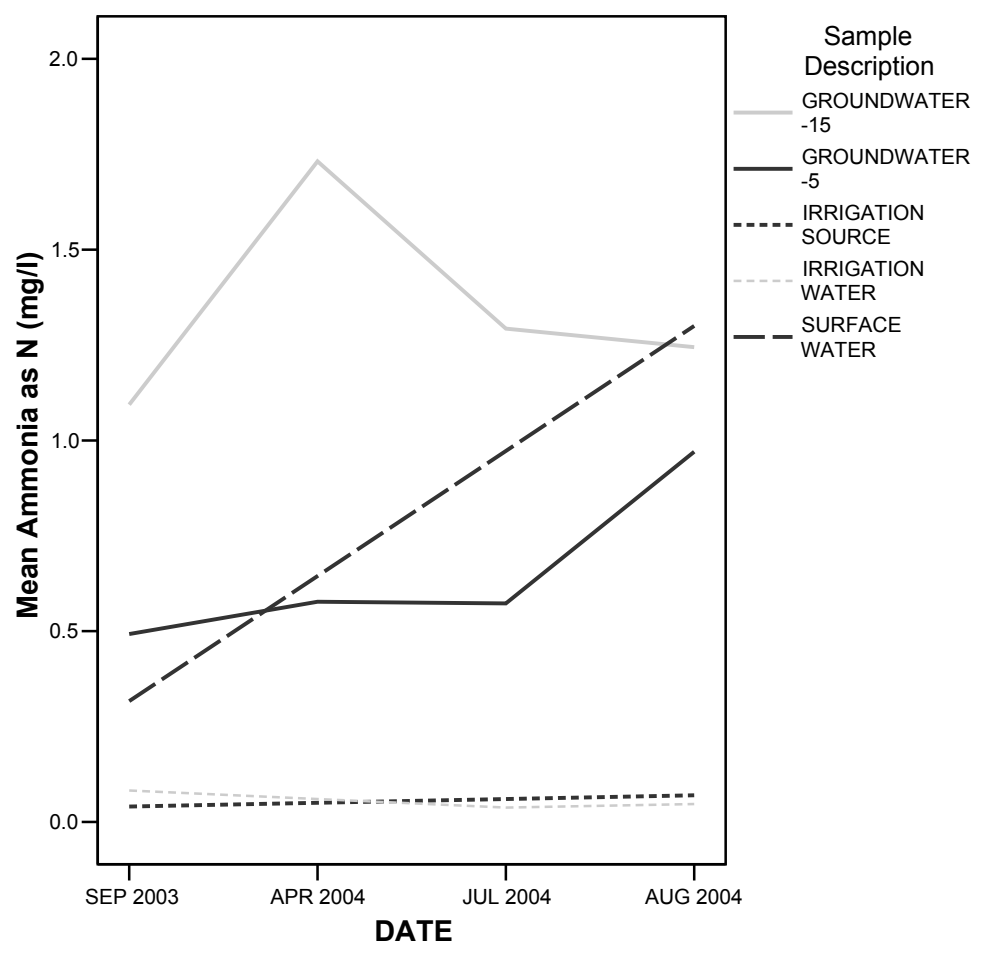

Figure 65. Nitrogen (ammonia) in surface and pore waters from April 2003 - August 2004.

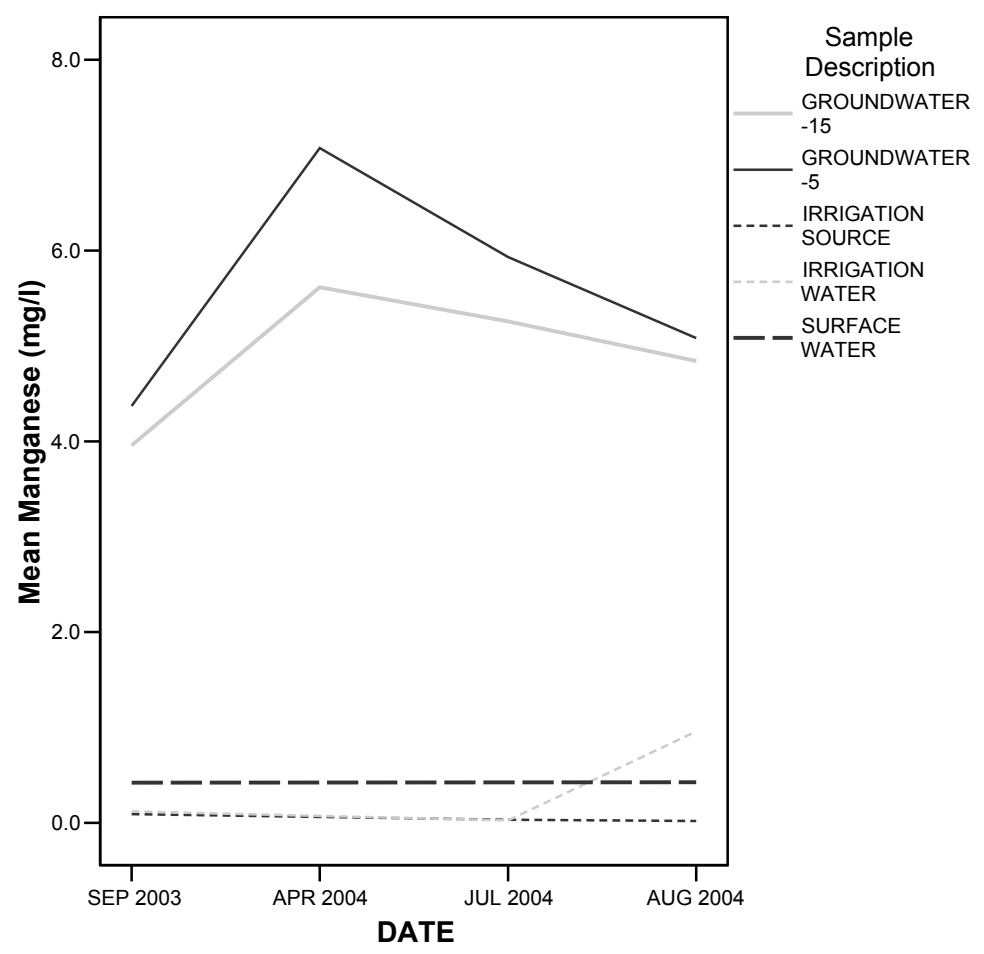

Figure 66. Manganese in surface and pore waters from April 2003 - August 2004. 


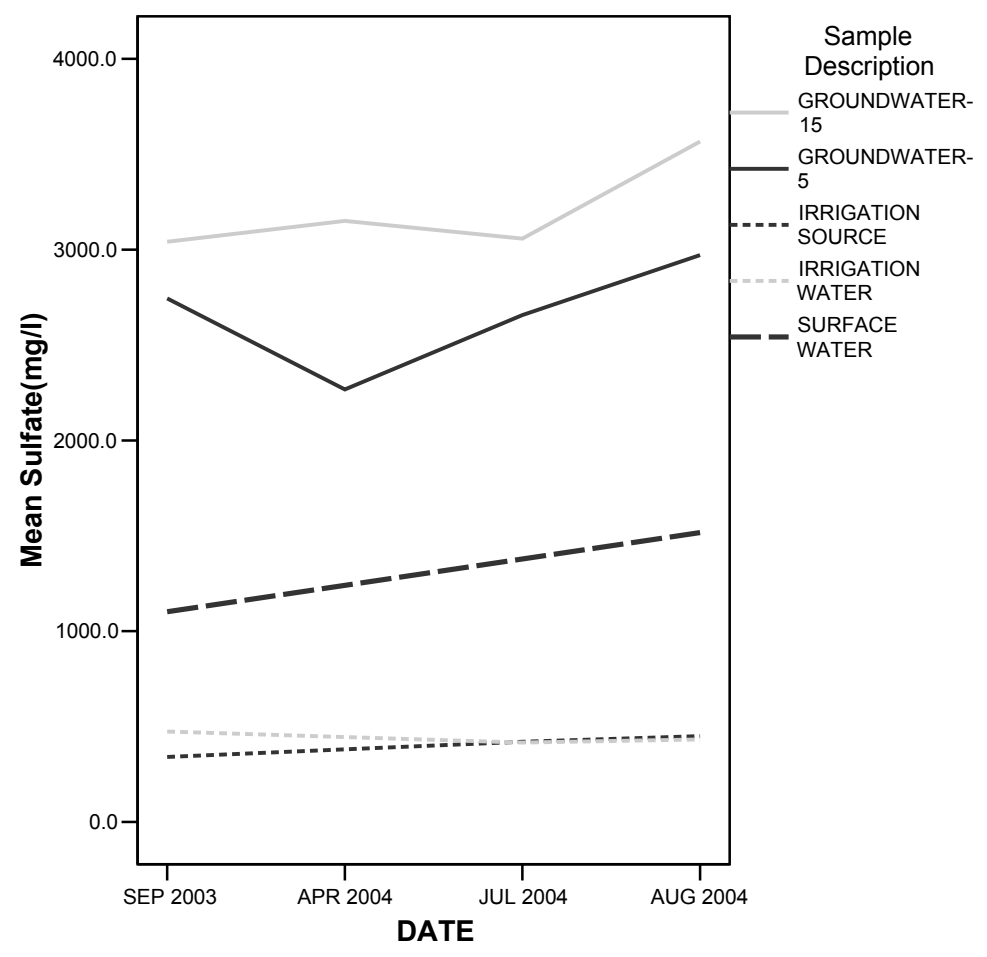

Figure 67. Sulfate in surface and pore waters from April 2003 - August 2004.

\subsection{Meteorology}

\subsubsection{Precipitation and Air Temperature}

Monthly precipitation and temperature were monitored at the PAF meteorological station, approximately $1 \mathrm{~km}$ from the CCWESTRS site in 2002. Monthly precipitation at the CCWESTRS site was higher during seedling establishment, while the summer months experienced below normal precipitation from May through early August. However, beginning in late AugustNovember weather patterns produced higher that normal precipitation. Figure 68 shows precipitation from January 2002 to October 2002, and includes normal precipitation values as a comparison. The project site was also equipped with two Qualimetric Tipping Bucket rain gages in order to ensure that the remote Paradise meteorological data was representative of the CCWESTRS site data. Figure 69 shows that there is good agreement with rainfall from the two sources of data.

Temperatures for the year averaged $24.9^{\circ} \mathrm{C}$, which was characterized by the National Climatic Data Center (www.ncdc.noaa.gov/oa/ncdc.html) as "much above normal". Temperatures for June $\left(23.6^{\circ} \mathrm{C}\right)$, July $\left(23.7^{\circ} \mathrm{C}\right)$, August $\left(25.3^{\circ} \mathrm{C}\right)$, and September $\left(22.2^{\circ} \mathrm{C}\right)$ were all above normal. 


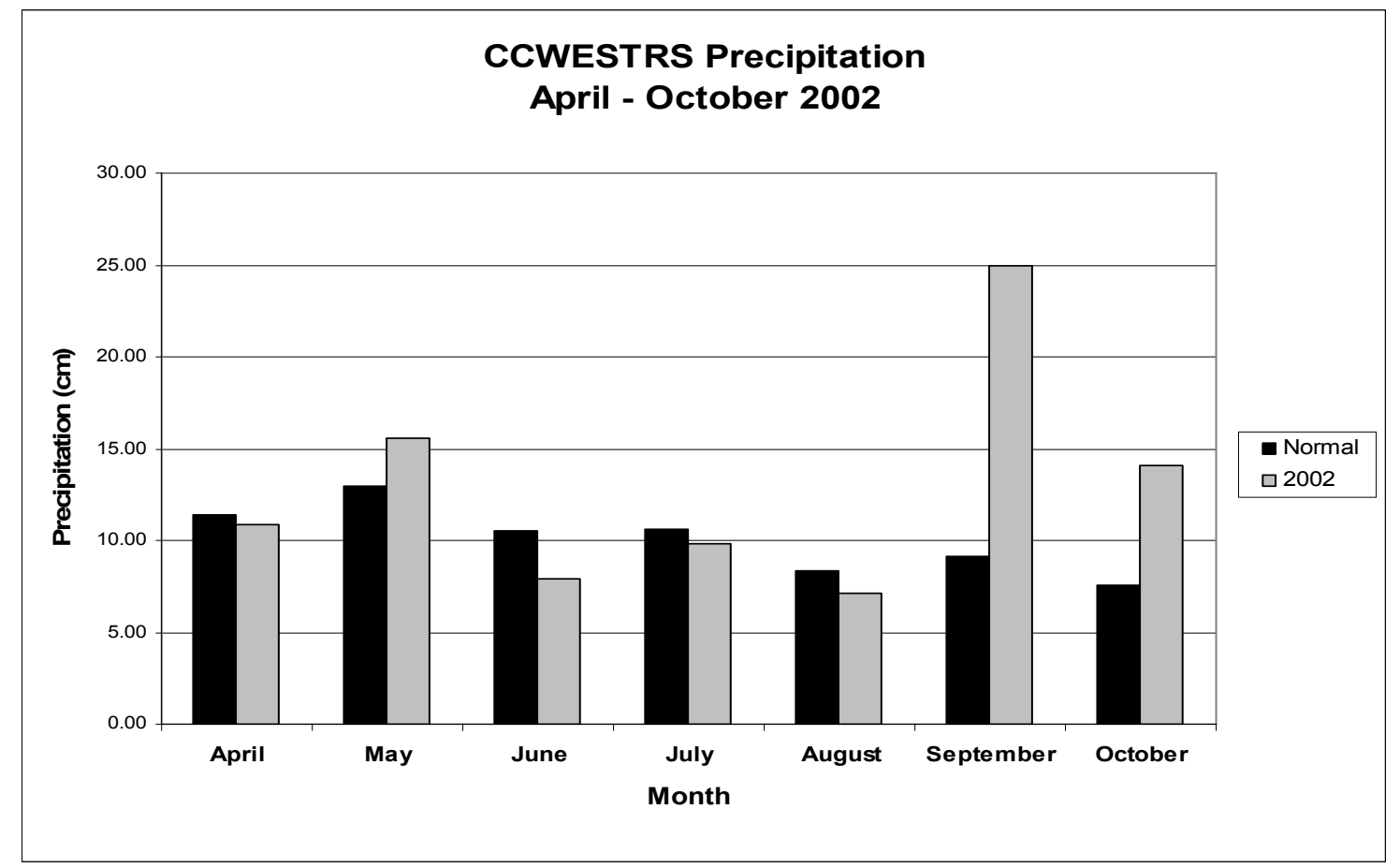

Figure 68. January - October 2002 CCWESTRS Precipitation Totals with Regional Norms.

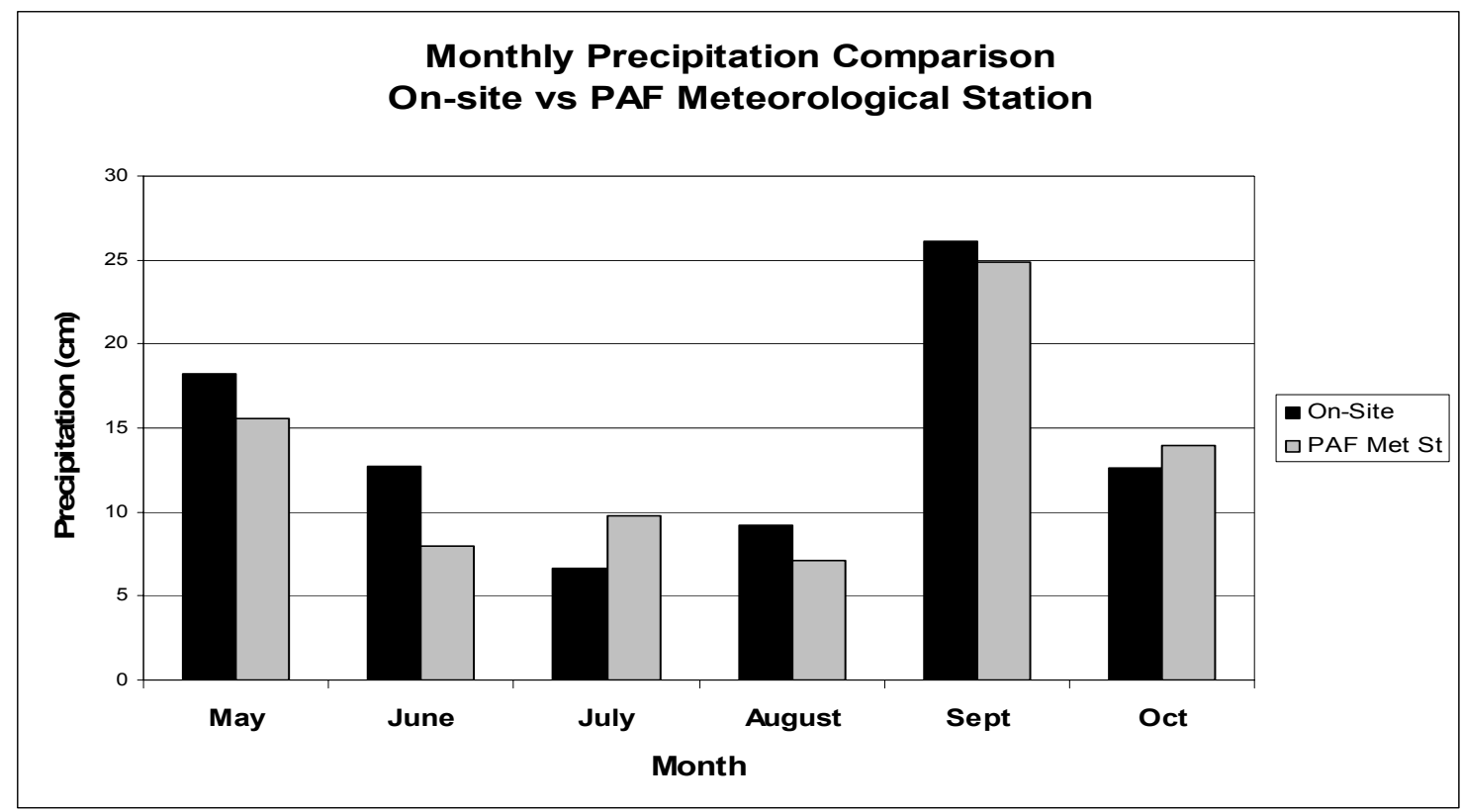

Figure 69. Comparison of rainfall data May to October 2002 collected at Paradise meteorological station and at CCWESTRS site.

Soil moisture measurements were obtained in early August 2002, when daily high temperatures were maintaining above $33^{\circ} \mathrm{C}$. Soil surface temperatures in the very dark FGD mulch were in excess of air temperatures (they were hot to the touch), but no actual subsurface soil temperature readings were obtained. Early August data indicated that the soil moisture in the zero mulch and mulched test plots was below the wilting point of about $9 \%$. During this same 
period, soil moisture in the FGD mulch exceeded the wilting point. Additional soil moisture measurements in August and October, however, indicated that soil moisture was adequate. Table 17 shows the results of the soil moisture measurements.

\begin{tabular}{|l|ll|l|l|l|l|}
\hline Date & $\begin{array}{l}\text { \% Soil Moisture (zero } \\
\text { mulch) }\end{array}$ & $\begin{array}{l}\text { \% Moisture in } \\
\text { mulch }\end{array}$ & $\begin{array}{l}\text { \% soil moisture under } \\
\text { mulch }\end{array}$ \\
\hline $8 / 7$ & $8.31(6.97-9.94)$ & & 18.15 & 9.14 & \\
\hline $8 / 22$ & 16.17 & 40.97 & 13.26 & \\
\hline $10 / 22$ & 17.58 & 42.96 & 16.77 & \\
\hline
\end{tabular}

Table 18. Results of soil moisture measurements.

In 2003, monthly precipitation and temperature were only monitored at the PAF meteorological station, approximately $1 \mathrm{~km}$ from the CCWESTRS site. This was done based on results from comparative studies during 2002 between on-site instrumentation and data from the meteorological station that indicated the meteorological station data accurately reflected conditions at the site. Supporting regional meteorological data was also available for many surrounding locations through various National Oceanic and Atmospheric Administration (NOAA) web-sites (http://lwf.ncdc.noaa.gov/oa/climate/research/2003/weekly.html). Monthly precipitation data from the PAF meteorological station indicated that the CCWESTRS site had experiencing below normal precipitation for much of the time since the initiation of the study (Figure 70). The 2002 growing season (spring and summer) precipitation was above normal, but most of the precipitation in the summer ended rather early and continued to be below normal for the remainder of 2002 and all of 2003 (quarterly basis).

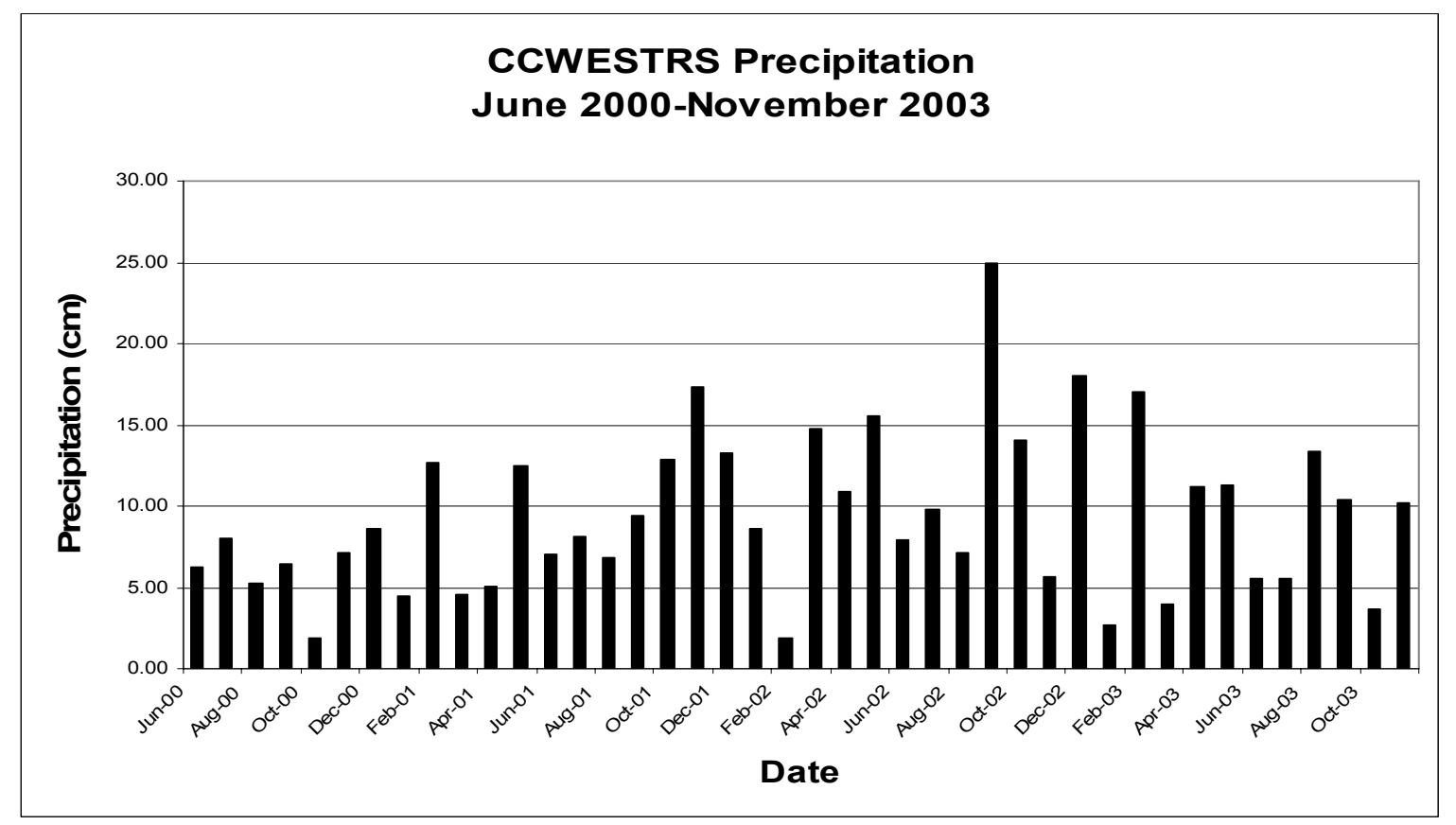

Figure 70. Quarterly precipitation amounts at the CCWESTRS site from July 2000 through November 2003.

Monthly precipitation amounts were below the long-term mean for the site during five of the seven months designated as the 2003 growing season. The 2003 growing season was extended into November due to the unseasonably high ambient air temperatures. (Figure 71). 


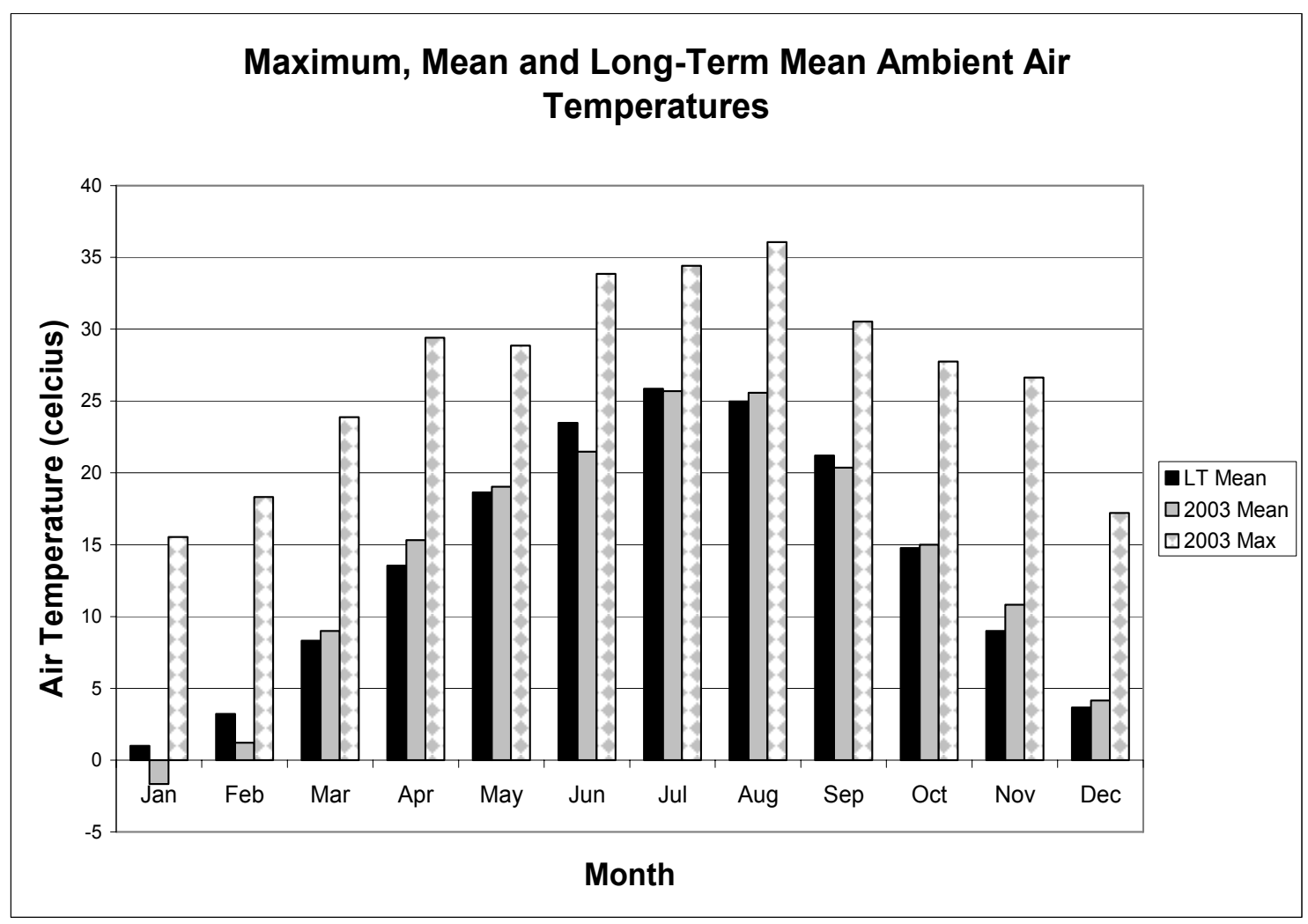

Figure 71. Maximum, mean, and long-term mean regional ambient air temperatures for the CCWESTRS site. Data recorded at Paducah, KY by NOAA.

Ambient precipitation was augmented with two levels of irrigation on $2 / 3$ of the study plots during the spring and summer of 2003 (Figure 58 Section 9.4.1.2). Precipitation plus irrigation amounts during May, June, and October were near to long-term means for the same time periods. Changes in irrigation rates for the months of July to September resulted in greater application rates. During July and October, the high irrigation treatment was approximately double normal precipitation, while the low irrigation approximated normal. During August and September, high irrigation more than tripled normal inputs, while low irrigation more than doubled them.

In 2004, precipitation patterns differed from those seen in 2003 with higher amounts falling in the spring and fall. Overall, total precipitation during the 2004 growing season dropped by 19 $\mathrm{cm}$ over the preceding year. This deficit precipitation pattern extended into 2005 and resulted in the lowest precipitation totals seen during the study (Figure 72). 


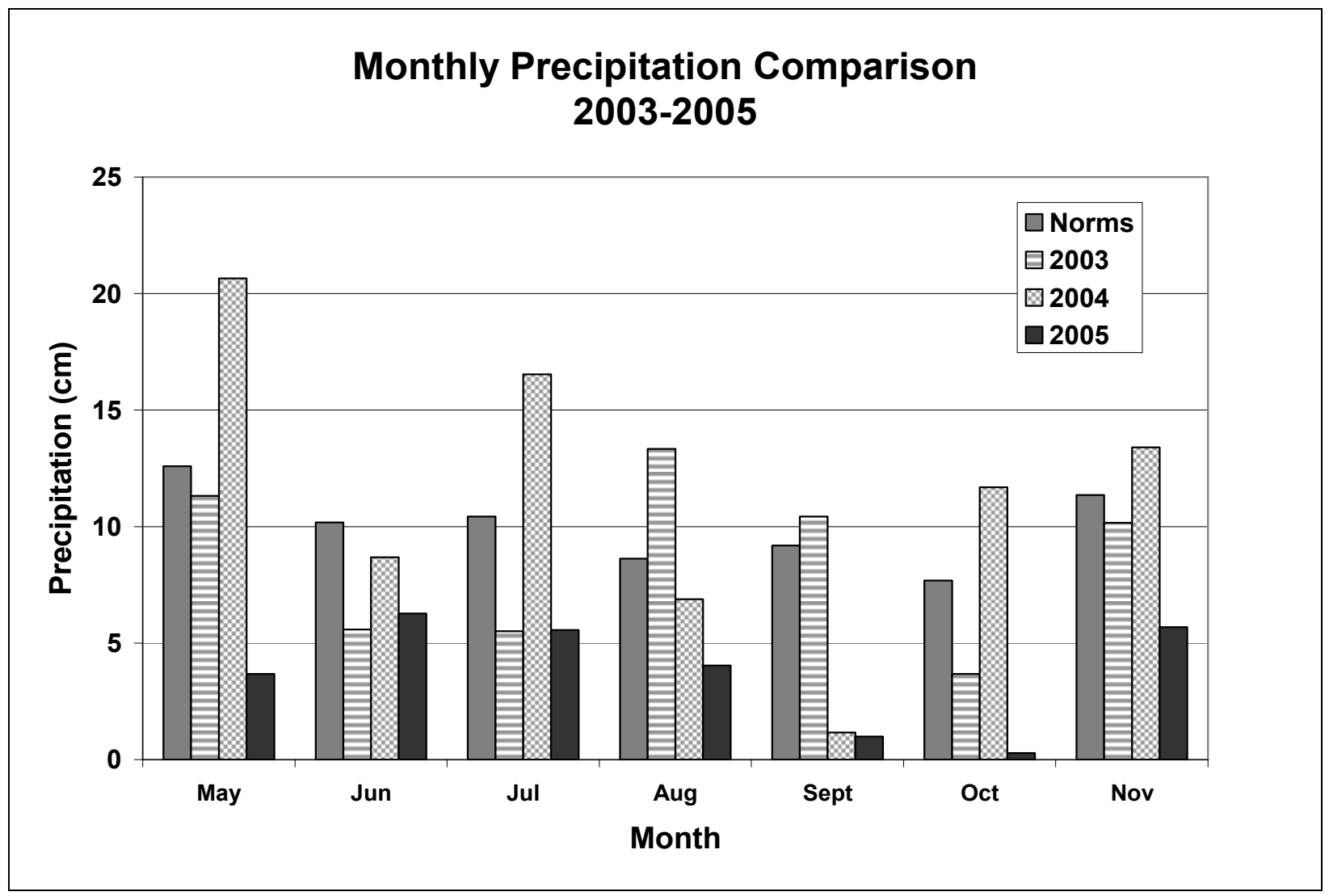

Figure 72. Monthly precipitation comparison at the CCWESTRS site for 2003-2005.

\subsubsection{Wind Speed}

The ability of a wind to continually sweep away moisture vapor from a wet surface (soil or plant leaf) is well documented. The drying effect of even a gentle wind is noticeable, but the capacity of high winds (especially under a steep vapor-pressure gradient) to enhance evaporation from both plants and soils is tremendous. Available regional meteorological data for the area encompassing the CCWESTRS study site (through National Oceanic and Atmospheric Administration (NOAA) web-sites) was questioned as being truly reflective of wind conditions encountered at the site. A check of long-term wind averages for Paducah, KY would indicate average wind speed to be less than $10 \mathrm{MPH}$ during a normal growing season, with wind gusts reaching a high as $35-50 \mathrm{MPH}$. Therefore, a WatchDog Model 550 Weather Station was installed at the site in late 2004 to monitor wind speed, relative humidity and air temperature.

The wind speeds monitored by the WatchDog weather station during the 2005 growing season are found in Figure 73. Although the daily mean wind speed might be significantly different between surrounding locations (data not shown), the monthly mean wind speed data for the CCWESTRS site agrees well with regional data (Table 19). 


\section{Wind Speed Statistics for the CCWESTRS Site 2005 Growing Season}

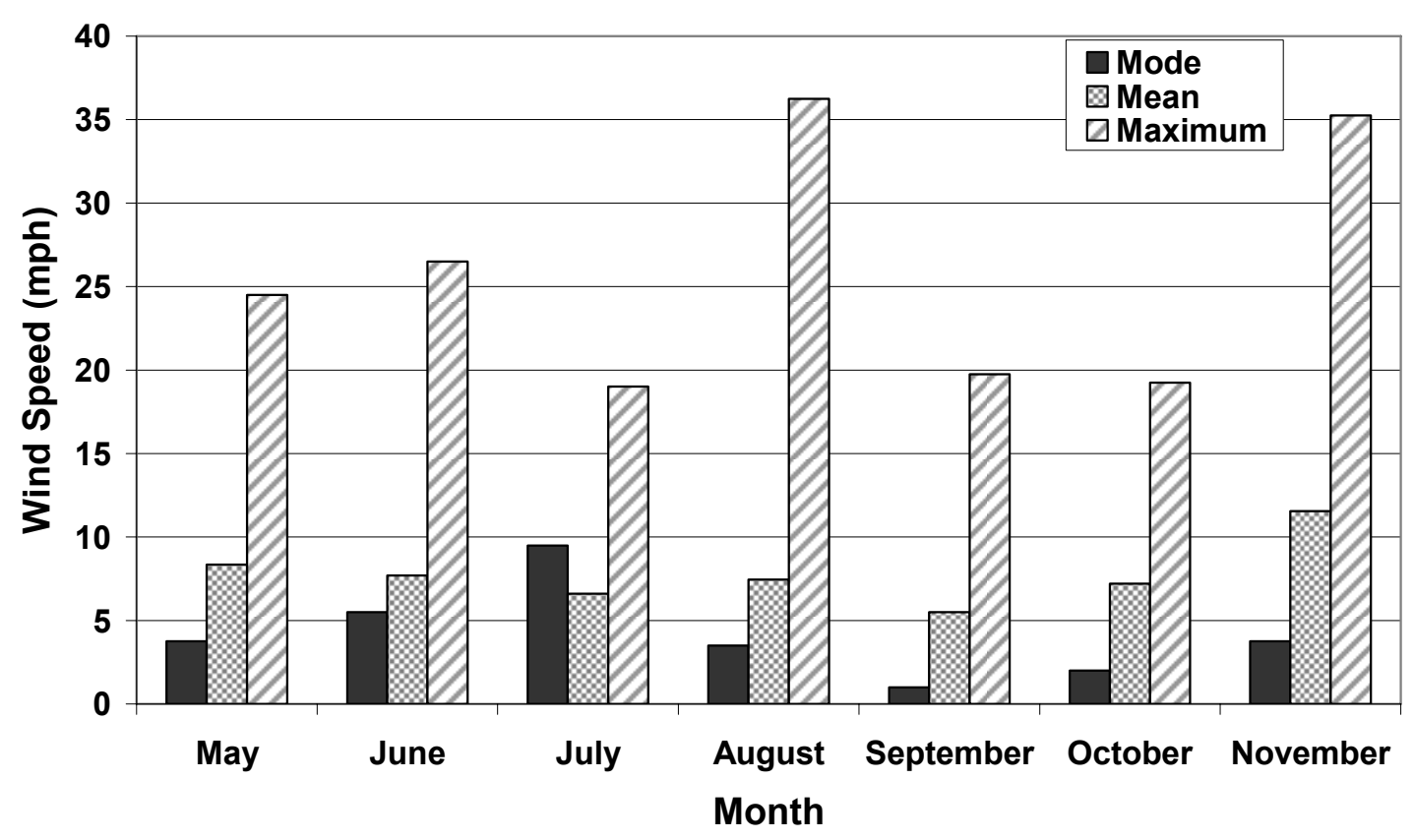

Figure 73. Wind speed statistics for the CCWESTRS site during the 2005 growing season.

\begin{tabular}{|c|c|c|c|c|c|c|c|}
\hline LOCATION & MAY & JUN & JUL & AUG & SEP & OCT & NOV \\
\hline$\overline{\text { HUNTSVILLE }}$, AL & $\overline{7.9}$ & $\overline{6.8}$ & $\overline{6}$ & $\overline{5.8}$ & $\overline{6.7}$ & $\overline{7.2}$ & $\overline{8.1}$ \\
\hline LITTLE ROCK, AR & 9 & 7.6 & 7.1 & 6.7 & 6.3 & 6.6 & 6.8 \\
\hline CAIRO, IL & 7.5 & 6.6 & 6.3 & 7.1 & 7.4 & 9 & 9.3 \\
\hline EVANSVILLE, IN & 7.9 & 7.1 & 6.2 & 5.8 & 6.4 & 6.9 & 8.7 \\
\hline PADUCAH, KY & 7.3 & 6.1 & 5.7 & 5.1 & 5.5 & 6.4 & 8.2 \\
\hline NASHVILLE, TN & 7.6 & 7 & 6.5 & 6.2 & 6.5 & 6.8 & 8.4 \\
\hline REGIONAL MEAN & 7.9 & 6.9 & 6.3 & 6.1 & 6.5 & 7.2 & 8.3 \\
\hline CCWESTRS & 8.3 & 7.7 & 6.6 & 7.4 & 5.5 & 7.2 & 11.5 \\
\hline
\end{tabular}

Table 19. Regional wind speed comparison.

\subsection{FGD Mulch Depth Field Study Monitoring}

The FGD Mulch Depth Field Study sub-plots were surveyed in April and November of 2002, with noted changes in regards to fescue suppression and vegetation colonization. Although one replicate of the sub-plots was lost to the construction of the main CCWESTRS study, the remaining three sets were surveyed. Within each sub-plot, visual estimates of percent coverage were determined for fescue, moss and other invading vegetation and FGD mulch. Possible 
changes to FGD mulch depth over time were evaluated on a sub-set of plots using a push probe to sample sub-plot interiors and original height markers (on initial PVC stakes) to evaluate subplot edges.

Although the average depth of FGD mulch along sub-plot edges may have been reduced (erosion) by as much as $64 \%$ (minimum of $42 \%$ ) since their establishment, the interiors of all sub-plots measured had changed little (mean $=5.2 \%$ ). In March 2001, fescue had only penetrated the FGD mulch in the 5- and 10-cm applications, limited to the sub-plot margins only. By November 2002, fescue had penetrated most of the interior of the 5- and 10-cm sub-plots and now comprises as much as $40 \%$ of the $15-\mathrm{cm}$ application (primarily along the margins). Only the $20-\mathrm{cm}$ applications still adequately suppress fescue (Table 20); however, several vegetative species colonize the FGD mulch in all sub-plots. The majority of coverage is moss with some species of the grass family (primarily fescue and panicum) beginning to seed directly into the FGD mulch itself. Thistle (and a limited number of other species belonging to the Asteraceae family) has been able to penetrate the FGD mulch in a few sub-plots. The immediate benefits of this colonization will mean reduced erosion, but will also produce microclimates for additional flora and fauna. Probable long-term effects will include both physical and chemical changes to the FGD mulch.

\begin{tabular}{|l|l|l|l|}
\hline $\begin{array}{l}\text { FGD Application } \\
\text { Rate } \mathbf{( c m )}\end{array}$ & Fescue & $\begin{array}{l}\text { Moss/Other } \\
\text { Vegetation }\end{array}$ & FGD Mulch \\
\hline 5 & 56 & 28 & 16 \\
\hline 10 & 27 & 16 & 57 \\
\hline 15 & 40 & 23 & 37 \\
\hline 20 & 2 & 52 & 46 \\
\hline
\end{tabular}

Table 20. Average coverage (\% of total surface within application group) of fescue, moss/ other vegetation and FGD Mulch.

By late summer 2002, there was an obvious difference in the vigor and overall health of the vegetation (primarily fescue) in and around the study plots. Fescue growing in the control plots (and the surrounding open areas) appeared stressed in comparison to vegetation in and around the FGD mulched plots. Samples were taken and submitted for analysis. Results indicated that plants in the control plots were deficient in N. On the other hand, fescue growing within the FGD mulch, or on the edge of it, was only considered "low" in nitrogen. This difference lends further credence to the observations made in the main study where the FGD mulch was considered to be a possible source of $\mathrm{N}$. It is, however, important to keep in mind that the fescue growing in or near the sludge was receiving more water than that growing in the open sections of the plots. The latter had already started to senesce, with about half of it having turned brown; meanwhile most of the fescue near the sludge was still green and growing.

The FGD Mulch Depth Field Study sub-plots were resurveyed in November 2003. Visual estimates of percent coverage were determined for fescue, moss, other invading vegetation and FGD mulch in each sub-plot. Possible changes to FGD mulch depth over time were qualitatively evaluated. 


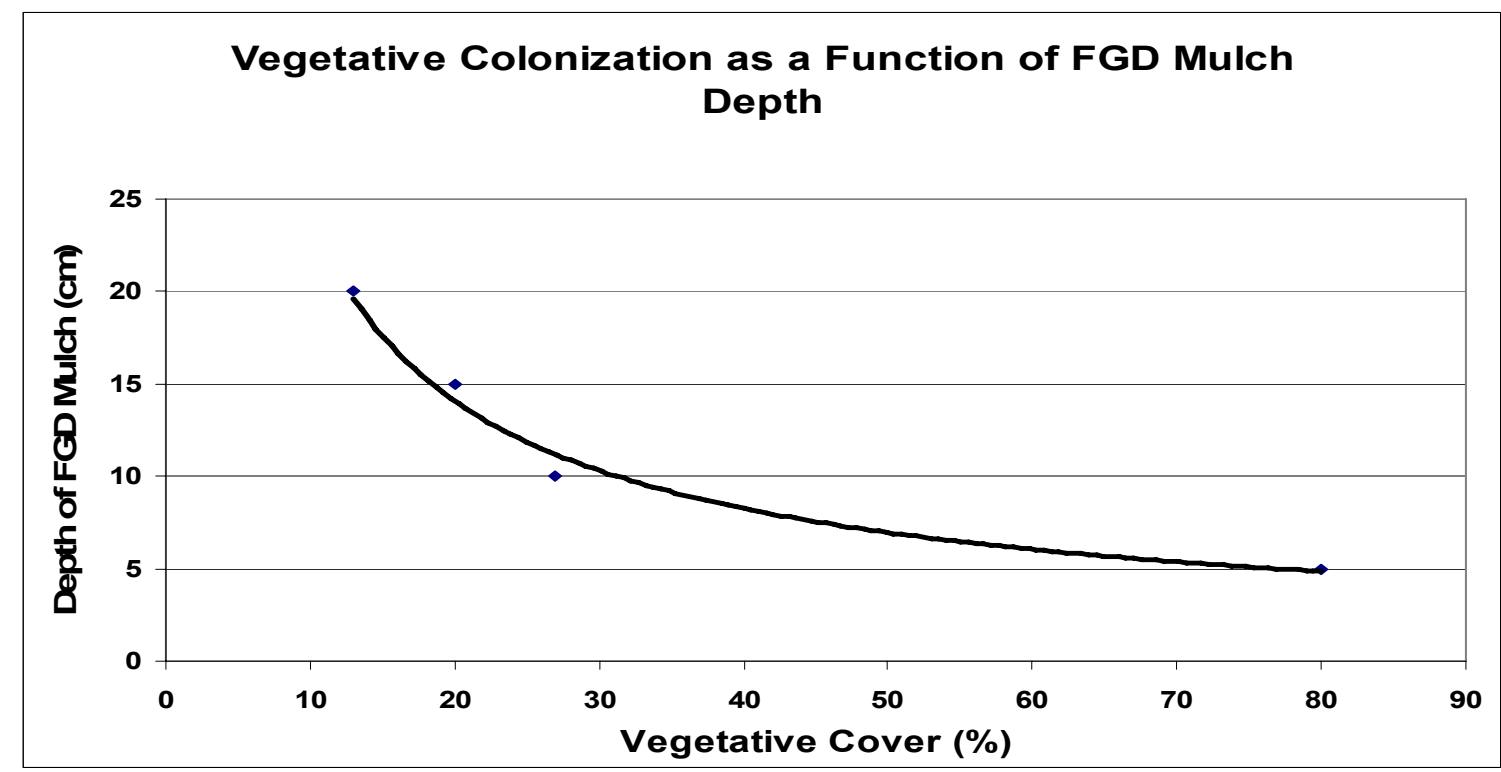

Figure 74. Percent vegetative cover on FGD Depth Study sub-plots as a function of FGD mulch depth. Values represent a mean of three replications for each treatment.

Compared to changes observed between 2001 and 2002, vegetative colonization and FGD settling appear to have reached equilibrium with site conditions by 2003. Fescue, milkweed, thistle and panicum continue to cover most of the sub-plots with depths of $15 \mathrm{~cm}$ or less (Figure 74) either by growing through the FGD mulch or directly seeding into the surface.

As noticed in the sub-plots in 2002, a species of moss continues to colonize the surface of the FGD mulch (Figure 75). This same condition has been noticed on FGD mulch surfaces in the main study, but not to the extent noticed here. These differences may be more closely related to micro-site differences since most of the main study FGD surfaces are exposed to more sun and wind. 


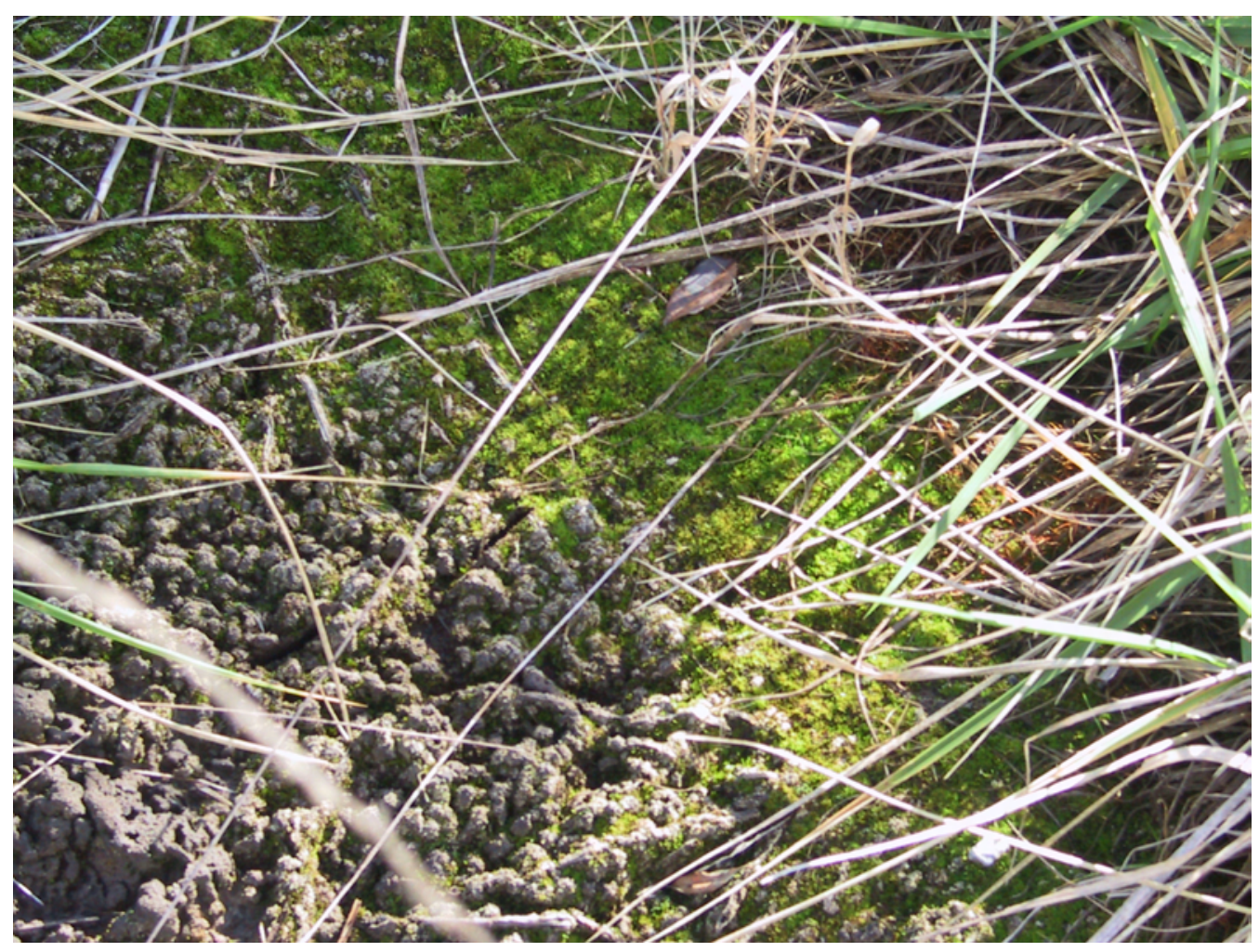

Figure 75. Colonization of moss species on surfaces of FGD mulch

By 2004, the moss had covered practically the entire FGD surface in all plots. The stagnation in growth of the higher order plants that had been observed the year before had ended and was probably due to the more favorable precipitation patterns in 2004 (see Figure 72, section 9.5 Meteorology). Vegetation (primarily fescue) had covered greater than $90 \%$ of the surface in the sub-plots with $5 \mathrm{~cm}$ of FGD material, while approximately $50 \%$ of the 10,15 and $20 \mathrm{~cm}$ subplots were covered (Figure 76). The obvious reduction in surface area coverage between years 2002 and 2003 may be explained by 1) the qualitative (not quantitative) nature of our sampling methodology, 2) the limited precipitation experienced during the summer of 2003 and 3 ) the droughty conditions that may develop within the FGD materials itself. In the sub-plots with the shallow FGD layer, plant roots are almost exclusively in the underlying soil which would have better soil moisture availability. In the deeper mulched sub-plots, many roots (especially those from plants that have seeded directly into the mulch) will be drawing their moisture from within the mulch itself. Under drought conditions, this available moisture would quickly become limited. 


\section{Percentage of Sub-Plot Surface Covered by Vegetation}

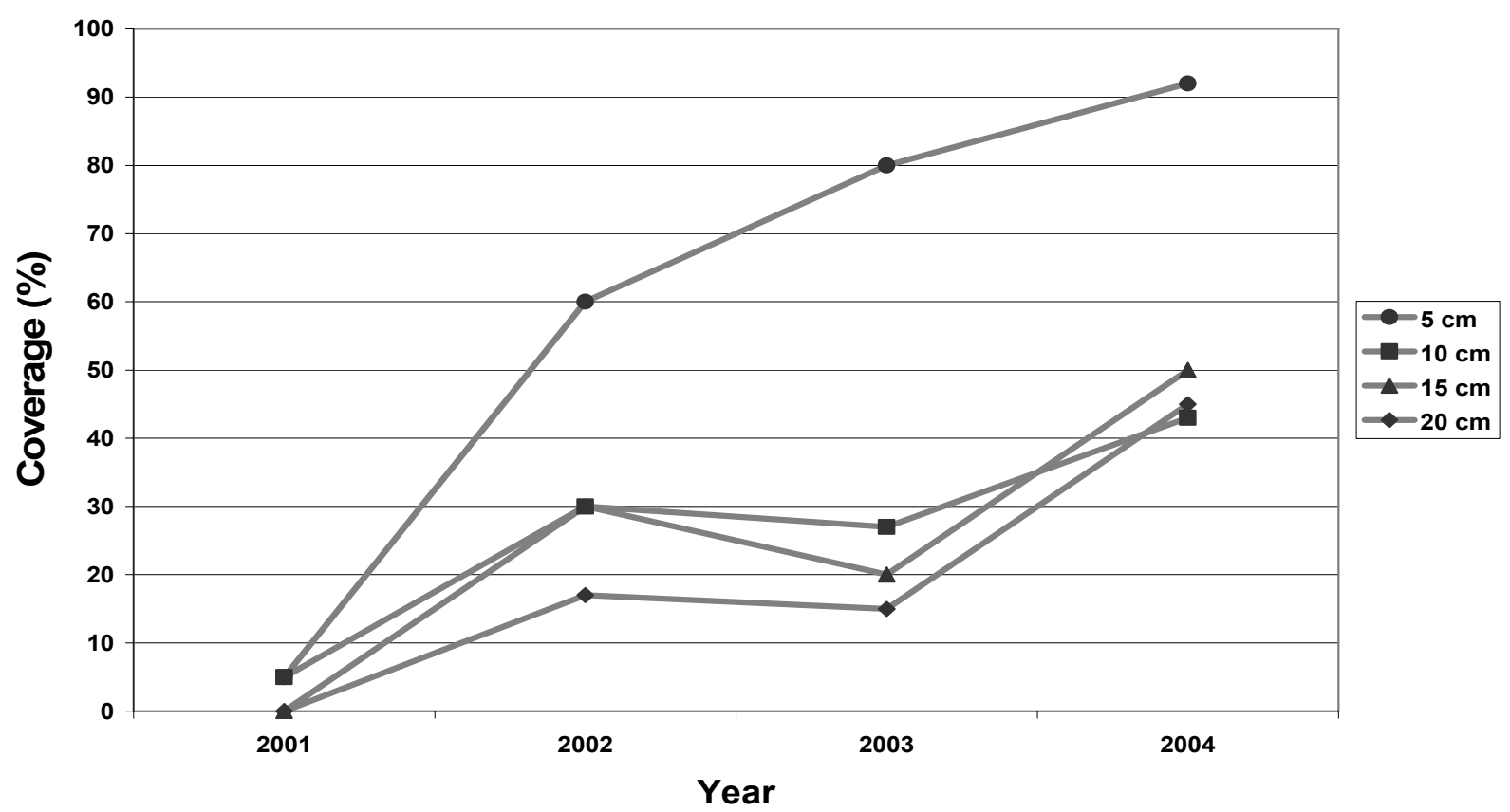

Figure 76. Percentage of sub-plot surface covered by vegetation from 2001-2004. Moss not included.

Observations associated with the Mulch Depth Field Study ended in the fall of 2004 with the construction of the ATOXIC project on the study site.

\subsection{Project costs}

Project expenditures from the DOE-NETL budget in Year 1 of the CCWESTRS project were $\$ 241,601$. Project expenditures in Year 2 were $\$ 446,897$. Project expenditures in Year 3 were $\$ 286,866$. Project expenditures in Year 4 were $\$ 127,500$. Project expenditures in Year 5 were $\$ 116,000$.

\subsection{Conclusions}

TVA and EPRI are evaluating and demonstrating integration of terrestrial carbon sequestration techniques with use of byproducts and wastewater from a coal-fired electric power plant. The industrial byproducts used during the demonstration include gypsum and process water from FGD system. The gypsum is being used as a soil amendment and the process water for periodic irrigation.

The integrated system is referred to as the CCWESTRS, or Carbon Capture and Water Emissions Treatment System. The CCWESTRS is located near TVA's Paradise Fossil Plant on reclaimed surface coal mine lands in the state of Kentucky. The CCWESTRS has been constructed on gently rolling reclaimed coal mine lands consisting of mine spoil. The lands are partially vegetated, but have a relatively low productivity potential.

In Year 1 of the project, greenhouse tests and field testing evaluated the following: 
(1) Tolerance of certain tree species to soil-borne B

(2) Tolerance of certain tree species to water-borne B

(3) Optimum depth of FGD gypsum by-product to serve as a mulch

Using the Paradise power plant FGD waste water as a source of irrigation on tree seedlings without first diluting the $B$ concentration will require careful planning and management. It is suggested that:

(1) The FGD water should be blended to $4 \mathrm{mg} \mathrm{B/l}$ or less prior to use.

(2) Allow trees to become fully established before applying diluted water.

(3) Do not saturate the soil with boronated waste water.

(4) Initially monitor $B$ and $N$ in leaves to help schedule irrigation and fertilization.

(5) Monitor the accumulation of B in the soil profile.

(6) Schedule leaching irrigation with low B water to prevent B accumulation in the soil.

(7) Continue to search for more tolerant trees and crop management techniques to reduce the risk of irrigating with boronated waste water.

Overall, results from this $B$ leaching study indicate that if wastewater containing $B$ is dripirrigated to match evapotranspiration during the growing season, most of the applied B will be retained in the upper part of the rooting zone during the growing season. Since B is somewhat mobile at our study site, winter precipitation likely will leach much of the B out of the rooting zone, resulting in lower levels of soil B at the beginning of each growing season. With this type of pattern, application of $25 \mathrm{~cm}$ ( $9.84 \mathrm{in}$ ) of water containing $7 \mathrm{mg} \mathrm{B/l}$ irrigation water (e.g., the fly ash pond water) would result in an accumulation of about $7 \mathrm{mg} \mathrm{B} / \mathrm{kg}$ soil in the rooting zone by the end of each growing season. During the first part of each growing season, significantly less than an additional $7 \mathrm{mg} \mathrm{B} / \mathrm{kg}$ soil will have accumulated. The greenhouse B tolerance study indicated that sycamore, cottonwood, sweet gum, and red maple will tolerate $10 \mathrm{mg} \mathrm{B} / \mathrm{kg}$ soil reasonably well for about one growing season or less. Some B leaf damage would probably occur during the last part of the growing season and concentrate in the autumn leaf litter to be leached out by rainfall. The combined results of the greenhouse B tolerance study and the field B leaching study suggest that sycamore, cottonwood, sweet gum, and red maple will tolerate an annual application of $25 \mathrm{~cm}(\sim 10 \mathrm{in})$ fly ash pond water reasonably well, but that $25 \mathrm{~cm}(\sim 10 \mathrm{in})$ of FGD wastewater ( $70 \mathrm{mg} \mathrm{B} / \mathrm{l})$ would be very damaging to the trees.

The preliminary test plan involves the application of three levels each of two types of coal-fired power plant byproducts -- three levels of FGD gypsum mulch, and three levels of FGD pond irrigation water. This design produces nine treatment levels $(3 \times 3)$, which are being tested with two species of hardwood trees (i.e., sweetgum and sycamore). Each treatment combination is being replicated three times, resulting in a total of 54 treatment plots (3 FGD gypsum levels $X 3$ irrigation water levels $\times 2$ tree species $\times 3$ replicates). Survival and growth response of plant species in terms of sequestering of carbon in plant material and soil will be the primary measure of effectiveness of each treatment.

Based on a 2001-2002 field study and April-November 2002 inspections of replicated test plots FGD gypsum placed on actively growing fescue, the Project Team determined that the full-scale demonstration should be tested with about 0-, 10-, and 20-cm depths of the FGD gypsum for mulch. In December 2001 to February 2002, FGD gypsum was applied as mulch at three levels: zero mulch, low mulch (10-cm depth), and high mulch (20-cm depth.) The 40.5-ha research area was subdivided into nine zones, each covered with one of the three levels of FGD gypsum mulch replicated three times. Exact application levels applied to each zone were randomly chosen. FGD gypsum was applied in 3.7-m wide strips, separated by 1.2-m wide strips of existing grass cover crop. 
$34,500 \mathrm{~m}^{3}$ of FGD gypsum was placed over a three month period from December 2001 to February 2002 at $10-\mathrm{cm}$ and $20-\mathrm{cm}$ depths. The total cost for placing the material was $\$ 159,000$, or about $\$ 4.61 / \mathrm{m}^{3}$. It is thought that the total cost is approximately one third higher than a "best case" estimate due to weather delays.

August 2002 measurements indicated that on the zero mulch plots, above-ground biomass was reduced considerably from baseline levels (from $6.45 \mathrm{~T} / \mathrm{ha}$ to an average of $2.82 \mathrm{~T} / \mathrm{ha}$ ), probably largely the result of bush-hogging the entire study area in late spring 2002.

After extensive greenhouse testing of a number of tree species for tolerance to $B$, and consideration of other factors such as drought tolerance, growth rate, and commercial value, sycamore and sweet gum were chosen as the optimum species for planting. Two rows of twoyear-old tree seedlings were planted in February-March 2002 in each 3.7-m wide row of gypsum treatment (except in plots with zero gypsum treatment) at $2.44 \mathrm{~m} \times 2.44 \mathrm{~m}$ spacing. This planting pattern resulted in a 2.4-m wide strip of gypsum between rows of trees on one side of a row and $0.6-\mathrm{m}$ wide strip of mulch plus $1.2 \mathrm{~m}$ of grass plus a second $0.6 \mathrm{~m}$ of mulch between rows on the opposite side.

Tree planting of $\sim 63,000$ sycamore and sweet gum seedlings began 2-23-02 and was completed 3-7-02. In May 2002, a survivorship survey was conducted in all plots for both tree species indicating that the percent survivorship for both species was greater than $85 \%$. In September 2002, seedling survival and vigor was poor across the entire study area. Sycamore average survival rate $(27 \%)$ was over twice that of sweet gum $(12 \%)$, and the percentage of healthy sycamore seedlings was considerably higher (17\% vs. $4 \%)$. Both species performed best under the high mulch treatment and worst under the zero mulch treatment. The high mulch application was more effective in reducing weed competition, especially from tall fescue and lespedeza species. Foliage was collected in June 2002 from all plots at the CCWESTRS site.

Within each of the nine zones of FGD gypsum treatment, the three irrigation treatments are being replicated randomly. Within each of the 27 irrigation areas (3 replicates of the nine possible gypsum-irrigation level combinations), half of the area have been planted to sycamore and half to sweet gum, in a split-plot design. This has resulted in 54 treatment plots of approximately 0.75 hectares each.

Due to various reasons and decisions, the irrigation system was not installed in 2002 as planned. One of the reasons was the initial poor performance of the seedlings, which showed significant leaf damage and symptoms of boron toxicity and heat stress, presumably from the FGD gypsum mulch. Rather than subject the trees to additional B stress from irrigation with water from the FGD pond, it was decided to allow the trees to adapt to conditions in a slower manner. Although rainfall was adequate through June 2002, July, and August rainfall was below normal and temperatures were above normal. Temporary irrigation with non-industrial fresh water was done in August 2002, but poor tree survival prompted a decision to cease irrigation and to replant the site in 2003.

In addition to the plantings on the 54 test plots, an experimental test cell was planted in a variety of trees that were tested in laboratory experiments for B tolerance but did not perform adequately to be selected as test species. The trees were planted in March to April 2002. The primary reason for this plot was to evaluate potential survival of the species under actual field conditions. Several observations were made related to these experiments that are significant and relevant to the main test plots experiment. 
Monthly precipitation and temperature were monitored. Monthly precipitation at the CCWESTRS site was higher during seedling establishment, while the summer months experienced below normal precipitation from May through early August. Temperatures for the year were characterized as "much above normal".

Soil moisture data was measured in early August that indicated that the soil moisture in the zero mulch and mulched test plots was below the wilting point of about $9 \%$. During this same period, soil moisture in the FGD mulch exceeded the wilting point. Additional soil moisture measurements in August and October, however, indicated that soil moisture was adequate. Soil surface temperatures in the very dark FGD mulch were in excess of air temperatures (they were hot to the touch), but no actual subsurface soil temperature readings were obtained.

\section{Year 3}

In February 2003, the entire site was bush-hogged to remove standing dead debris and facilitate planting. After inspecting and selecting quality seedling stock from state nurseries in Kentucky and Tennessee, replanting began 2-11-03 and was completed 3-12-03. Cursory survivorship estimates in early spring indicated that greater than $90 \%$ of the seedlings had broken dormancy. By August, a more quantitative survey would reveal that sycamore and sweet gum survivorship was greater than $80 \%$, as compared to $27 \%$ and $12 \%$ respectively in 2002 .

Installation of the drip irrigation system began in early March as tree planting was being completed. As designed, the irrigation system has the capacity to apply of up to $5 \mathrm{~cm}$ of irrigation water per week to all plots at an average rate of 1,413 liters per minute. The system was divided into two zones, with Zone 2 receiving one-half of the amounts of water that is applied to Zone 1. The irrigation water is pumped from an adjacent ash settling pond and is distributed through 1,107 drip lines that total $104,880 \mathrm{~m}$ in length. Though automated, daily checks and routine maintenance of the system insured proper operation throughout the growing season and resulted in targeted soil moisture regimes within each treatment. Any runoff generated by the irrigation system was minimized through the strategic placement of straw bales and barriers.

In order to evaluate the efficiency of the vegetation, soils and underlying geology in removing metals and nutrients from the incoming irrigation water, 14 pressure vacuum lysimeters were installed at 7 locations within the site in August 2003. The lysimeters were set at $1.5 \mathrm{~m}$ and 5.0 $\mathrm{m}$ depths for collecting samples of unsaturated zone flow-through as the irrigation water migrates vertically through the soil column. Two sets of samples were collected from the lysimeters in August and September 2003. Sample analyses were not performed during this reporting period, but will be completed for a full suite or metals, non-metals, nutrients, and field parameters.

Abundant spring precipitation and the installation of the irrigation system greatly improved seedling survival and vigor for both species in 2003 . As seen in 2002, differences in seedling survival and vigor were also related to species differences and the level of mulch. Both species reacted favorably to higher irrigation rates, but differed significantly in respect to mulch depth. Survival rates of sycamore seedlings were only slightly reduced in higher mulch plots, while the percentage of sweet gum survival dropped as mulch depth increased. Overall, seedling vigor (visual estimate) appeared high for both species throughout all treatments. Foliage samples taken in mid-summer revealed sufficient macronutrient levels in both species except for calcium (Ca) which was low in all treatments. Calcium seems to be slightly improved by mulching but not by irrigation. Boron is within normal range for zero mulch/zero irrigation treatments, but very 
high for both treatments with high irrigation (mulching also seems to increase B levels even further). Although B levels are high, sycamore seedlings show no signs of toxicity. Sweet gums do not look as healthy, but their appearance does not point to any particular nutrient limitation or excess

In August 2003, measurements of above ground biomass were taken following herbicidal treatments (applied the previous fall and spring), bush-hogging, and replanting. The above ground biomass consisted almost entirely of weed cover, since the tree seedlings planted earlier in the year were still quite small and widely spaced. For all plots, the mean above ground biomass had been reduced considerably from the baseline levels of $6.45 \mathrm{~T} / \mathrm{ha}$ (2001) and 2.40 T/ha (2002) to a mean of $0.99 \mathrm{~T} / \mathrm{ha}$.

\section{Year 4}

In April 2004, visual estimates of seedling survivorship indicated that essentially all of the seedlings had survived from 2003. Irrigation of the site was conducted from May to November and resulted in phenomenal growth of both the herbaceous cover and seedlings. As a result, the mean above ground biomass level had climbed dramatically from $0.99 \mathrm{~T} / \mathrm{ha}$ (2003) to 5.42 T/ha.

As in the previous year, foliage samples taken in mid-summer revealed sufficient macronutrient levels in both species except for calcium which was low in all treatments. Calcium (Ca) concentration seems to be slightly improved by mulching but not by irrigation. Boron is within normal range for zero mulch/zero irrigation treatments, but very high for both treatments with high irrigation (mulching also seems to increase B levels even further). Although boron levels are high, sycamore seedlings show no signs of any toxicity. Sweet gum seedlings appeared much healthier than in the proceeding year. Foliar discoloration in sweet gum seedlings (as seen in 2003) was limited primarily to low-lying, poorly-drained portions of the site and did not point to any particular nutrient limitation or excess.

Soils were more intensively sampled and evaluated during 2004. Soils were sampled shortly after the cessation of irrigation activities in November 2003 and again in April 2004 in order to access possible changes in soil chemistry as a result of irrigation and winter/spring rains. In general, mulching with FGD materials resulted in an overall increase in calcium, sulfur, and boron throughout the soil profile.

\section{Year 5}

The seasonal operation of the drip irrigation system began in early May and ended in midOctober (five weeks earlier than in previous years) due to a complete pump engine failure. Due to the degree of senesce observed in both tree species and the assumed adequacy of the existing soil moisture levels, a decision was made to forego obtaining a new engine until the beginning of the 2006 growing season. It was apparent from observations made during the year that the irrigation was enhancing growth of both the herbaceous cover and seedlings, especially sycamores. Precipitation at the site during 2005 was below normal. Plots not receiving irrigation continued to experience seedling mortally, especially those planted in sweet gum. The decline in biomass of sweet gum was offset by the increases in biomass of the sycamores and herbaceous layer. As a result, the mean above ground carbon level continued to climb to 6.34 $\mathrm{MT} / \mathrm{ha}$.

As in the previous years, foliage samples taken in mid-summer revealed sufficient macronutrient levels in both species except for calcium which was low in most treatments. Calcium (Ca) 
concentration seems to be slightly improved by mulching but not by irrigation. Manganese (Mn) concentrations were slightly deficient in some plots and may be attributed to its low availability in soils with a high soil $\mathrm{pH}$, high organic matter or poor drainage. Boron was within normal range for zero mulch/zero irrigation treatments, but very high for both treatments with high irrigation (mulching also seems to increase B levels even further). Although boron levels were higher than in previous years, sycamore seedlings showed no signs of boron toxicity. Boron levels in sweet gum seedlings were lower than in 2004 and could possibly be attributed to the overall stagnation in growth and lower plant uptake.

Below-ground biomass was measured in all plots during December. The average amount of carbon being stored below ground (roots and soil by depth increment across all treatments) in 2005 indicated a shift in carbon distribution with depth, as well as an overall decline in root carbon as compared to baseline estimates made in 2001. Baseline $C$ in coarse roots in the 0 to $30 \mathrm{~cm}$ interval was estimated at $1.65 \mathrm{~T} / \mathrm{ha}$ in 2001.2005 estimates of the same root fraction (including some fine roots) indicated a $67 \%$ decrease or $0.545 \mathrm{~T} / \mathrm{ha}$. Similar declines in root $\mathrm{C}$ were observed in the 30 to $60 \mathrm{~cm}$ and 60 to $90 \mathrm{~cm}$ depth intervals as well. This decline in the carbon stored in the roots may be due to shifts in the vegetation type (from a fescue dominated system to one dominated by Lespedeza and planted trees) or possibly affected as a result of herbicide treatments to remove vegetation prior to mulching and planting trees. In the base line estimates made in $2001,90 \%$ of the root carbon was found in the 0 to $30 \mathrm{~cm}$ depth interval. In 2005 , carbon measurements revealed that only $63 \%$ of root carbon is in the surface representing a shift in depth distribution that may also be attributed to vegetation changes.

FGD and soil from all plots were sampled at two depths $(0-25 \mathrm{~cm}$ and $26-50 \mathrm{~cm})$ in conjunction with below-ground biomass determinations. The sampling of the FGD gypsum was in response to the observation that plants (primarily in the herbaceous layer, but includes trees) are rooting directly in the mulch in many plots. Most nutrients were at acceptable levels for plant growth, although soil potassium and phosphorous in all plots were considered to be at deficient levels for optimum growth. Boron, calcium and sulfur concentrations are all higher in the FGD than the mineral soil, but do not differ significantly by either mulch or irrigation treatment as in the soil. Boron concentrations are significantly impacted by irrigation treatments, while calcium and sulfur concentrations are tied directly to mulch treatments. The results of the higher irrigation treatment is the continued accumulation of $B$ in the top $50 \mathrm{~cm}$ of the soil profile that is significantly higher than in either the zero or low irrigation treatments Calcium and sulfur continue to leach from the FGD mulch as indicated by the significant difference between their concentrations in the mulched and non-mulched plots.

Project expenditures from allocated DOE-NETL funding in Year 1 were $\$ 241,601$, in Year 2, $\$ 446,897$ and in Year 3, that total was $\$ 286,866$. Year 4 project expenditures were $\$ 127,500$. Year 5 project expenditures were $\$ 116,000$.

\section{References Cited}

Ausmus, B. S., N. T. Edwards, and M. Witkamp. 1976. Microbial immobilization of carbon, nitrogen, phosphorus, and potassium: Implications for forest ecosystem processes. In: J. M. Anderson and A. Macfadyen (eds.). The Role of Terrestrial and Aquatic Organisms in Decomposition Processes. pp. 397-416. Blackwell Scientific Publishers. Oxford. 474 pp.

Badruck, M, N. Kabay, M. Demircioglu, H., Mordogan, and U. Ipekoglu. 1999. Removal of Boron from Wastewater of Geothermal Power Plant by Selective lon-Exchange Resins. I. Batch Sorption - Elution Studies. Separation Science and Technology. 34 (13):2553-2569. 
Bergmann, W. 1992. Editor. Nutritional disorders of plants: development, visual and analytical diagnosis. 741 pages. VCH Publishers Inc., 303 N. W. $12^{\text {th }}$ Avenue, Deerfield Beach, FL 334421705. p. 164-185.

Bond, R. G., C. P. Straub, and R. Prober. 1973. Handbook of Environmental Control. p. 333334. CRC Press. Ann Arbor, MI.

Boron Fact Sheet. 2000. http://soils-earth.massey.ac.nz/cybsoil/poster/tracels/boron.htm.

Brown, P. H. and S. J. Barry. 1997. Boron mobility in plants. Plant and Soil. 193:85-101.

Brown, P. H. and H. Hu. 1998. Boron mobility and consequent management in different crops. In: Better Crops with Plant Food, No. 2. PPI, 655 Engineering Drive, Suite 110 Norcross, GA 30092-2837.

Brown, P. H. and B. J. Shelp. 1997. Boron mobility in plants. Plant and Soil. 193:85-101.

Brown, P. H. and K. Uriu. 1996. Nutrition deficiencies and toxicities: diagnosing and correcting imbalances, pp. 179-188, In: Warren Micke (ed.), Almond Production Manual, Publication 3364. University of California, Division of Agriculture and Nature Resource.

Brown, P. H., H. Hu, and W. G. Roberts. 1999. Occurrence of sugar alcohols determines boron toxicity symptoms of ornamental species. Journal of the American Society for Horticultural Science 124(4):347-352.

Choate, K. 1992. Paradise Fossil Plant waste water and storm runoff flows, calculations, and rationale. TVA Engineering Services. Chattanooga, TN.

Delcourt, H. R., and W. F. Harris. 1980. Carbon budget of the Southeastern U.S. biota: Analysis of historic change in trend from source to sink. Science 210:321-323.

Emanuel, W. R., W. M. Post, and H. H. Shugart. 1980. Modeling the role of terrestrial ecosystems in the global carbon cycle. In: Proc. 11th Annual Conference on Modeling and Simulation. pp. 803-810. Instrument Society of America. Pittsburgh, Pennsylvania.

EPRI. 1998. The Springdale Project: Applying Constructed Wetland Treatment to Coal Combustion By-Product Leachate. TR-111473. Palo Alto, CA.

Fenneman, N. M. and D. W. Johnson. 1946. Physical divisions of the United States. U. S. Geological Survey. 1 sheet, scale 1:7,000,000.

Gangloff, W. J., M. Ghodrati, J. T. Sims, and B. L. Vasilas. 1997. Influence of Fly Ash on Leachate Composition in an Excessively Drained Soil. Journal of Environmental Quality 26: 714-723.

Goldberg, S. and H. S. Forster. 1991. Boron sorption on calcareous soils and reference calcites. Soil Science. 152(4):304-310.

Goldberg, S. 1993. Chemistry and Mineralogy of Boron in soils. p. 3-40. In: U.C. Gupta, Ed. Boron and Its Role in Crop Production. CRC Press, Inc. 2000 Corporate Blvd., N.W., Boca Raton, FL 33431. 
Gupta, U. C. 1993. Boron and its role in crop production. p. 212 and 219. CRC Press. Ann Arbor, MI.

Harris, W. F., P. Sollins, N. T. Edwards, B. E. Dinger, and H. H. Shugart. 1975. Analysis of carbon flow and productivity in a temperate deciduous forest ecosystem. In D. E. Reichle, J. F. Franklin, and D. W. Goodall (Eds.). Productivity of World Ecosystems. pp. 116-122. National Academy of Sciences. Washington, D.C. 166 pp.

Hu, H. and P.H. Brown. 1997. Absorption of boron by plants. Plant and Soil. 193:49-58.

Khan, S., G. Shroff, J. Tarpara, and R. Srivastava. 1997. SCR Applications: Addressing Coal Characteristic Concerns. In: Proceedings: EPRI-DOE-EPA Combined Utility Air Pollutant Control Symposium: The Mega Symposium: Opening Plenary Session and NOX, EPRI (Palo Alto, CA), U.S. Department of Energy (Pittsburgh, PA), and U.S. Environmental Protection Agency, Air Pollution Prevention and Control Division, (Research Triangle Park, NC). EPRI Report TR-108683-V1.

Kronrad, G. D. 2002. Enhancement of Terrestrial Carbon Sinks Through Reclamation of Abandoned Mine Lands in the Appalachians. DOE National Energy Technology Laboratory project DE-FC26-00NT40931. Currently in progress.

Leyshon, A. J. and Y. Jame. 1993. Boron toxicity and irrigation management. Chapter 13. p. 207-226. In: U.C. Gupta (ed.). Boron and its role in crop production. CRC Press Inc. Boca Raton, FL.

Lindquist, K. F. and A. J. Danzig. 1998. Paradise Fossil Plant groundwater assessment. TVA Engineering Laboratory. WR98-1-64-124, Rev. 1. Norris, TN. 95 pp.

Lloyd, O. B. Jr., and W. L. Lyke. 1995. Ground water atlas of the United States -- Illinois, Indiana, Kentucky, Ohio, Tennessee. U.S. Geological Survey HA 730-K. http://capp.water.usgs.gov/gwa/ch_k/index.html

Matsi, T. and V. Z. Keramidas. 2001. Alkaline fly ash effects on boron sorption and desorption in soils. Soil Scence. Society of America Journal 65:1101-1108.

Myers, L. 2001. Incentives for Utilities to Invest in Reforestation-Limestone Run Project. Allegheny Energy. Monroeville, Pennsylvania.

Meyers, P., D. Wilcox, M. Montalvo, and S. Walsh. 2000. Boron removal from ultrapure water by boron selective ion exchange. Semiconductor Pure Water and Chemicals Conference. eche.com/content/Techarticles.

National Climatic Data Center. 2003. http://www.ncdc.noaa.gov/oa/ncdc.html.

Palumbo, A. 2000. Enhancing Carbon Sequestration and Reclamation of Degraded Lands with Fossil-Fuel Combustion Gypsums. Project currently underway by Oak Ridge National Laboratory, and Pacific Northwest National Laboratory, The Ohio State University, Virginia Polytechnic Institute. http://www.esd.ornl.gov/programs/microbes/CarbonPro.html.

Palumbo A.V., McCarthy J.F., Amonette J.E., Fisher L.S., Wullschleger S.D., Daniels W.L. 2004. Prospects for Enhancing Carbon Sequestration and Reclamation of Degraded Lands with 
Fossil-Fuel Combustion Byproducts. Advances in Environmental Research, Advances in Environmental Research 8:425-438.

Palumbo A.V., Fisher L.S., Tarver J.R., Amonette J.E., Daniels W.L. 2003. Leaching of Metals from Different Sources of Fly Ash: Implications for Use of Fly Ash in Promoting Carbon Sequestration. Submitted to Fuel.

Phelps, T. J., R. Lauf, and Y. Roh. 2002. Reducing boron toxicity by microbial sequestration. Oak Ridge National Laboratory internal report. Oak Ridge, TN.

Reardon, E. J. and D. Valle. 1997. Anion Sequestering by the Formation of Anionic Clays: Lime Treatment of Fly Ash Slurries. Environmental Science and Technology. 31:1218-1223.

Reed, S. 1988. Natural Systems for Waste Management. New York: McGraw Hill Inc.

Reichle, D. E., B. E. Dinger, N. T. Edwards, W. F. Harris, and P. Sollins. 1973. Carbon flow and storage in a forest ecosystem. In George M. Woodwell and Erene V. Pecan (eds.). Carbon and the Biosphere. Proc., 24th Brookhaven Symposium in Biology. pp. 345-365CONF-720510. 392 pp.

Roussopoulos, P. J. 2002. Terrestrial Sequestration of Carbon Dioxide. DOE National Energy Technology Laboratory project DE-AI26-99FT40625. Currently in progress.

Sposito, G. and S. J. Calderone. 1988. Boron uptake and accumulation by higher plants: A literature review. EPRI EA-5817 Research Project 2377-6. EPRI 3412. Hillview Avenue, Palo Alto, CA 94304

Srivastava R., A. Johnson, M. Geyer, and P. Quarles. 1997. Application of Selective Catalytic Reduction Technology on Coal-fired Electric Utility Boilers. In: Proceedings: EPRI-DOEEPA Combined Utility Air Pollutant Control Symposium: The Mega Symposium: Opening Plenary Session and NOX. EPRI (Palo Alto, CA), U.S. Department of Energy (Pittsburgh, PA), and U.S. Environmental Protection Agency, Air Pollution Prevention and Control Division, (Research Triangle Park, NC). EPRI Report TR-108683-V1.

SAS Institute. 1996. SAS/STAT user's guide. Version 6.12. SAS Inst., Cary, NC.

Stone, E. L. 1967. Microelement nutrition of forest trees: a review. p. 132-139 In: Bengston, G. W. et al. (eds.). Forest fertilization: theory and practice. TVA. Muscle Shoals, AL.

Tennessee Valley Authority. 2002. Installation of Flue Gas Desulfurization System on Paradise Fossil Plant Unit 3 Draft Environmental Assessment. TVA Environmental Policy and Planning. Knoxville, TN.

Tennessee Valley Authority. 2001. Environmental Decision Record, Carbon Capture and Water Emissions Treatment System (CCWESTRS). March 6, 2001. TVA National Environmental Policy Act Administration Staff. Knoxville, TN.

Tennessee Valley Authority. 1999. Environmental Assessment - Paradise Fossil Plant Units 1, 2, and 3 Selective Catalytic Reduction Systems for Nitrogen Oxide Control. Tennessee Valley Authority. TVA National Environmental Policy Act Administration Staff. Knoxville, TN. 
Tennessee Valley Authority. 1996. Environmental Assessment - Development of Ash Disposal Capacity at Paradise Fossil Plant. TVA National Environmental Policy Act Administration Staff. Knoxville, TN.

Terry, N. and S. N. Whiting. 1999. Phytoremediation of selenocyanate, arsenic, and boron in wastewater from Cinergy power plant. Department of Plant and Microbial Biology, University of California, Berkley, CA.

U.S. Department of Commerce. 1968. Climatic atlas of the United States (reprinted by the National Oceanic and Atmospheric Administration, 1979). Ashville, N.C. National Climatic Data Center. 80 p.

U.S. Dept. of Commerce. 1974. Environmental Science Services Administration and Environmental Data Service. Climatic Atlas of the United States.

USEPA.1995. Test Method for Evaluating Solid Waste: Physical/Chemical Methods. EPA 530/SE-846. U.S. Gov. Print Office, Washington, DC.

Van der Leeden, F., F. L. Troise, and D. K. Todd. 1990. The Water Encyclopedia. p. 466. Lewis Publishers. Chelsea, MI.

Wear, J. I. 1965. Boron. In C.A. Black et al. (ed.) Methods of soil analysis. Part 2. Agronomy 9:1059-1063.

Whiting, S. N, and N. Terry. 1999. Phytoremediaiton of selenocyanate, arsenic, and boron in wastewater from the Cinergy Power Plant. Dept. of Plant and Microbial Biology. University of California. Berkeley, CA.

\section{Selected Background Literature}

Adams, F. and B. L. Moore. 1983. Chemical factors affecting root growth in subsoil horizons of Coastal Plain soils. Soil Scence Society of America Journal 47: 99-102.

Akala, V. A. and R. Lal. 2001. Soil organic carbon pools and sequestration rates in reclaimed minesoils in Ohio. Journal of Environmental Quality 30:2098-2104.

Alexander, M. 1977. Introduction to soil microbiology. $2^{\text {nd }}$ ed. John Wiley and Sons. New York. $467 \mathrm{p}$.

Amichev, B. 2002. A revised methodology for estimation of forest soil carbon from spatial soils and forest inventory datasets. Virginia Tech, Department of Forestry. Presentation and abstract in: USDA Symposium on Natural Resource Management to Offset Greenhouse Gas Emissions. Raleigh, NC. November 19-21.

Amthor, J. S. 1999. Increasing atmospheric $\mathrm{CO}_{2}$ concentration, water use, and water stress: Scaling up from the plant to the landscape. In: Y. Luo and H. A. Mooney (eds.). Carbon Dioxide and Environmental Stress. Academic Press. pp. 33-59.

Amthor, J. S. 2000. The direct effect of elevated $\mathrm{CO}_{2}$ on nocturnal in situ leaf respiration in nine temperate deciduous tree species is small. Tree Physiology 20:139-144. 
Anderson, D. W. 1977. Early stages of soil formation on glacial till mine spoils in a semi-arid climate. Geoderma 19: 11-19.

Andrews, J. A., Johnson, J. E., Torbert, J. L., Burger, J. A. and D. L. Kelting. 1998. Minesoil and site properties associated with early height growth of eastern white pine. Journal of Environmental Quality 27:192-199.

Ashby, W. C. 1997. Soil ripping and herbicides enhance tree and shrub restoration on stripmines. Restoration Ecology 5: 169-177.

Ashby, W. C. 1998. Reclamation with trees pre- and post-SMCRA in southern Illinois, International Journal of Surface Mining Reclamation and Environment 12:117-121.

Ashby, W. C., W. G. Vogel, C. A. Kolar, and G. R. Philo. 1984. Productivity of stony soils on strip mines. In: J. D. Nichols et al., eds. Erosion and productivity of soils containing rock fragments. Spec. Pub. \#13. Soil Science Society of America, Madison, Wisconsin. Pp. 31-44.

Ashby, W. C., W. G. Vogel, and N. F. Rogers. 1985. Black locust in the reclamation equation. USDA Forest Service GTR NE-105.

Bachelet, D. 2002. Regional differences in the carbon source-link potential of natural vegetation in the conterminous US. Oregon State University. Presentation and abstract in: USDA Symposium on Natural Resource Management to Offset Greenhouse Gas Emissions. Raleigh, NC. November 19-21.

Banuelos, G. S., G. E. Cardon, B. Mackey, J. Ben-Asher, L. L. Wu, and P. Beuselinck. 1992. Boron and selenium removal in boron-laden soil by Birdsfoot Trefoil. In: P. R. Beuselinck (ed.). LOTUS Newsletter. 23:32-35.

Banuelos, G. S., G. E. Cardon, B. Mackey, J. Ben-Asher, L. L. Wu, P. Beuselinck, and S. Akohoue. 1993. Boron and selenium removal in boron-laden soils by four sprinkler-irrigated plant species. Journal of Environmental Quality 22:786-792.

Banuelos, G. S., G. E. Cardon, C. J. Phene, L. L. Wu, S. Akohoue, and S. Zambrzuski. 1993. Soil boron and selenium removal by three plant species. Plant and Soil 148:253-263.

Banuelos, G. S., G. E. Cardon, L. L. Wu, S. Zambrzuski, and S. Akohoue. 1992. Abstract: Using wild mustard and tall fescue to lower boron and selenium concentration in the soil. 89th Annual Meeting of the American Society for Horticultural Science, July 31 - August 6, 1992. Honolulu, HI.

Banuelos, G. S., and P. Bueselp. 1994. Remediation of selenium and boron contaminated soil with Lotus corniculatus L. pp. 167-171. In: Proceedings, First International Lotus Symposium, March 22-24. St. Louis, MO.

Barnhisel, R. I., R. G. Darmody, and W. L. Daniels (eds.). 2000. Reclamation of drastically disturbed lands. Number 41 in the series Agronomy. Amererican Society of Agronomy. Madison, WI. 1082 pp.

Barth, R. C., and B. K. Martin. 1984. Soil depth requirements for revegetation of surface-mined areas in Wyoming, Montana, and North Dakota. Journal of Environmental Quality 13: 399-404. 
Bates, R. 2002. The cost of sequestering carbon in northern red oak plantations on abandoned mined lands in West Virginia. Stephen F. Austin State University. Presentation and abstract in: USDA Symposium on Natural Resource Management to Offset Greenhouse Gas Emissions. Raleigh, NC. November 19-21.

Bell, J. C., R. L. Cunningham, and C. T. Anthony. 1994. Morphological characteristics of reconstructed prime farmland soils in western Pennsylvania. Journal of Environmental Quality 23: $515-520$.

Bell, R., B. Dell, and P. H. Brown. 1997. Boron in plants and soils. Kluwer Academic Press, Dordrecht, Netherlands. 400 pp.

Bellaloui, N., P. H. Brown, and A Dandekar. 1999 Manipulation of in-vivo sorbitol production alters boron uptake and transport in tobacco. Plant Physiology 119:735-741.

Birdsey, R. A. 1992. Carbon storage and accumulation in United States forest ecosystems. U.S. Department of Agriculture. Washington, D.C.

Birdsey, R. A., A. J. Plantinga, and L. S. Heath. 1993. Past and prospective carbon storage in United States forests. Forest Ecology and Management 58: 33-40.

Brodie, G. A. 2001. Passive treatment of acid drainage: technology overview and case history of the system treating acid drainage from a coal ash disposal site at the TVA Widows Creek Fossil Plant, Jackson County, AL. Tennessee Valley Authority, Public Power Institute. Chattanooga, TN.

Brown, P. H., H. Hu, and A. Dandekar. 1999 Transgenically enhanced sorbitol synthesis facilitates phloem boron transport and increases tolerance of tobacco to B deficiency. Plant Physiology 119:17-20.

Brown, P. H. and H. Hu. 1997. Does Boron play only a structural role in higher plants? Plant and Soil 196:211-215.

Brown, P. H. and H. Hu. 1998. Phloem Boron Mobility in Diverse Plant Species. Botical Acta 111:331-335.

Brown, P. H. and H. Hu. 1996. Phloem mobility of boron is species dependent: Evidence for phloem mobility in sorbitol-rich species. Annals of Botany 77:497-505.

Brown, S. 2002. Development and comparison of approaches for establishing baseline scenarios for land-use change and forestry projects. Winrock International. Presentation and abstract in: USDA Symposium on Natural Resource Management to Offset Greenhouse Gas Emissions. Raleigh, NC. November 19-21.

Brown, S., B. Lim, and B. Schlamadinger. 1999. Evaluating approaches for estimating net emissions of carbon dioxide from forest harvesting and wood products. IPCC/OECD/IEA Programme on National Greenhouse Gas Inventories.

Brown, S., J. Sathaye, M. Cannell, and P. Kauppi. 1996. Management of forests for mitigation of greenhouse gas emissions. In R. T. Watson, M.C. Zinyowera, and R.H. Moss (eds.), Climate Change 1995: Impacts, Adaptations and Mitigation of Climate Change: Scientific-Technical 
Analyses. Contribution of Working Group II to the Second Assessment Report of the Intergovernmental Panel on Climate Change, Cambridge University Press, Cambridge and New York, Chapter 24.

Bruce, J. P., M. Frome, E. Haites, H. H. Janzen, R. Lal and K. Paustian. 1998. Carbon sequestration in soil. Soil Water Conservation Society White Paper. 23 p.

Bruce, J.P., M. Frome, E. Haites, H. Janzen, R. Lal, and K. Paustian. 1999. Carbon sequestration in soils. Journal of Soil and Water Conservation 54:382-389.

Burger, J. and J. L. Torbert. 1997. Restoring forests on surface-mined land. Publication \# 460123. Virginia Cooperative Extension. Virginia Polytechnic Institute and State Univ. Blacksburg, Virginia.

Burkett, V. 2002. Concurrent ecological benefits of enhancing carbon sequestration in the southern US. USGS National Wetlands Research Center. Presentation and abstract in: USDA Symposium on Natural Resource Management to Offset Greenhouse Gas Emissions. Raleigh, NC. November 19-21.

Bussler, B. H., W. R. Byrnes, P. E. Pope, and W. R. Chaney. 1984. Properties of minesoil reclaimed for forest land use. Soil Science Society of America Journal 48: 178-184.

Butnor, J. 2002. Scaling-Up tree root biomass estimated with ground-penetrating radar. USDA FS, Southern Research Station. Presentation and abstract in: USDA Symposium on Natural Resource Management to Offset Greenhouse Gas Emissions. Raleigh, NC. November 19-21.

Cairns, M. A., S. Brown, E. H. Helmer, and G. A. Baumgardner. 1997. Root biomass allocation in the world's upland forests. Oecologia 111:1-11.

Carter, K. K. and A. G. Snow. 1990. Pinus virginiana Mill. Virginia pine. In: R. M. Burns and B. H. Honkala, eds. Silvics of North America, Vol. 1, Conifers. Agriculture handbook \#654. USDA Forest Service. Washington, D.C. p. 513-519.

Cerri, C. E. 2002. Measuring and monitoring soil carbon sequestration: A methodology assessment. CENA - USP / NREL - CSU. Presentation and abstract in: USDA Symposium on Natural Resource Management to Offset Greenhouse Gas Emissions. Raleigh, NC. November 19-21.

Chan, Y. H., and J. S. Olson. 1980. Limits on the organic storage of carbon from burning fossil fuels. Journal of Environmental Management 11:147-163.

Chen, J. 2002. Coupling effects of changing climate and management on Carbon Flux and storage in disturbed land mosaics. University of Toledo, Department of EEES. Presentation and abstract in: USDA Symposium on Natural Resource Management to Offset Greenhouse Gas Emissions. Raleigh, NC. November 19-21.

Chojnacky, D. 2002. Sampling and estimating biomass of down woody material, shrubs, and herbs. USDA - FS, USDA Forest Service. Presentation and abstract in: USDA Symposium on Natural Resource Management to Offset Greenhouse Gas Emissions. Raleigh, NC. November 19-21. 
Cole, C.V., K. Flach, J. Lee, D. Sauerbeck, and B. Stewart. 1993. Agricultural sources and sinks of carbon. Water, Air and Pollution 70:111-122.

Cox, F. R., 1980. Soil Survey of McLean and Muhlenberg Counties, Kentucky. USDA-NRCS.

Dale, V. H. 1998. Managing forests as ecosystems: A success story or a challenge ahead? In: M. L. Pace and P. M. Groffman (eds.). Successes, Limitations and Frontiers in Ecosystem Ecology. Springer-Verlag. New York. pp. 50-68.

Delcourt, H. R., D. C. West, and P. A. Delcourt. 1981. Forests of the southeastern United States: Quantitative maps for aboveground woody biomass, carbon, and dominance of major tree taxa. Ecology 62(4):879-887.

Dewar, R. C. and M. G. R. Cannell. 1992. Carbon sequestration in the trees, products, and soils of forest plantations: An Analysis Using UK Examples. Tree Physiology 11:49-71.

Dixon, R. K., S. Brown, R. A. Houghton, A. M. Solomon, M. C. Trexler, and J. Wisniewski. 1994. Carbon pools and flux of global forest ecosystems. Science 263:185-190.

Dordas, C. and P. H. Brown. 2000. Permeability of boron across plant membranes vesicles isolated from squash. Plant Physiology 214:1349-1361.

Dordas, C. and P. H. Brown. 2000. Permeability of boron across artificial membranes and factors affecting it. Journal of Membrane Biology 175:95-105.

Drinkwater, L. E., P. Wagoner, and M. Sarrantonio. 1998. Legume-based cropping systems have reduced carbon and nitrogen losses. Nature 396:262-265.

Ebinger, M. 2001. Soil organic carbon sequestration in reclaimed minesoils. In: 2001 Conference Proceedings First National Conference on Carbon Sequestration. National Energy Technology Laboratory. Pittsburg, PA.

Electric Power Research Institute (EPRI). 1995. Agriculture options for mitigation of greenhouse gas emissions. No. 63073. Palo Alto, CA.

Effland, W. 2002. Linking soil and land use/cover to estimate soil carbon storage. USDA NRCS. Presentation and abstract in: USDA Symposium on Natural Resource Management to Offset Greenhouse Gas Emissions. Raleigh, NC. November 19-21.

Eghball, B. 2002. Manure and $\mathrm{N}$ fertilizer effects on emission of greenhouse gasses from soil. USDA - ARS. Presentation and abstract in: USDA Symposium on Natural Resource Management to Offset Greenhouse Gas Emissions. Raleigh, NC. November 19-21.

Ellert, B. H., H. H. Janzen and T. Entz. 2002. Assessment of a method to measure temporal change in soil carbon storage. Soil Science Society of America Journal. 66:1687-1695.

Entry, J. 2002. Irrigation increases inorganic carbon in agricultural soils. USDA - ARS. Presentation and abstract in: USDA Symposium on Natural Resource Management to Offset Greenhouse Gas Emissions. Raleigh, NC. November 19-21.

Emanuel, W. R., A. W. King, and W. M. Post. 1993. A dynamic model of terrestrial carbon cycling. In: M. Heimann (ed.), The Global Carbon Cycle. Proc., NATO Advanced Research 
Institute Workshop on the Global Carbon Cycle. pp. 239-260. El Ciocco, Italy. Sept. 8-20, 1991. NATO ASI Series, Vol. I. Springer-Verlag. Heidelberg, FRG.

EPRI. 1996. $\mathrm{CO}_{2}$ offset opportunities in Siberian forests. TR-106059. Palo Alto, CA.

EPRI. 1999a. Effects of forest management and elevated carbon dioxide on soil C storage. No. 58961. Palo Alto, CA.

EPRI. 1999b. Coal ash utilization for soil amendment to enhance water relations and turf growth, EPRI. TR-111318. Palo Alto, CA.

EPRI. 1999c. Utilization of coal combustion by-products in agriculture and land reclamation. TR112746. Palo Alto, CA.

EPRI. 1999d. A framework for hedging the risk of greenhouse gas regulations. TR-113642. Palo Alto, CA.

EPRI. 1999e. Revegetation of a co-managed utility waste disposal area: A southwestern site. TR-113939. Palo Alto, CA.

EPRI. 1999f. Restoration of eroded land using coal fly ash and biosolids. TR-113940. Palo Alto, CA.

EPRI. 1999g. Improvement of Plants for Selenium and Heavy Metal Phytoremediation Through Genetic Engineering. TR-114219. Palo Alto, CA.

EPRI. 1999h. The Tennessee Valley Authority constructed wetland at Widows Creek: Role of vegetation in the removal of trace elements. TR-114220. Palo Alto, CA

EPRI. 2002. Economic Evaluation of $\mathrm{CO}_{2}$ Storage and Sink Enhancement Options. Interim Report 1005250. Palo Alto, CA.

Finn, R. F. 1953. Foliar nitrogen and growth of certain mixed and pure forest plantings. Journal of Forestry 51: 31-33.

Fisher, M. J., I. M. Rao, M. A. Ayarza, C. E. Lascano, J. I. Sanz, R. J. Thomas, and R. R. Vera. 1994. Carbon storage by introduced deep rooted grasses in the South American savannas. Nature 371: 236-238.

Garten, C. T., Jr., and S. D. Wullschleger. 1999. Soil carbon inventories under a bioenergy crop (switchgrass): measurement limitations. Journal of Environmental Quality 28:1359-1365.

Garten, C. T., Jr., and S. D. Wullschleger. 2000. Soil carbon dynamics beneath switchgrass as indicated by stable isotope analysis. Journal of Environmental Quality 29:645-653.

Garten, C. T., Jr., W. M. Post, III, P. J. Hanson, and L. W. Cooper. 1999. Forest soil carbon inventories and dynamics along an elevation gradient in the southern Appalachian Mountains. Biogeochemistry 45:115-145.

Garten, C. T. Jr. 2002. Soil carbon storage beneath recently established tree plantations in Tennessee and South Carolina, USA. Biomass and Bioenergy 23:93-102. 
Gilliam, F. 2002. Effects of silvicultural practices on soil carbon in a central Appalachian hardwood forest ecosystem. Marshall University, Department of Biological Sciences. Presentation and abstract in: USDA Symposium on Natural Resource Management to Offset Greenhouse Gas Emissions. Raleigh, NC. November 19-21.

Gleason, R. 2002. Prairie wetlands of North America important for carbon storage. USGS Northern Prairie Wildlife Research Center. Presentation and abstract in: USDA Symposium on Natural Resource Management to Offset Greenhouse Gas Emissions. Raleigh, NC. November 19-21.

Goldberg, S., D. L. Corwin, P. J. Shouse, and D. L. Suarez. 2005. Prediction of boron adsorption by field samples of diverse textures. Soil Sci. Soc. Am. J. 69:1379-1388.

Golchin, A., J. M. Oades, and J. O. Skjemstad. 1994. Soil structure and carbon cycling. Australian Journal of Soil Research 32: 1043-1068.

Gonzalez-Sangregorio, M. V., M. C. Trasar-Cepeda, M. C. Leiros, F. Gil-Sotres, and F. GuitianOjea. 1991. Early stages of lignite mine soil genesis: Changes in biochemical properties. Soil Biology and Biochemistry 23: 589-595.

Grandy, S. 2002. Soil aggregation and organic matter quality: Effects on carbon turnover. Michigan State University - WK Kellogg Biological Station. Presentation and abstract in: USDA Symposium on Natural Resource Management to Offset Greenhouse Gas Emissions. Raleigh, NC. November 19-21.

Graves, D. H., J. M. Ringe, M. H. Pelkki, R. J. Sweigard, and R. Warner. 2000. High value tree reclamation research. pp. 413-421 in Singhal and Mehrotra, (eds.) Environmental Issues and Management in Energy and Mineral Production. Balkema, Rotterdam, The Netherlands.

Grew, E. S. and L M. Anovitz. 1996. Boron mineralogy, petrology, and geochemistry. Reviews in mineralogy. Vol. 33. Mineralogical Soc. Amer. Washington, DC. 862 pp.

Guo, Y., R. Amundson, P. Gong and Q. Yu. 2006. Quality and spatial variability of soil carbon in the conterminous United States. Soil Science Society of America Journal 70:590-600.

Guo, Y., P. Gong, R. Amundson and Q. Yu. 2006. Analysis of factors controlling soil carbon in the conterminous United States. Soil SCience Society of America Journal 70:601-612.

Hallberg, G. R., N. C. Wollenhaupt, and G. A. Miller. 1978. A century of soil development in spoil derived from loess in lowa. Soil Science Society of America Journal 42: 339-343.

Hamilton, S. 2002. Liming of agricultural soils: A source of sink for $\mathrm{CO}_{2}$ ? Michigan State University. Presentation and abstract in: USDA Symposium on Natural Resource Management to Offset Greenhouse Gas Emissions. Raleigh, NC. November 19-21.

Hanson, P. J., and W. A. Hoffman. 1994. Emissions of non-methane organic compounds and carbon dioxide from forest floor cores. Soil Science Society of America Journal 58(2):553-5.

Harding, R. B. and E. J. Jokela. 1994. Long-term effects of forest fertilization on site organic matter and nutrients. Soil Science Society of America Journal 58:216-221. 
Harmon, M. E., O. N. Krankina, M. Yatskov, and E. Matthews. 2001. Predicting broad-scale carbon stores of woody detritus from plot-level data. Pp. 533-552 in R. Lal, J. M. Kimble, R. F. Follett, and B. A. Stewart, eds. Assessment methods for soil carbon. Lewis Publishers, Boca Raton, FL.

Harmon, M. E. and J. Sexton. 1996. Guidelines for Measurements of Woody Detritus in Forest Ecosystems. US LTER Publication No. 20. US LTER Network Office, University of Washington, Seattle, WA, USA.

Houghton, R. A. 1995. Changes in the storage of terrestrial carbon since 1850. pp. 45-65 in R. Lal, J. Kimble, E. Levine, and B. A. Stewart, eds. Soils and global change. CRC Lewis Publishers, Boca Raton, FL.

Houghton, R.A. 1996. Terrestrial sources and sinks of carbon inferred from terrestrial data. Tellus B 48:420-432.

Houghton, R. A., J. L. Hackler, and R. C. Daniels (ed.). 1995. Continental scale estimates of the biotic carbon flux from land cover change: 1850 to 1980. ORNL/CDIAC-79 (NDP-050).

Hu, Hening, P. H. Brown, and J.M. Labavitch. 1996. Species variability in boron requirement is correlated with cell wall pectin. Journal of Experimental Botany 47(295):227-232.

Hu, H. N., S. G. Penn, C. B. Lebrilla, and P. H. Brown. 1997. Isolation and characterization of soluble boron complexes in higher plants - The mechanism of phloem mobility of boron. Plant Physiology 113(2):649-655.

Huang, C. 2002. Carbon sequestration in cherrybark oak stands in the lower Mississippi river valley. Stephen F. Austin University. Presentation and abstract in: USDA Symposium on Natural Resource Management to Offset Greenhouse Gas Emissions. Raleigh, NC. November 19-21.

IPCC. 1991. Climate Change IPPC Response Strategies. Island Press, Washington, DC, 272 $\mathrm{pp}$.

IPCC. 1997a. Revised 1996 IPCC Guidelines for National Greenhouse Gas Inventories Reporting Instructions (Volume 1). Houghton, J.T., L. G. Meria Filho, B. Lim, K. Treanton, I. Mamaty, Y. Bonduki, D.J. Griggs, and B.A. Callender (Eds.). Intergovernmental Panel on Climate Change.

IPCC 1997b. Revised 1996 IPCC Guidelines for National Greenhouse Gas Inventories Workbook (Volume 2). Houghton, J.T., L. G. Meria Filho, B. Lim, K. Treanton, I. Mamaty, Y. Bonduki, D.J. Griggs, and B.A. Callender (Eds.). Intergovernmental Panel on Climate Change.

IPCC 1997c. Revised 1996 IPCC Guidelines for National Greenhouse Gas Inventories Reference Manual (Volume 3). Houghton, J.T., L. G. Meria Filho, B. Lim, K. Treanton, I. Mamaty, Y. Bonduki, D.J. Griggs, and B.A. Callender (Eds.). Intergovernmental Panel on Climate Change.

IPCC. 2000. Land Use, Land Use Change, and Forestry. Cambridge University Press, Cambridge, UK.

Jenny, H. 1941. Factors of Soil Formation. Dover Publications, New York. 
Jenkins, J. 2002. Optimizing field methods for measuring and modeling c cycling: A pilot test in the Delaware river basin. USDA - FS NGCP. Presentation and abstract in: USDA Symposium on Natural Resource Management to Offset Greenhouse Gas Emissions. Raleigh, NC. November 19-21.

Johnsen, K. 2002. Impacts of pine plantation forestry on carbon sequestration in the southern united states. USDA - FS, Southern Research Station. Presentation and abstract in: USDA Symposium on Natural Resource Management to Offset Greenhouse Gas Emissions. Raleigh, NC. November 19-21.

Johnson, D. W, and P. S. Curtis. 2001. Effects of forest management on soil C and N storage: meta analysis. Forest Ecology Management 140:227-238.

Johnson, D. W., and D. E. Todd Jr. 1998. Effects of harvesting on forest productivity and soil carbon storage in a mixed oak forest. Pp. 351-363 in R. Lal, J. M. Kimble, R. F. Follett, and B. A. Stewart, eds. Management of Carbon Sequestration in Soil. CRC Lewis Publishing, Boca Raton.

Kadlec, R. H. and R. L. Knight. 1995. Treatment of Wetlands. Lewis Publishers. New York.893 pp.

Kadlec, R. H. and R. L. Knight. 1995. Treatment Wetlands. Lewis Publishers. Chelsea, MI.

Kant, Z. 2002. Compatibility of carbon sequestration and biodiversity restoration and protection projects. The Nature Conservancy. Presentation and abstract in: USDA Symposium on Natural Resource Management to Offset Greenhouse Gas Emissions. Raleigh, NC. November 19-21.

Kauppi, P. E., K. Mielikainen, and K. Kuusela. 1992. Biomass and carbon budget of European forests, 1971 to 1990 . Science 256: 70-74.

Kelly, J. M. and P. A. Mays. 2005. Soil carbon changes after 26 years in a Cumberland Plateau hardwood forest. Soil Science Society of America Journal 69:691-694.

Kern, J. S., and M. G. Johnson. 1993. Conservation tillage impacts on national soil and atmospheric carbon levels. Soil Science Society of America Journal 57: 200-210.

King, A. W., W. R. Emanuel, S. D. Wullschleter, and W. M. Post. 1995. In search of the missing carbon sink: A model of terrestrial biospheric response to land-use change and atmospheric $\mathrm{CO}_{2}$. Tellus 47B:501-519.

King, A. W., W. M. Post, and S. D. Wullschleger. 1997. The potential response of terrestrial carbon storage to changes in climate and atmospheric $\mathrm{CO}_{2}$. Climatic Change 35:199-227.

King, D. 2002. Trade-based carbon sequestration accounting. King and Associates, Inc. Presentation and abstract in: USDA Symposium on Natural Resource Management to Offset Greenhouse Gas Emissions. Raleigh, NC. November 19-21.

Kinsman, J.D., and M.C. Trexler. 1993. Terrestrial carbon management and electric utilities. Water, Air \& Soil Pollution 70:545-60.

Koch, G. W. and H. A. Mooney (eds.). 1996. Carbon dioxide and terrestrial ecosystems. Academic Press. San Diego, CA 
Kost, D. A., J. P. Vimmerstedt, and J. H. Brown. 1998. Topsoiling, ripping, and fertilizing effects on tree growth and nutrition on calcareous minesoils. Forest Ecology and Management 103: 307-319.

Kush, J. 2002. Longleaf pine: The southern pine for increasing storage of terrestrial carbon? Auburn University - Forestry \& Wildlife Science. Presentation and abstract in: USDA Symposium on Natural Resource Management to Offset Greenhouse Gas Emissions. Raleigh, NC. November 19-21.

Kustas, W. 2002. Field to regional-scale monitoring of net carbon exchange with satellite remote sensing. USDA - ARS Hydrology \& Remote Sensing Lab. Presentation and abstract in: USDA Symposium on Natural Resource Management to Offset Greenhouse Gas Emissions. Raleigh, NC. November 19-21.

Lal, R. 1999. Soil management and restoration for C sequestration to mitigate the accelerated greenhouse effect. Progress in Environmental Science 1:307-326.

Lal, R. 2000. Soil aggregation and C sequestration. p. 317-329. In Global climate change and tropical ecosystems. R. Lal, J. M. Kimble and B. A. Stewart (eds.). CRC

Press, Inc., Boca Raton, FL.

Lal, R. J. (ed.). 2001. Soil carbon sequestration and the greenhouse effect. SSSA Special Publication No. 57. Soil Sci. Soc. Amer. Madison, WI. 236 pp.

Lal, R., J. Kimble, R.F. Follett, and C.V. Cole. 1998. The potential for U.S. cropland to sequester carbon and mitigate the greenhouse effect. Sleeping Bear Press. Ann Arbor, MI. 128 pp.

Lal, R. and J.M. Kimble. 1997. Conservation tillage for carbon sequestration. Nutrient Cycle Agroecosyst. 49:243-253.

Lal, R., J. M. Kimble, and R. F. Follett. 1998. Land use and soil C pools in terrestrial ecosystems. Pp. 1-10 in R. Lal, J. M. Kimble, R. F. Follett, and B. A. Stewart, eds. Management of Carbon Sequestration in Soil. CRC Lewis Publisher, Boca Raton.

Lal, R., J. M. Kimble, R. F. Follett and C. V. Cole. 1998. The potential of U.S. cropland to sequester carbon and mitigate the greenhouse effect. Ann Arbor Press, Chelsea, MI. pp.128.

Lal, R. and J. P. Bruce. 1999. The potential of world cropland soils to sequester C and mitigate the greenhouse effect. Environ. Sci. Policy. 2:77-185.

Lal, R., R. F. Follett, J. Kimble, and C. V. Cole. 1999. Managing U.S. cropland to sequester carbon in soil. J. Soil Water Conserv. 54:374-381.

Laperche, V. and J. M. Bigham. 2002. Quantitative, chemical and mineralogical characterization of flue gas desulfurization by-products. Journal of Environmental Quality 31:979-988.

Larson, M. M., and J. P. Vimmerstedt. 1983. Evaluation of 30-year-old plantations of stripmined land in east central Ohio. The Ohio State University Ohio Agricultural Research and Development Center, Wooster, Ohio. 
Lauf, R., T. J. Phelps, and Y. Roh. 2001. Biomineralization for carbon sequestration. Fourth quarter report for FY 2001. FEAA036. Oak Ridge National Laboratory. Oak Ridge, TN.

$\mathrm{Li}$, C. 2002. Modeling impacts of management on carbon dynamics in forested wetlands ecosystems. University of New Hampshire, Complex Systems Research Center. Presentation and abstract in: USDA Symposium on Natural Resource Management to Offset Greenhouse Gas Emissions. Raleigh, NC. November 19-21.

Lindzen, R.S. 1994. On the scientific basis for global warming scenarios. Environmental Pollution 83:125-134.

Liski, J., T. Karjalainen, A. Pussinen, G. J. Nabuurs, and P. Kauppi. 2000. Trees as carbon sinks and sources in the European Union. Environmental Science and Policy 3: 91-97.

Listrom, G. A. 1952. Effects of grading strip-mined lands on the early survival and growth of planted trees. USDA Forest Service. Tech Rep. NC-130.

Little, D. W. and L. F. Lefevre. 2001. Advances and changing costs in reverse osmosis and ionic exchange systems. Solid State Technology. 1-4-01.

Liu, S. 2002. Contemporary trends of carbon dynamics and biological potential of carbon sequestration in the US South. EROS Data Center. Presentation and abstract in: USDA Symposium on Natural Resource Management to Offset Greenhouse Gas Emissions. Raleigh, NC. November 19-21.

Ma, S. 2002. Increases in soil respiration following burning and thinking treatments in an oldgrowth, mixed-conifer forest. University of Toledo, Department of EEES. Presentation and abstract in: USDA Symposium on Natural Resource Management to Offset Greenhouse Gas Emissions. Raleigh, NC. November 19-21.

MacDicken, K. 1997a. A guide to monitoring carbon storage in forestry and agroforestry projects. Winrock International, 1611 N. Kent St., Suite 600, Arlington, VA 22209, USA.

MacDicken, K. 1997b. Project specific monitoring and verification: state of the art and challenges. Mitigation and Adaptation Strategies for Global Change 2:27-38.

Machulla, G., M. A. Burns and K. M. Scow. 2005. Microbial properties of mine spoil materials in the initial stages of soil development. Soil Science Society of America Journal 69(4):10691077.

Maclaren, J. P., 1996. Plantation forestry-its role as a carbon sink: conclusions from calculations based on New Zealand's planted forest estate. In M. J. Apps and D. T. Price (eds), Forest Ecosystems, Forest Management, and the Global Carbon Cycle Springer Verlag, Berlin, pp.257-270.

Manion, M. 2002. Estimating the potential cost and scale of forest carbon sequestration in New England forests. Sr. Analyst, Union of Concerned Scientists. Presentation and abstract in: USDA Symposium on Natural Resource Management to Offset Greenhouse Gas Emissions. Raleigh, NC. November 19-21. 
Markewich, H. 2002. US geological survey terrestrial carbon studies, Mississippi river basin, USA. U.S. Geological Survey. Presentation and abstract in: USDA Symposium on Natural Resource Management to Offset Greenhouse Gas Emissions. Raleigh, NC. November 19-21.

Marland, E. 2002. Estimating carbon sequestration in forest products. Appalachian State University. Presentation and abstract in: USDA Symposium on Natural Resource Management to Offset Greenhouse Gas Emissions. Raleigh, NC. November 19-21.

Marland, G. and S. Marland. 1992. Should we store carbon in trees? Water, Air \& Soil Pollution 6(4):181-95.

Marland, G. and B. Schlamadinger. 1997. Forests for carbon sequestration or fossil fuel substitution? A sensitivity analysis. Biomass and Bioenergy 13:389-397.

Marland, G. and B. Schlamadinger. 1999. Carbon sequestered, carbon displaced and the Kyoto context. Proc. TAPPI Inernational Environmental Conference 1:283-289.

McCracken, K. L., W. H. McDowell, R. D. Harter and C. V. Evans. 2002. Dissolved organic carbon retention in soils: comparison of solution and soil measurements. Soil Science Society of America Journal 66:563-568.

McClaughlin, S. B., and R. K. McConathy. 1979. Temporal and spatial patterns of carbon allocation in the canopy of White Oak. Canadian Journal of Botany 57(13):1407-1413.

McLaughlin, S. B., and B. Kohut. 1991. The effects of atmospheric deposition and ozone on carbon allocation and associated physiological processes in red spruce. In: C. Eagar and M. B. Adams (eds.). Ecology and Decline of Red Spruce in the Eastern United States. pp. 338-382. Springer-Verlag.

McNulty, S. 2002. Current and future insect impacts in North American carbon sequestration. USDA - FS SGCP. Presentation and abstract in: USDA Symposium on Natural Resource Management to Offset Greenhouse Gas Emissions. Raleigh, NC. November 19-21.

Mickler, B. 2002. Historic and projected trends in forest carbon in the southern United States. Man Tech International. Presentation and abstract in: USDA Symposium on Natural Resource Management to Offset Greenhouse Gas Emissions. Raleigh, NC. November 19-21.

Minitab. 2000 MINITAB 13.1. Minitab Inc., State College, PA.

Motavalli, P. P., C. A. Palm, W. J. Parton, E. T. Elliot, and S. D. Frey. 1994. Comparisons of laboratory and modeling simulation methods for estimating soil carbon pools in tropical forest soils. Soil Biology and Biochemistry 26: 935-944.

Mooney, S. 2002. Costs of measuring soil carbon. Montana State University, Department of Agricultural Economics. Presentation and abstract in: USDA Symposium on Natural Resource Management to Offset Greenhouse Gas Emissions. Raleigh, NC. November 19-21.

Moulton, R. J., and K. Richards. 1990. Costs of sequestering carbon through tree planting and forest management in the United States. U.S. Forest Service, Washington, D.C.

Moshiri, G. A. 1993. Constructed wetlands for water quality improvement, Lewis Publishers. Chelsea, MI. 
Muncy, J. A. 1992. A guide for environmental protection and best management practices for Tennessee Valley Authority transmission construction and maintenance activities. Tech. Note TVA/LR/NRM 92/1.

Murray, B. 2002. Water quality co-benefits of greenhouse gas reductions incentives in agriculture and forestry. Presentation and abstract in: USDA Symposium on Natural Resource Management to Offset Greenhouse Gas Emissions. Raleigh, NC. November 19-21.

Murray, B. 2002. Alternative methods for establishing carbon baselines: Afforestation of Mississippi bottomlands hardwoods. Presentation and abstract in: USDA Symposium on Natural Resource Management to Offset Greenhouse Gas Emissions. Raleigh, NC. November 19-21.

Nabuurs, G. J., A. J. Dolman, E. Verkaik, P. J. Kuikman, C. A. van Diepen, A. P. Whitmore, W. P. Daaman, O. Oenema, P. Kabat, and G. M. J. Mohren. 1999. Article 3.3 and 3.4 of the Kyoto

Plante, A. F., R. T. Conant, C. E. Stewart, K. Paustian and J. Six. 2006. Impact of soil texture on the distribution of soil organic matter in physical and chemical fractions. Soil Science Society of America Journal 70:287-296.

Protocol: consequences for industrialized countries' commitment, the monitoring needs and possible side effects. Environmental Science and Policy 3: 123-134.

Nabuurs, G.J. and R. Sikkema. 1998. The role of harvested wood products in national carbon balances- an evaluation of alternatives for IPCC guidelines. IBN-Research Report 98/3, Institute for Forestry and Nature Research, Wageningen, The Netherlands. 25 pp.

NCASI Progress Report. 1999. Optimizing Land Application of Wastes for Short Rotation Woody Crops.

Nelson, D. W. and L. E. Sommers. 1986. Total C, organic C, and organic matter. p 961-1010. In A. Klute (ed.) Methods of soil analysis. Part 3. ASA, Madison, WI.

Neuhauser, E. F., L. P. Abrahamson, E. H. White, D. J. Robison, J. M. Peterson, and W. H. Benjamin. 1997. Northeast energy perspective: willow biomass - bioenergy industry development. In: (B.J. Stokes, ed.) Proceedings of the First Conference of the Short-rotation Woody Crops Operations Working Group, Sept. 23-25, 1996, Paducah, Kentucky. USDA Forest Service, Auburn, Alabama. Pp. 45-52

Niyogi, D. 2002. Assessing environmental feedback on carbon assimilation over southeastern US. NCSU - MEAS. Presentation and abstract in: USDA Symposium on Natural Resource Management to Offset Greenhouse Gas Emissions. Raleigh, NC. November 19-21.

Norby, R. J., E. G. O'Neill, and S. D. Wullschleger. 1995. Belowground responses to atmospheric carbon dioxide in forests. In: J. M. Kelly and W. W. McFee (eds.). Carbon Forms and Functions in Forest Soils. pp. 397-419. Soil Science Society of America. Madison, WI.

Norby, R. J., S. D. Wullschlerger, and C. A. Gunderson. 1996. Tree responses to elevated $\mathrm{CO}_{2}$ and implications for forests. In: Carbon Dioxide and Terrestrial Ecosystem. G. W. Koch and H. A. Mooney (eds.). pp. 1-22. Academic Press. San Diego, California. 
Nyomora, A. M. S., R. N. Sah, P. B. Brown, and R. O. Miller. 1997. Boron determination in biological materials by inductively coupled plasma atomic emission and mass spectrometry: effects of sample dissolution methods. Fresenius Jouranl of Analytical Chemistry 357:11851191.

Nyomora, A. M. S., P. H. Brown, K. Pinney, and V. S. Polito. 2000. Foliar application of boron to almond trees affects pollen quality. Journal of the American Society for Horticultural Science. 125:265-270.

Nyomora, A. M. S., P. H. Brown, and B. Krueger. 1999. Effects of rate and time of boron application on almond tissue B concentration and productivity. Horticultural Science 34:242-245.

O'Neill, E. G. 1994. Responses of soil biota to elevated atmospheric carbon dioxide. In: Proceedings of Below-ground Responses to Atmospheric $\mathrm{CO}_{2}$ : Implications for Plants, Soil Biota and Ecosystem Processes Workshop. Pellston, Michigan. Kluwer Academic Publishers. Wageningen, The Netherlands. Special Issue Plant and Soil 165:55-65. July 1994.

Oren, R. 2002. Soil fertility modifies source-sink interactions and carbon sequestration in a pine forest under ambient and elevated atmosphere $\mathrm{CO}_{2}$ concentrations. Duke University, Division of Environmental Science \& Policy. Presentation and abstract in: USDA Symposium on Natural Resource Management to Offset Greenhouse Gas Emissions. Raleigh, NC. November 19-21.

Palumbo, A. 2002. Development of measurement techniques for carbon and microbial communities on mine soil. Oak Ridge National Laboratory. Presentation and abstract in: USDA Symposium on Natural Resource Management to Offset Greenhouse Gas Emissions. Raleigh, NC. November 19-21.

Pan, Y. 2002. Impacts of increased anthropogenic nitrogen deposition on forest carbon sequestration and $\mathrm{N}$ leaching. USDA - FS. Presentation and abstract in: USDA Symposium on Natural Resource Management to Offset Greenhouse Gas Emissions. Raleigh, NC. November 19-21.

Parton, W. J., D. S. Schimel, C. V. Cole, and D. S. Ojima. 1987. Analysis of factors controlling soil organic matter levels in Great Plains grasslands. Soil Science Society of America Journal 51: 1173-1179.

Paul, K. 2002. Modeling carbon sequestration following Afforestation of reforestation: Prediction of carbon turnover in forest litter and soil using the FullCAM model. CSIRO Forestry and Forest Products. Presentation and abstract in: USDA Symposium on Natural Resource Management to Offset Greenhouse Gas Emissions. Raleigh, NC. November 19-21.

Paul, E.A., K. Paustian, E.T. Eliott and C.V. Cole, (eds.). 1997. Soil Organic matter in temperate agroecosystems: Long term experiments in North America. CRC Press. Boca Raton, FL. pp. 430.

Paustian, K., O. Andren, H.H. Janzen, R. Lal, P. Smith, G. Tian, H. Tiessen, M. Van Noorwijk, and P.L. Woomer. 1997a. Agricultural Soils as a sink to mitigate $\mathrm{CO}_{2}$ emissions. Soil Use and Managmentt. 13:230-244.

Paustian, K., H.P. Collins, and E.A. Paul. 1997b. Management controls on soil carbon. pp 1549. In: Paul, E.A., K. Paustian, E.T. Elliot, and C.V. Cole (eds) Soil Organic Matter in Temperate Agroecosystems: Long-Term Experiments in North America. CRC Press. Boca Raton, FL. 
Pavan, M. S., F. T. Bingham, and P. F. Pratt. 1982. Toxicity of aluminum to coffee in Ultisols and Oxisols amended with $\mathrm{CaCO}_{3}, \mathrm{MgCO}_{3}$, and $\mathrm{CaSO}_{4}$. Soil Science Society of America Journal 46: 1201-1207.

Pedersen, T. A., A. S. Rogowski, and R. Pennock Jr. 1980. Physical characteristics of some minesoils. Soil Science Society of America Journal 44: 321-328.

Penn, S. G., Hu, H. N., Brown, P. B., and C. B. Lebrilla. 1997. Direct analysis of sugar alcohol borate complexes in plant extracts by matrix-assisted laser desorption/ionization Fourier transform mass spectrometry. Analytical Chemistry 69(N13):2471-2477.

Perika, S., N. Bellaloui, C. Greve, H. Hu, and P. H. Brown. 2000. Boron Transport and Sugar Metabolism in Olive. HortScience. (In-Press)

Perkins, H. F., and P. S. Troth. 1981. Soil development in kaolin spoil. Soil Science 131: 290295.

Picchioni, G. A., P. H. Brown, S. A. Weinbaum, and T. T. Muraoka. 1997. Macronutrient allocation to leaves and fruit of mature alternate-bearing Pistachio trees: magnitude and seasonal patterns at the whole-canopy level. Journal of American Horticulutural Science 122:267-274.

Pichtel, J. R., W. A. Dick, and P. Sutton. 1994. Comparison of amendments and managementpractices for long-term reclamation of abandoned mine lands. Journal of Environmental Quality 23: 766-772.

Post W. M., A. W. King, and S. D. Wullschleger. 1997. Historical variations in terrestrial biospheric carbon storage. Global Biogeochemical Cycles 11:99-109.

Post, W. M., A. W. King, and S. D. Wullschleger. 1996. Soil organic matter models and global estimates of soil organic carbon. In: D. S. Powlson, P. Smith, and J. U. Smith (eds.). Evaluation of Soil Organic Matter Models. pp. 201-222. NATO ASI Ser. 138. Springer-Verlag, Berlin.

Post, W. M., R. C. Izaurralde, L. K. Mann, and N. Bliss. 1999. Monitoring and verification of soil organic carbon sequestration. In: Symposium: Carbon sequestration in soils science, monitoring and beyond, December 3-5, St. Michaels, MD.

Potter, S. 2002. An approach for estimating soil carbon using the national nutrient loss database. Texas A\&M University - Blackland Research Center. Presentation and abstract in: USDA Symposium on Natural Resource Management to Offset Greenhouse Gas Emissions. Raleigh, NC. November 19-21.

Potter, C.S. and S.A. Klooster. 1997. Global model estimates of carbon and nitrogen storage in litter and soil pools: response to changes in vegetation quality and biomass allocation. Tellus Ser. B. 49B:1-17.

Preve, R. E., J. A. Burger, and R. E. Kreh. 1984. Influence of mine spoil type, fertilizer, and mycorrhizae on pines seeded in greenhouse trays. Journal of Environmental Quality 13: 387391. 
Punshon, T., D. C. Adriano and J. T. Weber. 2001. Effect of Flue Gas Desulfurization residue on plant establishment and soil and leachate quality. Journal of Environmental Quality 30:10711080.

Radtke, P. 2002. Modeling deadwood C production and decay in loblolly pine plantations to improve accuracy of carbon stock assessments. Virginia Tech, Department of Forestry. Presentation and abstract in: USDA Symposium on Natural Resource Management to Offset Greenhouse Gas Emissions. Raleigh, NC. November 19-21.

Reeves, III, J. 2002. Spectroscopic methods for the determination of soil carbon. USDA. Presentation and abstract in: USDA Symposium on Natural Resource Management to Offset Greenhouse Gas Emissions. Raleigh, NC. November 19-21.

Reicosky, D. Tillage-Induced variation in terrestrial carbon stocks and $\mathrm{CO}_{2}$ loss across an eroded landscape. USDA - ARS. Presentation and abstract in: USDA Symposium on Natural Resource Management to Offset Greenhouse Gas Emissions. Raleigh, NC. November 19-21.

Reid, R. J., J. E. Hayes, A. Post, J. C. R. Stangoulis and R. D. Graham. 2004. A critical analysis of the causes of boron toxicity in plants. Plant, Cell \& Environment 27(11): 1405-1414.

Richter, D. D., D. Markewitz, S. E. Trumbore, and C. G. Wells. 1999. Rapid accumulation and turnover of soil carbon in a re-establishing forest. Nature 400: 56-58.

Riemenschneider, D. E., D. A. Netzer, and W. E. Berguson. 1997. Intensive culture of hybrid poplars in Minnesota. IN (B.J. Stokes, ed.) Proceedings of the First Conference of the Shortrotation Woody Crops Operations Working Group, Sept. 23-25, 1996, Paducah, Kentucky. USDA Forest Service, Auburn, Alabama. Pp. 53-58.

Rickman, R. W., C. L. Douglas, Jr., S. L. Albrecht L. G. Bundy, and J. L. Berc. 2001. CQESTR: a model to estimate carbon sequestration in agricultural soils. Journal of Soil and Water Conservation 56:3.

Roberts, J. A., W. L. Daniels, J. C. Bell, and J. A. Burger. 1988. Early stages of mine soil genesis in a southwest Virginia spoil lithosequence. Soil Science Society of American Journal 52: 716-723.

Rodrique, J. A. and J. A. Burger. 2004. Forest soil productivity of mined land in the midwestern and eastern coalfield regions. Soil Science Society of America Journal 68:833-844.

Robinson, D. 2002. Enhancing carbon sequestration in natural stands. NCSU - Forestry. Presentation and abstract in: USDA Symposium on Natural Resource Management to Offset Greenhouse Gas Emissions. Raleigh, NC. November 19-21.

Rogers, J. 2002. Carbon sequestration and the red river national wildlife refuge: A case study. The Conservation Fund. Presentation and abstract in: USDA Symposium on Natural Resource Management to Offset Greenhouse Gas Emissions. Raleigh, NC. November 19-21.

Rosecrance, R. C., S. A. Weinbaum, and P. H. Brown. 1996. Assessment of nitrogen, phosphorus, and potassium uptake capacity and root growth in mature alternate-bearing pistachio (Pistacia vera) trees. Tree Physiology 16:949-956. 
Rosenberg, N. J., R. C. Izaurralde, and E. L. Malone (eds.). 1999. Carbon Sequestration in Soils: Science, Monitoring and Beyond. Battelle Press. Columbus, $\mathrm{OH}$.

Rosenberg, N. J., V. Cole, and K. Paustian. 1998. Mitigation of greenhouse gas emissions by the agricultural sector. New technologies, policies and measures offer potential to mitigate emissions while improving productivity and ecosystem health: An Introductory Editorial. Climatic Change 40:1-5.

Rosenberg, N. J. and R. C. Izaurralde. 2000. Storing carbon in agricultural soils to mitigate global warming. Issue paper 14. CAST. Ames, IA. 8pp.

Rosenzweig, C. and D. Hillel. 2000. Soils and global climate change: Challenges and opportunities. Soil Science 165:47-56.

Row, C. Carbon storage and potential value for selected southern forest management options. Row Associates. Presentation and abstract in: USDA Symposium on Natural Resource Management to Offset Greenhouse Gas Emissions. Raleigh, NC. November 19-21.

Sah, R and P.H. Brown. 1999. Isotope ratio determination in boron analysis. Biological Trace Element Research. 66: 39-53.

Sah, R. N. and P. H. Brown. 1997. Techniques for boron determination and their application to the analysis of plant and soil samples. Plant and Soil 193:15-33.

Santer, B.D., K.E. Taylor, T.M.L. Wigley, J.E. Penner, P.D. Jones and U. Cubasch. 1995. Towards the detection and attribution of an anthropogenic effect on climate. Climate Dynamics 12:77-100.

Schafer, W. M., G. A. Nielson, and W. D. Nettleton. 1980. Minesoil genesis and morphology in a spoil chronosequence in Montana. Soil Science Society of American Journal 44: 802-807.

Schlamadinger, B. and G. Marland. 1996. The Role of Forest and Bioenergy Strategies in the Global Carbon Cycle. Biomass and Bioenergy 10: 275-300.

Schlamadinger, B. and G. Marland. 2000. Land use and global climate change: Forest, Land management, and the Kyoto Protocol. Pew Center of Global Climate Change, Arlington, VA. pp. 54.

Schlesinger, W.H. 1990. Evidence from chronosequence studies for a low carbon-storage potential of soils. Nature 348:(6298)232-234.

Schlesinger, W. H. 1991. Biogeochemistry: An analysis of global change. Academic Press, Inc, San Diego.

Schoeneberger, M. 2002. Agroforestry: Having your carbon and eating it too. USDA National Agroforestry Center. Presentation and abstract in: USDA Symposium on Natural Resource Management to Offset Greenhouse Gas Emissions. Raleigh, NC. November 19-21.

Schoenholtz, S. H., and J. A. Burger. 1984. Influence of cultural treatments on survival and growth of pines on strip-mined sites. Reclamation and Revegetation Research 3:23-237. 
Schoenholtz, S.H., J. A. Burger, and R. E. Kreh. 1992. Fertilizer and organic amendment effects on mine soil properties and revegetation success. Soil Science Society of America Journal 56: 117-1184.

Scott, N. 2002. Forest management effects on carbon sequestration at howland forest, Maine, USA. Woods Hole Research Center. Presentation and abstract in: USDA Symposium on Natural Resource Management to Offset Greenhouse Gas Emissions. Raleigh, NC. November 19-21.

Seiler, R. 1996. Synthesis of data from studies by the National Irrigation Water Quality Program. Water Resources Bulletin. $6^{\text {th }}$ ser. 32:1233-1245.

Shukla, M. K., R. Lal, J. Underwood and M. Ebinger. 2004. Physical and hydrological characteristics of reclaimed minesoils in southeastern Ohio. Soil Science Society of America Journal 68(4):1352-1359.

Shukla, M. K., R. Lal and M. H. Ebinger. 2005. Physical and chemical properties of a minespoil eight years after reclamation in northeastern Ohio. Soil Science Society of America Journal. 69(4):1288-1297.

Sikora, F.J ., L. L. Behrends, G. A. Brodie, and H. N Taylor. 1999. Anaerobic wetlands for treating acid mine drainage: $\mathrm{Cu}, \mathrm{Ni}, \mathrm{Pb}, \mathrm{Zn}$, and $\mathrm{Se}$ removal. (Under peer review for Journal of Environmental Quality).

Skog, K. 2002. A proposal for a widely applicable method countries can use to estimate carbon stored in harvested wood products and the uncertainly of such estimates. USDA - FS, Forest Products Laboratory. Presentation and abstract in: USDA Symposium on Natural Resource Management to Offset Greenhouse Gas Emissions. Raleigh, NC. November 19-21.

Smith, G. 2002. Water quality and carbon offsets: The Deschutes riparian restoration project. Environmental Resources Trust. Presentation and abstract in: USDA Symposium on Natural Resource Management to Offset Greenhouse Gas Emissions. Raleigh, NC. November 19-21.

Smith, G. 2002. Designing sampling systems to detect carbon stored in soil or forest sequestration projects. Environmental Resources Trust. Presentation and abstract in: USDA Symposium on Natural Resource Management to Offset Greenhouse Gas Emissions. Raleigh, NC. November 19-21.

Sobek, A. A., J. G. Skousen, and S. E. Fisher Jr. 2000. Chemical and physical properties of overburdens and minesoils. Pp. 77-104 in R. I. Barnhisel, R. G. Darmody,

and W. L. Daniels, eds. Reclamation of drastically disturbed lands. American Agronomy Society, Madison, WI.

Sparling, G. P., D. Wheeler, E. T. Vesley and L. A. Schipper. 2006. What is soil organic matter worth? Journal of Environmental Quality. 35:548-557.

Stanley, B. 2002. Improving carbon offset measurement techniques and protecting biodiversity through pilot reforestation. The Nature Conservancy. Presentation and abstract in: USDA Symposium on Natural Resource Management to Offset Greenhouse Gas Emissions. Raleigh, NC. November 19-21.

Stevenson, F.J. 1994. Humus chemistry: Genesis, Composition, Reactions. Wiley, NY. pp. 496. 
TVA Engineering Laboratory. 1998. Paradise Fossil Plant Groundwater Assessment. WR98-164-124 rev.1. Norris, TN.

Tate III., R. L. 1985. Microorganisms, ecosystem disturbance and soil-formation processes. Pp. 1-33 in R. L. Tate III. and D. A. Klein, eds. Soil Reclamation Processes. Marcel Dekker, Inc, New York, NY.

Thomas, D., and I. Jansen. 1985. Soil development in coal mine spoils. Journal of Soil and Water Conservation 40: 439-442.

Thompson, J. 2002. Soil carbon storage estimation in central hardwood forest watersheds using quantitative soil-landscape modeling. NCSU, Department of Soil Science. Presentation and abstract in: USDA Symposium on Natural Resource Management to Offset Greenhouse Gas Emissions. Raleigh, NC. November 19-21.

Thornton, F. C. In review. B. R. Bock, A. D. Behel, A. Houston, and D. D. Tyler. Utilization of waste materials to promote hardwood tree growth. Southern Journal of Applied Forestry, In Review.

Thurman, N. C., and J. C. Sencindiver. 1986. Properties, classification, and interpretations of minesoils at two sites in West Virginia. Soil Science Society of America Journal 50: 181-185

Torbert, J. L., and J. A. Burger. 2000. Forest land reclamation. pp. 371-398 in R. I. Barnhisel, R. G. Darmody, and W. L. Daniels, eds. Reclamation of drastically disturbed lands. American Agronomy Society, Madison, WI.

Torbert, J. L., and J. A. Burger. 1994. Influence of grading intensity on ground cover establishment, erosion, and tree establishment on steep slopes. pp. 226-231. International Land Reclamation and Mine Drainage Conference and the Third International Conference on the Abatement of Acidic Drainage, Pittsburg, PA.

Torbert, J. L., A. R. Tuladhar, J. A. Burger, and J. C. Bell. 1988. Minesoil property effects on the height of ten-year-old white pine. Journal of Environmental Quality 17: 189-192.

Torbert, J. L., J. A. Burger, and W.L. Daniels. 1990. Pine growth variation associated with overburden rock type on a reclaimed surface mine in Virginia. Journal of Environmental Quality 19: 88-92.

Torbert, J. L., J. A. Burger, and T. Probert. 1995. Evaluation of techniques to improve white pine establishment on an Appalachian minesoil. Journal of Environmental Quality 24: 869-873.

Trettin, C. 2002. Wetlands - an integral component of the forest landscape: Perspectives and research needs. USDA - FS Center for Forested Wetlands Research. Presentation and abstract in: USDA Symposium on Natural Resource Management to Offset Greenhouse Gas Emissions. Raleigh, NC. November 19-21.

Trumbore, S. E. 1997. Potential responses of soil organic carbon to global environmental change. Proceedings of the National Academy of Science. 94:(16)8284-8291.

United States Department of Agriculture (USDA), Natural Resource Conservation Service (NRCS). 1996. Soil Survey Laboratory methods manual. pp. 693. 
Ussiri, D. A. N. and R. Lal. 2005. Carbon sequestration in reclaimed minesoils. 2005.

Critical reviews in plant science. 24:151-165.

US Dept of Commerce, Climatic Atlas of the US, Environmental Science Services Admin, Environmental Data Service, June 1968.

United States Department of Energy (USDOE). 1999. Carbon Sequestration: State of the Science, A working paper for road mapping future carbon sequestration R\&D. USDOE, Washington, D.C.

U.S. Department of Energy. 2000. Carbon Sequestration Research and Development. DOE/SC/FE-1. Washington, D.C.

USEPA. 1995. Test method for evaluating solid waste: Physical/chemical methods. EPA 530/SW-846. U.S. Gov. Print. Office, Washington, D.C.

Vance, E. 2002. Factors controlling forest soil carbon change. NCASI. Presentation and abstract in: USDA Symposium on Natural Resource Management to Offset Greenhouse Gas Emissions. Raleigh, NC. November 19-21.

Vann C. 2002. Carbon sequestration and methane emissions in bald cypress microcosms exposed to elevated atmospheric carbon dioxide. Presentation and abstract in: USDA Symposium on Natural Resource Management to Offset Greenhouse Gas Emissions. Raleigh, NC. November 19-21.

Vimmerstedt, J. P., M. C. House, M. M. Larson, J. D. Kasile, and B. L. Bishop. 1989. Nitrogen and carbon accretion on Ohio Coal Minesoils: Influence of soil-forming factors. Landscape and Urban Planning 17: 99-111.

Vine, E., J. Sathaye, and W. Makundi. 1999. The monitoring, evaluation, reporting, verification, and certification of climate change forest projects. LBNL-41877, Lawrence Berkeley National Laboratory, Berkeley, CA.

Vogt, K. A., D. J. Vogt, S. Brown, J. P. Tilley, R. L. Edmonds, W. L. Silver, and T. G. Siccama. 1995. Dynamics of forest floor and soil organic matter accumulation in boreal, temperate, and tropical forests. pp. 159-175 in R. Lal, J. Kimble, E. Levine, and B. A. Stewart, eds. Soil Management and Greenhouse Effect. CRC Lewis Publishers, Boca Raton.

Wade, G. L., R. L. Thompson, and W. G. Vogel. 1985. Success of trees and shrubs in an 18year-old planting on mine spoil. USDA Forest Service, Res Paper NE-567 pp. 10.

Wallace, A. 1994. Soil organic matter must be restored to near original levels. Commun. Soil Sci. Plant Anal. 25:29-35.

Wear, D. 2002. Afforestation potential in the US south. USDA - FS, Forestry Sciences Laboratory. Presentation and abstract in: USDA Symposium on Natural Resource Management to Offset Greenhouse Gas Emissions. Raleigh, NC. November 19-21.

Williams, J. 2002. Carbon sequestration in soils with consideration of $\mathrm{CO}_{2}$ emissions from production inputs: An economic analysis. Kansas State University, Department of Agricultural 
Economics. Presentation and abstract in: USDA Symposium on Natural Resource Management to Offset Greenhouse Gas Emissions. Raleigh, NC. November 19-21.

Williams, M. A. 2004. The potential of U.S. forest soils to sequester carbon and mitigate the greenhouse effect. CRC Press LLC, Boca Raton, FL 33431. 429p. ISBN 1-56670-583-5.

Winjum, J.K., S. Brown, and B. Schlamadinger. 1998: Forest harvests and wood products: sources and sinks of atmospheric carbon dioxide. Forest Science 44: 272-284.

Winjum, J. K., and P. E. Schroeder. 1997. Forest plantations of the world: their extent, ecological attributes and carbon storage. Agricultural and Forest Meterology 84: 153-167.

Yermiyahu, U., R. Keren and Y. Chen. 2001. Effect of composted organic matter on boron uptake by plants. Soil Science Society of America Journal 65:1436-1441.

Yoder, R. E. 1936. A direct method of aggregate analysis and a study of a physical nature of erosion losses. Journal of American Society of Agronomy. 28:337-351.

Youssefi, F., P. H. Brown, and S. A. Weinbaum. 1999. Regulation of nitrogen uptake at the whole plant level: A study in almond trees. Horticulture Technology 9:598-600.

Zeleznik, J. D., and J. G. Skousen. 1996. Survival of three tree species on old reclaimed surface mines in Ohio. Journal of Environmental Quality 25: 1429-1435.

Zilberman, D., and D. Sunding. 2001. Climate change policy and the agricultural sector. pp. 629-643 in R. Lal, J. M. Kimble, R. F. Follett, and B. A. Stewart, eds. Assessment methods for soil carbon. Lewis Publishing, Boca Raton, FL.

Zhang, X. 2002. Carbon sequestration of Afforestation/reforestation and deforestation of China in the past two decades. The Chinese Academy of Forestry. Presentation and abstract in: USDA Symposium on Natural Resource Management to Offset Greenhouse Gas Emissions. Raleigh, NC. November 19-21. 


\section{List of Acronyms and Abbreviations}

\begin{tabular}{|c|c|}
\hline $\begin{array}{l}\text { B } \\
\text { BMP }\end{array}$ & $\begin{array}{l}\text { Boron } \\
\text { Best Management Practice }\end{array}$ \\
\hline CCWESTRS & Carbon Capture and Water Emissions Treatment System \\
\hline $\mathrm{cm}$ & Centimeter \\
\hline $\mathrm{CO}_{2}$ & Carbon Dioxide \\
\hline DAP & Days after planting \\
\hline DOE & United States Department of Energy \\
\hline EA & Environmental assessment \\
\hline EDR & Environmental decision record \\
\hline EPRI & Electric Power Research Institute \\
\hline ET & Evapotranspiration \\
\hline FGD & Flue gas desulfurization \\
\hline g & Gram \\
\hline gal & Gallon \\
\hline GIS & Geographic Information System \\
\hline ha & Hectare \\
\hline $\mathrm{H}_{2} \mathrm{O}$ & Water \\
\hline KDEP & Kentucky Department for Environmental Protection \\
\hline $\mathrm{kg}$ & Kilogram \\
\hline I & Liter \\
\hline LDI & Leaf damage index \\
\hline Iph & Liters per hour \\
\hline Ipm & Liters per minute \\
\hline $\mathrm{m}$ & Meter \\
\hline $\mathrm{mg}$ & Milligram \\
\hline Mw & Megawatt \\
\hline $\mathrm{N}, \mathrm{N}_{2}$ & Nitrogen \\
\hline NEPA & National Environmental Policy Act \\
\hline NETL & National Energy Technology Laboratory \\
\hline NPDES & National Pollutant Discharge Elimination System \\
\hline $\mathrm{NO}_{\mathrm{x}}$ & Nitrogen Oxides (both nitric oxide and nitrogen dioxide) \\
\hline $\mathrm{O}$ & Oxygen \\
\hline PAF & Paradise Fossil Plant \\
\hline SCR & Selective Catalytic Reduction \\
\hline SMCRA & Surface Mining Control and Reclamation Act (1977) \\
\hline $\mathrm{SO}_{2}$ & Sulfur Dioxide \\
\hline $\mathrm{SO}_{\mathrm{x}}$ & Sulfur Oxides (both sulfur dioxide and sulfur trioxide) \\
\hline TVA & Tennessee Valley Authority \\
\hline U.S. & United States \\
\hline USEPA & United States Environmental Protection Agency \\
\hline
\end{tabular}




\section{Appendices}

Appendix 1. Common and scientific names of plant species referred to in this report.

\begin{tabular}{|c|c|c|}
\hline Aleppo pine & & Pinus halepensis \\
\hline American elm & & Ulmus americana. \\
\hline Arizona cypress & & Cupressus arizonica \\
\hline Barley & & Elyhordeum \\
\hline Black locust & & Robinia pseudoacacia \\
\hline Box-Elder & & Acer negundo \\
\hline Broom Sedge & & Andropogon virginicus \\
\hline Carolina Geranium & & Geranium carolianum \\
\hline Cattail & & Typha latifolia \\
\hline Corn & & e.g., Plagiobothrys or Zea spp. \\
\hline Cotton & Gossy & pium spp. \\
\hline Eastern Cottonwood & & Populus deltoides \\
\hline Eastern Red Cedar & & Juniperus virginiana \\
\hline Eastern Redbud & & Cercis canadensis \\
\hline Fig & & Ficus \\
\hline Grapes & & Vitis \\
\hline Honey-Locust & Gledit & sia triacanthos \\
\hline Incense cedar & & Calocedrus decurrens \\
\hline Kidney beans & & Phaseolus vulgaris \\
\hline Korean Lespedeza & & Lespedeza stipulacea \\
\hline Lespedeza & & Lespedeza sericea \\
\hline Live oak & & Quercus virginiana. \\
\hline Moss & & Bryophytes \\
\hline Pea & & Lathyrus \\
\hline Peach & & Prunus persica \\
\hline Pecan & & Carya illinoinensis \\
\hline Pokeweed & & Phytolacca \\
\hline Pokeweed & & Phytolacca americana \\
\hline Potato & & Solanum tuberosum \\
\hline Prickly lettuce & & Lactuca serriola \\
\hline Prickly Lettuce & Lactuc & a scariola \\
\hline Rabbitfoot grass & & Polypogon monspeliensis \\
\hline Red maple & & Acer rubrum. \\
\hline Reed & & Phragmites australis \\
\hline Sericea Lespedeza & & Lespedeza sericea \\
\hline Sour Clover & & Melilotus indica \\
\hline Sugar beet & & Beta procumbens \\
\hline Sweetgum & & Liquidambar styraciflua \\
\hline Sycamore & & Platanus occidentalis \\
\hline Tall fescue & & Festuca arundinacea \\
\hline Tall Fescue & & Festuca arundinacea \\
\hline Thalia & & Thalia dealbata \\
\hline Thistle & & Cirsium sp. \\
\hline Tobacco & & Nicotiana. \\
\hline Tomato & & Solanum lycopersicum \\
\hline Tulip poplar (Yellow & lar) & Liriodendron tulipifera \\
\hline
\end{tabular}


Turnip

Venus' Looking Glass

Violet

Virginia Creeper

Walnut

Water hyacinth

White oak

White pine
Brassica septiceps

Triodanis perfoliata

Viola sp.

Parthenocissus quinquefolia

Juglans

Eichhornia

Quercus alba

Pinus strobus 
Appendix 2. Results of baseline surface water chemistry analyses.

\begin{tabular}{|c|c|c|c|c|c|c|}
\hline Sample De & escription & Analysis & Result & Units & MDL & $\begin{array}{l}\text { Analysis } \\
\text { Date }\end{array}$ \\
\hline $\begin{array}{l}\text { PAF-FGD } \\
5 A\end{array}$ & STILLING & POND- Aluminum, Total & 0.95 & $\mathrm{mg} / \mathrm{L}$ & 0.05 & $06 / 13 / 2001$ \\
\hline $\begin{array}{l}\text { PAF-FGD } \\
5 A\end{array}$ & STILLING & POND- Ammonia as $\mathrm{N}$ & 0.14 & $\mathrm{mg} / \mathrm{L}$ & 0.01 & $06 / 05 / 2001$ \\
\hline $\begin{array}{l}\text { PAF-FGD } \\
5 A\end{array}$ & STILLING & POND- Antimony, Total & 0.012 & $\mathrm{mg} / \mathrm{L}$ & 0.001 & $06 / 12 / 2001$ \\
\hline $\begin{array}{l}\text { PAF-FGD } \\
5 A\end{array}$ & STILLING & POND- Arsenic, Total & 0.006 & $\mathrm{mg} / \mathrm{L}$ & 0.001 & 06/09/2001 \\
\hline $\begin{array}{l}\text { PAF-FGD } \\
5 A\end{array}$ & STILLING & POND- Barium, Total & 0.069 & $\mathrm{mg} / \mathrm{L}$ & 0.01 & $06 / 13 / 2001$ \\
\hline $\begin{array}{l}\text { PAF-FGD } \\
5 A\end{array}$ & STILLING & POND- Beryllium, Total & 0.0053 & $\mathrm{mg} / \mathrm{L}$ & 0.001 & $06 / 13 / 2001$ \\
\hline $\begin{array}{l}\text { PAF-FGD } \\
5 A\end{array}$ & STILLING & POND- Boron, Total & 62 & $\mathrm{mg} / \mathrm{L}$ & 0.2 & $06 / 13 / 2001$ \\
\hline $\begin{array}{l}\text { PAF-FGD } \\
5 A\end{array}$ & STILLING & $\begin{array}{c}\text { POND- } \underset{\text { Hardness }}{\mathrm{Ca}} \stackrel{\mathrm{Mg}}{\mathrm{C}} \quad \text { Calculatec } \\
\end{array}$ & 2700 & $\begin{array}{l}\mathrm{mg} / \mathrm{L} \\
\mathrm{CaCO} 3\end{array}$ & & $06 / 14 / 2001$ \\
\hline $\begin{array}{l}\text { PAF-FGD } \\
5 A\end{array}$ & STILLING & POND- Cadmium, Total & 0.055 & $\mathrm{mg} / \mathrm{L}$ & 0.0001 & 06/08/2001 \\
\hline $\begin{array}{l}\text { PAF-FGD } \\
5 A\end{array}$ & STILLING & POND- Calcium, Total & 570 & $\mathrm{mg} / \mathrm{L}$ & 0.1 & $06 / 13 / 2001$ \\
\hline $\begin{array}{l}\text { PAF-FGD } \\
5 A\end{array}$ & STILLING & POND- Chemical Oxygen Demand & $<M D L$ & $\mathrm{mg} / \mathrm{L}$ & 20 & $06 / 11 / 2001$ \\
\hline $\begin{array}{l}\text { PAF-FGD } \\
5 A\end{array}$ & STILLING & POND- Chloride, Total & 400 & $\mathrm{mg} / \mathrm{L}$ & 1 & 06/08/2001 \\
\hline $\begin{array}{l}\text { PAF-FGD } \\
5 A\end{array}$ & STILLING & POND- Chromium, Total & 0.007 & $\mathrm{mg} / \mathrm{L}$ & 0.001 & 06/08/2001 \\
\hline $\begin{array}{l}\text { PAF-FGD } \\
5 A\end{array}$ & STILLING & POND- Cobalt, Total & 0.029 & $\mathrm{mg} / \mathrm{L}$ & 0.001 & $06 / 13 / 2001$ \\
\hline $\begin{array}{l}\text { PAF-FGD } \\
5 A\end{array}$ & STILLING & POND- Copper, Total & 0.0047 & $\mathrm{mg} / \mathrm{L}$ & 0.001 & 06/08/2001 \\
\hline $\begin{array}{l}\text { PAF-FGD } \\
5 A\end{array}$ & STILLING & POND- Copper, Total & $<M D L$ & $\mathrm{mg} / \mathrm{L}$ & 0.01 & $06 / 13 / 2001$ \\
\hline $\begin{array}{l}\text { PAF-FGD } \\
5 A\end{array}$ & STILLING & POND- Filterable Residue & 5800 & $\mathrm{mg} / \mathrm{L}$ & 10 & 06/06/2001 \\
\hline $\begin{array}{l}\text { PAF-FGD } \\
5 A\end{array}$ & STILLING & POND- Fluoride, Total & 29 & $\mathrm{mg} / \mathrm{L}$ & 0.1 & $06 / 14 / 2001$ \\
\hline $\begin{array}{l}\text { PAF-FGD } \\
5 A\end{array}$ & STILLING & POND- Inorganic Carbon, Total & 3 & $\mathrm{mg} / \mathrm{L}$ & 1 & $06 / 14 / 2001$ \\
\hline $\begin{array}{l}\text { PAF-FGD } \\
5 A\end{array}$ & STILLING & POND- Iron, Total & 0.35 & $\mathrm{mg} / \mathrm{L}$ & 0.01 & $06 / 13 / 2001$ \\
\hline $\begin{array}{l}\text { PAF-FGD } \\
5 A\end{array}$ & STILLING & POND- Lead , Total & $<M D L$ & $\mathrm{mg} / \mathrm{L}$ & 0.001 & $06 / 11 / 2001$ \\
\hline $\begin{array}{l}\text { PAF-FGD } \\
5 A\end{array}$ & STILLING & POND- Magnesium, Total & 320 & $\mathrm{mg} / \mathrm{L}$ & 0.01 & $06 / 13 / 2001$ \\
\hline $\begin{array}{l}\text { PAF-FGD } \\
5 A\end{array}$ & STILLING & POND- Manganese, Total & 1.3 & $\mathrm{mg} / \mathrm{L}$ & 0.005 & $06 / 13 / 2001$ \\
\hline PAF-FGD & STILLING & POND- Mercury, Total & 0.0015 & $\mathrm{mg} / \mathrm{L}$ & 0.0002 & 06/07/2001 \\
\hline
\end{tabular}




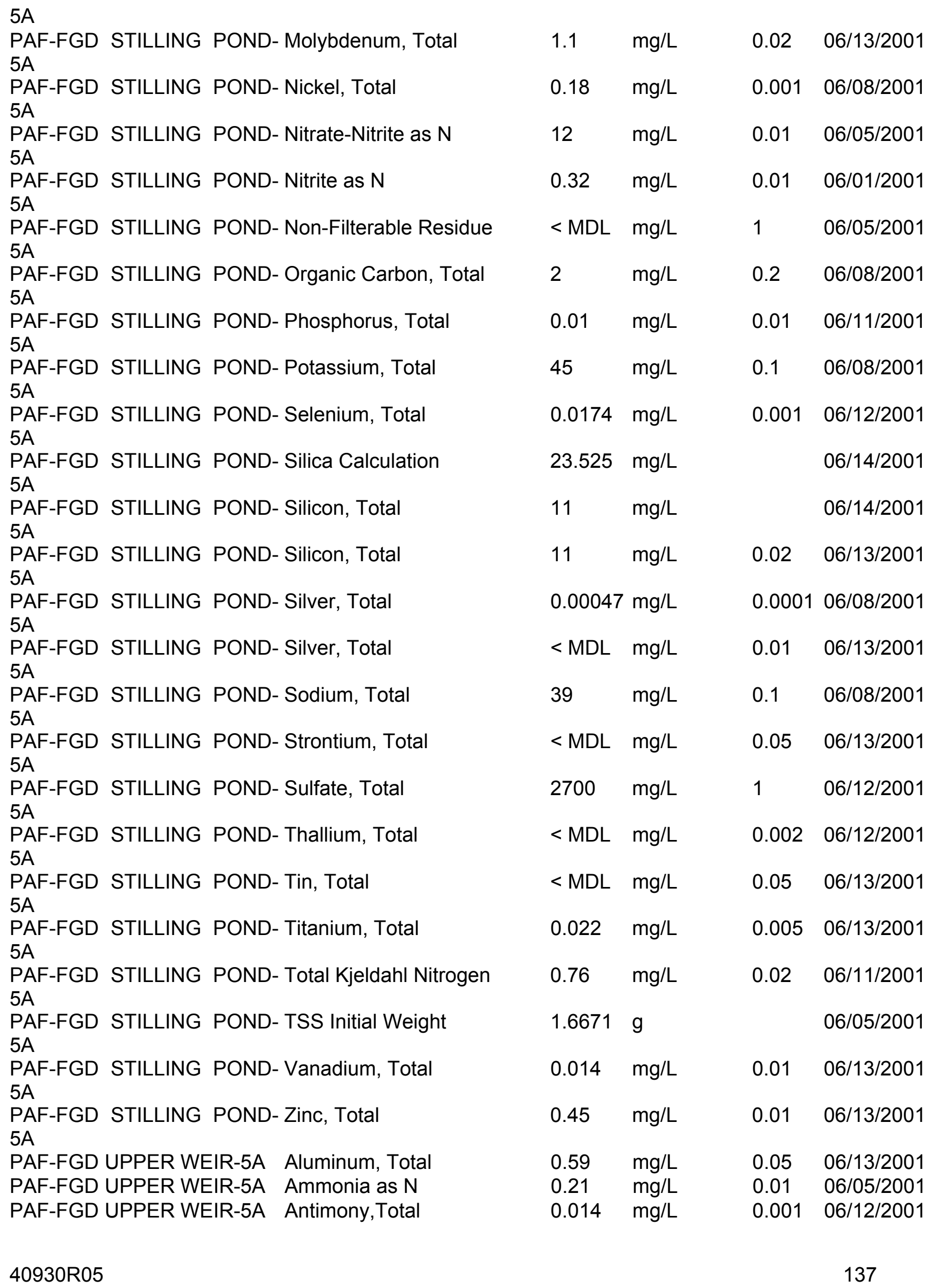




\begin{tabular}{|c|c|c|c|c|c|}
\hline PAF-FGD UPPER WEIR-5A & Arsenic, Total & 0.008 & $\mathrm{mg} / \mathrm{L}$ & 0.001 & 06/09/2001 \\
\hline PAF-FGD UPPER WEIR-5A & Barium, Total & 0.061 & $\mathrm{mg} / \mathrm{L}$ & 0.01 & $06 / 13 / 2001$ \\
\hline PAF-FGD UPPER WEIR-5A & Beryllium, Total & 0.0051 & $\mathrm{mg} / \mathrm{L}$ & 0.001 & 06/13/2001 \\
\hline PAF-FGD UPPER WEIR-5A & Boron, Total & 61 & $\mathrm{mg} / \mathrm{L}$ & 0.2 & 06/13/2001 \\
\hline PAF-FGD UPPER WEIR-5A & $\begin{array}{l}\text { Ca \& } \\
\text { Hardness }\end{array}$ & 2700 & $\begin{array}{l}\mathrm{mg} / \mathrm{L} \\
\mathrm{CaCO} 3\end{array}$ & & 06/14/2001 \\
\hline PAF-FGD UPPER WEIR-5A & Cadmium, Total & 0.056 & $\mathrm{mg} / \mathrm{L}$ & 0.0001 & 06/08/2001 \\
\hline PAF-FGD UPPER WEIR-5A & Calcium, Total & 560 & $\mathrm{mg} / \mathrm{L}$ & 0.1 & $06 / 13 / 2001$ \\
\hline PAF-FGD UPPER WEIR-5A & Chemical Oxygen Demand & 24 & $\mathrm{mg} / \mathrm{L}$ & 20 & $06 / 11 / 2001$ \\
\hline PAF-FGD UPPER WEIR-5A & Chloride, Total & 380 & $\mathrm{mg} / \mathrm{L}$ & 1 & 06/08/2001 \\
\hline PAF-FGD UPPER WEIR-5A & Chromium, Total & 0.0055 & $\mathrm{mg} / \mathrm{L}$ & 0.001 & 06/08/2001 \\
\hline PAF-FGD UPPER WEIR-5A & Cobalt, Total & 0.026 & $\mathrm{mg} / \mathrm{L}$ & 0.001 & 06/13/2001 \\
\hline PAF-FGD UPPER WEIR-5A & Copper, Total & $<M D L$ & $\mathrm{mg} / \mathrm{L}$ & 0.001 & $06 / 11 / 2001$ \\
\hline PAF-FGD UPPER WEIR-5A & Copper, Total & $<M D L$ & $\mathrm{mg} / \mathrm{L}$ & 0.01 & 06/13/2001 \\
\hline PAF-FGD UPPER WEIR-5A & Filterable Residue & 6800 & $\mathrm{mg} / \mathrm{L}$ & 10 & 06/06/2001 \\
\hline PAF-FGD UPPER WEIR-5A & Fluoride, Total & 32 & $\mathrm{mg} / \mathrm{L}$ & 0.1 & $06 / 14 / 2001$ \\
\hline PAF-FGD UPPER WEIR-5A & Inorganic Carbon, Total & 12 & $\mathrm{mg} / \mathrm{L}$ & 1 & $06 / 14 / 2001$ \\
\hline PAF-FGD UPPER WEIR-5A & Iron, Total & 0.24 & $\mathrm{mg} / \mathrm{L}$ & 0.01 & $06 / 13 / 2001$ \\
\hline PAF-FGD UPPER WEIR-5A & Lead, Total & $<M D L$ & $\mathrm{mg} / \mathrm{L}$ & 0.001 & $06 / 11 / 2001$ \\
\hline PAF-FGD UPPER WEIR-5A & Magnesium, Total & 320 & $\mathrm{mg} / \mathrm{L}$ & 0.01 & $06 / 13 / 2001$ \\
\hline PAF-FGD UPPER WEIR-5A & Manganese, Total & 1.4 & $\mathrm{mg} / \mathrm{L}$ & 0.005 & $06 / 13 / 2001$ \\
\hline PAF-FGD UPPER WEIR-5A & Mercury, Total & 0.0009 & $\mathrm{mg} / \mathrm{L}$ & 0.0002 & 06/07/2001 \\
\hline PAF-FGD UPPER WEIR-5A & Molybdenum, Total & 0.97 & $\mathrm{mg} / \mathrm{L}$ & 0.02 & $06 / 13 / 2001$ \\
\hline PAF-FGD UPPER WEIR-5A & Nickel, Total & 0.18 & $\mathrm{mg} / \mathrm{L}$ & 0.001 & 06/08/2001 \\
\hline PAF-FGD UPPER WEIR-5A & Nitrate-Nitrite as $\mathrm{N}$ & 12 & $\mathrm{mg} / \mathrm{L}$ & 0.01 & $06 / 11 / 2001$ \\
\hline PAF-FGD UPPER WEIR-5A & Nitrite as $\mathrm{N}$ & 0.23 & $\mathrm{mg} / \mathrm{L}$ & 0.01 & 06/01/2001 \\
\hline PAF-FGD UPPER WEIR-5A & Non-Filterable Residue & 4 & $\mathrm{mg} / \mathrm{L}$ & 1 & 06/05/2001 \\
\hline PAF-FGD UPPER WEIR-5A & Organic Carbon, Total & 2 & $\mathrm{mg} / \mathrm{L}$ & 0.2 & 06/09/2001 \\
\hline PAF-FGD UPPER WEIR-5A & Phosphorus, Total & 0.01 & $\mathrm{mg} / \mathrm{L}$ & 0.01 & $06 / 11 / 2001$ \\
\hline PAF-FGD UPPER WEIR-5A & Potassium, Total & 43 & $\mathrm{mg} / \mathrm{L}$ & 0.1 & 06/08/2001 \\
\hline PAF-FGD UPPER WEIR-5A & Selenium, Total & 0.0075 & $\mathrm{mg} / \mathrm{L}$ & 0.001 & 06/12/2001 \\
\hline PAF-FGD UPPER WEIR-5A & Silica Calculation & 23.525 & $\mathrm{mg} / \mathrm{L}$ & & $06 / 14 / 2001$ \\
\hline PAF-FGD UPPER WEIR-5A & Silicon, Total & 11 & $\mathrm{mg} / \mathrm{L}$ & & $06 / 14 / 2001$ \\
\hline PAF-FGD UPPER WEIR-5A & Silicon, Total & 11 & $\mathrm{mg} / \mathrm{L}$ & 0.02 & $06 / 13 / 2001$ \\
\hline PAF-FGD UPPER WEIR-5A & Silver, Total & $<M D L$ & $\mathrm{mg} / \mathrm{L}$ & 0.0001 & 06/08/2001 \\
\hline PAF-FGD UPPER WEIR-5A & Silver, Total & $<M D L$ & $\mathrm{mg} / \mathrm{L}$ & 0.01 & $06 / 13 / 2001$ \\
\hline PAF-FGD UPPER WEIR-5A & Sodium, Total & 51 & $\mathrm{mg} / \mathrm{L}$ & 0.1 & 06/08/2001 \\
\hline PAF-FGD UPPER WEIR-5A & Strontium, Total & $<M D L$ & $\mathrm{mg} / \mathrm{L}$ & 0.05 & 06/13/2001 \\
\hline PAF-FGD UPPER WEIR-5A & Sulfate, Total & 2800 & $\mathrm{mg} / \mathrm{L}$ & 1 & $06 / 12 / 2001$ \\
\hline PAF-FGD UPPER WEIR-5A & Thallium, Total & 0.0074 & $\mathrm{mg} / \mathrm{L}$ & 0.002 & $06 / 21 / 2001$ \\
\hline PAF-FGD UPPER WEIR-5A & Tin, Total & $<M D L$ & $\mathrm{mg} / \mathrm{L}$ & 0.05 & 06/13/2001 \\
\hline PAF-FGD UPPER WEIR-5A & Titanium, Total & 0.015 & $\mathrm{mg} / \mathrm{L}$ & 0.005 & 06/13/2001 \\
\hline PAF-FGD UPPER WEIR-5A & Total Kjeldahl Nitrogen & 0.76 & $\mathrm{mg} / \mathrm{L}$ & 0.02 & 06/11/2001 \\
\hline PAF-FGD UPPER WEIR-5A & TSS Initial Weight & 1.6773 & g & & $06 / 05 / 2001$ \\
\hline PAF-FGD UPPER WEIR-5A & Vanadium, Total & 0.012 & $\mathrm{mg} / \mathrm{L}$ & 0.01 & $06 / 13 / 2001$ \\
\hline PAF-FGD UPPER WEIR-5A & Zinc, Total & 0.41 & $\mathrm{mg} / \mathrm{L}$ & 0.01 & 06/13/2001 \\
\hline PAF-FGD LOWER WEIR-5A & Aluminum, Total & 1 & $\mathrm{mg} / \mathrm{L}$ & 0.05 & 06/13/2001 \\
\hline PAF-FGD LOWER WEIR-5A & Ammonia as $\mathrm{N}$ & 0.3 & $\mathrm{mg} / \mathrm{L}$ & 0.01 & 06/05/2001 \\
\hline PAF-FGD LOWER WEIR-5A & Antimony,Total & $<M D L$ & $\mathrm{mg} / \mathrm{L}$ & 0.001 & $06 / 12 / 2001$ \\
\hline PAF-FGD LOWER WEIR-5A & Arsenic, Total & 0.009 & $\mathrm{mg} / \mathrm{L}$ & 0.001 & 06/09/2001 \\
\hline
\end{tabular}




\begin{tabular}{|c|c|c|c|c|c|}
\hline PAF-FGD LOWER WEIR-5A & Barium, Total & 0.057 & $\mathrm{mg} / \mathrm{L}$ & 0.01 & $06 / 13 / 2001$ \\
\hline PAF-FGD LOWER WEIR-5A & Beryllium, Total & 0.0048 & $\mathrm{mg} / \mathrm{L}$ & 0.001 & $06 / 13 / 2001$ \\
\hline PAF-FGD LOWER WEIR-5A & Boron, Total & 56 & $\mathrm{mg} / \mathrm{L}$ & 0.2 & 06/13/2001 \\
\hline PAF-FGD LOWER WEIR-5A & $\begin{array}{l}\mathrm{Ca} \& \mathrm{Mg} \text { Calculate } \\
\text { Hardness }\end{array}$ & 2700 & $\begin{array}{l}\mathrm{mg} / \mathrm{L} \\
\mathrm{CaCO} 3\end{array}$ & & $06 / 14 / 2001$ \\
\hline PAF-FGD LOWER WEIR-5A & Cadmium, Total & 0.054 & $\mathrm{mg} / \mathrm{L}$ & 0.0001 & 06/08/2001 \\
\hline PAF-FGD LOWER WEIR-5A & Calcium, Total & 560 & $\mathrm{mg} / \mathrm{L}$ & 0.1 & $06 / 13 / 2001$ \\
\hline PAF-FGD LOWER WEIR-5A & Chemical Oxygen Demand & $<$ MDL & $\mathrm{mg} / \mathrm{L}$ & 20 & $06 / 11 / 2001$ \\
\hline PAF-FGD LOWER WEIR-5A & Chloride, Total & 350 & $\mathrm{mg} / \mathrm{L}$ & 1 & 06/08/2001 \\
\hline PAF-FGD LOWER WEIR-5A & Chromium, Total & 0.0064 & $\mathrm{mg} / \mathrm{L}$ & 0.001 & 06/08/2001 \\
\hline PAF-FGD LOWER WEIR-5A & Cobalt, Total & $<\mathrm{MDL}$ & $\mathrm{mg} / \mathrm{L}$ & 0.001 & $06 / 13 / 2001$ \\
\hline PAF-FGD LOWER WEIR-5A & Copper, Total & $<M D L$ & $\mathrm{mg} / \mathrm{L}$ & 0.001 & $06 / 14 / 2001$ \\
\hline PAF-FGD LOWER WEIR-5A & Copper, Total & $<M D L$ & $\mathrm{mg} / \mathrm{L}$ & 0.01 & 06/13/2001 \\
\hline PAF-FGD LOWER WEIR-5A & Filterable Residue & 6300 & $\mathrm{mg} / \mathrm{L}$ & 10 & 06/06/2001 \\
\hline PAF-FGD LOWER WEIR-5A & Fluoride, Total & 25 & $\mathrm{mg} / \mathrm{L}$ & 0.1 & $06 / 14 / 2001$ \\
\hline PAF-FGD LOWER WEIR-5A & Inorganic Carbon, Total & 22 & $\mathrm{mg} / \mathrm{L}$ & 1 & $06 / 14 / 2001$ \\
\hline PAF-FGD LOWER WEIR-5A & Iron, Total & 4.4 & $\mathrm{mg} / \mathrm{L}$ & 0.01 & 06/13/2001 \\
\hline PAF-FGD LOWER WEIR-5A & Lead, Total & $<M D L$ & $\mathrm{mg} / \mathrm{L}$ & 0.001 & $06 / 11 / 2001$ \\
\hline PAF-FGD LOWER WEIR-5A & Magnesium, Total & 310 & $\mathrm{mg} / \mathrm{L}$ & 0.01 & 06/13/2001 \\
\hline PAF-FGD LOWER WEIR-5A & Manganese, Total & 1.6 & $\mathrm{mg} / \mathrm{L}$ & 0.005 & $06 / 13 / 2001$ \\
\hline PAF-FGD LOWER WEIR-5A & Mercury, Total & 0.001 & $\mathrm{mg} / \mathrm{L}$ & 0.0002 & 06/07/2001 \\
\hline PAF-FGD LOWER WEIR-5A & Molybdenum, Total & 0.91 & $\mathrm{mg} / \mathrm{L}$ & 0.02 & $06 / 13 / 2001$ \\
\hline PAF-FGD LOWER WEIR-5A & Nickel, Total & 0.15 & $\mathrm{mg} / \mathrm{L}$ & 0.001 & 06/08/2001 \\
\hline PAF-FGD LOWER WEIR-5A & Nitrate-Nitrite as $\mathrm{N}$ & 10 & $\mathrm{mg} / \mathrm{L}$ & 0.01 & $06 / 11 / 2001$ \\
\hline PAF-FGD LOWER WEIR-5A & Nitrite as $\mathrm{N}$ & 0.12 & $\mathrm{mg} / \mathrm{L}$ & 0.01 & 06/01/2001 \\
\hline PAF-FGD LOWER WEIR-5A & Non-Filterable Residue & 11 & $\mathrm{mg} / \mathrm{L}$ & 1 & 06/05/2001 \\
\hline PAF-FGD LOWER WEIR-5A & Organic Carbon, Total & 2.2 & $\mathrm{mg} / \mathrm{L}$ & 0.2 & 06/09/2001 \\
\hline PAF-FGD LOWER WEIR-5A & Phosphorus, Total & $<\mathrm{MDL}$ & $\mathrm{mg} / \mathrm{L}$ & 0.01 & $06 / 11 / 2001$ \\
\hline PAF-FGD LOWER WEIR-5A & Potassium, Total & 40 & $\mathrm{mg} / \mathrm{L}$ & 0.1 & 06/08/2001 \\
\hline PAF-FGD LOWER WEIR-5A & Selenium, Total & 0.0083 & $\mathrm{mg} / \mathrm{L}$ & 0.001 & $06 / 12 / 2001$ \\
\hline PAF-FGD LOWER WEIR-5A & Silica Calculation & 20.103 & $\mathrm{mg} / \mathrm{L}$ & & $06 / 14 / 2001$ \\
\hline PAF-FGD LOWER WEIR-5A & Silicon, Total & 9.4 & $\mathrm{mg} / \mathrm{L}$ & & $06 / 14 / 2001$ \\
\hline PAF-FGD LOWER WEIR-5A & Silicon, Total & 9.4 & $\mathrm{mg} / \mathrm{L}$ & 0.02 & $06 / 13 / 2001$ \\
\hline PAF-FGD LOWER WEIR-5A & Silver, Total & $<M D L$ & $\mathrm{mg} / \mathrm{L}$ & 0.0001 & 06/08/2001 \\
\hline PAF-FGD LOWER WEIR-5A & Silver, Total & $<M D L$ & $\mathrm{mg} / \mathrm{L}$ & 0.01 & 06/13/2001 \\
\hline PAF-FGD LOWER WEIR-5A & Sodium, Total & 74 & $\mathrm{mg} / \mathrm{L}$ & 0.1 & 06/08/2001 \\
\hline PAF-FGD LOWER WEIR-5A & Strontium, Total & $<M D L$ & $\mathrm{mg} / \mathrm{L}$ & 0.05 & $06 / 13 / 2001$ \\
\hline PAF-FGD LOWER WEIR-5A & Sulfate, Total & 2700 & $\mathrm{mg} / \mathrm{L}$ & 1 & $06 / 12 / 2001$ \\
\hline PAF-FGD LOWER WEIR-5A & Thallium, Total & $<M D L$ & $\mathrm{mg} / \mathrm{L}$ & 0.002 & $06 / 12 / 2001$ \\
\hline PAF-FGD LOWER WEIR-5A & Tin, Total & $<\mathrm{MDL}$ & $\mathrm{mg} / \mathrm{L}$ & 0.05 & $06 / 13 / 2001$ \\
\hline PAF-FGD LOWER WEIR-5A & Titanium, Total & 0.024 & $\mathrm{mg} / \mathrm{L}$ & 0.005 & $06 / 13 / 2001$ \\
\hline PAF-FGD LOWER WEIR-5A & Total Kjeldahl Nitrogen & 0.84 & $\mathrm{mg} / \mathrm{L}$ & 0.02 & $06 / 11 / 2001$ \\
\hline PAF-FGD LOWER WEIR-5A & TSS Initial Weight & 1.6742 & g & & 06/05/2001 \\
\hline PAF-FGD LOWER WEIR-5A & Vanadium, Total & 0.017 & $\mathrm{mg} / \mathrm{L}$ & 0.01 & $06 / 13 / 2001$ \\
\hline PAF-FGD LOWER WEIR-5A & Zinc, Total & 0.4 & $\mathrm{mg} / \mathrm{L}$ & 0.01 & $06 / 13 / 2001$ \\
\hline PAF-CATFISH POND-5A & Aluminum, Total & 0.31 & $\mathrm{mg} / \mathrm{L}$ & 0.05 & 06/13/2001 \\
\hline PAF-CATFISH POND-5A & Ammonia as $\mathrm{N}$ & 0.12 & $\mathrm{mg} / \mathrm{L}$ & 0.01 & 06/05/2001 \\
\hline PAF-CATFISH POND-5A & Antimony, Total & $<M D L$ & $\mathrm{mg} / \mathrm{L}$ & 0.001 & $06 / 12 / 2001$ \\
\hline PAF-CATFISH POND-5A & Arsenic, Total & 0.003 & $\mathrm{mg} / \mathrm{L}$ & 0.001 & 06/09/2001 \\
\hline PAF-CATFISH POND-5A & Barium, Total & 0.012 & $\mathrm{mg} / \mathrm{L}$ & 0.01 & 06/13/2001 \\
\hline
\end{tabular}




\begin{tabular}{|c|c|c|c|c|c|}
\hline PAF-CATFISH POND-5A & Beryllium, Total & $<M D L$ & $\mathrm{mg} / \mathrm{L}$ & 0.001 & $06 / 13 / 2001$ \\
\hline PAF-CATFISH POND-5A & Boron, Total & 14 & $\mathrm{mg} / \mathrm{L}$ & 0.2 & $06 / 13 / 2001$ \\
\hline PAF-CATFISH POND-5A & $\begin{array}{l}\text { Ca \& Mg Calculated } \\
\text { Hardness }\end{array}$ & 1400 & $\begin{array}{l}\mathrm{mg} / \mathrm{L} \\
\mathrm{CaCO} 3\end{array}$ & & $06 / 14 / 2001$ \\
\hline PAF-CATFISH POND-5A & Cadmium, Total & $<M D L$ & $\mathrm{mg} / \mathrm{L}$ & 0.0001 & 06/08/2001 \\
\hline PAF-CATFISH POND-5A & Calcium, Total & 270 & $\mathrm{mg} / \mathrm{L}$ & 0.1 & $06 / 13 / 2001$ \\
\hline PAF-CATFISH POND-5A & Chemical Oxygen Demand & $<M D L$ & $\mathrm{mg} / \mathrm{L}$ & 20 & $06 / 11 / 2001$ \\
\hline PAF-CATFISH POND-5A & Chloride, Total & 180 & $\mathrm{mg} / \mathrm{L}$ & 1 & 06/08/2001 \\
\hline PAF-CATFISH POND-5A & Chromium, Total & $<M D L$ & $\mathrm{mg} / \mathrm{L}$ & 0.001 & $06 / 08 / 2001$ \\
\hline PAF-CATFISH POND-5A & Cobalt, Total & $<M D L$ & $\mathrm{mg} / \mathrm{L}$ & 0.001 & 06/13/2001 \\
\hline PAF-CATFISH POND-5A & Copper, Total & $<M D L$ & $\mathrm{mg} / \mathrm{L}$ & 0.001 & 06/08/2001 \\
\hline PAF-CATFISH POND-5A & Copper, Total & $<M D L$ & $\mathrm{mg} / \mathrm{L}$ & 0.01 & $06 / 13 / 2001$ \\
\hline PAF-CATFISH POND-5A & Filterable Residue & 3100 & $\mathrm{mg} / \mathrm{L}$ & 10 & $06 / 06 / 2001$ \\
\hline PAF-CATFISH POND-5A & Fluoride, Total & 0.24 & $\mathrm{mg} / \mathrm{L}$ & 0.1 & $06 / 14 / 2001$ \\
\hline PAF-CATFISH POND-5A & Inorganic Carbon, Total & 44 & $\mathrm{mg} / \mathrm{L}$ & 1 & $06 / 14 / 2001$ \\
\hline PAF-CATFISH POND-5A & Iron, Total & 0.84 & $\mathrm{mg} / \mathrm{L}$ & 0.01 & 06/13/2001 \\
\hline PAF-CATFISH POND-5A & Lead, Total & $<M D L$ & $\mathrm{mg} / \mathrm{L}$ & 0.001 & $06 / 11 / 2001$ \\
\hline PAF-CATFISH POND-5A & Magnesium, Total & 170 & $\mathrm{mg} / \mathrm{L}$ & 0.01 & 06/13/2001 \\
\hline PAF-CATFISH POND-5A & Manganese, Total & 0.1 & $\mathrm{mg} / \mathrm{L}$ & 0.005 & $06 / 13 / 2001$ \\
\hline PAF-CATFISH POND-5A & Mercury, Total & $<M D L$ & $\mathrm{mg} / \mathrm{L}$ & 0.0002 & 06/07/2001 \\
\hline PAF-CATFISH POND-5A & Molybdenum, Total & $<\mathrm{MDL}$ & $\mathrm{mg} / \mathrm{L}$ & 0.02 & $06 / 13 / 2001$ \\
\hline PAF-CATFISH POND-5A & Nickel, Total & 0.0096 & $\mathrm{mg} / \mathrm{L}$ & 0.001 & 06/08/2001 \\
\hline PAF-CATFISH POND-5A & Nitrate-Nitrite as N & 0.98 & $\mathrm{mg} / \mathrm{L}$ & 0.01 & 06/05/2001 \\
\hline PAF-CATFISH POND-5A & Nitrite as $\mathrm{N}$ & $<M D L$ & $\mathrm{mg} / \mathrm{L}$ & 0.01 & $06 / 01 / 2001$ \\
\hline PAF-CATFISH POND-5A & Non-Filterable Residue & 78 & $\mathrm{mg} / \mathrm{L}$ & 1 & $06 / 05 / 2001$ \\
\hline PAF-CATFISH POND-5A & Organic Carbon, Total & 5.2 & $\mathrm{mg} / \mathrm{L}$ & 0.2 & $06 / 09 / 2001$ \\
\hline PAF-CATFISH POND-5A & Phosphorus, Total & 0.06 & $\mathrm{mg} / \mathrm{L}$ & 0.01 & $06 / 11 / 2001$ \\
\hline PAF-CATFISH POND-5A & Potassium, Total & 11 & $\mathrm{mg} / \mathrm{L}$ & 0.1 & 06/08/2001 \\
\hline PAF-CATFISH POND-5A & Selenium, Total & $<M D L$ & $\mathrm{mg} / \mathrm{L}$ & 0.001 & $06 / 12 / 2001$ \\
\hline PAF-CATFISH POND-5A & Silica Calculation & 9.196 & $\mathrm{mg} / \mathrm{L}$ & & $06 / 14 / 2001$ \\
\hline PAF-CATFISH POND-5A & Silicon, Total & 4.3 & $\mathrm{mg} / \mathrm{L}$ & & $06 / 14 / 2001$ \\
\hline PAF-CATFISH POND-5A & Silicon, Total & 4.3 & $\mathrm{mg} / \mathrm{L}$ & 0.02 & $06 / 13 / 2001$ \\
\hline PAF-CATFISH POND-5A & Silver, Total & $<M D L$ & $\mathrm{mg} / \mathrm{L}$ & 0.0001 & 06/08/2001 \\
\hline PAF-CATFISH POND-5A & Silver, Total & $<M D L$ & $\mathrm{mg} / \mathrm{L}$ & 0.01 & $06 / 13 / 2001$ \\
\hline PAF-CATFISH POND-5A & Sodium, Total & 210 & $\mathrm{mg} / \mathrm{L}$ & 0.1 & $06 / 08 / 2001$ \\
\hline PAF-CATFISH POND-5A & Strontium, Total & $<\mathrm{MDL}$ & $\mathrm{mg} / \mathrm{L}$ & 0.05 & $06 / 13 / 2001$ \\
\hline PAF-CATFISH POND-5A & Sulfate, Total & 1600 & $\mathrm{mg} / \mathrm{L}$ & 1 & $06 / 12 / 2001$ \\
\hline PAF-CATFISH POND-5A & Thallium, Total & $<\mathrm{MDL}$ & $\mathrm{mg} / \mathrm{L}$ & 0.002 & $06 / 12 / 2001$ \\
\hline PAF-CATFISH POND-5A & Tin, Total & $<M D L$ & $\mathrm{mg} / \mathrm{L}$ & 0.05 & $06 / 13 / 2001$ \\
\hline PAF-CATFISH POND-5A & Titanium, Total & 0.01 & $\mathrm{mg} / \mathrm{L}$ & 0.005 & $06 / 13 / 2001$ \\
\hline PAF-CATFISH POND-5A & Total Kjeldahl Nitrogen & 0.73 & $\mathrm{mg} / \mathrm{L}$ & 0.02 & $06 / 11 / 2001$ \\
\hline PAF-CATFISH POND-5A & TSS Initial Weight & 1.6805 & g & & $06 / 05 / 2001$ \\
\hline PAF-CATFISH POND-5A & Vanadium, Total & $<M D L$ & $\mathrm{mg} / \mathrm{L}$ & 0.01 & $06 / 13 / 2001$ \\
\hline PAF-CATFISH POND-5A & Zinc, Total & $<M D L$ & $\mathrm{mg} / \mathrm{L}$ & 0.01 & $06 / 13 / 2001$ \\
\hline PAF-POTATO POND-5A & Aluminum, Total & 0.14 & $\mathrm{mg} / \mathrm{L}$ & 0.05 & $06 / 13 / 2001$ \\
\hline PAF-POTATO POND-5A & Ammonia as $\mathrm{N}$ & 0.02 & $\mathrm{mg} / \mathrm{L}$ & 0.01 & $06 / 05 / 2001$ \\
\hline PAF-POTATO POND-5A & Antimony, Total & $<M D L$ & $\mathrm{mg} / \mathrm{L}$ & 0.001 & $06 / 12 / 2001$ \\
\hline PAF-POTATO POND-5A & Arsenic, Total & 0.002 & $\mathrm{mg} / \mathrm{L}$ & 0.001 & 06/09/2001 \\
\hline PAF-POTATO POND-5A & Barium, Total & 0.046 & $\mathrm{mg} / \mathrm{L}$ & 0.01 & $06 / 13 / 2001$ \\
\hline PAF-POTATO POND-5A & Beryllium, Total & $<M D L$ & $\mathrm{mg} / \mathrm{L}$ & 0.001 & $06 / 13 / 2001$ \\
\hline
\end{tabular}




\begin{tabular}{|c|c|c|c|c|c|}
\hline PAF-POTATO POND-5A & Boron, Total & 1.4 & $\mathrm{mg} / \mathrm{L}$ & 0.2 & $06 / 13 / 2001$ \\
\hline PAF-POTATO POND-5A & $\begin{array}{l}\mathrm{Ca} \& \\
\text { Hardness }\end{array}$ & 180 & $\begin{array}{l}\mathrm{mg} / \mathrm{L} \\
\mathrm{CaCO} 3\end{array}$ & & $06 / 14 / 2001$ \\
\hline PAF-POTATO POND-5A & Cadmium, Total & 0.0021 & $\mathrm{mg} / \mathrm{L}$ & 0.0001 & 06/08/2001 \\
\hline PAF-POTATO POND-5A & Calcium, Total & 37 & $\mathrm{mg} / \mathrm{L}$ & 0.1 & $06 / 13 / 2001$ \\
\hline PAF-POTATO POND-5A & Chemical Oxygen Demand & 32 & $\mathrm{mg} / \mathrm{L}$ & 20 & $06 / 11 / 2001$ \\
\hline PAF-POTATO POND-5A & Chloride, Total & 1.6 & $\mathrm{mg} / \mathrm{L}$ & 1 & 06/08/2001 \\
\hline PAF-POTATO POND-5A & Chromium, Total & $<M D L$ & $\mathrm{mg} / \mathrm{L}$ & 0.001 & 06/08/2001 \\
\hline PAF-POTATO POND-5A & Cobalt, Total & $<M D L$ & $\mathrm{mg} / \mathrm{L}$ & 0.001 & $06 / 13 / 2001$ \\
\hline PAF-POTATO POND-5A & Copper, Total & 0.004 & $\mathrm{mg} / \mathrm{L}$ & 0.001 & 06/08/2001 \\
\hline PAF-POTATO POND-5A & Copper, Total & 0.01 & $\mathrm{mg} / \mathrm{L}$ & 0.01 & $06 / 13 / 2001$ \\
\hline PAF-POTATO POND-5A & Filterable Residue & 270 & $\mathrm{mg} / \mathrm{L}$ & 10 & $06 / 06 / 2001$ \\
\hline PAF-POTATO POND-5A & Fluoride, Total & 0.22 & $\mathrm{mg} / \mathrm{L}$ & 0.1 & $06 / 14 / 2001$ \\
\hline PAF-POTATO POND-5A & Inorganic Carbon, Total & 21 & $\mathrm{mg} / \mathrm{L}$ & 1 & $06 / 14 / 2001$ \\
\hline PAF-POTATO POND-5A & Iron, Total & 0.27 & $\mathrm{mg} / \mathrm{L}$ & 0.01 & $06 / 13 / 2001$ \\
\hline PAF-POTATO POND-5A & Lead , Total & 0.0027 & $\mathrm{mg} / \mathrm{L}$ & 0.001 & $06 / 11 / 2001$ \\
\hline PAF-POTATO POND-5A & Magnesium, Total & 21 & $\mathrm{mg} / \mathrm{L}$ & 0.01 & $06 / 13 / 2001$ \\
\hline PAF-POTATO POND-5A & Manganese, Total & 0.06 & $\mathrm{mg} / \mathrm{L}$ & 0.005 & $06 / 13 / 2001$ \\
\hline PAF-POTATO POND-5A & Mercury, Total & $<M D L$ & $\mathrm{mg} / \mathrm{L}$ & 0.0002 & 06/07/2001 \\
\hline PAF-POTATO POND-5A & Molybdenum, Total & $<M D L$ & $\mathrm{mg} / \mathrm{L}$ & 0.02 & 06/13/2001 \\
\hline PAF-POTATO POND-5A & Nickel, Total & 0.013 & $\mathrm{mg} / \mathrm{L}$ & 0.001 & 06/08/2001 \\
\hline PAF-POTATO POND-5A & Nitrate-Nitrite as $\mathrm{N}$ & 0.26 & $\mathrm{mg} / \mathrm{L}$ & 0.01 & $06 / 05 / 2001$ \\
\hline PAF-POTATO POND-5A & Nitrite as $\mathrm{N}$ & $<M D L$ & $\mathrm{mg} / \mathrm{L}$ & 0.01 & $06 / 05 / 2001$ \\
\hline PAF-POTATO POND-5A & Non-Filterable Residue & 8 & $\mathrm{mg} / \mathrm{L}$ & 1 & $06 / 05 / 2001$ \\
\hline PAF-POTATO POND-5A & Organic Carbon, Total & 6.5 & $\mathrm{mg} / \mathrm{L}$ & 0.2 & $06 / 09 / 2001$ \\
\hline PAF-POTATO POND-5A & Phosphorus, Total & 0.04 & $\mathrm{mg} / \mathrm{L}$ & 0.01 & $06 / 11 / 2001$ \\
\hline PAF-POTATO POND-5A & Potassium, Total & 4.2 & $\mathrm{mg} / \mathrm{L}$ & 0.1 & $06 / 08 / 2001$ \\
\hline PAF-POTATO POND-5A & Selenium, Total & $<M D L$ & $\mathrm{mg} / \mathrm{L}$ & 0.001 & $06 / 12 / 2001$ \\
\hline PAF-POTATO POND-5A & Silica Calculation & 0.984 & $\mathrm{mg} / \mathrm{L}$ & & $06 / 14 / 2001$ \\
\hline PAF-POTATO POND-5A & Silicon, Total & 0.46 & $\mathrm{mg} / \mathrm{L}$ & & $06 / 14 / 2001$ \\
\hline PAF-POTATO POND-5A & Silicon, Total & 0.46 & $\mathrm{mg} / \mathrm{L}$ & 0.02 & $06 / 13 / 2001$ \\
\hline PAF-POTATO POND-5A & Silver, Total & $<M D L$ & $\mathrm{mg} / \mathrm{L}$ & 0.0001 & 06/08/2001 \\
\hline PAF-POTATO POND-5A & Silver, Total & $<M D L$ & $\mathrm{mg} / \mathrm{L}$ & 0.01 & 06/13/2001 \\
\hline PAF-POTATO POND-5A & Sodium, Total & 6 & $\mathrm{mg} / \mathrm{L}$ & 0.1 & 06/08/2001 \\
\hline PAF-POTATO POND-5A & Strontium, Total & $<\mathrm{MDL}$ & $\mathrm{mg} / \mathrm{L}$ & 0.05 & $06 / 13 / 2001$ \\
\hline PAF-POTATO POND-5A & Sulfate, Total & 97 & $\mathrm{mg} / \mathrm{L}$ & 1 & $06 / 12 / 2001$ \\
\hline PAF-POTATO POND-5A & Thallium, Total & $<M D L$ & $\mathrm{mg} / \mathrm{L}$ & 0.002 & $06 / 12 / 2001$ \\
\hline PAF-POTATO POND-5A & Tin, Total & $<M D L$ & $\mathrm{mg} / \mathrm{L}$ & 0.05 & $06 / 13 / 2001$ \\
\hline PAF-POTATO POND-5A & Titanium, Total & $<M D L$ & $\mathrm{mg} / \mathrm{L}$ & 0.005 & $06 / 13 / 2001$ \\
\hline PAF-POTATO POND-5A & Total Kjeldahl Nitrogen & 0.85 & $\mathrm{mg} / \mathrm{L}$ & 0.02 & $06 / 11 / 2001$ \\
\hline PAF-POTATO POND-5A & TSS Initial Weight & 1.0929 & g & & $06 / 05 / 2001$ \\
\hline PAF-POTATO POND-5A & Vanadium, Total & $<M D L$ & $\mathrm{mg} / \mathrm{L}$ & 0.01 & $06 / 13 / 2001$ \\
\hline PAF-POTATO POND-5A & Zinc, Total & $<M D L$ & $\mathrm{mg} / \mathrm{L}$ & 0.01 & $06 / 13 / 2001$ \\
\hline PAF-FLY ASH POND-5A & Aluminum, Total & 0.73 & $\mathrm{mg} / \mathrm{L}$ & 0.05 & $06 / 13 / 2001$ \\
\hline PAF-FLY ASH POND-5A & Ammonia as $\mathrm{N}$ & 0.02 & $\mathrm{mg} / \mathrm{L}$ & 0.01 & $06 / 05 / 2001$ \\
\hline PAF-FLY ASH POND-5A & Antimony,Total & $<M D L$ & $\mathrm{mg} / \mathrm{L}$ & 0.001 & $06 / 12 / 2001$ \\
\hline PAF-FLY ASH POND-5A & Arsenic, Total & 0.004 & $\mathrm{mg} / \mathrm{L}$ & 0.001 & 06/09/2001 \\
\hline PAF-FLY ASH POND-5A & Barium, Total & 0.074 & $\mathrm{mg} / \mathrm{L}$ & 0.01 & $06 / 13 / 2001$ \\
\hline PAF-FLY ASH POND-5A & Beryllium, Total & $<\mathrm{MDL}$ & $\mathrm{mg} / \mathrm{L}$ & 0.001 & $06 / 13 / 2001$ \\
\hline PAF-FLY ASH POND-5A & Boron, Total & 4.3 & $\mathrm{mg} / \mathrm{L}$ & 0.2 & $06 / 13 / 2001$ \\
\hline
\end{tabular}




\begin{tabular}{|c|c|c|c|c|c|}
\hline PAF-FLY ASH POND-5A & $\begin{array}{l}\mathrm{Ca} \quad \mathrm{Mg} \quad \text { Calculate } \\
\text { Hardness }\end{array}$ & 370 & $\begin{array}{l}\mathrm{mg} / \mathrm{L} \\
\mathrm{CaCO} 3\end{array}$ & & $06 / 14 / 2001$ \\
\hline PAF-FLY ASH POND-5A & Cadmium, Total & 0.00045 & $\mathrm{mg} / \mathrm{L}$ & 0.0001 & 06/08/2001 \\
\hline PAF-FLY ASH POND-5A & Calcium, Total & 92 & $\mathrm{mg} / \mathrm{L}$ & 0.1 & $06 / 13 / 2001$ \\
\hline PAF-FLY ASH POND-5A & Chemical Oxygen Demand & $<M D L$ & $\mathrm{mg} / \mathrm{L}$ & 20 & $06 / 11 / 2001$ \\
\hline PAF-FLY ASH POND-5A & Chloride, Total & 37 & $\mathrm{mg} / \mathrm{L}$ & 1 & $06 / 08 / 2001$ \\
\hline PAF-FLY ASH POND-5A & Chromium, Total & $<\mathrm{MDL}$ & $\mathrm{mg} / \mathrm{L}$ & 0.001 & $06 / 08 / 2001$ \\
\hline PAF-FLY ASH POND-5A & Cobalt, Total & $<\mathrm{MDL}$ & $\mathrm{mg} / \mathrm{L}$ & 0.001 & $06 / 13 / 2001$ \\
\hline PAF-FLY ASH POND-5A & Copper, Total & 0.0035 & $\mathrm{mg} / \mathrm{L}$ & 0.001 & $06 / 08 / 2001$ \\
\hline PAF-FLY ASH POND-5A & Copper, Total & 0.017 & $\mathrm{mg} / \mathrm{L}$ & 0.01 & $06 / 13 / 2001$ \\
\hline PAF-FLY ASH POND-5A & Filterable Residue & 700 & $\mathrm{mg} / \mathrm{L}$ & 10 & $06 / 06 / 2001$ \\
\hline PAF-FLY ASH POND-5A & Fluoride, Total & 1.5 & $\mathrm{mg} / \mathrm{L}$ & 0.1 & $06 / 14 / 2001$ \\
\hline PAF-FLY ASH POND-5A & Inorganic Carbon, Total & 26 & $\mathrm{mg} / \mathrm{L}$ & 1 & $06 / 14 / 2001$ \\
\hline PAF-FLY ASH POND-5A & Iron, Total & 1 & $\mathrm{mg} / \mathrm{L}$ & 0.01 & $06 / 13 / 2001$ \\
\hline PAF-FLY ASH POND-5A & Lead, Total & 0.0019 & $\mathrm{mg} / \mathrm{L}$ & 0.001 & $06 / 11 / 2001$ \\
\hline PAF-FLY ASH POND-5A & Magnesium, Total & 34 & $\mathrm{mg} / \mathrm{L}$ & 0.01 & $06 / 13 / 2001$ \\
\hline PAF-FLY ASH POND-5A & Manganese, Total & 0.084 & $\mathrm{mg} / \mathrm{L}$ & 0.005 & $06 / 13 / 2001$ \\
\hline PAF-FLY ASH POND-5A & Mercury, Total & $<M D L$ & $\mathrm{mg} / \mathrm{L}$ & 0.0002 & $06 / 07 / 2001$ \\
\hline PAF-FLY ASH POND-5A & Molybdenum, Total & 0.1 & $\mathrm{mg} / \mathrm{L}$ & 0.02 & $06 / 13 / 2001$ \\
\hline PAF-FLY ASH POND-5A & Nickel, Total & 0.0065 & $\mathrm{mg} / \mathrm{L}$ & 0.001 & 06/08/2001 \\
\hline PAF-FLY ASH POND-5A & Nitrate-Nitrite as $\mathrm{N}$ & 1.3 & $\mathrm{mg} / \mathrm{L}$ & 0.01 & $06 / 05 / 2001$ \\
\hline PAF-FLY ASH POND-5A & Nitrite as $\mathrm{N}$ & 0.01 & $\mathrm{mg} / \mathrm{L}$ & 0.01 & 06/01/2001 \\
\hline PAF-FLY ASH POND-5A & Non-Filterable Residue & 16 & $\mathrm{mg} / \mathrm{L}$ & 1 & 06/05/2001 \\
\hline PAF-FLY ASH POND-5A & Organic Carbon, Total & 3.3 & $\mathrm{mg} / \mathrm{L}$ & 0.2 & 06/09/2001 \\
\hline PAF-FLY ASH POND-5A & Phosphorus, Total & 0.05 & $\mathrm{mg} / \mathrm{L}$ & 0.01 & $06 / 11 / 2001$ \\
\hline PAF-FLY ASH POND-5A & Potassium, Total & 5.2 & $\mathrm{mg} / \mathrm{L}$ & 0.1 & $06 / 08 / 2001$ \\
\hline PAF-FLY ASH POND-5A & Selenium, Total & 0.002 & $\mathrm{mg} / \mathrm{L}$ & 0.001 & $06 / 12 / 2001$ \\
\hline PAF-FLY ASH POND-5A & Silica Calculation & 7.485 & $\mathrm{mg} / \mathrm{L}$ & & $06 / 14 / 2001$ \\
\hline PAF-FLY ASH POND-5A & Silicon, Total & 3.5 & $\mathrm{mg} / \mathrm{L}$ & & $06 / 14 / 2001$ \\
\hline PAF-FLY ASH POND-5A & Silicon, Total & 3.5 & $\mathrm{mg} / \mathrm{L}$ & 0.02 & $06 / 13 / 2001$ \\
\hline PAF-FLY ASH POND-5A & Silver, Total & $<M D L$ & $\mathrm{mg} / \mathrm{L}$ & 0.0001 & 06/08/2001 \\
\hline PAF-FLY ASH POND-5A & Silver, Total & $<M D L$ & $\mathrm{mg} / \mathrm{L}$ & 0.01 & $06 / 13 / 2001$ \\
\hline PAF-FLY ASH POND-5A & Sodium, Total & 18 & $\mathrm{mg} / \mathrm{L}$ & 0.1 & 06/08/2001 \\
\hline PAF-FLY ASH POND-5A & Strontium, Total & $<\mathrm{MDL}$ & $\mathrm{mg} / \mathrm{L}$ & 0.05 & $06 / 13 / 2001$ \\
\hline PAF-FLY ASH POND-5A & Sulfate, Total & 290 & $\mathrm{mg} / \mathrm{L}$ & 1 & $06 / 12 / 2001$ \\
\hline PAF-FLY ASH POND-5A & Thallium, Total & $<M D L$ & $\mathrm{mg} / \mathrm{L}$ & 0.002 & $06 / 12 / 2001$ \\
\hline PAF-FLY ASH POND-5A & Tin, Total & $<M D L$ & $\mathrm{mg} / \mathrm{L}$ & 0.05 & 06/13/2001 \\
\hline PAF-FLY ASH POND-5A & Titanium, Total & 0.029 & $\mathrm{mg} / \mathrm{L}$ & 0.005 & $06 / 13 / 2001$ \\
\hline PAF-FLY ASH POND-5A & Total Kjeldahl Nitrogen & 0.56 & $\mathrm{mg} / \mathrm{L}$ & 0.02 & $06 / 11 / 2001$ \\
\hline PAF-FLY ASH POND-5A & TSS Initial Weight & 1.6746 & $g$ & & $06 / 05 / 2001$ \\
\hline PAF-FLY ASH POND-5A & Vanadium, Total & $<\mathrm{MDL}$ & $\mathrm{mg} / \mathrm{L}$ & 0.01 & $06 / 13 / 2001$ \\
\hline PAF-FLY ASH POND-5A & Zinc, Total & $<M D L$ & $\mathrm{mg} / \mathrm{L}$ & 0.01 & $06 / 13 / 2001$ \\
\hline PAF-BOOT POND-5A & Aluminum, Total & 1.1 & $\mathrm{mg} / \mathrm{L}$ & 0.05 & $06 / 13 / 2001$ \\
\hline PAF-BOOT POND-5A & Ammonia as $\mathrm{N}$ & 0.07 & $\mathrm{mg} / \mathrm{L}$ & 0.01 & $06 / 05 / 2001$ \\
\hline PAF-BOOT POND-5A & Antimony, Total & $<\mathrm{MDL}$ & $\mathrm{mg} / \mathrm{L}$ & 0.001 & $06 / 12 / 2001$ \\
\hline PAF-BOOT POND-5A & Arsenic, Total & $<M D L$ & $\mathrm{mg} / \mathrm{L}$ & 0.001 & 06/09/2001 \\
\hline PAF-BOOT POND-5A & Barium, Total & 0.02 & $\mathrm{mg} / \mathrm{L}$ & 0.01 & $06 / 13 / 2001$ \\
\hline PAF-BOOT POND-5A & Beryllium, Total & $<\mathrm{MDL}$ & $\mathrm{mg} / \mathrm{L}$ & 0.001 & $06 / 13 / 2001$ \\
\hline PAF-BOOT POND-5A & Boron, Total & 11 & $\mathrm{mg} / \mathrm{L}$ & 0.2 & $06 / 13 / 2001$ \\
\hline PAF-BOOT POND-5A & $\mathrm{Ca} \quad \& \quad \mathrm{Mg}$ & 1200 & $\mathrm{mg} / \mathrm{L}$ & & $06 / 14 / 2001$ \\
\hline
\end{tabular}


PAF-BOOT POND-5A PAF-BOOT POND-5A PAF-BOOT POND-5A PAF-BOOT POND-5A PAF-BOOT POND-5A PAF-BOOT POND-5A PAF-BOOT POND-5A PAF-BOOT POND-5A PAF-BOOT POND-5A PAF-BOOT POND-5A PAF-BOOT POND-5A PAF-BOOT POND-5A PAF-BOOT POND-5A PAF-BOOT POND-5A PAF-BOOT POND-5A PAF-BOOT POND-5A PAF-BOOT POND-5A PAF-BOOT POND-5A PAF-BOOT POND-5A PAF-BOOT POND-5A PAF-BOOT POND-5A PAF-BOOT POND-5A PAF-BOOT POND-5A PAF-BOOT POND-5A PAF-BOOT POND-5A PAF-BOOT POND-5A PAF-BOOT POND-5A PAF-BOOT POND-5A PAF-BOOT POND-5A PAF-BOOT POND-5A PAF-BOOT POND-5A PAF-BOOT POND-5A PAF-BOOT POND-5A PAF-BOOT POND-5A PAF-BOOT POND-5A PAF-BOOT POND-5A PAF-BOOT POND-5A PAF-BOOT POND-5A PAF-BOOT POND-5A PAF-BOOT POND-5A PAF-SOUTH POND-5A PAF-SOUTH POND-5A PAF-SOUTH POND-5A PAF-SOUTH POND-5A PAF-SOUTH POND-5A PAF-SOUTH POND-5A PAF-SOUTH POND-5A PAF-SOUTH POND-5A
Hardness

Cadmium, Total

Calcium, Total

Chemical Oxygen Demand

Chloride, Total

Chromium, Total

Cobalt, Total

Copper, Total

Copper, Total

Filterable Residue

Fluoride, Total

Inorganic Carbon, Total

Iron, Total

Lead, Total

Magnesium, Total

Manganese, Total

Mercury, Total

Molybdenum, Total

Nickel, Total

Nitrate-Nitrite as $\mathrm{N}$

Nitrite as $\mathrm{N}$

Non-Filterable Residue

Organic Carbon, Total

Phosphorus, Total

Potassium, Total

Selenium, Total

Silica Calculation

Silicon, Total

Silicon, Total

Silver, Total

Silver, Total

Sodium, Total

Strontium, Total

Sulfate, Total

Thallium, Total

Tin, Total

Titanium, Total

Total Kjeldahl Nitrogen

TSS Initial Weight

Vanadium, Total

Zinc, Total

Aluminum, Total

Ammonia as $\mathrm{N}$

Antimony, Total

Arsenic, Total

Barium, Total

Beryllium, Total

Boron, Total

$\mathrm{Ca} \& \mathrm{Mg}$ Calculated 840 Hardness
$\mathrm{CaCO} 3$

$0.00064 \mathrm{mg} / \mathrm{L}$

$250 \mathrm{mg} / \mathrm{L}$

$43 \mathrm{mg} / \mathrm{L}$

$180 \mathrm{mg} / \mathrm{L}$

$0.0026 \mathrm{mg} / \mathrm{L}$

$<\mathrm{MDL} \mathrm{mg} / \mathrm{L}$

$0.0037 \mathrm{mg} / \mathrm{L}$

$<\mathrm{MDL} \mathrm{mg} / \mathrm{L}$

$3000 \mathrm{mg} / \mathrm{L}$

$0.26 \mathrm{mg} / \mathrm{L}$

$45 \mathrm{mg} / \mathrm{L}$

$1.8 \mathrm{mg} / \mathrm{L}$

$<\mathrm{MDL} \mathrm{mg} / \mathrm{L}$

$150 \mathrm{mg} / \mathrm{L}$

$0.72 \mathrm{mg} / \mathrm{L}$

$<\mathrm{MDL} \mathrm{mg} / \mathrm{L}$

$<\mathrm{MDL} \mathrm{mg} / \mathrm{L}$

$0.0082 \mathrm{mg} / \mathrm{L}$

$<\mathrm{MDL} \mathrm{mg} / \mathrm{L}$

$<\mathrm{MDL} \mathrm{mg} / \mathrm{L}$

$10 \mathrm{mg} / \mathrm{L}$

$8 \mathrm{mg} / \mathrm{L}$

$0.16 \mathrm{mg} / \mathrm{L}$

$10 \mathrm{mg} / \mathrm{L}$

$<\mathrm{MDL} \mathrm{mg} / \mathrm{L}$

$13.473 \mathrm{mg} / \mathrm{L}$

$6.3 \mathrm{mg} / \mathrm{L}$

$6.3 \mathrm{mg} / \mathrm{L}$

$<\mathrm{MDL} \mathrm{mg} / \mathrm{L}$

$<\mathrm{MDL} \mathrm{mg} / \mathrm{L}$

$180 \mathrm{mg} / \mathrm{L}$

$<\mathrm{MDL} \mathrm{mg} / \mathrm{L}$

$1500 \mathrm{mg} / \mathrm{L}$

$<\mathrm{MDL} \mathrm{mg} / \mathrm{L}$

$<\mathrm{MDL} \mathrm{mg} / \mathrm{L}$

$0.016 \mathrm{mg} / \mathrm{L}$

$1.7 \mathrm{mg} / \mathrm{L}$

$1.6753 \mathrm{~g}$

$<\mathrm{MDL} \mathrm{mg} / \mathrm{L}$

$<\mathrm{MDL} \mathrm{mg} / \mathrm{L}$

$0.14 \mathrm{mg} / \mathrm{L}$

$0.04 \mathrm{mg} / \mathrm{L}$

$<\mathrm{MDL} \mathrm{mg} / \mathrm{L}$

$0.002 \mathrm{mg} / \mathrm{L}$

$0.016 \mathrm{mg} / \mathrm{L}$

$<\mathrm{MDL} \mathrm{mg} / \mathrm{L}$

$6.9 \mathrm{mg} / \mathrm{L}$

$\mathrm{mg} / \mathrm{L}$

$\mathrm{CaCO} 3$
$0.000106 / 08 / 2001$

$0.1 \quad 06 / 13 / 2001$

$20 \quad 06 / 11 / 2001$

$1 \quad 06 / 08 / 2001$

$0.00106 / 08 / 2001$

$0.001 \quad 06 / 13 / 2001$

$0.001 \quad 06 / 08 / 2001$

$0.01 \quad 06 / 13 / 2001$

$10 \quad 06 / 06 / 2001$

$0.1 \quad 06 / 14 / 2001$

$1 \quad 06 / 14 / 2001$

$0.01 \quad 06 / 13 / 2001$

$0.001 \quad 06 / 11 / 2001$

$0.01 \quad 06 / 13 / 2001$

$0.005 \quad 06 / 13 / 2001$

$0.0002 \quad 06 / 07 / 2001$

$0.02 \quad 06 / 13 / 2001$

$0.001 \quad 06 / 08 / 2001$

$0.01 \quad 06 / 05 / 2001$

$0.01 \quad 06 / 01 / 2001$

$1 \quad 06 / 05 / 2001$

$0.2 \quad 06 / 09 / 2001$

$0.01 \quad 06 / 11 / 2001$

$0.1 \quad 06 / 08 / 2001$

$0.001 \quad 06 / 12 / 2001$

$06 / 14 / 2001$

$06 / 14 / 2001$

$0.02 \quad 06 / 13 / 2001$

$0.000106 / 08 / 2001$

$0.01 \quad 06 / 13 / 2001$

$0.1 \quad 06 / 08 / 2001$

$0.05 \quad 06 / 13 / 2001$

$1 \quad 06 / 12 / 2001$

$0.002 \quad 06 / 12 / 2001$

$0.05 \quad 06 / 13 / 2001$

$0.005 \quad 06 / 13 / 2001$

$0.0206 / 11 / 2001$

$06 / 05 / 2001$

$0.01 \quad 06 / 13 / 2001$

$0.01 \quad 06 / 13 / 2001$

$0.05 \quad 06 / 13 / 2001$

$0.01 \quad 06 / 05 / 2001$

$0.001 \quad 06 / 12 / 2001$

$0.001 \quad 06 / 13 / 2001$

$0.01 \quad 06 / 13 / 2001$

$0.001 \quad 06 / 13 / 2001$

$0.2 \quad 06 / 13 / 2001$

$06 / 14 / 2001$ 


\begin{tabular}{|c|c|c|c|c|c|}
\hline PAF-SOUTH POND-5A & Cadmium, Total & $<M D L$ & $\mathrm{mg} / \mathrm{L}$ & 0.0001 & 06/08/2001 \\
\hline PAF-SOUTH POND-5A & Calcium, Total & 170 & $\mathrm{mg} / \mathrm{L}$ & 0.1 & $06 / 13 / 2001$ \\
\hline PAF-SOUTH POND-5A & Chemical Oxygen Demand & 32 & $\mathrm{mg} / \mathrm{L}$ & 20 & $06 / 11 / 2001$ \\
\hline PAF-SOUTH POND-5A & Chloride, Total & 68 & $\mathrm{mg} / \mathrm{L}$ & 1 & 06/08/2001 \\
\hline PAF-SOUTH POND-5A & Chromium, Total & $<M D L$ & $\mathrm{mg} / \mathrm{L}$ & 0.001 & 06/08/2001 \\
\hline PAF-SOUTH POND-5A & Cobalt, Total & $<M D L$ & $\mathrm{mg} / \mathrm{L}$ & 0.001 & $06 / 13 / 2001$ \\
\hline PAF-SOUTH POND-5A & Copper, Total & $<M D L$ & $\mathrm{mg} / \mathrm{L}$ & 0.001 & $06 / 08 / 2001$ \\
\hline PAF-SOUTH POND-5A & Copper, Total & $<M D L$ & $\mathrm{mg} / \mathrm{L}$ & 0.01 & 06/13/2001 \\
\hline PAF-SOUTH POND-5A & Filterable Residue & 1900 & $\mathrm{mg} / \mathrm{L}$ & 10 & 06/06/2001 \\
\hline PAF-SOUTH POND-5A & Fluoride, Total & 0.78 & $\mathrm{mg} / \mathrm{L}$ & 0.1 & $06 / 14 / 2001$ \\
\hline PAF-SOUTH POND-5A & Inorganic Carbon, Total & 49 & $\mathrm{mg} / \mathrm{L}$ & 1 & $06 / 14 / 2001$ \\
\hline PAF-SOUTH POND-5A & Iron, Total & 0.37 & $\mathrm{mg} / \mathrm{L}$ & 0.01 & $06 / 13 / 2001$ \\
\hline PAF-SOUTH POND-5A & Lead, Total & $<M D L$ & $\mathrm{mg} / \mathrm{L}$ & 0.001 & $06 / 11 / 2001$ \\
\hline PAF-SOUTH POND-5A & Magnesium, Total & 100 & $\mathrm{mg} / \mathrm{L}$ & 0.01 & $06 / 13 / 2001$ \\
\hline PAF-SOUTH POND-5A & Manganese, Total & 0.026 & $\mathrm{mg} / \mathrm{L}$ & 0.005 & $06 / 13 / 2001$ \\
\hline PAF-SOUTH POND-5A & Mercury, Total & $<\mathrm{MDL}$ & $\mathrm{mg} / \mathrm{L}$ & 0.0002 & $06 / 07 / 2001$ \\
\hline PAF-SOUTH POND-5A & Molybdenum, Total & $<M D L$ & $\mathrm{mg} / \mathrm{L}$ & 0.02 & $06 / 13 / 2001$ \\
\hline PAF-SOUTH POND-5A & Nickel, Total & 0.0022 & $\mathrm{mg} / \mathrm{L}$ & 0.001 & 06/08/2001 \\
\hline PAF-SOUTH POND-5A & Nitrate-Nitrite as $\mathrm{N}$ & 0.04 & $\mathrm{mg} / \mathrm{L}$ & 0.01 & 06/05/2001 \\
\hline PAF-SOUTH POND-5A & Nitrite as $\mathrm{N}$ & $<M D L$ & $\mathrm{mg} / \mathrm{L}$ & 0.01 & $06 / 01 / 2001$ \\
\hline PAF-SOUTH POND-5A & Non-Filterable Residue & 8 & $\mathrm{mg} / \mathrm{L}$ & 1 & 06/05/2001 \\
\hline PAF-SOUTH POND-5A & Organic Carbon, Total & 6.6 & $\mathrm{mg} / \mathrm{L}$ & 0.2 & 06/09/2001 \\
\hline PAF-SOUTH POND-5A & Phosphorus, Total & 0.05 & $\mathrm{mg} / \mathrm{L}$ & 0.01 & $06 / 11 / 2001$ \\
\hline PAF-SOUTH POND-5A & Potassium, Total & 10 & $\mathrm{mg} / \mathrm{L}$ & 0.1 & 06/08/2001 \\
\hline PAF-SOUTH POND-5A & Selenium, Total & $<M D L$ & $\mathrm{mg} / \mathrm{L}$ & 0.001 & $06 / 12 / 2001$ \\
\hline PAF-SOUTH POND-5A & Silica Calculation & 0.577 & $\mathrm{mg} / \mathrm{L}$ & & $06 / 14 / 2001$ \\
\hline PAF-SOUTH POND-5A & Silicon, Total & 0.27 & $\mathrm{mg} / \mathrm{L}$ & & $06 / 14 / 2001$ \\
\hline PAF-SOUTH POND-5A & Silicon, Total & 0.27 & $\mathrm{mg} / \mathrm{L}$ & 0.02 & $06 / 13 / 2001$ \\
\hline PAF-SOUTH POND-5A & Silver, Total & $<M D L$ & $\mathrm{mg} / \mathrm{L}$ & 0.0001 & 06/08/2001 \\
\hline PAF-SOUTH POND-5A & Silver, Total & $<M D L$ & $\mathrm{mg} / \mathrm{L}$ & 0.01 & 06/13/2001 \\
\hline PAF-SOUTH POND-5A & Sodium, Total & 190 & $\mathrm{mg} / \mathrm{L}$ & 0.1 & 06/08/2001 \\
\hline PAF-SOUTH POND-5A & Strontium, Total & $<M D L$ & $\mathrm{mg} / \mathrm{L}$ & 0.05 & $06 / 13 / 2001$ \\
\hline PAF-SOUTH POND-5A & Sulfate, Total & 960 & $\mathrm{mg} / \mathrm{L}$ & 1 & $06 / 12 / 2001$ \\
\hline PAF-SOUTH POND-5A & Thallium, Total & $<M D L$ & $\mathrm{mg} / \mathrm{L}$ & 0.002 & $06 / 15 / 2001$ \\
\hline PAF-SOUTH POND-5A & Tin, Total & $<\mathrm{MDL}$ & $\mathrm{mg} / \mathrm{L}$ & 0.05 & $06 / 13 / 2001$ \\
\hline PAF-SOUTH POND-5A & Titanium, Total & 0.0065 & $\mathrm{mg} / \mathrm{L}$ & 0.005 & 06/13/2001 \\
\hline PAF-SOUTH POND-5A & Total Kjeldahl Nitrogen & 1.3 & $\mathrm{mg} / \mathrm{L}$ & 0.02 & $06 / 11 / 2001$ \\
\hline PAF-SOUTH POND-5A & TSS Initial Weight & 1.6856 & g & & 06/05/2001 \\
\hline PAF-SOUTH POND-5A & Vanadium, Total & $<M D L$ & $\mathrm{mg} / \mathrm{L}$ & 0.01 & $06 / 13 / 2001$ \\
\hline PAF-SOUTH POND-5A & Zinc, Total & $<M D L$ & $\mathrm{mg} / \mathrm{L}$ & 0.01 & $06 / 13 / 2001$ \\
\hline PAF-POOH BEAR POND-5A & Aluminum, Total & 0.087 & $\mathrm{mg} / \mathrm{L}$ & 0.05 & $06 / 13 / 2001$ \\
\hline PAF-POOH BEAR POND-5A & Ammonia as $\mathrm{N}$ & 1.3 & $\mathrm{mg} / \mathrm{L}$ & 0.01 & 06/05/2001 \\
\hline PAF-POOH BEAR POND-5A & Antimony,Total & $<M D L$ & $\mathrm{mg} / \mathrm{L}$ & 0.001 & $06 / 12 / 2001$ \\
\hline PAF-POOH BEAR POND-5A & Arsenic, Total & $<M D L$ & $\mathrm{mg} / \mathrm{L}$ & 0.001 & $06 / 11 / 2001$ \\
\hline PAF-POOH BEAR POND-5A & Barium, Total & 0.013 & $\mathrm{mg} / \mathrm{L}$ & 0.01 & $06 / 13 / 2001$ \\
\hline PAF-POOH BEAR POND-5A & Beryllium, Total & $<M D L$ & $\mathrm{mg} / \mathrm{L}$ & 0.001 & $06 / 13 / 2001$ \\
\hline PAF-POOH BEAR POND-5A & Boron, Total & 5.4 & $\mathrm{mg} / \mathrm{L}$ & 0.2 & $06 / 13 / 2001$ \\
\hline PAF-POOH BEAR POND-5A & $\begin{array}{l}\text { Ca \& } \mathrm{Mg} \\
\text { Hardness }\end{array}$ & 1600 & $\begin{array}{l}\mathrm{mg} / \mathrm{L} \\
\mathrm{CaCO} 3\end{array}$ & & $06 / 05 / 2001$ \\
\hline PAF-POOH BEAR POND-5A & Cadmium, Total & $<M D L$ & $\mathrm{mg} / \mathrm{L}$ & 0.0001 & 06/08/2001 \\
\hline
\end{tabular}




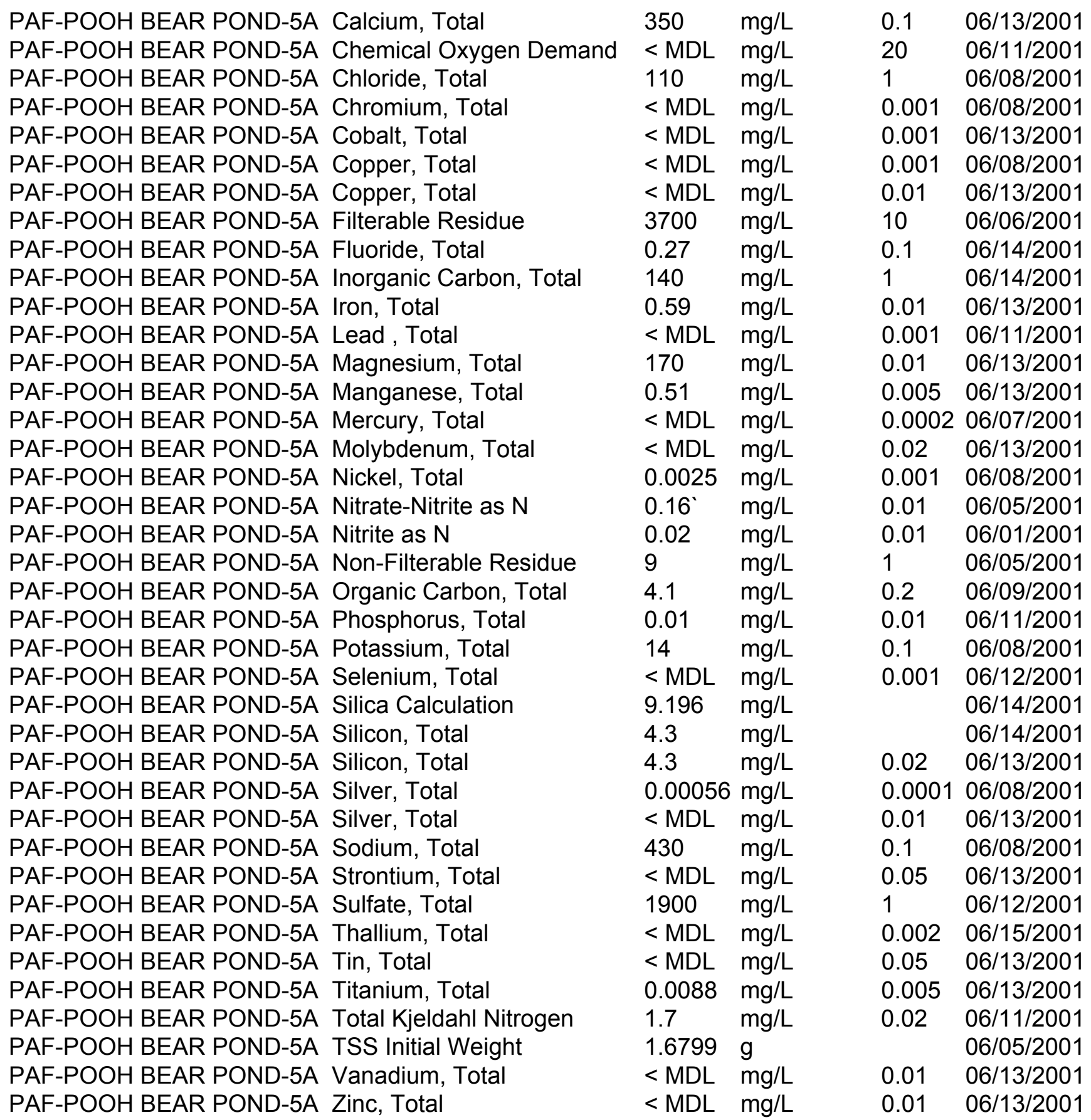




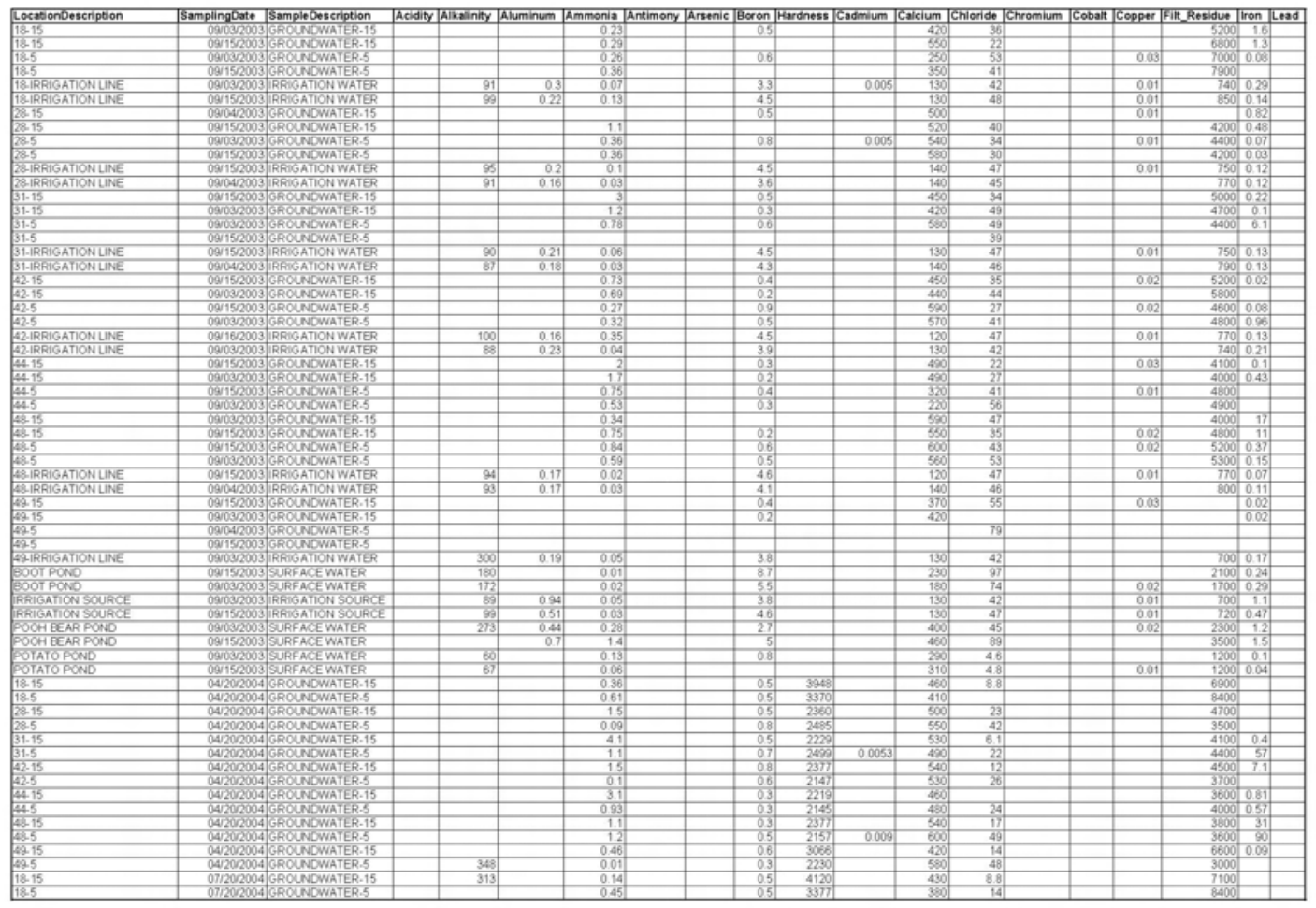




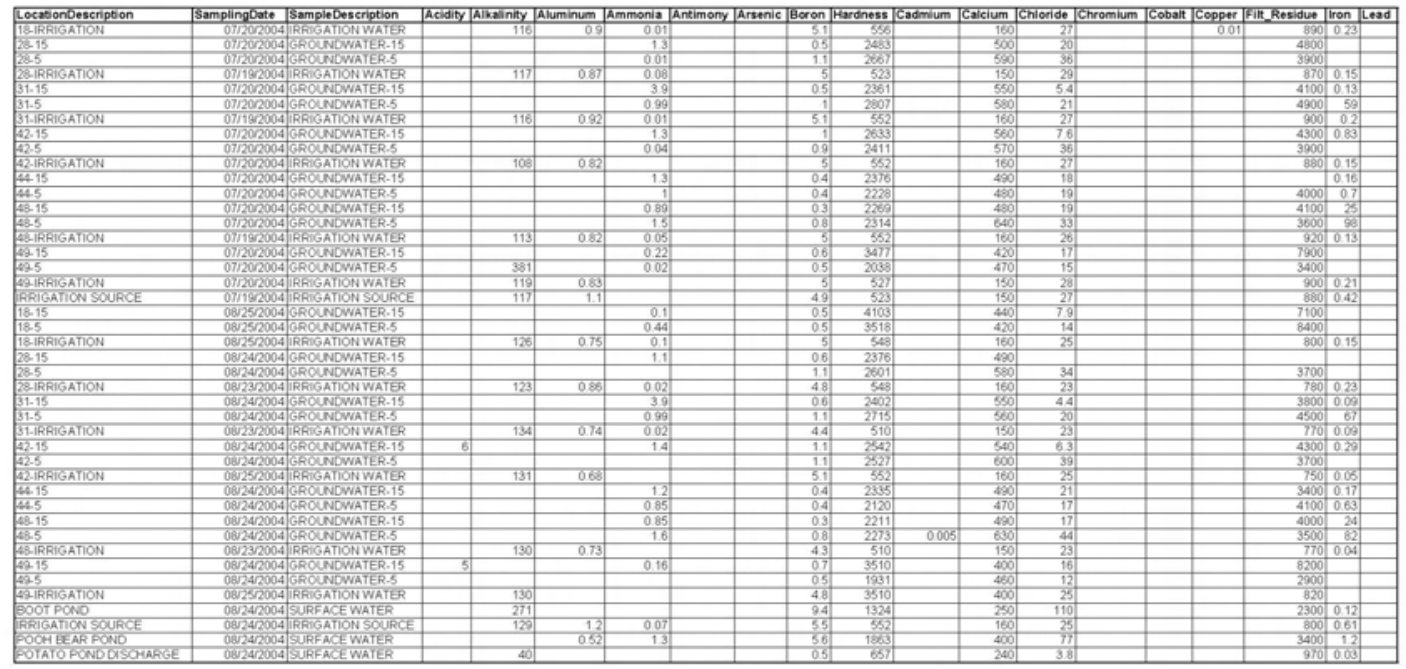




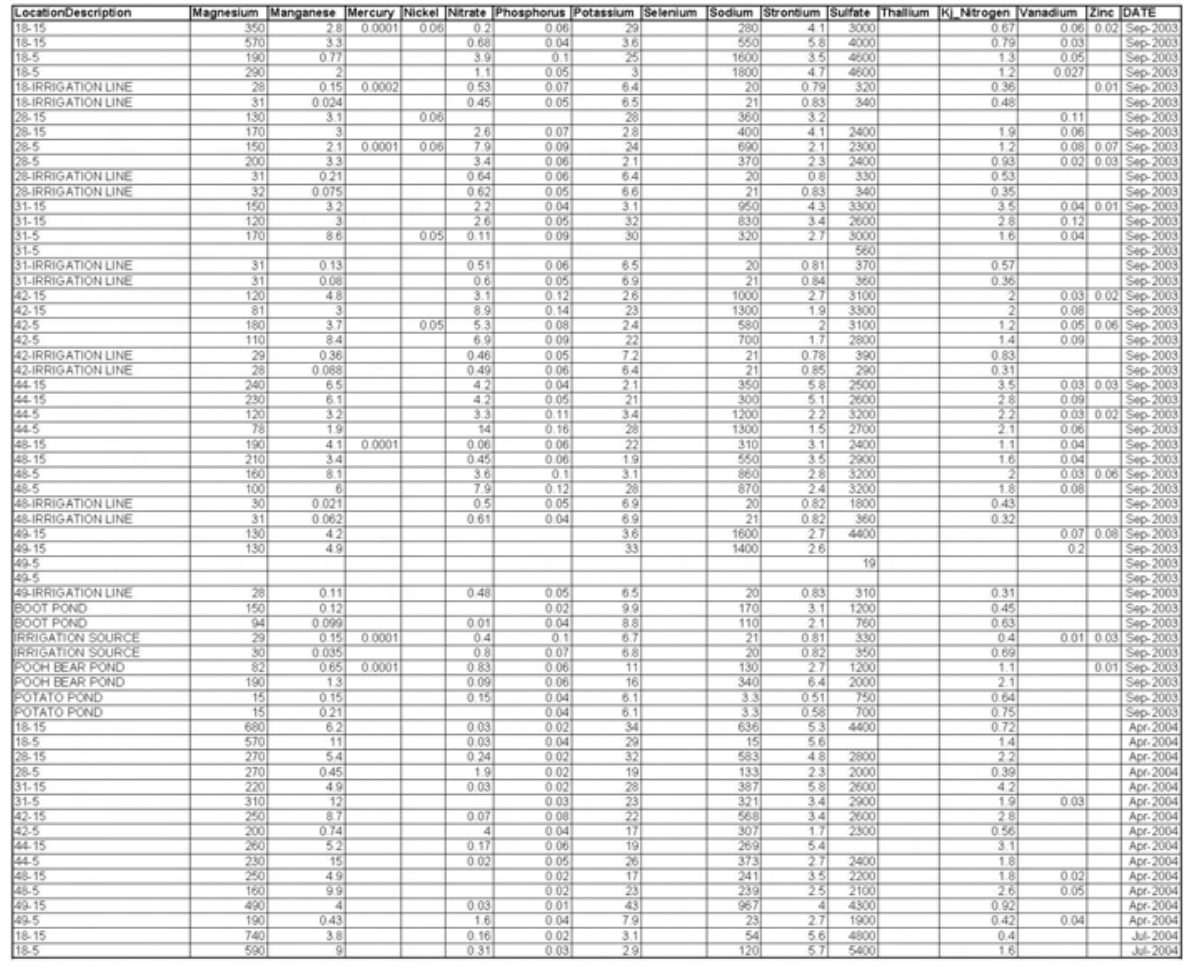




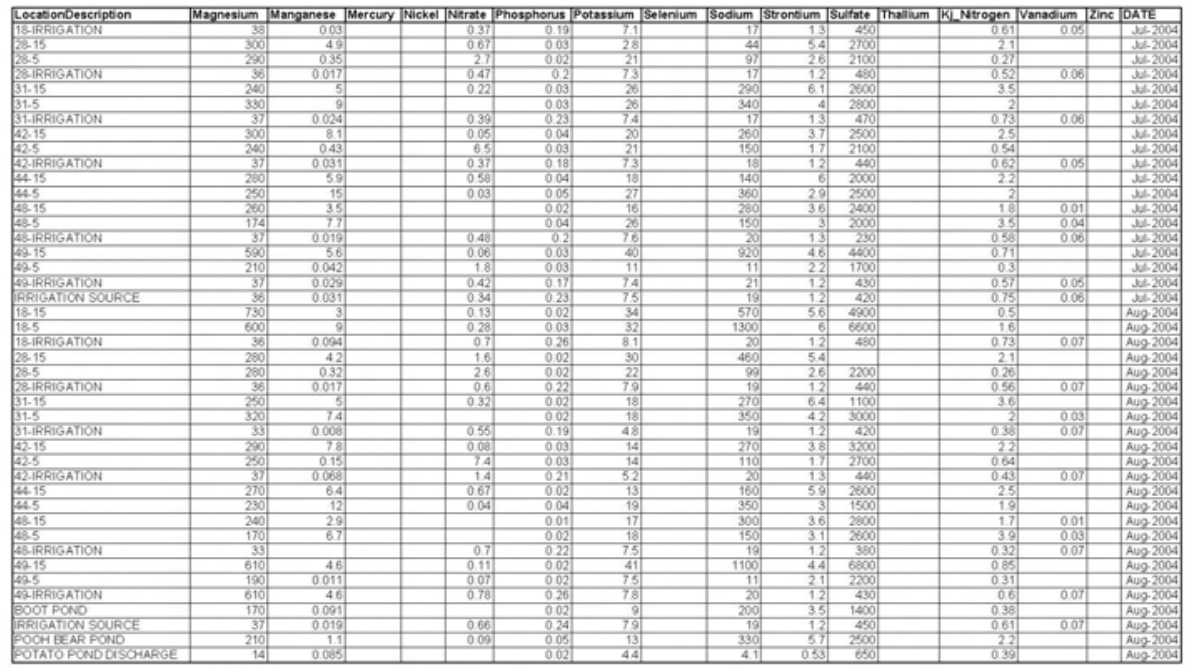




\title{
Appendix 3. Drilling and lysimeter installation report
}

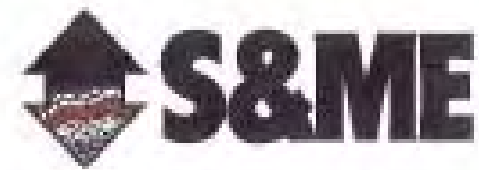

October 1, 2003

Ternessee Valley Autbority

Exvixomenta! Engineering Servicas Eas

1101 Market Street

Chatianooga, Tennessee 37402

\section{Since 1973}

Three Decades .... Three Beoseons Wr Mateil. Wis nespond. He valin.

ATIENTION: $\quad$ Ms. Nannette Brodic, MR2S

Refereno:

\author{
DRILLING AND LYSIMETER INSTALLATION SERVICES \\ Paradise Fossil Plant \\ Muhlentburg Coanty, Keatucky \\ S.EME Project No, 1432-03.379
}

Dear Ms. Brodie:

SEME, trc. (S\&ME) is pleasod to submit this report summarizing the drilling and lysancter installation services for the above referenod project completed under the terms and cobditions of TVA Contrat \$21706, Task $\$ 6007$ and within the seope of services oetlined in our Proposal for Drilline and Lysimeter Installistion Services No. 3203484, dated July 24, 2003.

On August 11, 2003, equipmeat und S\&ME personat for this projoct were mobilized from Louisville, Teanessoc. On August 12 through 14, 2003, S8ME completed the driling and installation of fourtecn lysimeters bear the TVA Paradise Fossil Plant in accordance with TVA and the insirunsent manafactures' guidelines.

As roxuested, the fysimeters pairs were installed to dopths of enther 5 or 15 foet. Borcholes required for the lysimeter installations waro conpleted by advancing 3-1/4 inch inside diamsier hollow stem augers with an all-terrain CME 550-X dritl rig Boreholes were ndvanced into the Ay-ash deposits approxdmately one foot beyoad the desited lysimeter depths. The asditonal depith was compleied to account for potential maierial cave in during anger renoval.

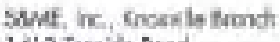

1413 Tepien Boed

Inimib Jeneses 3727 wormentinintucem 
Lponi conpletisn of the drilling, Jonse material that caved into the hole was tamped with a weight attachad to a rope. Beatonite pellets were utilized to fill the remainder of the overdrilled borchole depth. As instructed by the manufactures" guidelines, a silica flour slurry was muxed to the consisiency of mertar. The sitica slury was tremmied to the depth of the borchole to insure proper deposition. The lysimeter was attachod to a PVC riser was iben lowered into the horehole. The porves ceramic cup of the Soil Water Samiglar, Model 1990, was submerged into the silica shury and stahilizad for the remainder of the back-filling activitics. The drill cattings were sieved to remeve rock with a particle size greater than $L / 4$ inch in diancler. The sieved soil was atilized as backlill material. Sieved material was tamped with tive weight sttached fo the rope to prevent settling. Additional layer(s) of beatonite pellets and/or powder were utilizod to isolate the lysimeter and prevent diroct sarfice waser intrusion. Boringlysimeter installation logs lave been completed for each of the lysimeters and are attached.

We appreciate the upporturity to have been of service to you on this project and look forward to working with you in the future. Should you have any questions, please call.

Sincerely,

S\&ME, lac.

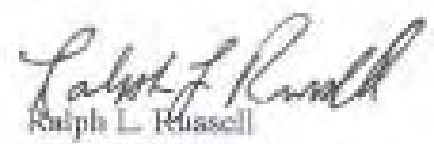

Stiff Profersional

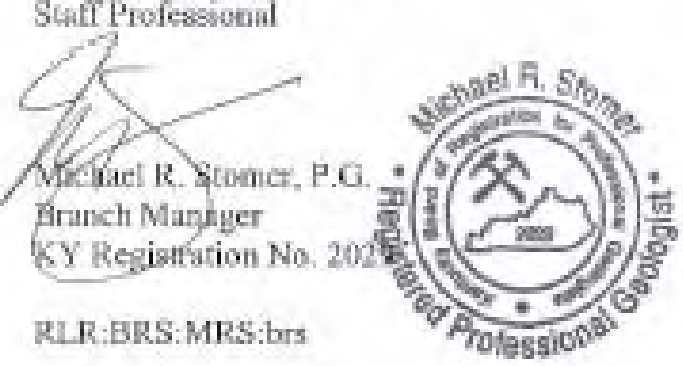

Mtachuents: Boriag/Lysimeter Inatallation I oges

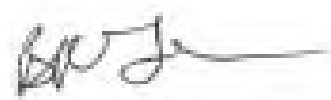

Brad R. Salsbury

Drillang Services Manager

2

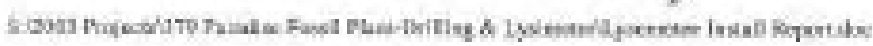




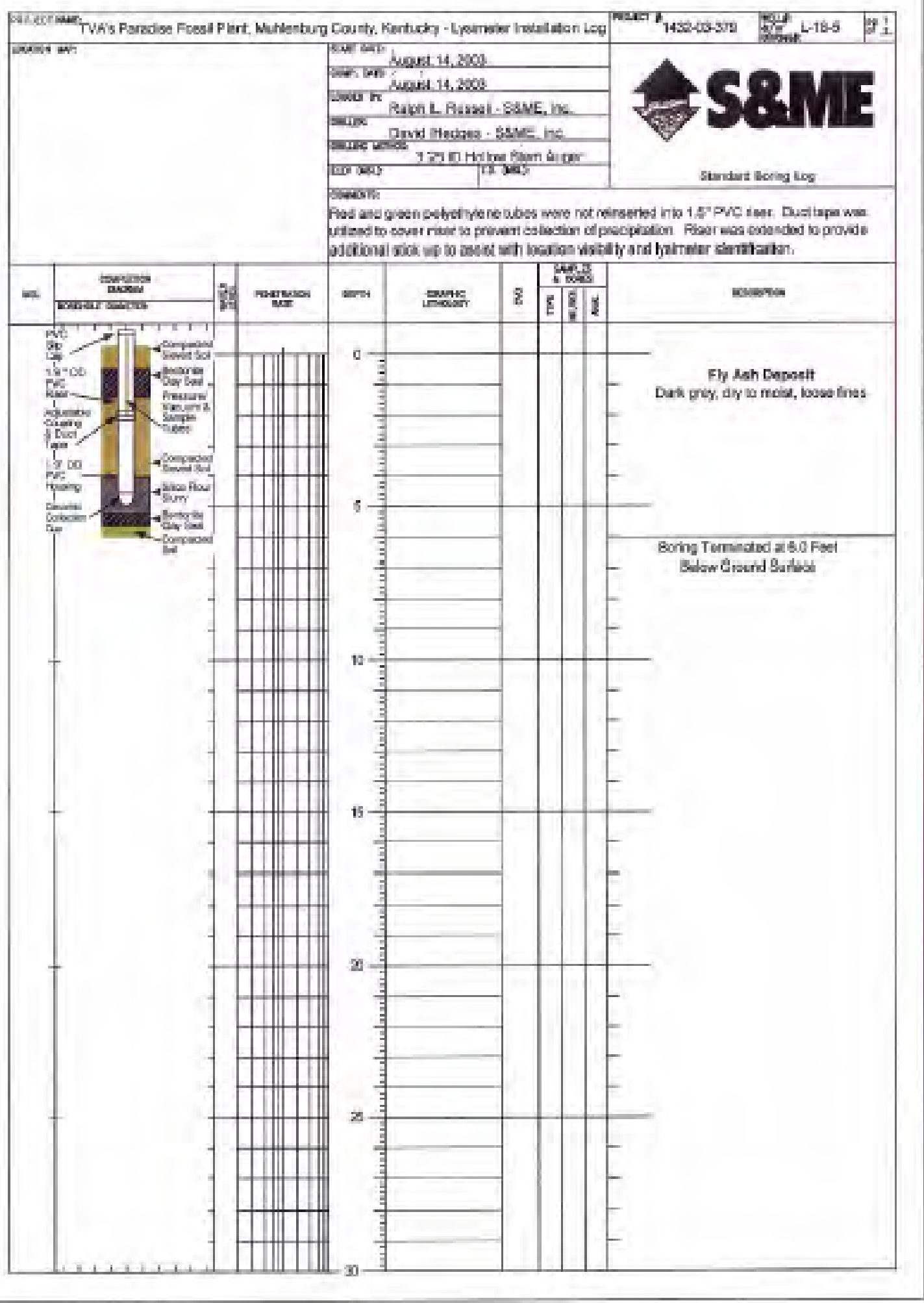




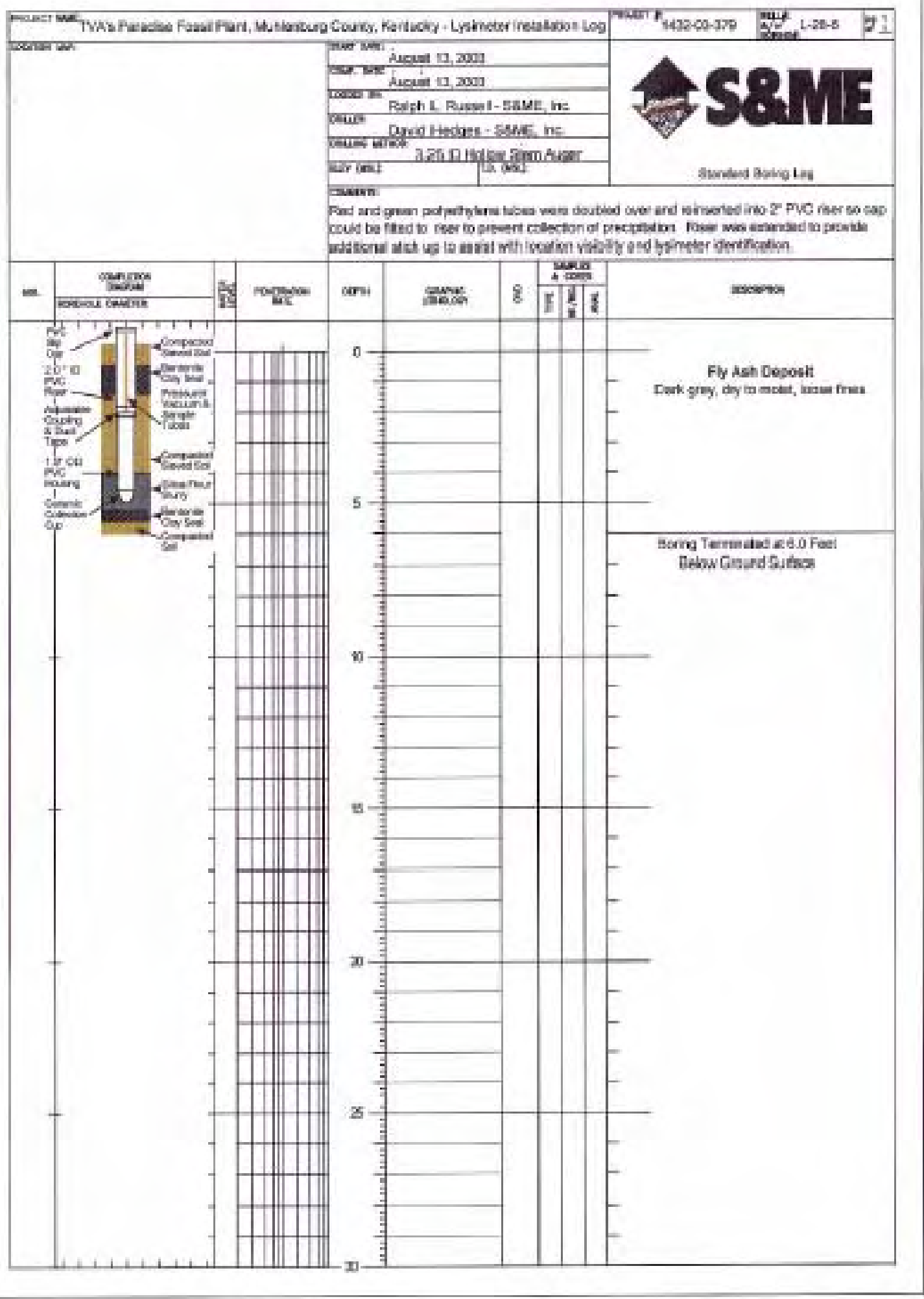




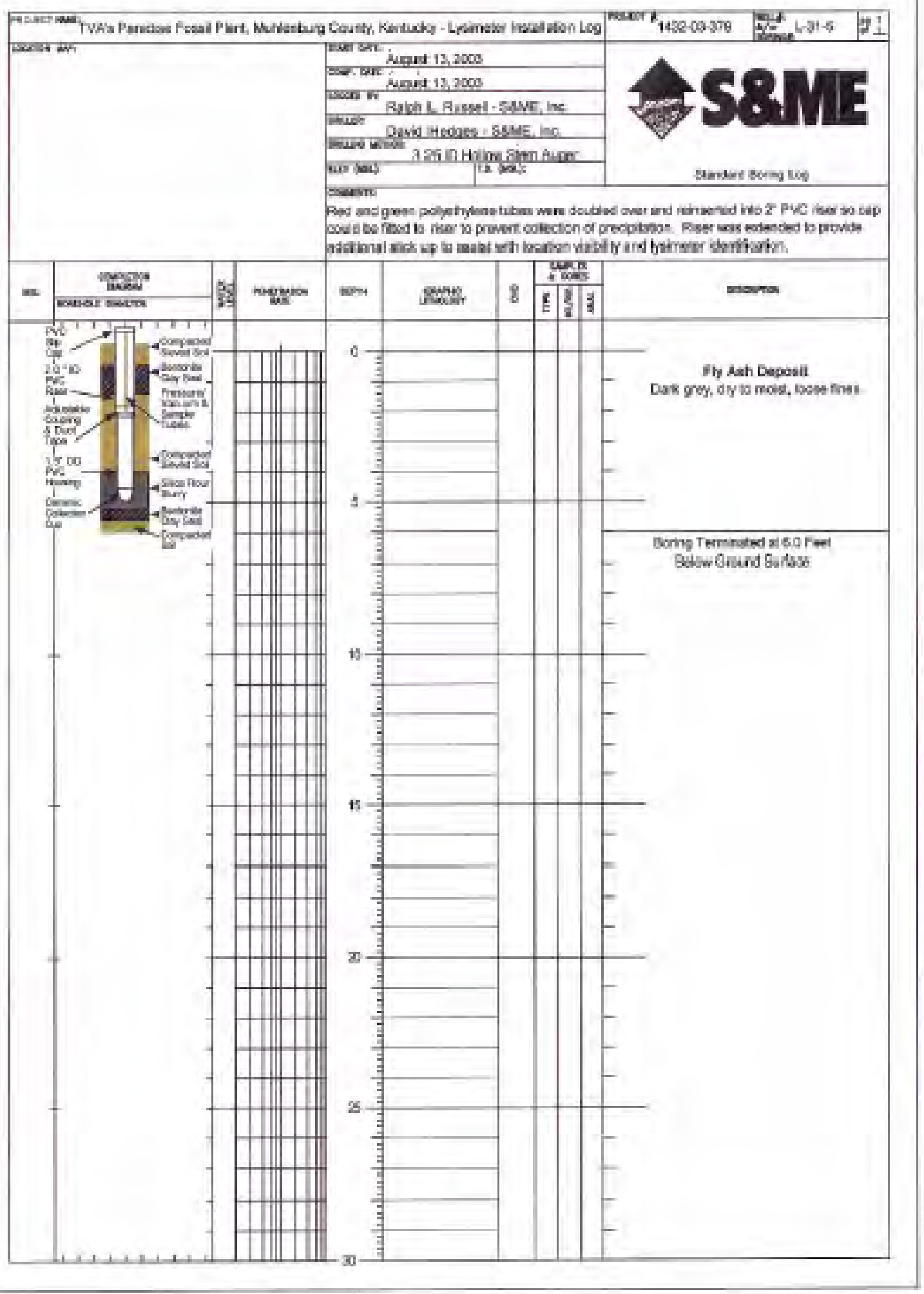




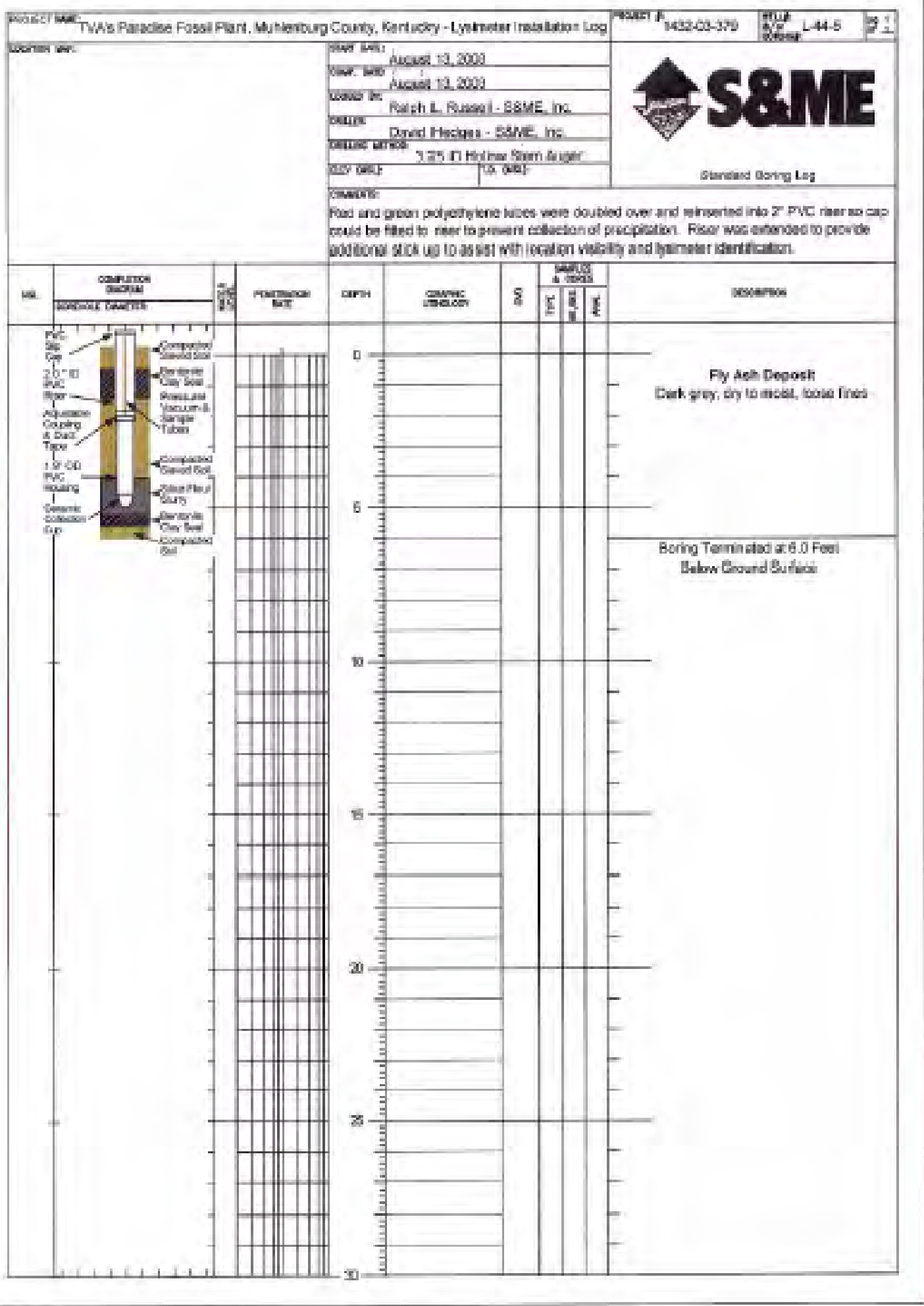




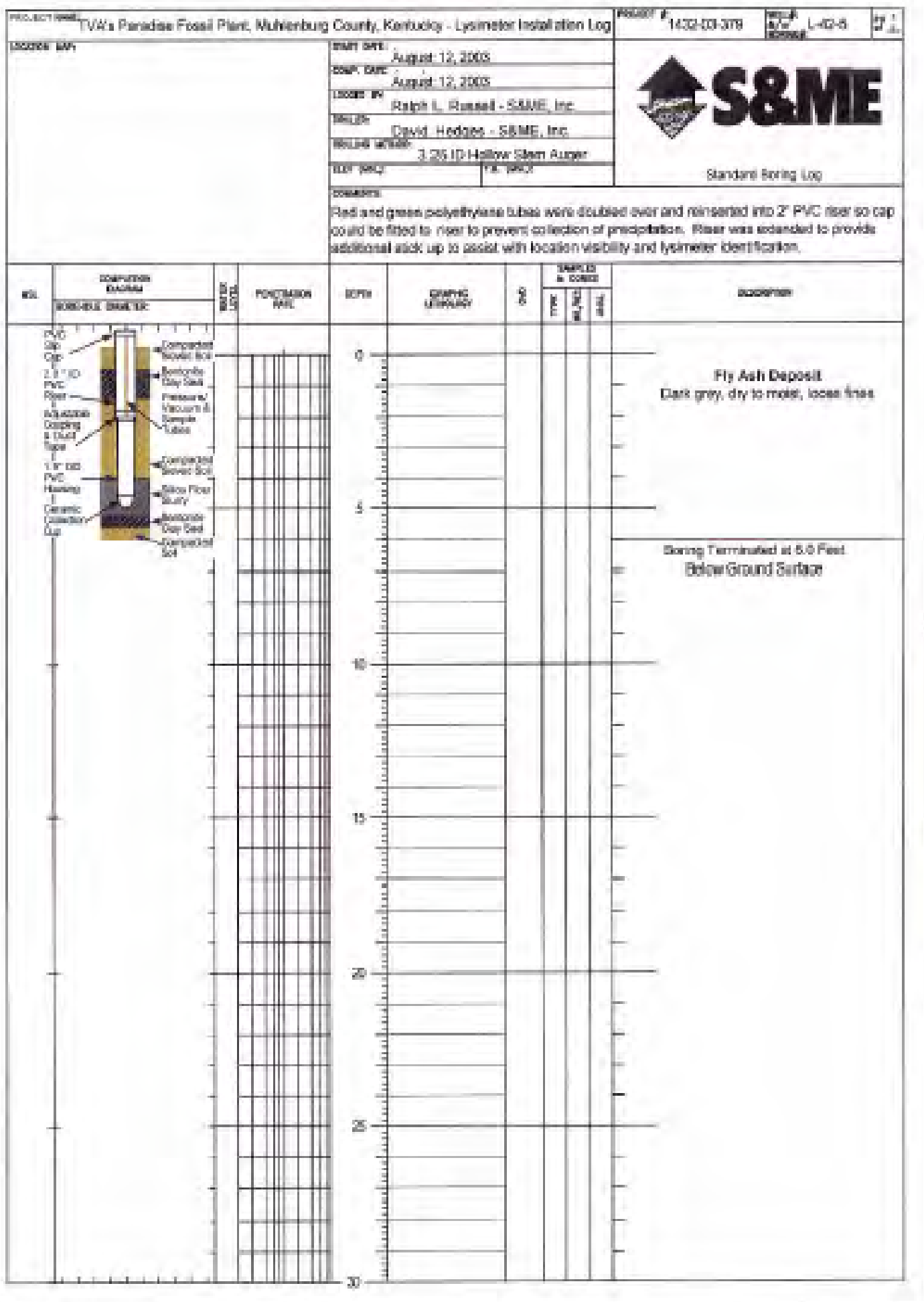




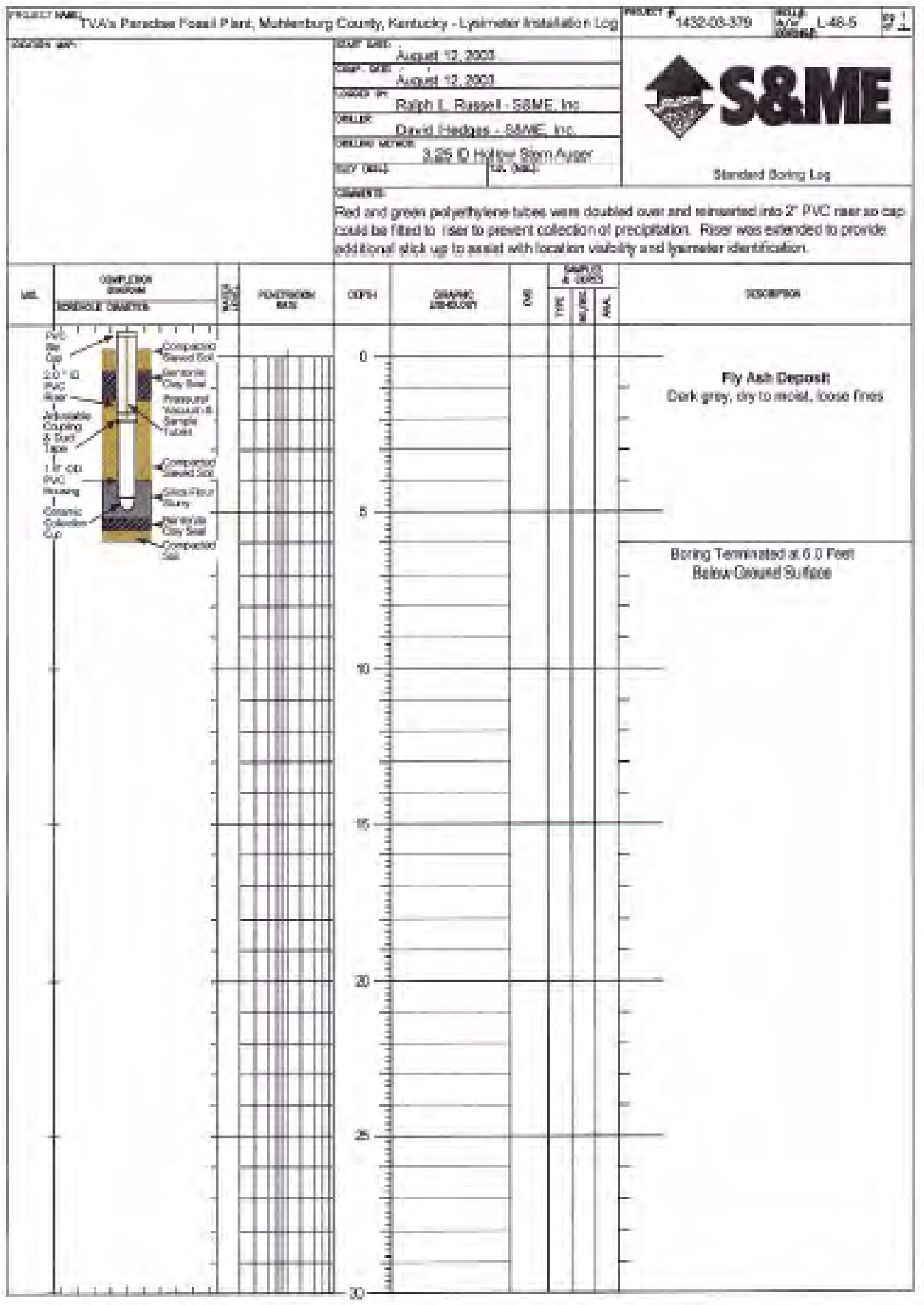




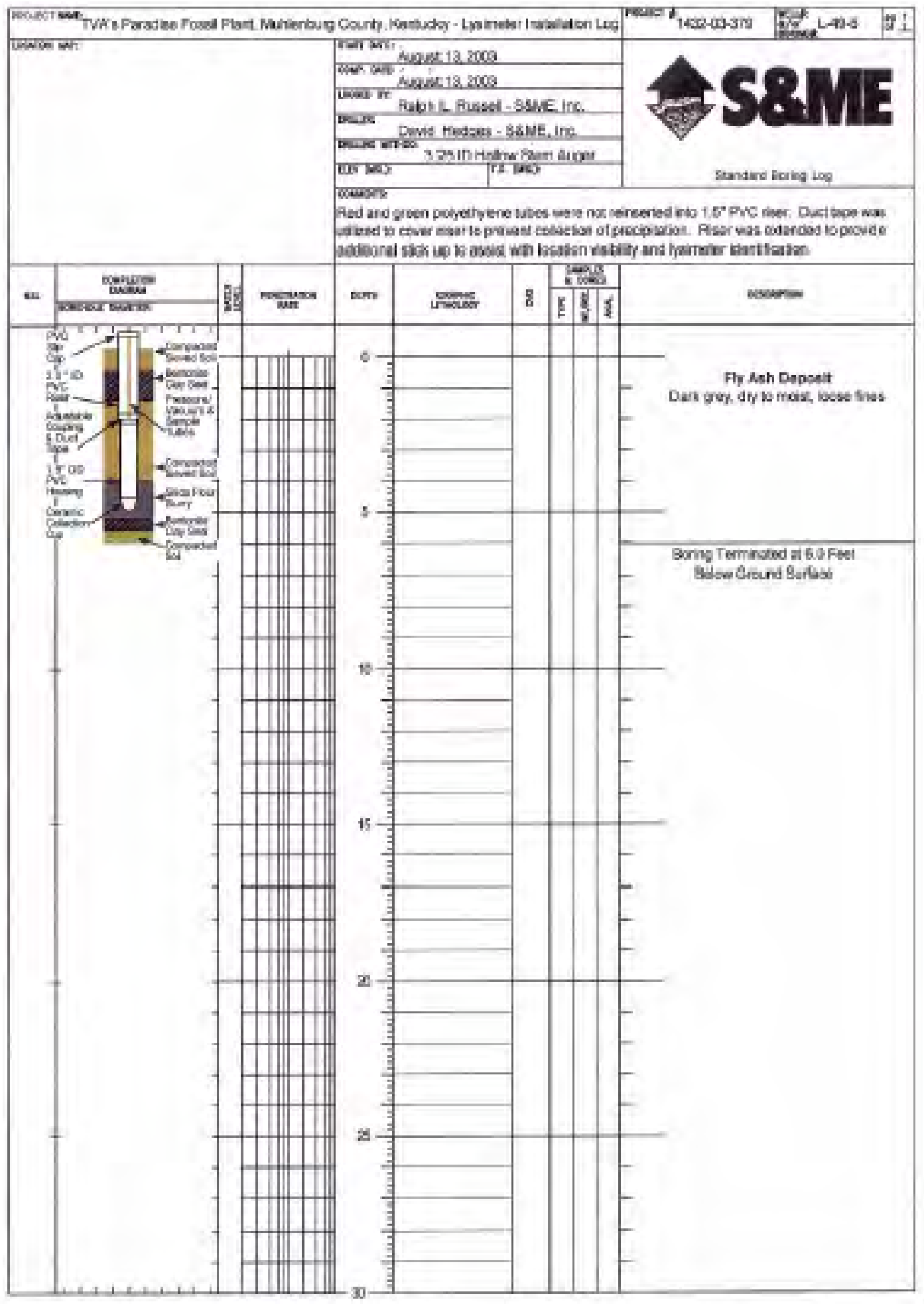




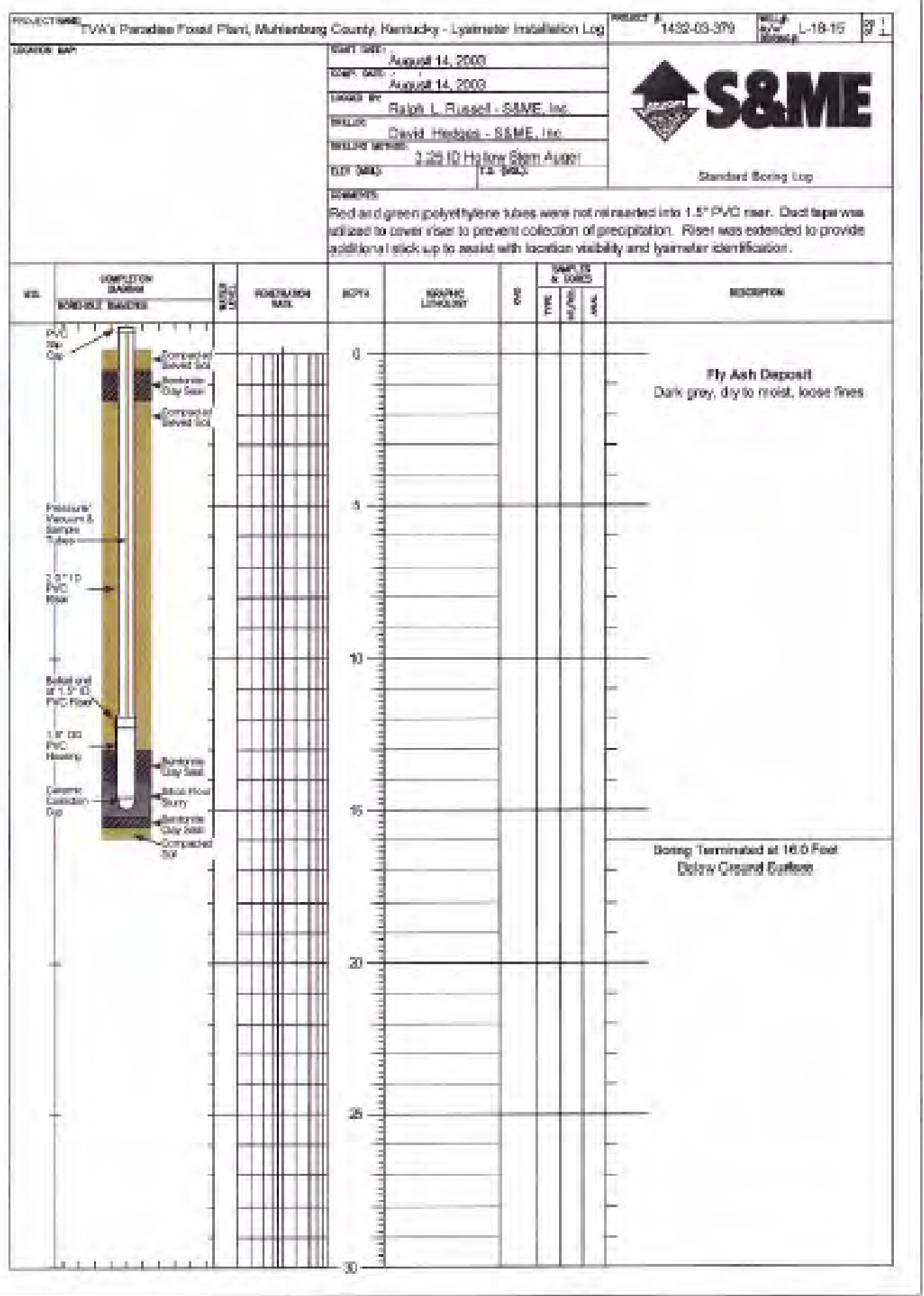




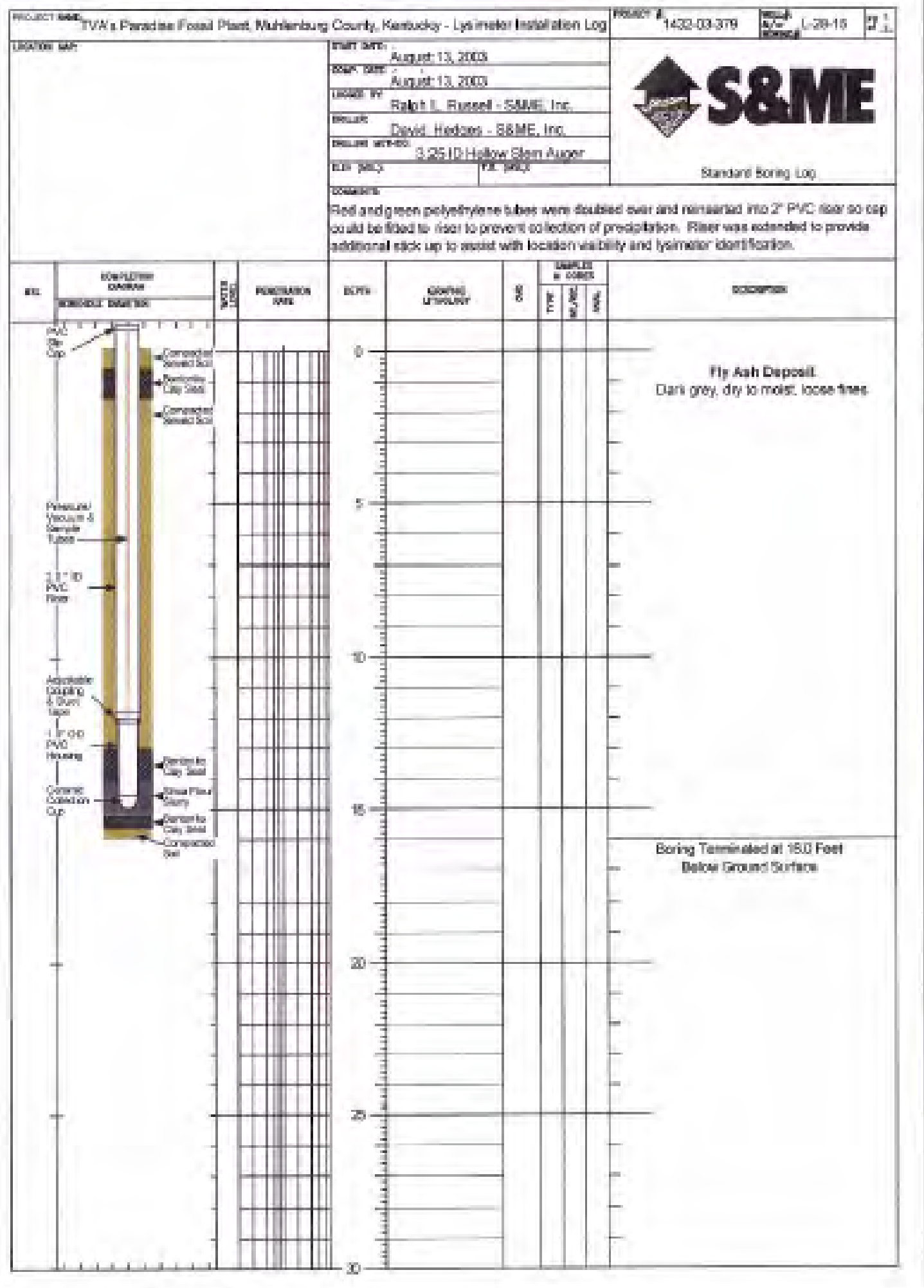




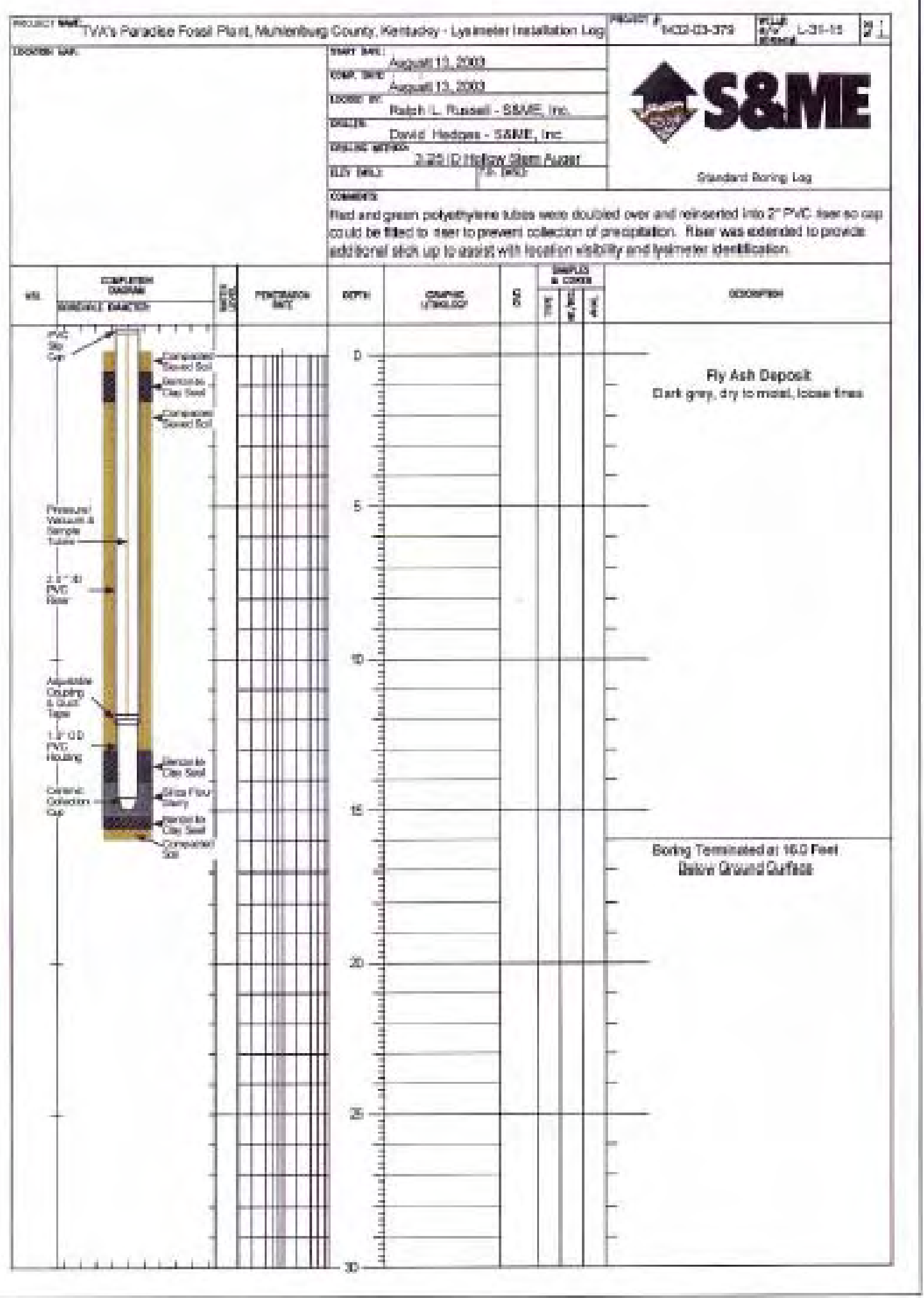




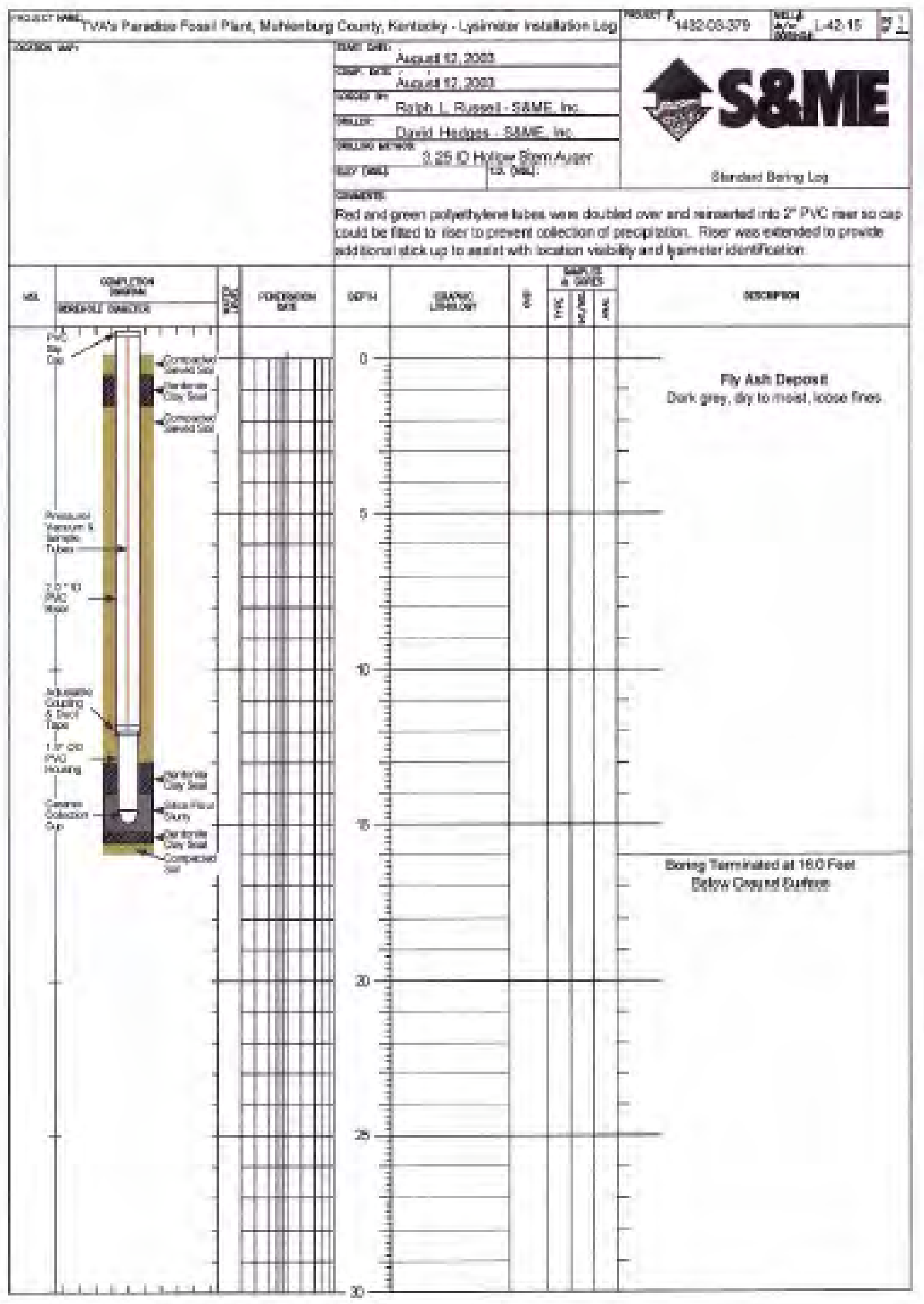




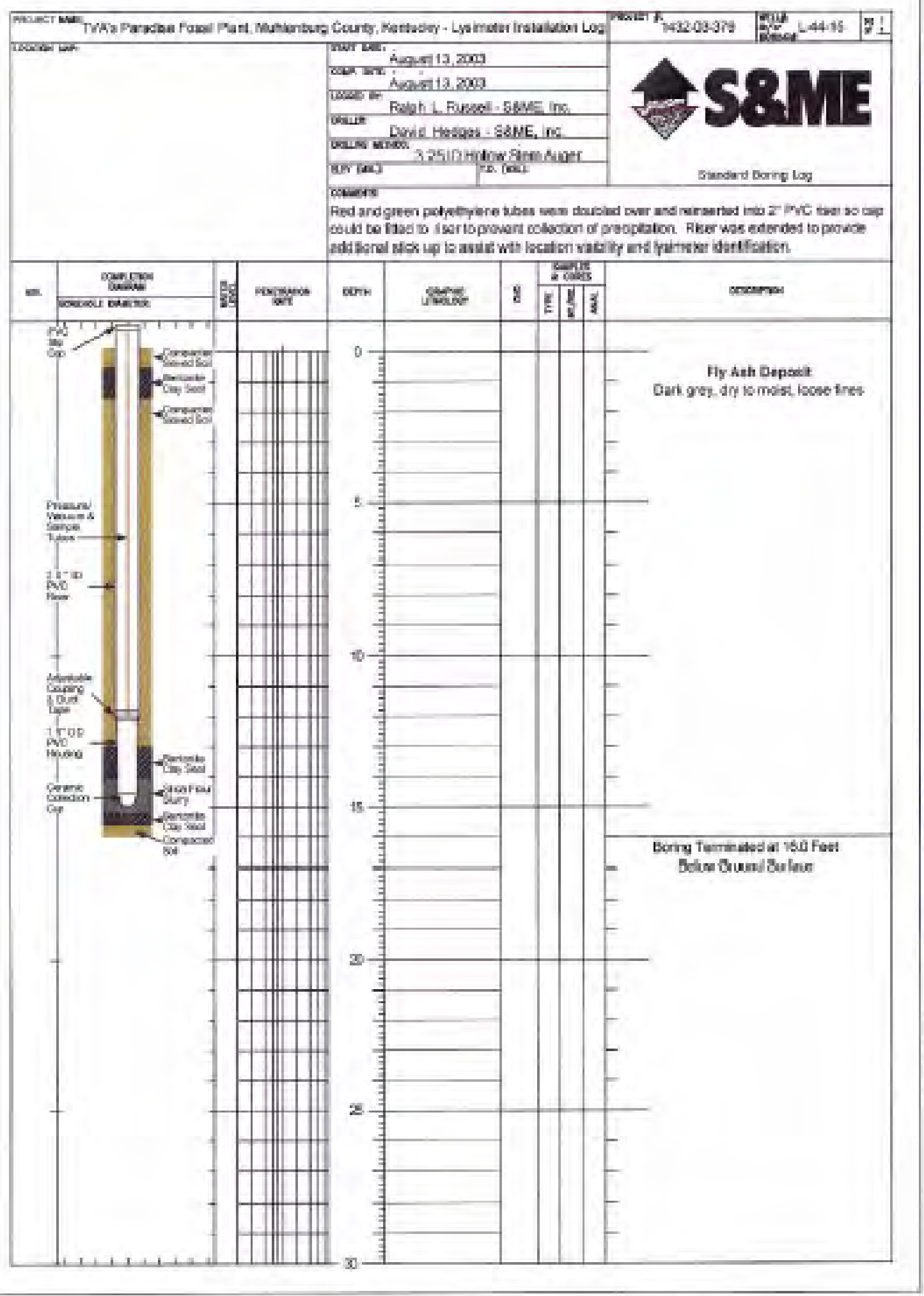




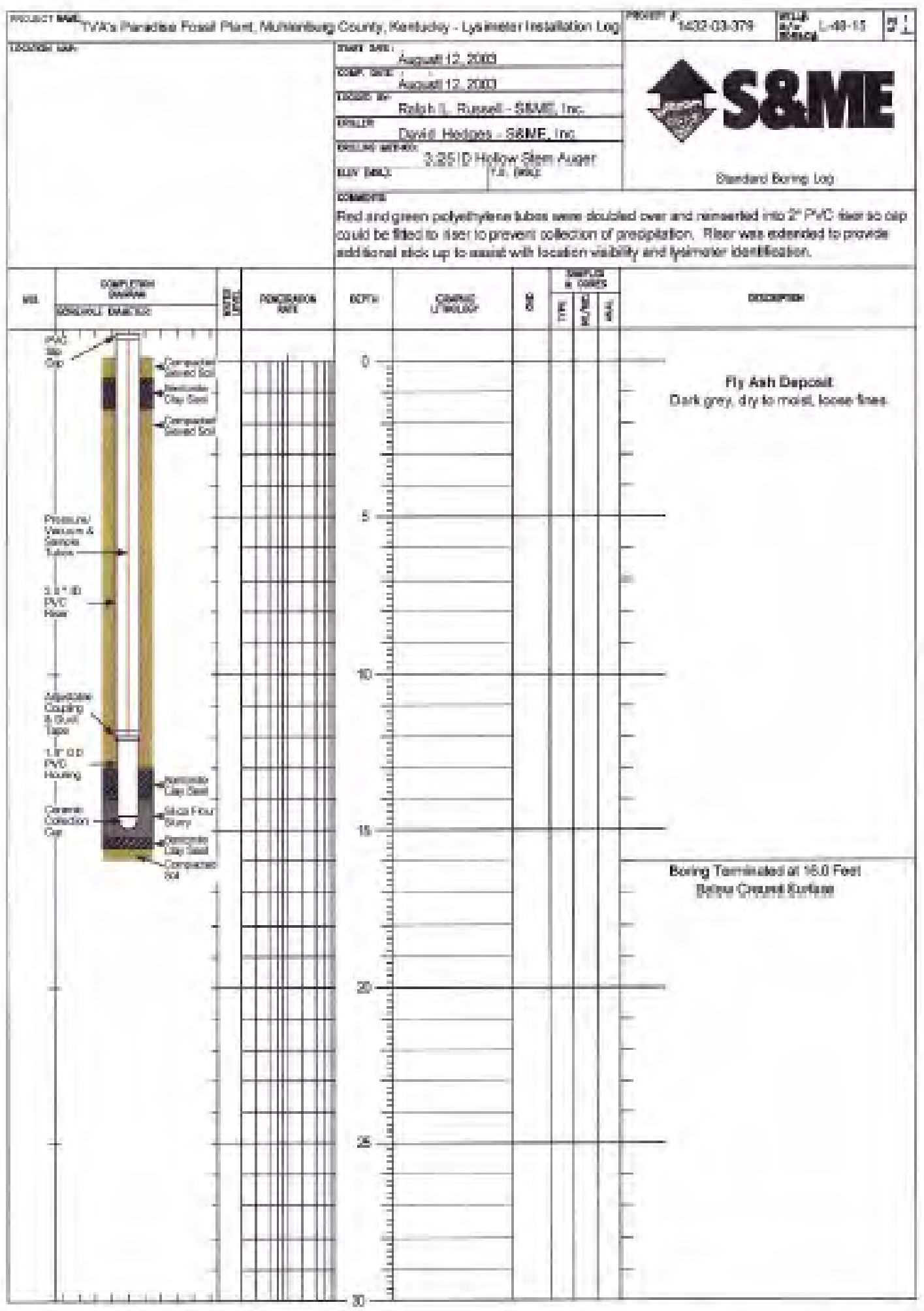




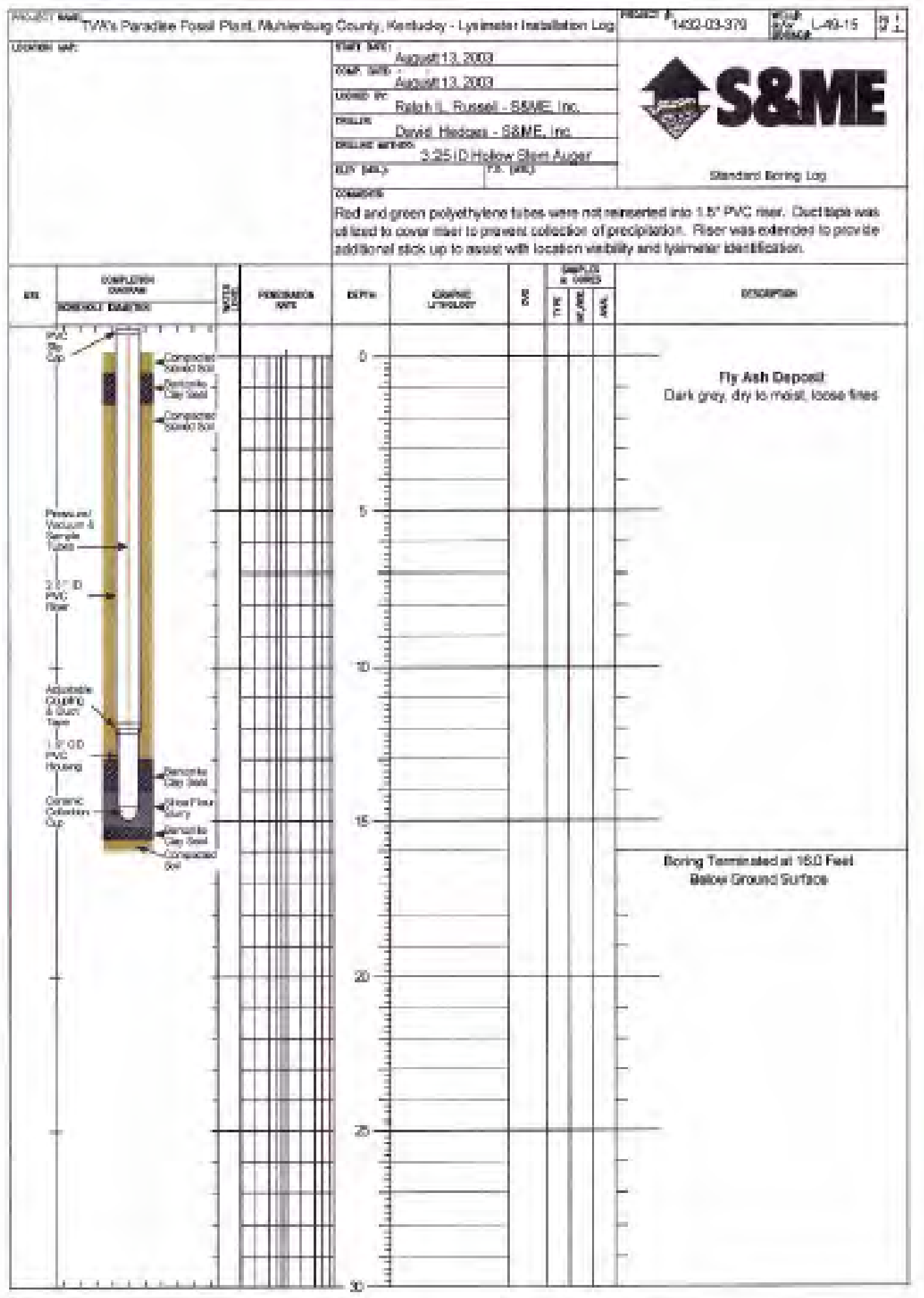




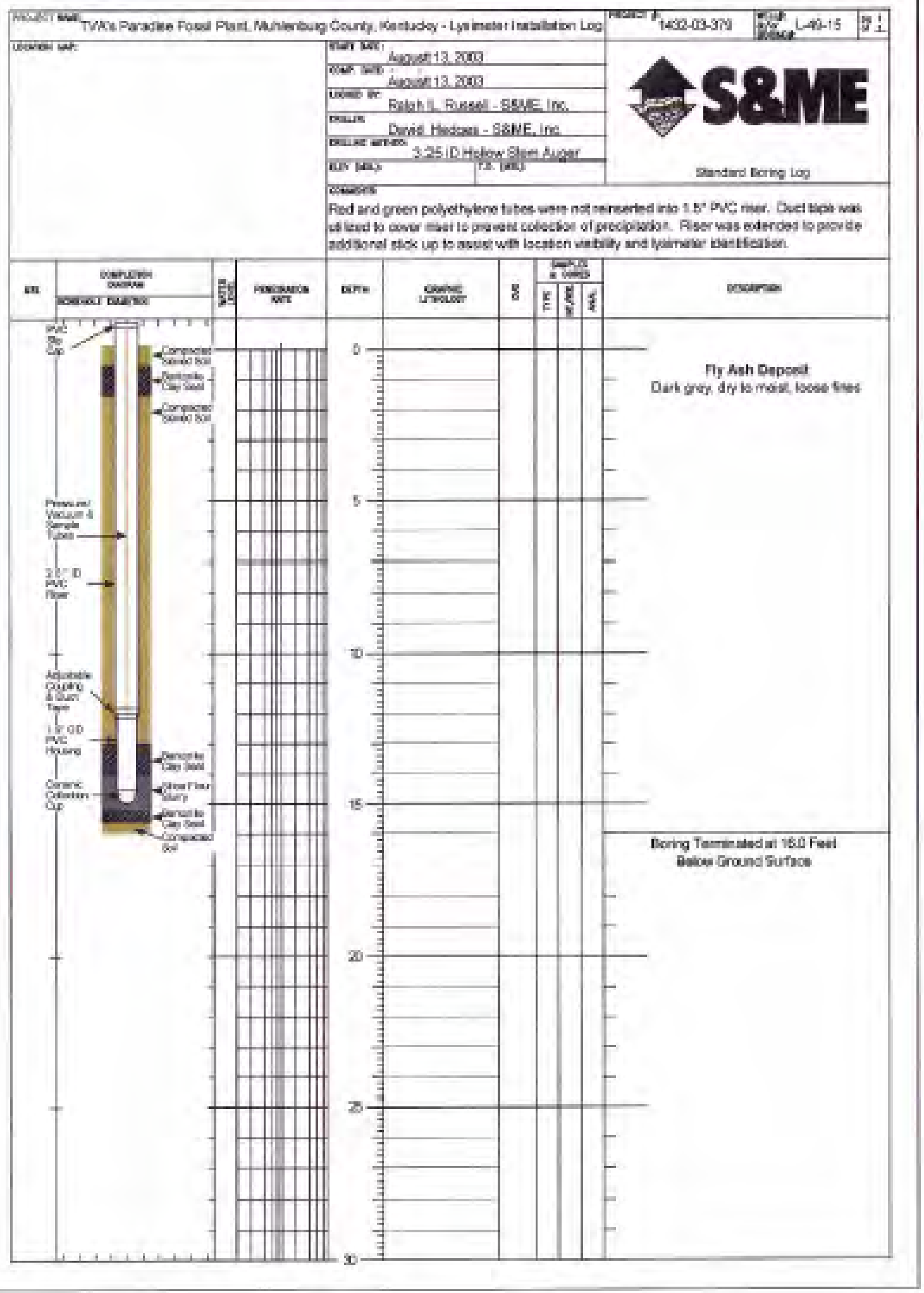

